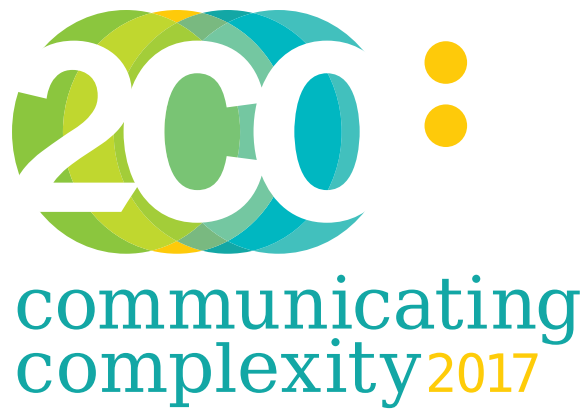

INTERNATIONAL DESIGN CONFERENCE

edited by:

N. Ceccarelli, C. Jiménez-Martínez 

2CO: COmmunicating Complexity

Contributions from the 2017 Tenerife Conference

Tenerife / Spain / $21^{\text {st }}-25^{\text {th }}$ October

edited by

Nicolò Ceccarelli

and

Carlos Jiménez-Martínez 
This publication contains the developments of large part of the communications presented during the 2 nd edition of the International Design Conference 2CO COmmunicating COmplexity, which took place from 23 to 25 November 2017 at the University of La Laguna, in Tenerife, the Canary Islands, Spain.

The conference was jointly organized by the Department of Architecture, Design and Planning of the University of Sassari (Alghero), Italy, and the Department of Fine Arts of the University of La Laguna, Tenerife, Spain.

\section{www.2coconference.org}

Conference Chair: Nicolò Ceccarelli

Conference Co-chair: Alfonso Ruiz Rallo

Book Editors: Nicolò Ceccarelli

and Carlos Jiménez-Martínez

Graphic Project: Marco Sironi and Carlo Turri

Publishing House: Universidad de La Laguna.

Apt. 456. 38200 San Cristóbal de La Laguna.

Santa Cruz de Tenerife, Spain. 2019

ISBN: 978-84-09-10171-9

DOI: https://doi.org/10.25145/b.2COcommunicating.2020

We wish to thank everyone who contributed to make this publication possible.

Special thanks to Cabildo Insular de Tenerife for supporting this book.

\section{(9) $(1) \Theta \Theta$}

Creative Commons Licence Attribution-Non Commercial-No Derivatives 4.0 International (CC BY-NC-ND 4.0)

Every effort has been made to contact copyright holders and to ensure that all the information presented is correct. Some of the facts in this volume may be subject to debate or dispute. If proper copyright acknowledgment has not been made, or for clarifications and corrections, please contact the publishers and we will correct the information in future reprintings, if any. 


\section{Scientific board}

\section{Nicolò Ceccarelli}

Department of Architecture, Design and Planning, University of Sassari. Alghero, Italy

Conference Chair

\section{Alfonso Ruiz Rallo \\ Fine Arts Department, Universidad de La Laguna ULL, Tenerife, Spain \\ Conference Co-Chair}

\section{Deniz Leblebici Basar}

Istanbul Technical University (ITU) Istanbul, Turkey

\section{Letizia Bollini}

University of Milano-Bicocca, Milan, Italy

\section{Alessandra Bosco}

University of San Marino, San Marino

\section{Alfredo Calosci}

Department of Architecture, Design and Planning, University of Sassari, Alghero, Italy

\section{Paolo Ciuccarelli}

Density Design lab., Politecnico di Milano, Italy

\section{José Luis Cueto Lominchar}

Fine Arts Faculty, Universitat Politècnica de València UPV, Spain

\section{Marina Estela Graça}

Department of Communication, Arts and Design University of Algarve, Portugal

\section{Peter Hodges}

Faculty of Creative Industries, School of Media, University of Glamorgan, Cardiff, Wales

\section{Carlos Jiménez Martínez}

Fine Arts Department, Universidad de La Laguna ULL, Tenerife, Spain

\section{Elena González Miranda}

Fine Arts Faculty, Universidad del País Vasco-Euskal Herriko Unibertsitatea UPVEHU, Spain

\section{Ian Mitchell}

Department of Graphic Arts, John Moores University, Liverpool, UK

\section{Antoni Mañach Moreno}

ESDi Higher School of Design, Universitat Ramon Llull (URL), Barcelona, Spain

\section{Eleni Mouri}

Graphic Design Department, Technological Educational Institute (TEI), Athens, Greece

\section{Luciano Perondi}

ISIA, Urbino, Italy

\section{Daniela Piscitelli}

Università della Campania Luigi Vanvitelli, Naples, Italy

\section{Alfredo Rivero Rivero}

Fine Arts Department, Universidad de La Laguna ULL, Spain

\section{Nuria Rodríguez Calatayud}

Fine Arts Faculty, Universidad Politécnica de Valencia UPV, Spain

\section{Marco Sironi}

Department of Architecture, Design and Planning, University of Sassari, Alghero, Italy

\section{Michael Stoll}

Design Department, Augsburg University of Applied Sciences, Germany

\section{Gülname Turan}

Istanbul Technical University (ITU), Istanbul, Turkey

\section{Michele Zannoni}

University of San Marino, San Marino 


\section{$2 \mathrm{CO2}$ is jointly organized by}

Department of Architecture, Design and Planning, University of Sassari, Alghero, Italy

Fine Arts Department, Universidad de La Laguna ULL, Tenerife, Spain

\section{Organizing committee}

\section{Carlos Jiménez Martínez}

2CO Secretary. Department of Fine Arts. University of La Laguna

\section{Marco Sironi}

Department of Architecture, Design and Planning, University of Sassari, Alghero, Italy

\section{Sabrina Melis}

Department of Architecture, Design and Planning, University of Sassari, Alghero, Italy

\section{Keynote Speakers}

\section{Kelli Anderson}

artist / designer and tinkerer

\section{Paolo Ciuccarelli}

Scientific Director, DensityDesign Research Lab - Politecnico di Milano

\section{Jaime Serra}

Multidisciplinary artist, columnist and journalist

\section{Academic partners}

Università degli Studi di Milano - Bicocca, Dipartimento di Psicologia

Department of Graphic Design, TEI

Athens, Fine art and Design

Istanbul Technical University, Department of Industrial Design

Augsburg University of Applied Sciences, Department of Design

Universitat Politècnica de València UPV, Spain, Fine Arts Faculty

Liverpool School of Art \& Design, Liverpool John Moores University

UNISRM Design, Università degli Studi della Repubblica di San Marino

\section{Partners}

Di CA, Asociación de Profesionales y Empresas de Diseño de Canarias

Aiap, Associazione Italiana Design della Comunicazione Visiva

Tenerife Design Week, Connecting Creative Comunities

\section{In collaboration with}

Estrategia 2030, Cabildo de Tenerife | intech

FDCAN, Fondo de Desarrollo de Canarias

MEDI, Marco Estratégico de Desarrollo Insular

Aula Cultural de Diseño, Universidad de La Laguna 
About this Book $\quad$ ix

Slow Complexity xi

(Nicolò Ceccarelli)

2CO : ADI Design Index 2018 xxiv

The Conference

Keynote speakers $\quad 2$

The History of Infographics_Exhibit

The Tenerife 2CO2 workshops experience $\quad 6$

(Carlos Jiménez-Martínez)

\section{Full papers}

\subsection{Infographics}

Lisa Borgenheimer

Information // Message

Friederike Brockhaus and Peter Sedlmeier

Using Pictograms improves the Understanding of

Stock\&Flow-System

Alfredo Calosci

Beyond visual Literacy. Communication Design as a

Cultural Mediation Process

Maria Rosaria Digregorio

When Everything Goes Wrong Make a Diagram

Elena González-Miranda and Tania Quindós

Principles of Design of Icons Systems for the Screen

Chris Jackson and Jona
Please Contribute

Ian Mitchell

Infographics: Absent without Leave

Anne-Marie Moore

Needs and Aspirations to the Designers of Info-Graphics

Luciano Perondi, Marco Ferrari and Donato Ricci 
Luciano Perondi, Berta Martini, Giulia Bonora,

Daniele De Rosa, Giampiero Dalai and Adelaide Imperato

The Topography of Dante's Inferno.

Transmission of Knowledge and the Creation of Synsemic Didactic Tools

\subsection{Interactive Data Visualization}

Letizia Bollini

A User-Centered Perspective on Interactive Data Visualization. A Digital Flâneries into the Documentation of Historical Italian Mind Science Archive

Michele Invernizzi, Michele Mauri and Paolo Ciuccarelli

Visual Monitoring of Complex Algorithms

Massimo Menichinelli, Giovanni Profeta and Serena Cangiano

Visualizing Open Communities. Guidelines from Three

Case Studies

\subsection{Informative Animation}

Nicolo Ceccarelli, Alfredo Calosci and Marco Sironi

Picturing 700 Years of History. Charting political and social Relationships from the Statuti Sassaresi, a XIV

Century Manuscript Statute-Book

Matteo Moretti and Valeria Burgio

The Role of Movement in Data Visualization:

Animation as an Agent of Meaning

Eleni Mouri

That is Visually Believable, it is true? Case Study:

JACHALAY, an "Informative" Film

\subsection{Info-Environments}

Alessandra Bosco, Elena La Maida and Michele Zannoni

Visual Tools for a Multiple Cross-Reading System in the Exhibition Contexts

Veronica Dal Buono

Shaping Complexity in Visual Identities:

Managing Dynamic Brands for Cultural and Educational Institutions 
Álvaro Sanchis Gandia, Nuria Rodríguez Calatayud,

David Heras Evangelio and Melani Lleonart Garcia

User Experience in Mobile Apps for Museums and

Exhibition Spaces

Marco Sironi, Alfredo Calosci and Nicolò Ceccarelli

Communication Strategies for Scientific Dissemination.

The mUNISS Historical Scientific Museum

Alan Mee

Visualising Spatial Complexity of Urban Sites

\section{Junior track}

Lorella Camellina

Venice Vega Park: History, "more Media" and new

Narrative Paradigms

Lorella Camellina, Gian Andrea Giacobone

Exploring Humanity Combining Data Visualization with Digital Art

\section{Posters}

Teresa Arozena Bonnet

Time Maps. Photography as the Display of Duration

Bernardo A. Candela Sanjuan

Canary lslands Design System: a Visual Representation of a Theoretical, Instrumental and Operational Model

Tania Quindós, Elena González-Miranda

Typography and Geometry in an Information Graphic

C. Pérez-González, M.Colebrook, J.-L.Roda-García, C. Rosa Remedios,

P. González Yanes, T.González Dos Santos, V.Plaza Martín

Analysis of Incidents registered by the 1-1-2 Canarias Emergency Services by using Data Science Techniques with the R Software

I. Sánchez-Berriel, L.M. Moreno de Antonio, E. García Martín, A. Hernández Hernández, B. González González, A. Cabrera Díaz, J.A. González Yanes, R. Betancor-Villalba, J. Javier Hernández 


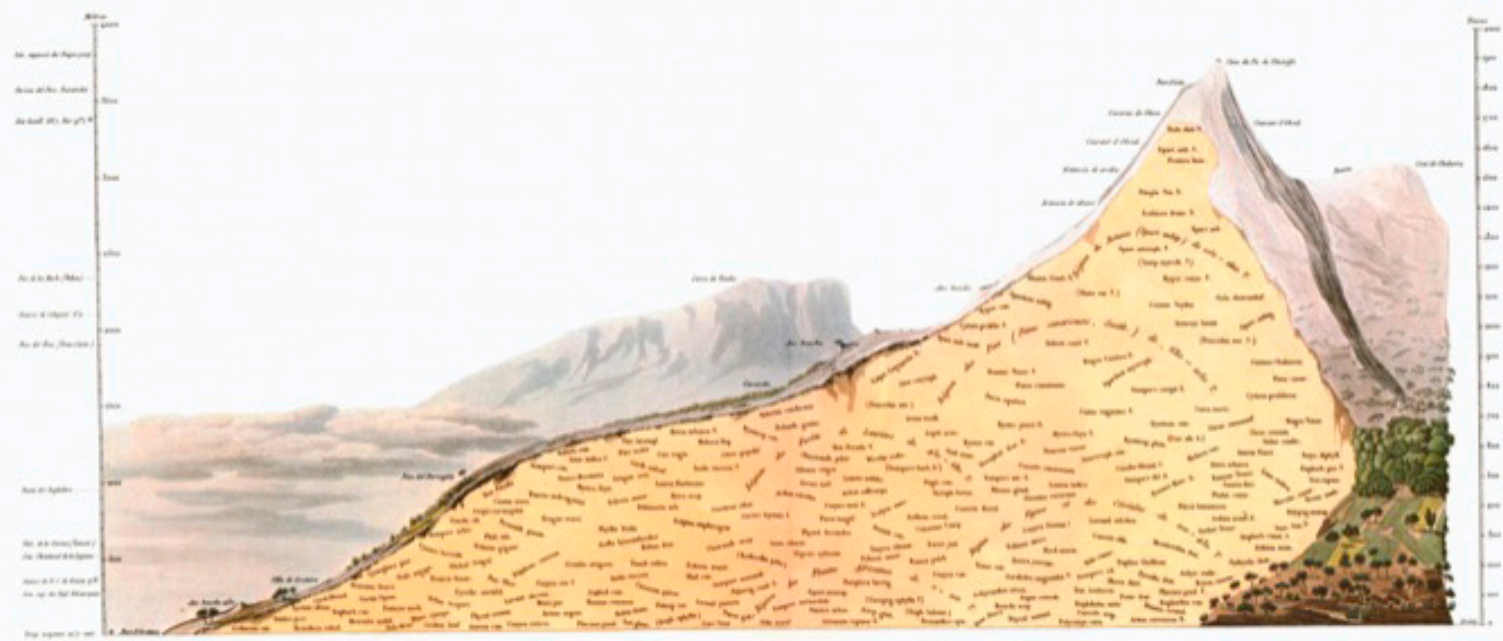

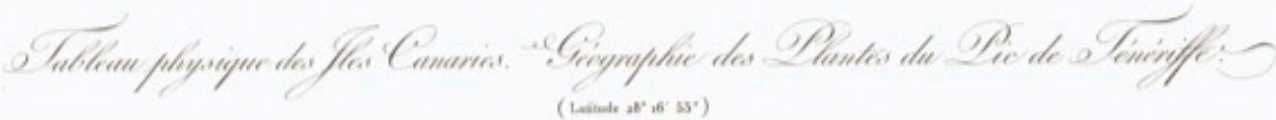

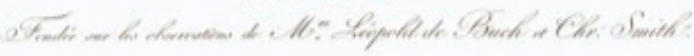

Geography of the plants of Tenerife, made from the observations of Leopoldo de Buch and Carlos Smith, who accompanied Alexander von Humboldt on the ascent to the peak of the Teide volcano (Tenerife, 1799).

From A. von Humboldt, Atlas géographique et physique des règions équinoxiales du nouveau continent, Paris 1814. 


\section{About this Book}

This volume presents the contributions to the second edition of the 2CO Communicating Complexity international Design Conference.

The event, co-organized by DADU, Department of Architecture, Design and Planning of the University of Sassari (Alghero), Italy, and the Faculty of Fine Arts of the Universidad de La Laguna, Tenerife, Spain, took place in Tenerife on 21-25 November 2017, and included the international conference and a series of design workshops.

The volume collects various classes of contributions presented during the event: long papers, short papers/junior track, posters, on the conference's four main areas of interest:

informative-animation;

interactive data visualization;

info-graphics;

informative environments.

All contributions where reviewed and selected through a blind peer-review process by the Conference's Scientific Committee. 


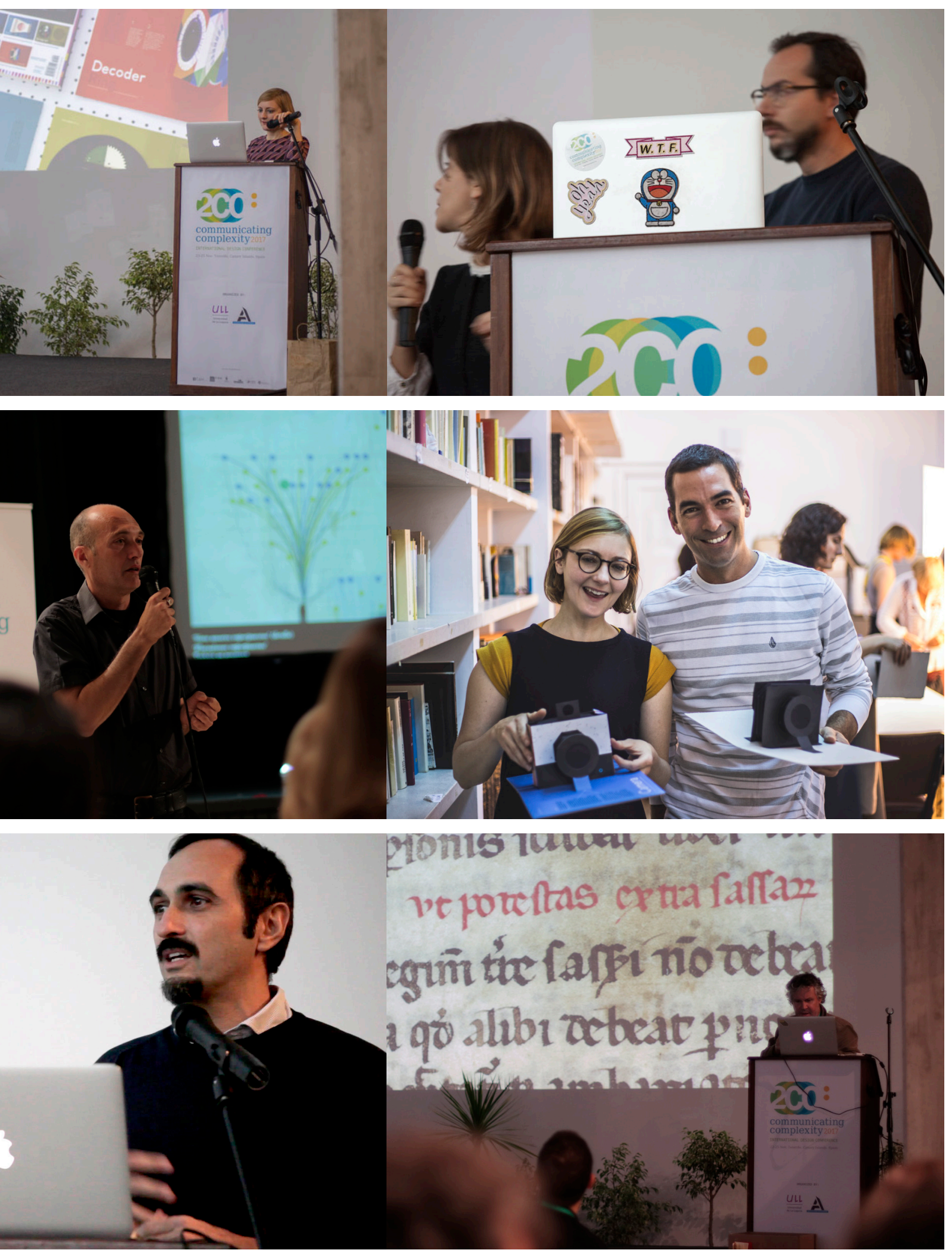




\title{
Slow Complexity
}

\author{
Nicolò Ceccarelli
}

Six years from its first appearance, two international conferences and three everyday 'regional' gatherings, after our first Alghero event, I wish to take advantage of the publishing of this volume to make a first assessment about what we have achieved so far, and on our current efforts in communicating complexity.

Stemming from a community of italian and European scholars working in the public sector university, 2CO communicating complexity, was conceived as a space for exploring languages, approaches and technologies to respond to the emerging need for making the complex information typical of our times increasingly accessible through design.

The project originated within a group of researchers that, despite being primarily engaged in academic research, actively cultivate the design practice and pursue cross-fertilization between the domains of research and professional practice, hence combining, whenever possible, theoretical work with projects affecting 'real' people.

This particular point of view is effectively described in a passage from the call for abstracts page of the conference's 2013 first edition, which stated how the organizing committee was: "looking for contributions and approaches that describe on-going experiences, completed projects, case studies in design methodologies. The focus is on 'practical' design-oriented approaches, however, more theory and methodology-centered contributions are also welcome".

Over the last few decades design has responded to the massive transformations that have affected our society evolving into a vast and comprehensive discipline. This entailed adapting to emerging challenges that have become less tangible, more inter-connected and complex. Design has evolved, embracing new areas, facing new challenges. This also applies to information design. 
A lot of water has gone under the bridge since E. D. Tufte's superb trilogy* presented something that looked immediately familiar - even obvious - to many of us, having only flipped through a few pages: shaping visual information so to turning the complex into something simple and understandable, is one of design's finest tasks.

Information Design is today in the spotlight, but this has not always been the case. Possibly because of its intrinsic practicalness, it has in fact been long underestimated by the graphic design community. Apart for a few celebrated cases - Isotype, to name one - or for the occasional love affairs between graphic designers and pictograms this branch of design has often been reduced to an appendix, a mere utility, a pastime. Only recently has info-design managed to establish itself as a key topic, gaining space in the professional battlefield, defining its boundaries as a discipline. The info-designer has taken the place and prestige held by the web designer at the turn of the Millenium. Some leading firms in info-design and data-visualization have eventually reached the top of the professional design ladder, while some of the bright individuals who lead them are heralded as design gurus. The subject of advanced university curricula around the world and of advanced research efforts in celebrated university laboratories, info-design has today grown to the point of becoming the subject of a few heroic design narratives.

Of course, this is much more than just another design fashion. The information society in which we live and work has reached unprecedented peaks of complexity, leading to an increased urge to explain, display, visualize. The combination between the rise in specialization in every area of knowledge and the impetuous growth in the production (and consumption...) of informative contents, has generated an extraordinary multiplicative effect. Furthermore, in the wake of a generalized increasing social demand for direct participation, a growing arena of public and private bodies; governmental and non-governmental organizations, administrations 
and corporate companies, are increasingly engaged in disseminating data and information of public interest.

Interestingly, as the growth in the supply/demand of information may make us feel as if we were literally immersed in information, only seldom are these actually accessible: readable, translatable, understandable, in other terms useful, to non-insiders.

Responding to these demands, the emerging democratizing trends for open data, transparent information, and to the growing and apparently unstoppable hunger of 'visual explanations', is what ultimately triggered the $2 \mathrm{CO}$ venture. The project's domain of activity lies then the space between the profile of the designer as a transformer, proposed by Marie Neurath, and that of the information architect outlined by Richard Saul Wurman. Here, we believe, is to be found one of the most urgent tasks for the communication design community: minimizing the distance between data, information and the public by reducing their complexity, hence translating it into accessible formats. The COmmunicating COmplexity project moves then from acknowledging the rapid transformations taking place in the communication system scenario both in the relationships between production / use of information and in the modifications affecting the ways we use to inform and get informed, and models itself on the format of a quasi-scientific society of designers/researchers.

\section{A formula}

2CO was therefore thought of in first place as a cultural endeavor. The international Design Conference, initiated in 2013 as a periodic event, has developed through time into a flexible platform from which a growing community can articulate a series of initiatives of dissemination, education, training, publishing and exhibition.

As anticipated, in its quest to explore how we can translate the information complexity characteristic of our time into something more 
accessible to the public, 2CO COmmunicating COmplexity stands somewhere between theory and practice and on the contamination between different knowledge areas and observation points. A short overview of the arena of experts we have involved - mainly as keynote speakers - to the first two editions of the Conference, helps to illustrate the particular angle we have given to the project.

For the Alghero's 2013 edition we were able to invite: Paul Wells, director of the Animation Academy at Loughborough University, UK, a key figure in animation studies, a scholar whose background combines an excellent theoretical base with collaborations with the BBC in producing tv programs; Santiago Ortiz, a leading founder of Bestiario.org, a team of creative explorers who opened the path of digital design in the area of making complexity visible; Michael Stoll, a worldwide highly respected connoisseurs of info-graphics and a Professor at the University of Augsburg, owner of one of the most complete historical collections of info-graphic artifacts; Dave Daniels, a visual designer and motion-grapher who in parallel to a long term personal research on the connections between images, movement and music, has carried out exceptional design work for events such as the Led Zeppelin 2007 reunion concert, or Roger Waters" “The Wall" Berlin concert.

For the 2017 Tenerife edition on the other side, we were lucky to have with us Kelli Anderson, a Brooklyn-based visual designer who, combining curiosity, design wit, aesthetic expertise and a sensible use of technology, reminds a designer-artist-inventor of almost Renaissance memory; Paolo Ciuccarelli, currently Professor at Boston's Northeastern University after leading Milan's celebrated Density Design research laboratory and pursuing the idea of information design as a humanistic practice; Jaime Serra, one of the central figures of the Iberian movement of info-periodismo who in his work pursues the cross-fertilization between info-design and artistic expression. 
Aside from the exceptional quality of these presenters, added value is given by the variety and breadth of approaches and points of view they represent as a whole, which can be very helpful to address the challenges ahead of us, and makes us think we are on the right track for the task.

\section{CO Junior-Track}

Another feature of our project is the care given to the scholars and designers of the future: our students. Each 2CO conference begins with a special session of a category we have labeled 'Junior- track', directed to freshly graduated students starting to make their first steps within the territories of research. The Junior-track is a sign of interest, a tangible encouragement to scholarly paths which are naturally not yet fully mature (the contributions of this category, originally limited to the format of poster presentation have, starting from the 2017 edition, been brought to that of a 'short paper'). This dedicated session aims at opening a space and a real opportunity for interaction, among young designers-researchers, their peers from other universities and other countries, and a chance to confront their ideas with the scholars, experts and professionals gathered for the conference.

\section{Education in COmmunicating COmplexity: the $2 \mathrm{CO}$ workshops}

Another important evolutive step in the $2 \mathrm{CO}$ project is connected with the exploration of the educational dimension of communicating complexity. The amazing potential behind the effort of setting up an international conference, often ends up being only partially exploited. Special guests and keynote speakers come and go - often without really getting in touch with the community gathered for the conference. Meanwhile, securing some academic acknowledgment 
(having a paper accepted, presenting it, having it published...) seems to have become nowadays the attendees' prime, often sole, concern.

The 2CO workshops project, started at the Tenerife 2017 conference, is what we devised to make the most of this great deal of expertise, looking to explore ways to translate such knowledge into didactic terms. Open to students as well as to local professionals, the workshops obviously represent for the hosting institutions not to be missed learning opportunities, as well as priceless intensive didactic resources in terms of contents, stimuli, ideas. The main idea was to take maximum advantage of the presence of experts - our keynote speakers and some of our guests - by engaging them to lead a series of design workshops. So we asked some of our 2CO workshops leaders to challenge themselves with a specific formula. Rather than having them replicating their most successful workshops, we engaged them to leave their comfort-zone, venturing in co-leading a workshop with someone from a different field, bringing to the project a combination of points of view and expertise. The ideal $2 \mathrm{CO}$ workshop is based on the spark that can only be produced when you have two voices, two approaches, two different skills, two languages and two cultures, having them meet halfway, in a possibly partially unexplored, territory.

This seems to us, a great way of exploring, and learning everyone, not only the students - something new.

This experimental path was started in 2017 with the two workshops: Processing complexity. How to design great information graphics_ lead by Alfredo Calosci and Michael Stoll/Lisa Borgenheimer. In-camera simplicity. Animation basics for data presentation lead by Nicolò Ceccarelli and Eleni Tsampra Complemented by a a series of other interesting workshops: Dialograma, el juego de diagramar la dialéctica_ lead by Jaime Serra 
Visualizing ethical values in Design praxis: the challenge of professional deontology towards the strengthening of democracy lead by Antoni Mañach

Draw me a coffee. A collaborative experience to understand how to design complexity lead by Letizia Bollini .

The extra-bonus workshop This book is a camera, lead by Kelli Anderson completed the picture.

\section{COeveryday}

2COeveryday is a formula recently introduced as a part of our 'platform' vision. Intended primarily as an element of continuity between the organization of the main conferences, a 2COeveryday gathering is a condensed seminar, organized in collaboration with one of the partners of our scientific network. Structured as a one-day session, the event hosts a series of presentations and, whenever possible, one or more workshops. 2COeveryday completely reverses the typical format of the international conference. To make it happen, in fact, a selected team of 2CO's core members travels to a specific destination to meet local scholars, professionals, students from partner schools.

The idea behind this sort of 'traveling show' is to put together a series of small decentralized gatherings aimed at promoting a firsthand exchange with 2CO's extended community.

So far three 2COeveryday events have taken place: in Liverpool, UK (may 2018) organized with the School of Art and Design of Liverpool John Moores University; Milan, Italy (February 2019) organized with Density Design at the Politecnico di Milano and finally in Cerezales de Condado, near Leon, in the North of Spain (September 2019), organized in cooperation with Fundación Cerezales Antonino y Cinia (FCAYC). 
Typically structured in two (morning and afternoon) sessions around an informal lunch, the event showcases a limited number of presentations, planned with the local organizing partner. The program includes contributions from 2CO researchers and by professionals, scholars and PhD students from the area, selected either on the grounds of a direct invitations or of a rather informal word of mouth-kind of call.

The relaxed format, generous presentation time (at least 30 minutes per presentation, plus questions and answers) and the general informal atmosphere, are instrumental in shaping the event. Nevertheless, the decisive factor is possibly the event's distinctive 'academic freedom'. Participating to a 2COeveryday gathering, in fact, does not imply presenting a paper.

This encourages the involvement of professionals, whom are often not too comfortable with spending the time and energy it usually takes to make an on-going experiment or a side-project 'academically presentable'. The relaxed and non-competitive atmosphere, meanwhile, stimulates scholars to present on-going projects. Possibly not ready for a more format setting, these often receive very precious feedback and suggestions for their future development from colleagues and experts in the field.

In each of the three events we organized so far, this combination has generated a series of very positive effects. The local design community has acknowledged and appreciated the effort -a small group of people visiting from international locations, at their own expense, to share a piece of work or research - responding with great enthusiasm.

Most of all, some exceptionally interesting work - in part presented here in the side boxes - has emerged. Ultimately, organizing a local event in this format is easier, much more convenient: in fact more fun. The format really makes it possible to get to know the people, understand the context, establish connections. 
Giovanni Magni, Accurat, Milano, 2COeveryday Milan, February 2019.

Selected by a team of scientists from UC Berkeley and Arizona State University, Accurat has served as design leader in a DARPA-funded project aimed at developing next-generation methods for social science research. The project combines the two approaches to visual information of scientist and designers, to develop datavisualization-driven open-source software resources for crowd-sourced experimentation. The resulting halfway encounter is the starting point for the development of a model in which visual information becomes a facilitator for producing new knowledge.
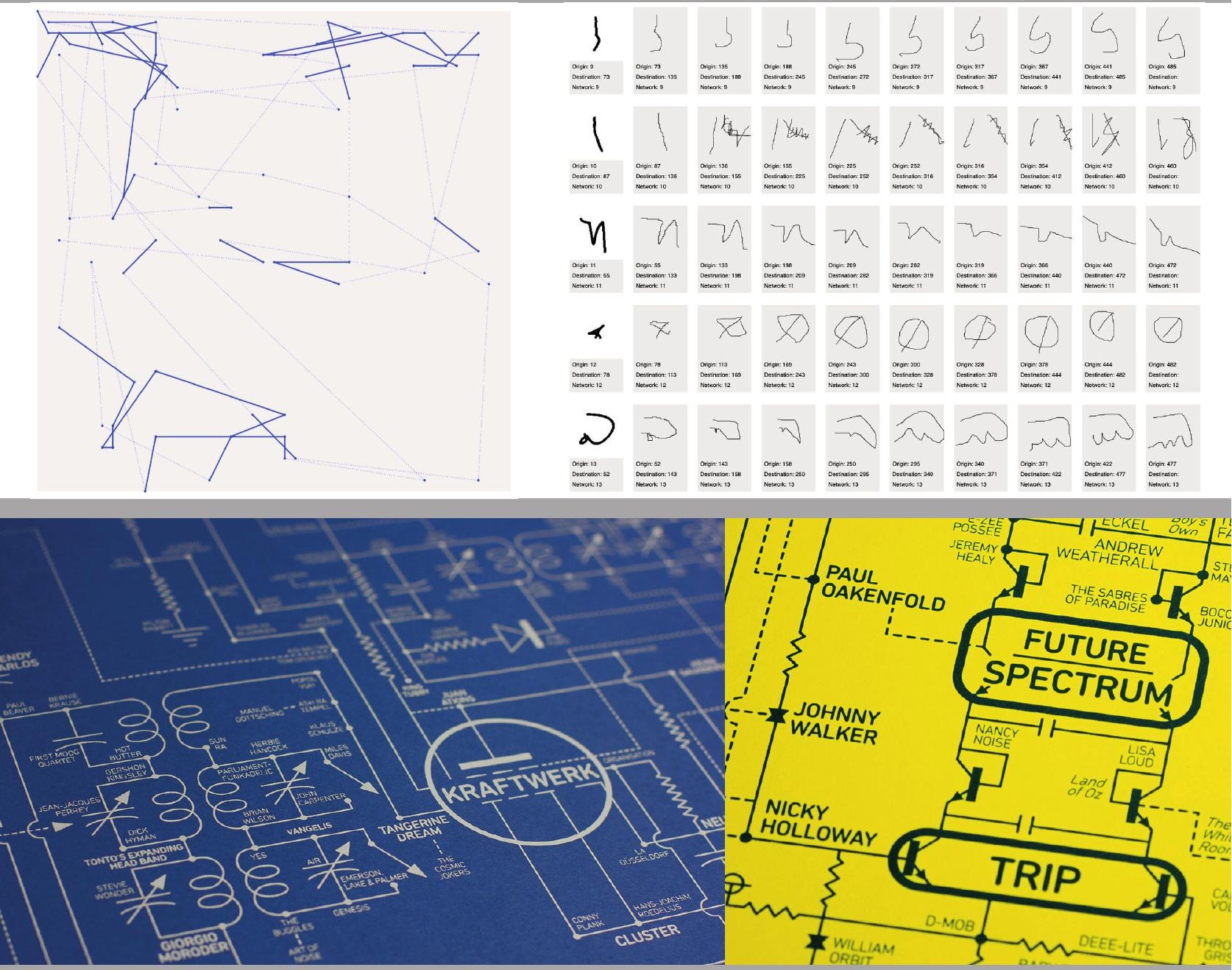

James Quail, Dorothy, Liverpool, 2COeveryday Liverpool, May 2018.

Started as a personal project, James Quail's Love Maps chart, with painstaking care, the evolutions, influences and interconnections between bands and contemporary counter-culture. Composed as conceptual maps, the series - which includes variety of musical domains such as Dance, Hip-Hop, Elec- tric, Alternative - are not intended to offer a neutral point of view, being rather filtered through the author's personal sensitivity and experience as a music enthusiast, often a direct witness of the events. Almost a series of style exercises, the masterly composed maps demonstrate the power of visual design to incorporate into a chart something fluid as musical atmosphere. 


\section{Going Slow...}

Finally, allow me to mention another distinctive trait of the project, which I like to think as as our slow food model: the convivial atmosphere on which we try to shape any $2 \mathrm{CO}$ event.

Widely well known today as an international brand Slow Food was started in Northern Italy in the mid'Eighties as a non-profit organization aimed at promoting an easy approach to life. As stated in its original manifesto, the slow food idea was against those who mistake a frantic life for efficiency, promoting good food (...see, almost like 'good' design...), either as a very 'gourmet-like' tangible factor, and as a metaphor for an attitude to a relaxed and convivial life. In this perspective food becomes the centerpiece of a cultural approach that positively associates time, quality of traditional local ingredients, genius-loci, and socialization. The slow adjective hence becomes a synonymous of caring, in terms of human connections.

In this frame, and possibly in association with the 'Mediterranean' roots of our project, in any of our events special care in given to ensuring the right space and time for people to share, interact, get in touch with each other. The relatively small size of our events helps in leaving those meaningful pockets, for taking the time it takes, making space for a conference to reconnect with its proper etymological meaning of cum-ferire, coming together. Call it human factors: in our slow vision the informal, interpersonal moments between presentation sessions, are as relevant as the actual presentations. So we put some effort in making these opportunities take place, and we are absolutely delighted whenever we see a student and a design guru chatting informally around a pasta plate.

So, I really cannot say which of the two distinctively Italian factors, the slow food-like approach or the idea of conducting research work through the design practice - in fact possibly both - have played a major role in granting our project one the acknowledgments that has 
Katia Prada, el abrelatas, Spain. 2COeveryday Cerezales de Condado, September 2019.

With her Calendario de Siembra, Katia revisited an evergreen commodity, the planting calendar/almanac. With her elegant adaptation of this ancient tool providing information on planting, sowing and harvesting of horticultural crops, Katia has turned the basic illustrated model into an ingenious time-based visual artifact. The result works both as a practical tool providing information on a variety of interconnected factors ranging form water and soil conditions to the moon phases, and a promotional poster for MrNatural, the project's commissioner.
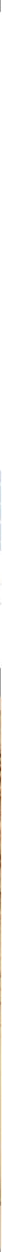

Matteo Bonera, The Visual Agency, 2COeveryday Cere zales de Condado, September 2019.

Codex-Atlanticus.it, a classic and very elegant example of digital enabler, developed by The Visual Agency and the Ambrosiana Library in Milano, opens up new ways of exploring a unique historical artifact: the Codex Atlanticus, Leonardo da
Vinci's largest repository of texts, sketches, design ideas and notes. The opening panoramic overview of the interactive system offers to users access to the document's contents according to subject matters and themes. An interesting feature is is the possibility to reorganize the Codex's pages according to their chronological order of creation. 

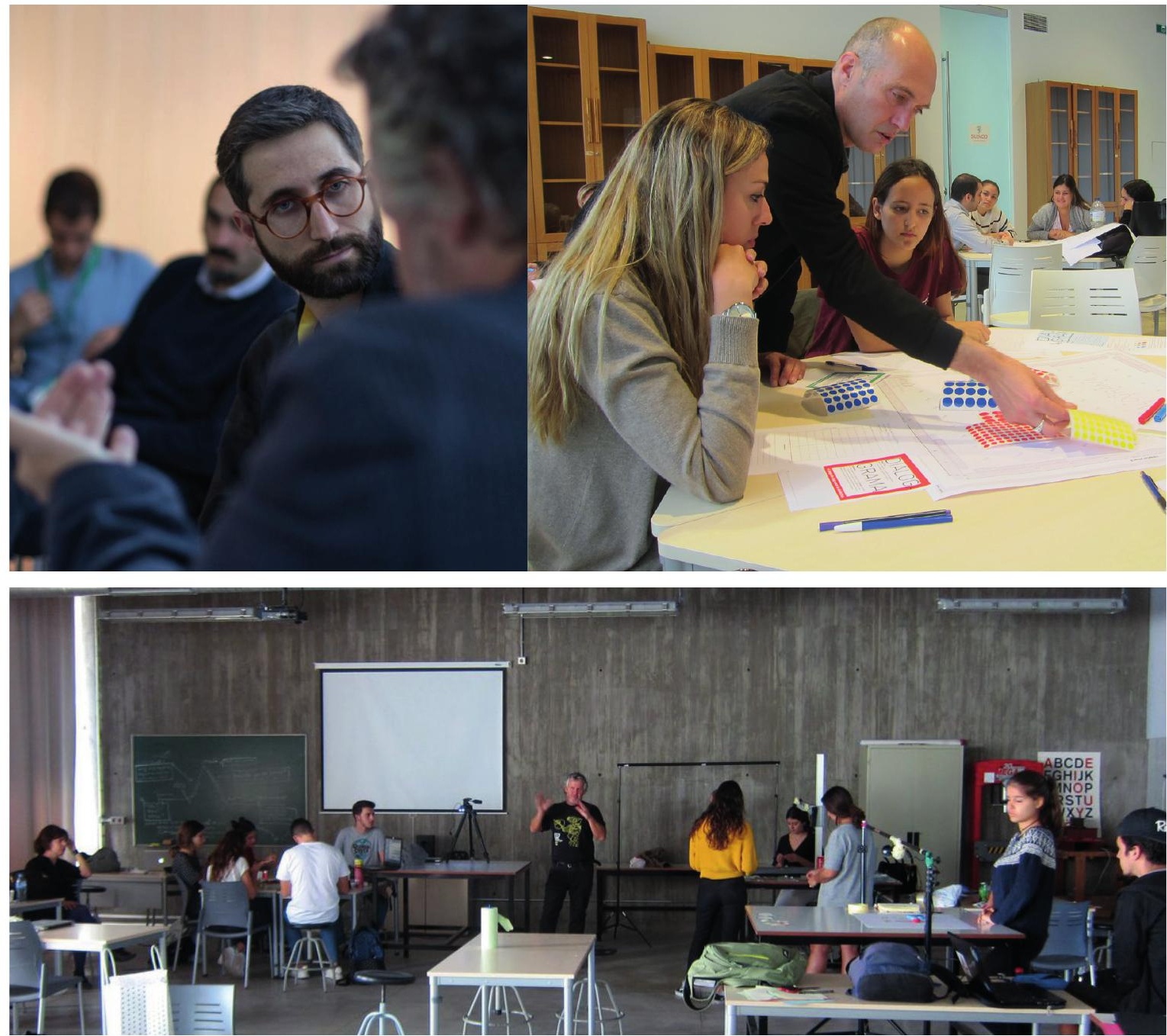

made us most proud over the last years. The inclusion of 2CO in the 'Studies and cultural initiatives based on design' category of the 2018 ADI Design iNDEX**.

Although we clearly don't think our project to be necessarily better than others, we certainly treasure some of the traits that make it special, if not unique. It is a small legacy deserving of being nurtured, and worthy of the huge efforts and small sacrifices it takes to make it run.

* "The Visual Display of Quantitative Information" (1983); "Visual explanations" (1990); “Envisioning Information" (1997)

Graphic Press, Cheshire Connecticut.
** Founded in 1957 ADI, the Italian Association for Industrial Design is Italy's main Design. Every year ADI selects a group of designs in various categories to be included in the ADI Design Index, from which... every two years the winners of the Compasso d'Oro. 


\section{CO : ADI DESIGN INDEX 2018}
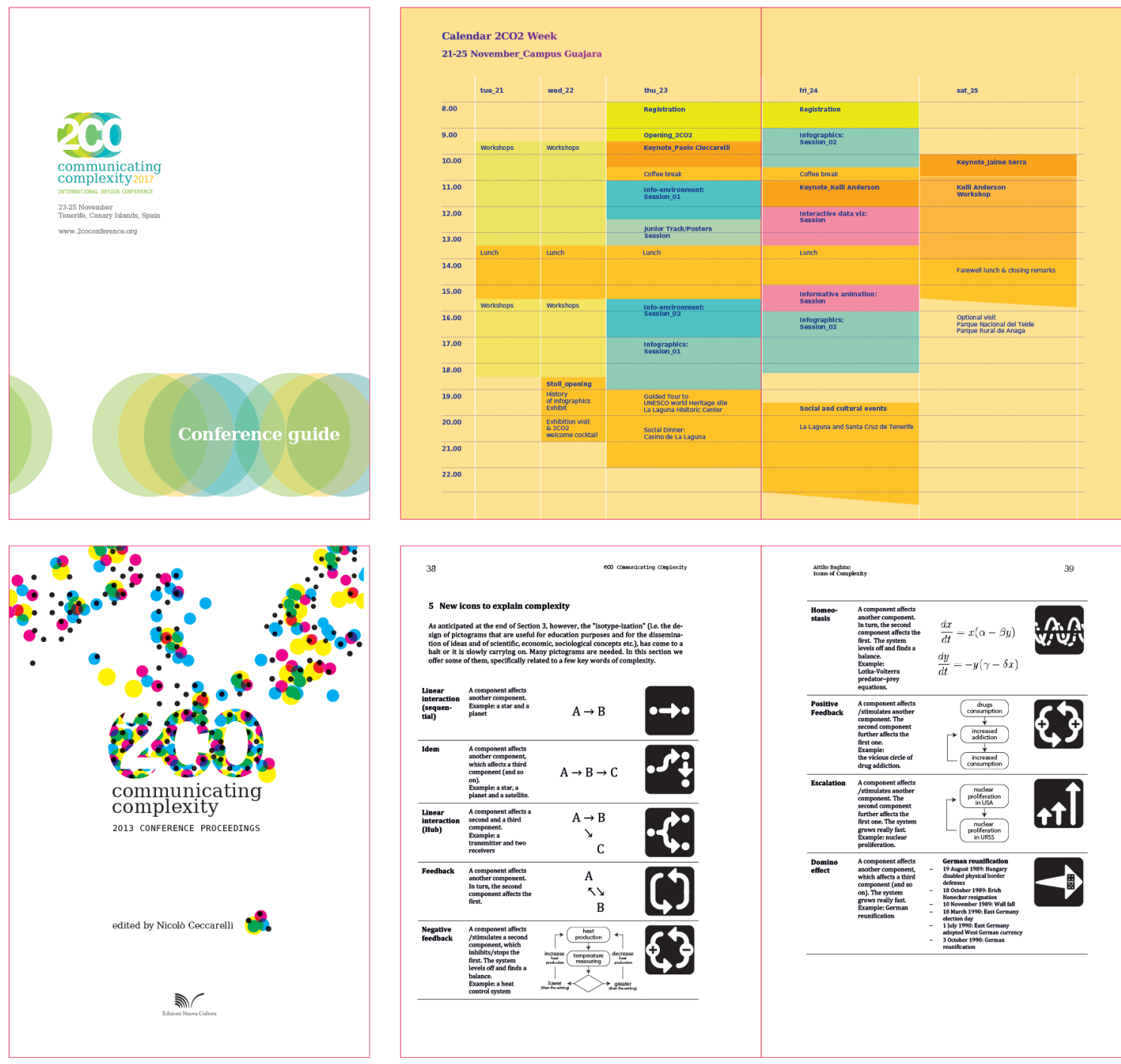


\section{)$(40=20$}

PALERAE, FN FPAN TE $: 0, \ldots$

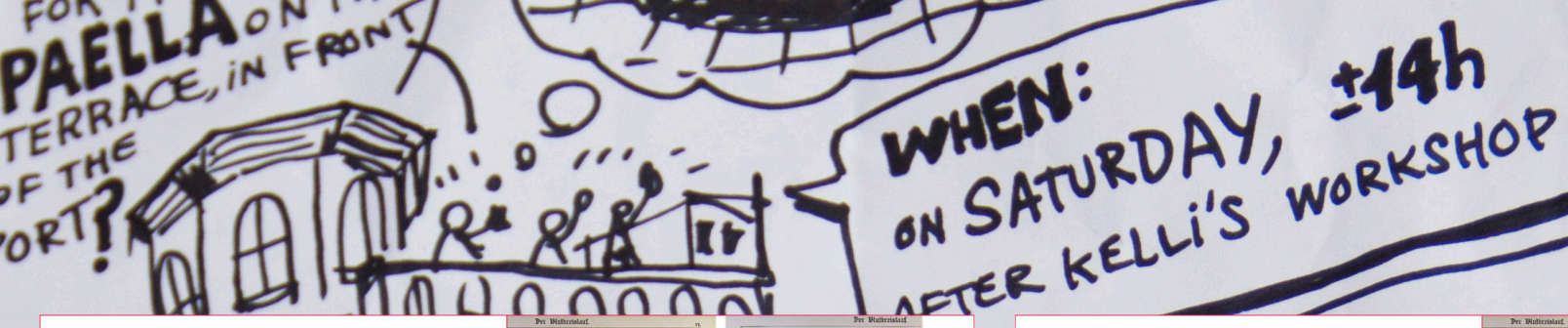

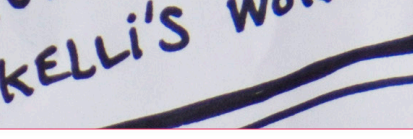

Michael Stoll_opening address
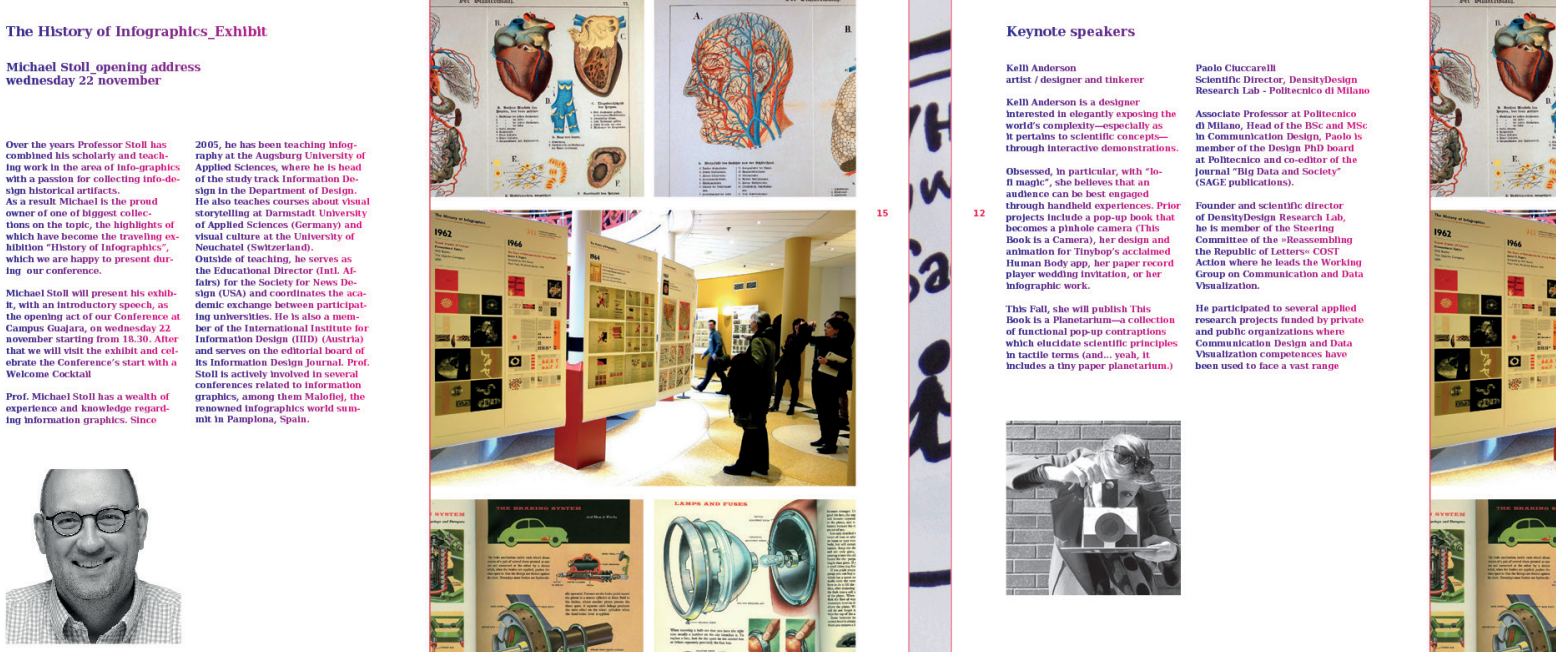

$=02$
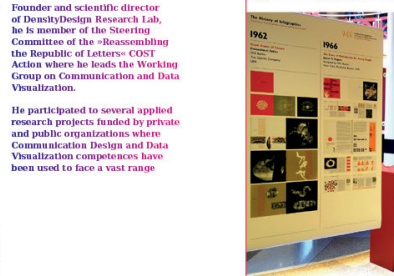

$2 \mu$

루
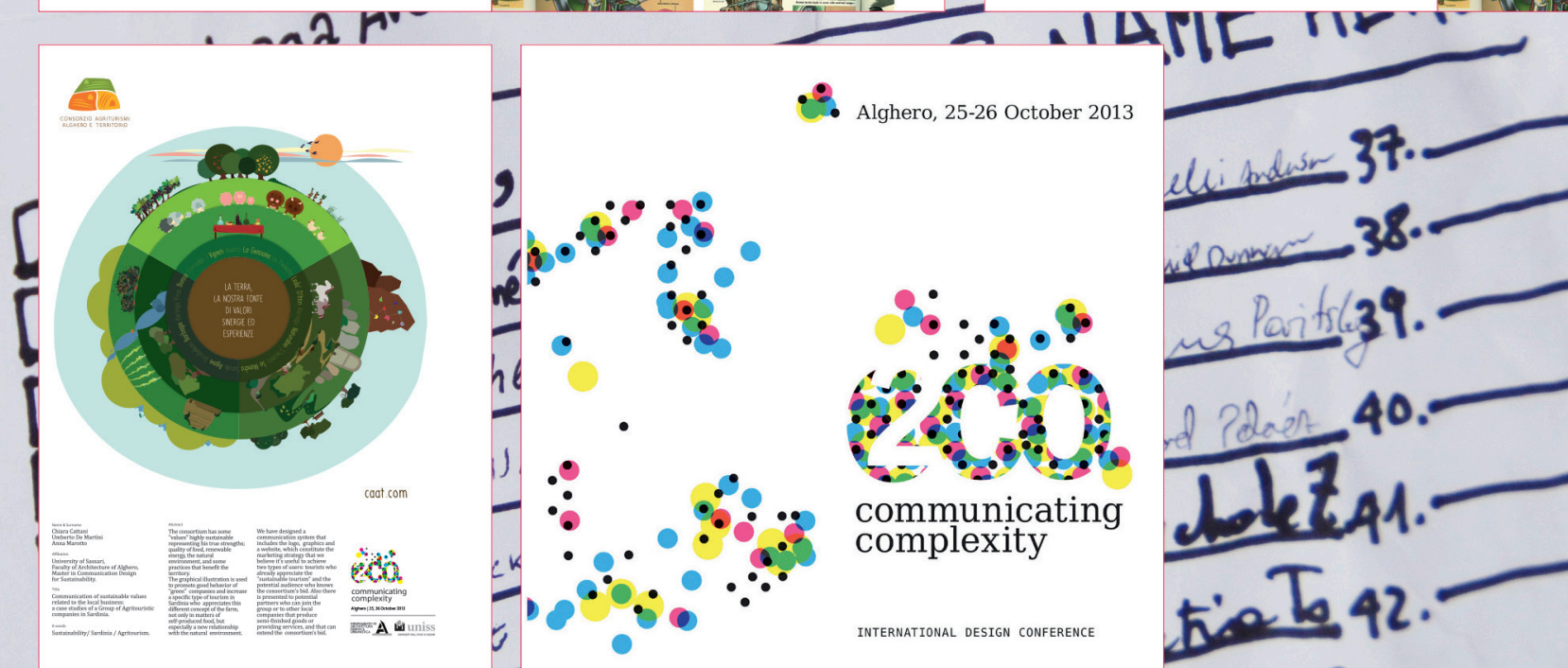

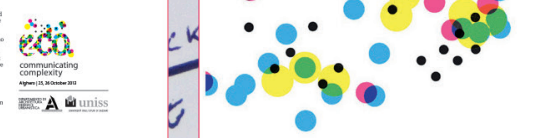

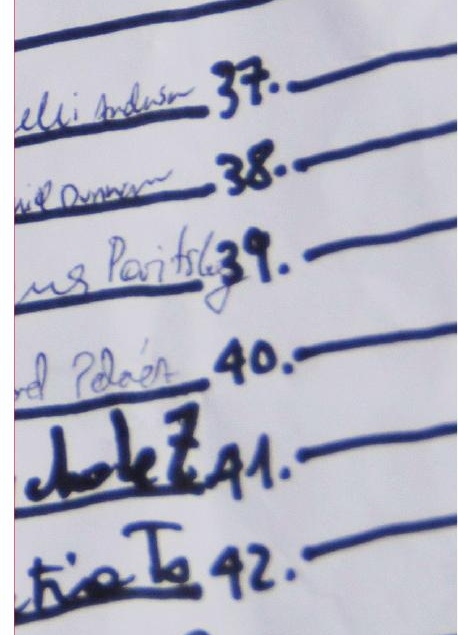

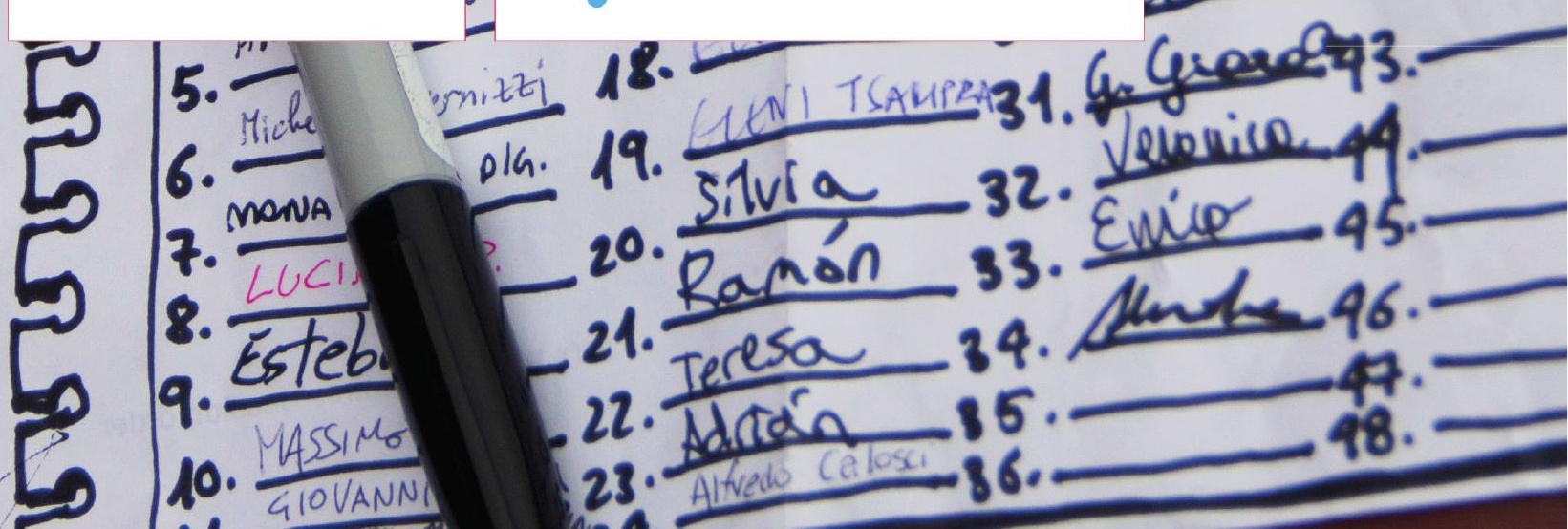




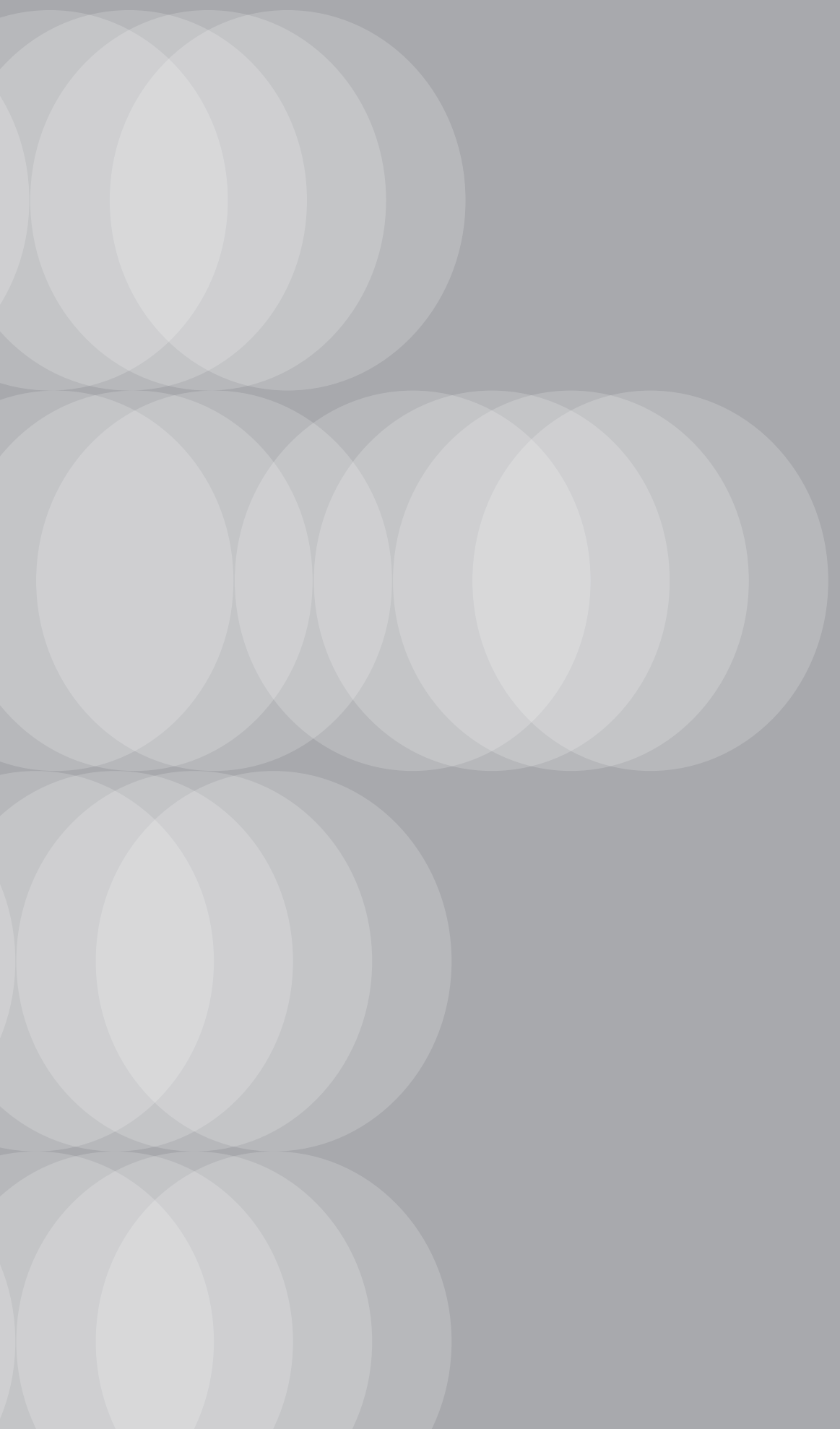


The Conference 


\section{Keynote speakers}

\section{Kelli Anderson \\ artist / designer and tinkerer}

Kelli Anderson is a designer interested in elegantly exposing the world's complexity-especially as it pertains to scientific concepts-through interactive demonstrations.

Obsessed, in particular, with "lo-fi magic", she believes that an audience can be best engaged through handheld experiences. Prior projects include a pop-up book that becomes a pinhole camera (This Book is a Camera), her design and animation for Tinybop's acclaimed Human Body app, her paper record player wedding invitation, or her infographic work.

This Fall, she will publish This Book is a Planetarium-a collection of functional pop-up contraptions which elucidate scientific principles in tactile terms (and... yeah, it includes a tiny paper planetarium.)

\section{Paolo Ciuccarelli \\ Scientific Director, DensityDesign Research Lab - Politecnico di Milano}

Associate Professor at Politecnico di Milano, Head of the BSc and MSc in Communication Design, Paolo is member of the Design PhD board at Politecnico and co-editor of the journal "Big Data and Society" (SAGE publications).

Founder and scientific director of DensityDesign Research Lab, he is member of the Steering Committee of the »Reassembling the Republic of Letters « COST Action where he leads the Working Group on Communication and Data Visualization.

He participated to several applied research projects funded by private and public organizations where Communication Design and Data Visualization competences have been

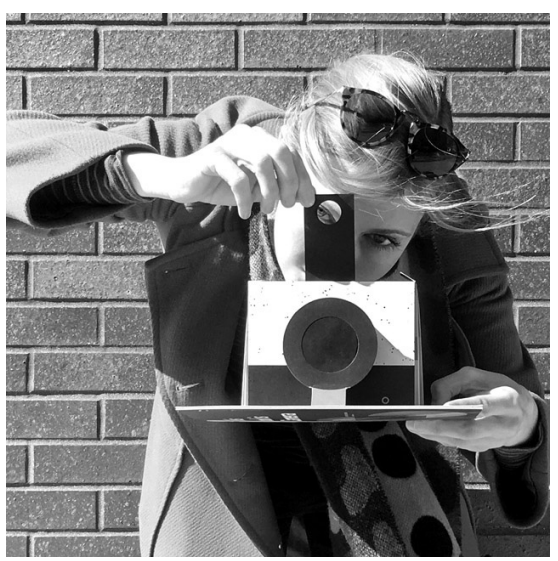


used to face a vast range of complex issues, from bringing data in the hands of non-expert users - the public - to mapping the evolution of technoscientific controversies on the web and supporting the peculiar inquiry process of Digital Humanities scholars.

The activity of the DensityDesign research lab focuses on the visual representation of complex phenomena and the development of interfaces and tools for enhancing the culture and the practice of Data and Information Visualization.

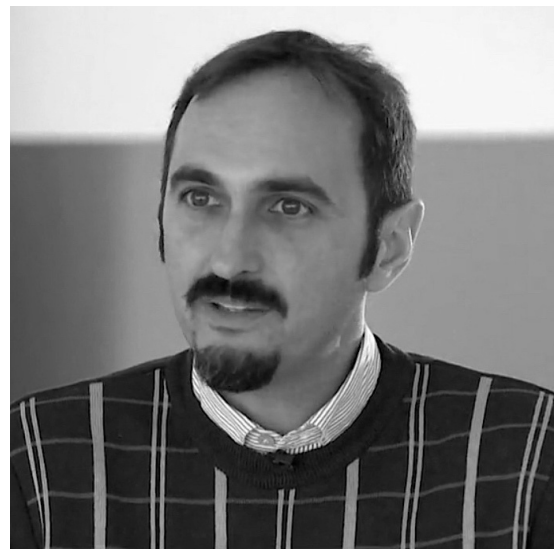

\section{Jaime Serra Multidisciplinary artist, columnist and journalist}

Jaime Serra is a leading figure in infography. Since the 90's, his pioneering work for many international newspapers has played a key role in shaping infographic as a genre, pushing the envelope of its application domain and defining it as a new language for making information accessible.

His work encompasses organically exhibits, installations, infographic pieces in editorial formats.

Acknowledged with more than a hundred awards and honors, Jaime has lectured and presented his work throughout the world in events, meetings and conferences on journalism, design and data visualization.

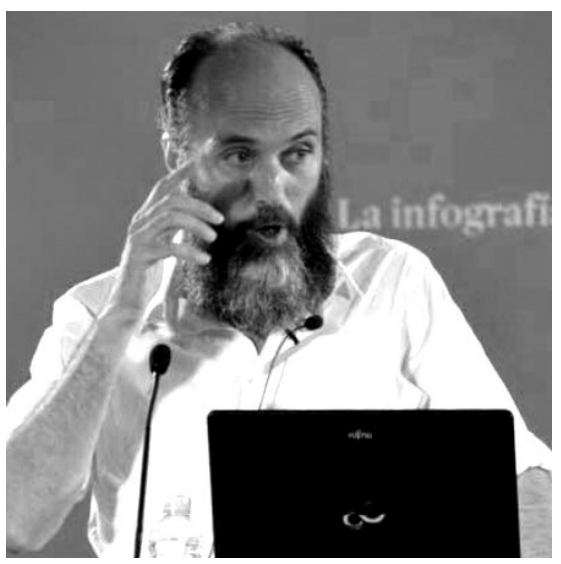




\section{The History of Infographics_Exhibit}

\section{Michael Stoll \\ Augsburg University of Applied Sciences, Germany}

Over the years Professor Stoll has combined his scholarly and teaching work in the area of info-graphics with a passion for collecting info-design historical artifacts.

As a result Michael is the proud owner of one of biggest collections on the topic, the highlights of which have become the traveling exhibition "History of Infographics", which we are happy to present during our conference.

Michael Stoll will present his exhibit, with an introductory speech, as the opening act of our Conference at Campus Guajara, on wednesday 22 november starting from 18.30. After that we will visit the exhibit and celebrate the Conference's start with a Welcome Cocktail

Prof. Michael Stoll has a wealth of experience and knowledge regarding infor- mation graphics. Since 2005, he has been teaching infography at the Augsburg University of Applied Sciences, where he is head of the study track Information Design in the Department of Design. He also teaches courses about visual storytelling at Darmstadt University of Applied Sciences (Germany) and visual culture at the University of Neuchatel (Switzerland).

Outside of teaching, he serves as the Educational Director (Intl. Affairs) for the Society for News Design (USA) and coordinates the academic exchange between participating universities.

$\mathrm{He}$ is also a member of the International Institute for Information Design (IIID) (Austria) and serves on the editorial board of its Information Design Journal. Prof. Stoll is actively involved in several conferences related to information graphics, among them Malofiej, the renowned infographics world summit in Pamplona, Spain. 

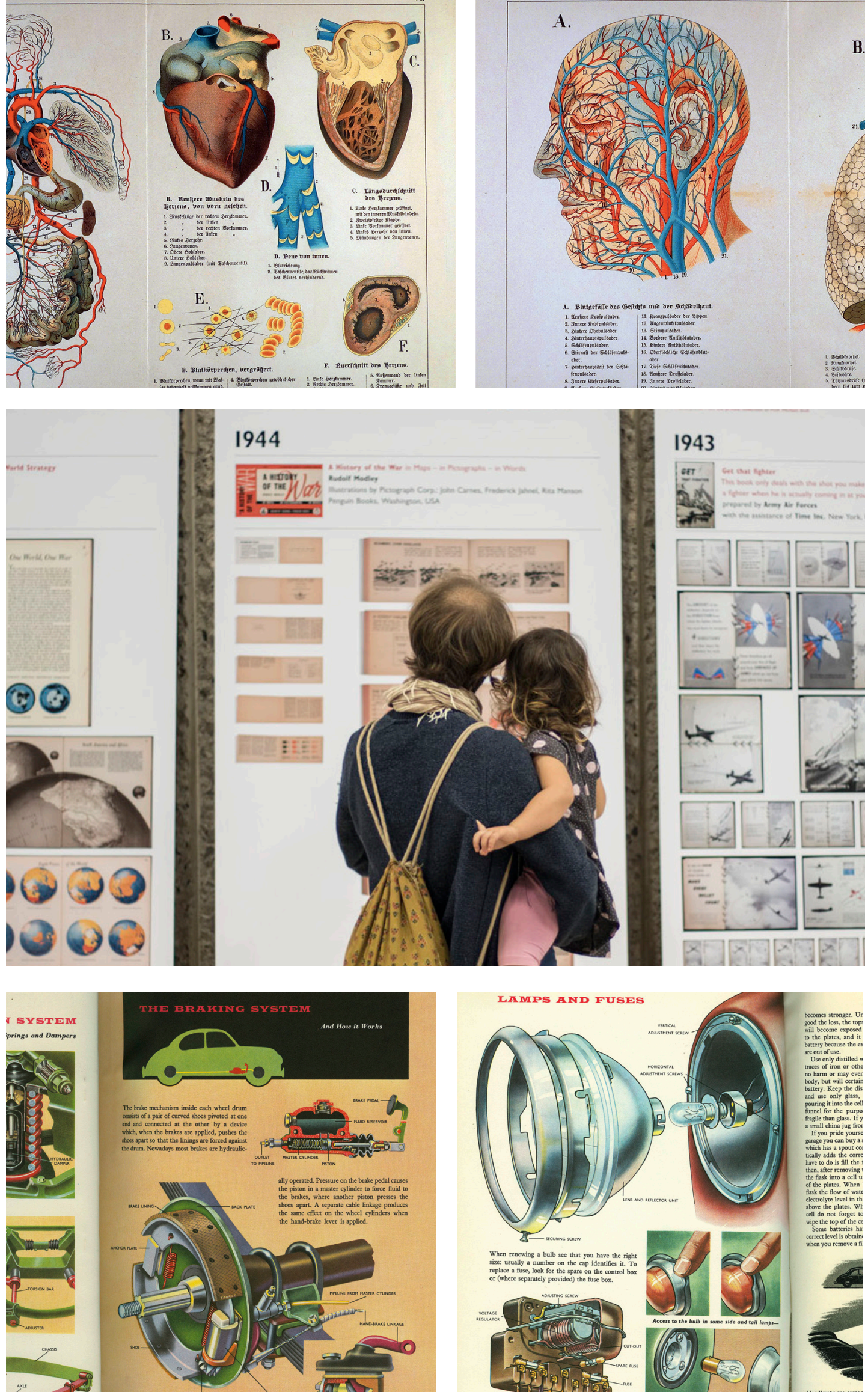


\section{The Tenerife 2CO2 workshops experience:}

\section{making the conference a space for learning by practicing and creating community}

Carlos Jiménez-Martínez

Learning strategies based on workshops have a long tradition in the design domain for the educational advantages they offer. Their formula allows individuals and groups to learn through practice, developing capabilities and fine-tuning skills which are based on personal strengths and needs. Workshops also provide an educational framework that nurtures the collaborative development of prototypes pivoting on the quality, richness and intensity of the process itself. Finally, they are convivial tools allowing participants to break, at least temporarily, inertia and routine, favouring the exploration of alternative ways and paces of thinking and doing.

In the event of the Tenerife 2017 conference, the 2CO organizing committee decided to enhance the program through a series of intensive design workshops addressed to professionals, young researchers and students. A way to start an exploration on the didactic issues associated with communicating complexity, and a strategy for warming up the program, fostering the student's engagement. The 2CO workshops took place on 21-22 November, immediately before the beginning of the conference.

A workshop lead by the NYC-based keynote speaker Kelli Anderson also took place as final, farewell event, offering its participants a practical workshop, about creating a personal pinhole camera-book from cardboard. A cozy, moment of relax after the busy conference days.

Three distinct set of workshops took place:

the 2CO workshops_educational explorations lead by the 2CO core community; the professional workshops_learning opportunities mainly directed to local professionals;

the educational workshops_a series of workshop directed to local and visiting students.

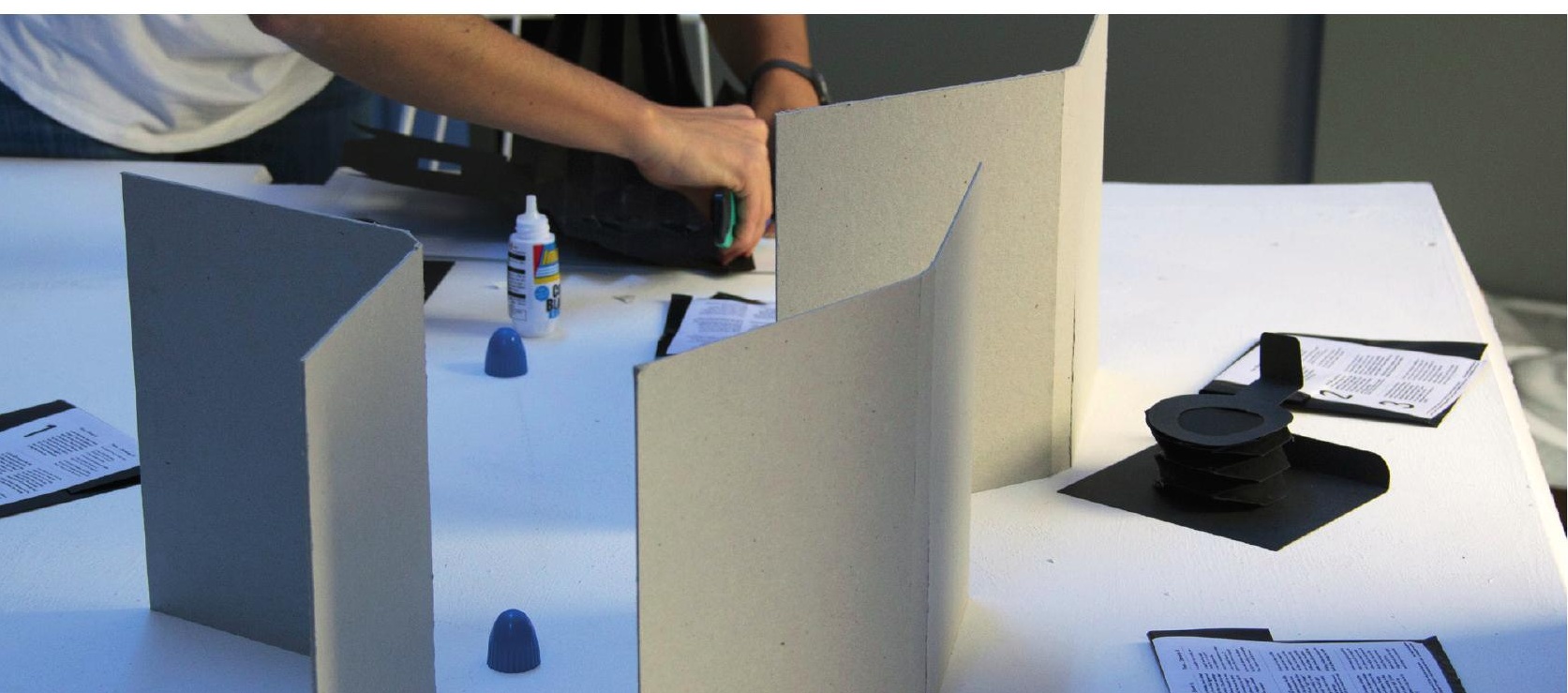



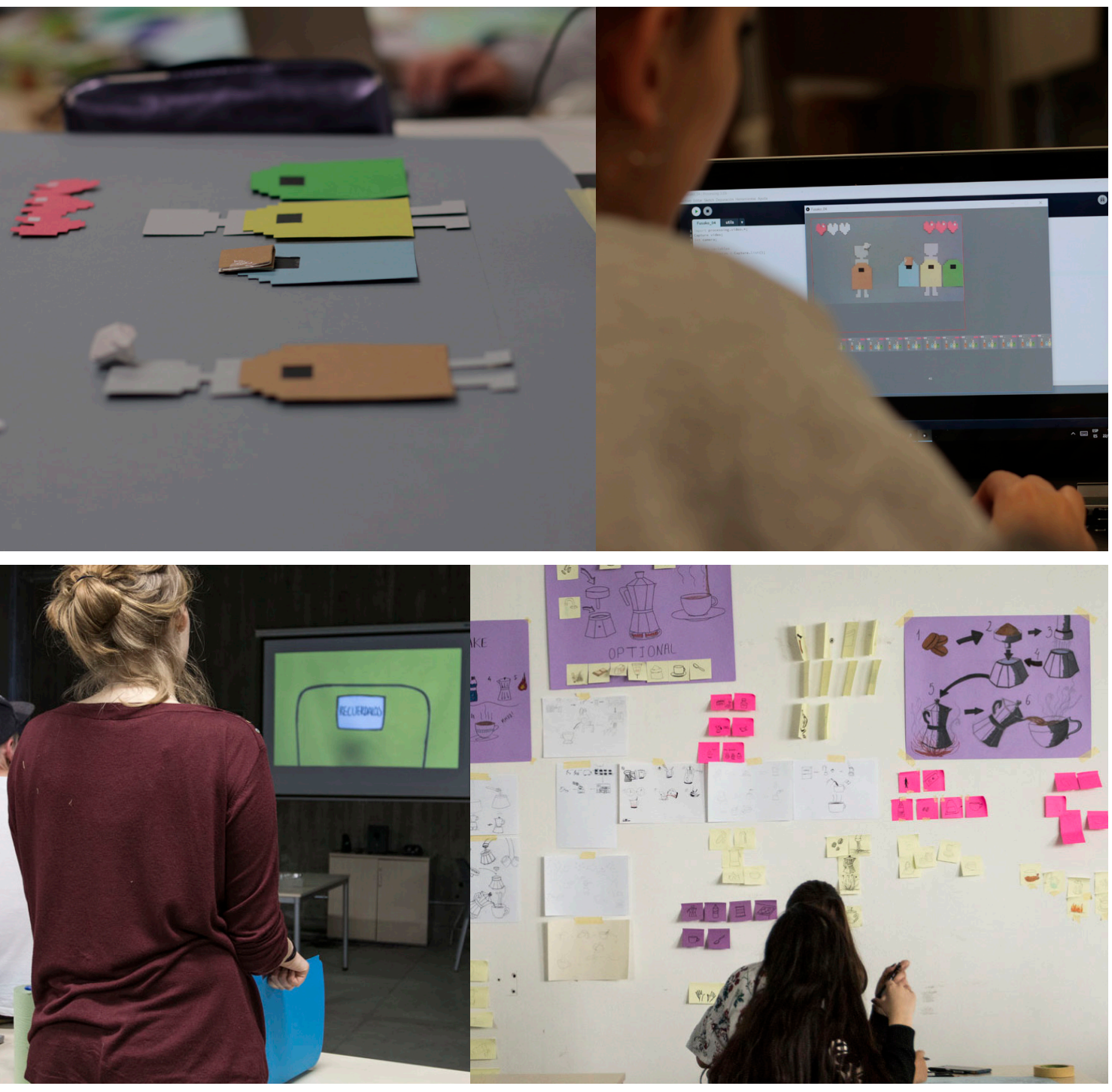

ii

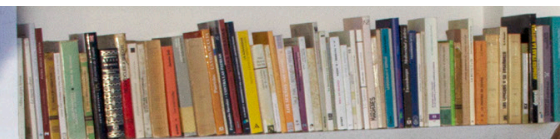




\section{1. $2 \mathrm{CO}$ workshops.}

\section{$16 \mathrm{~h}$ in 2 sessions of $8 \mathrm{~h} / \mathrm{day}$}

\subsection{Processing complexity. How to} design great information graphics Lead by Alfredo Calosci and Lisa Borgenheimer (who replaced Michael Stoll) Information graphics, is not just about "illustration", rather it involves a set of "rules" that produces a final result. Code may be used at different stages of the process starting from the data mining and until the final rendering. During this workshop, discussions about the making of "dataViz", and a short "hands-on" session on creative coding with Processing were carried out.

\subsection{In-camera simplicity. Animation basics for data presentation}

Lead by Nicolò Ceccarelli and Eleni

Tsampra

The workshop, that has since the Tenerife startup been replicated various times, combines two key elements: a crash course on basics for stop-motion (in-camera) animation, using objects and substitution tricks and techniques, paired with the discussion/presentation of key storytelling strategies. The goal of the two-day activity was to assist participants in producing short animated informative films with basic equipment and every-day materials, starting from real data about sustainability in Tenerife.

\section{Professional workshops. $8 \mathrm{~h}$ in 2 sessions of $4 \mathrm{~h} / \mathrm{day}$}

\subsection{Dialograma. The game of dia- gramming the dialectic.}

Lead by Jaime Serra

The workshop is an artistic action in the form of a table game called Dialograma (acronym for dialectics and diagram) that allows to construct a diagram from an intangible such as the dialectic between a group of people. Players debate a number of topics during a set time. After discussing each of the themes, players place the chips that represented their 'opponents' on the game board, according to two criteria:

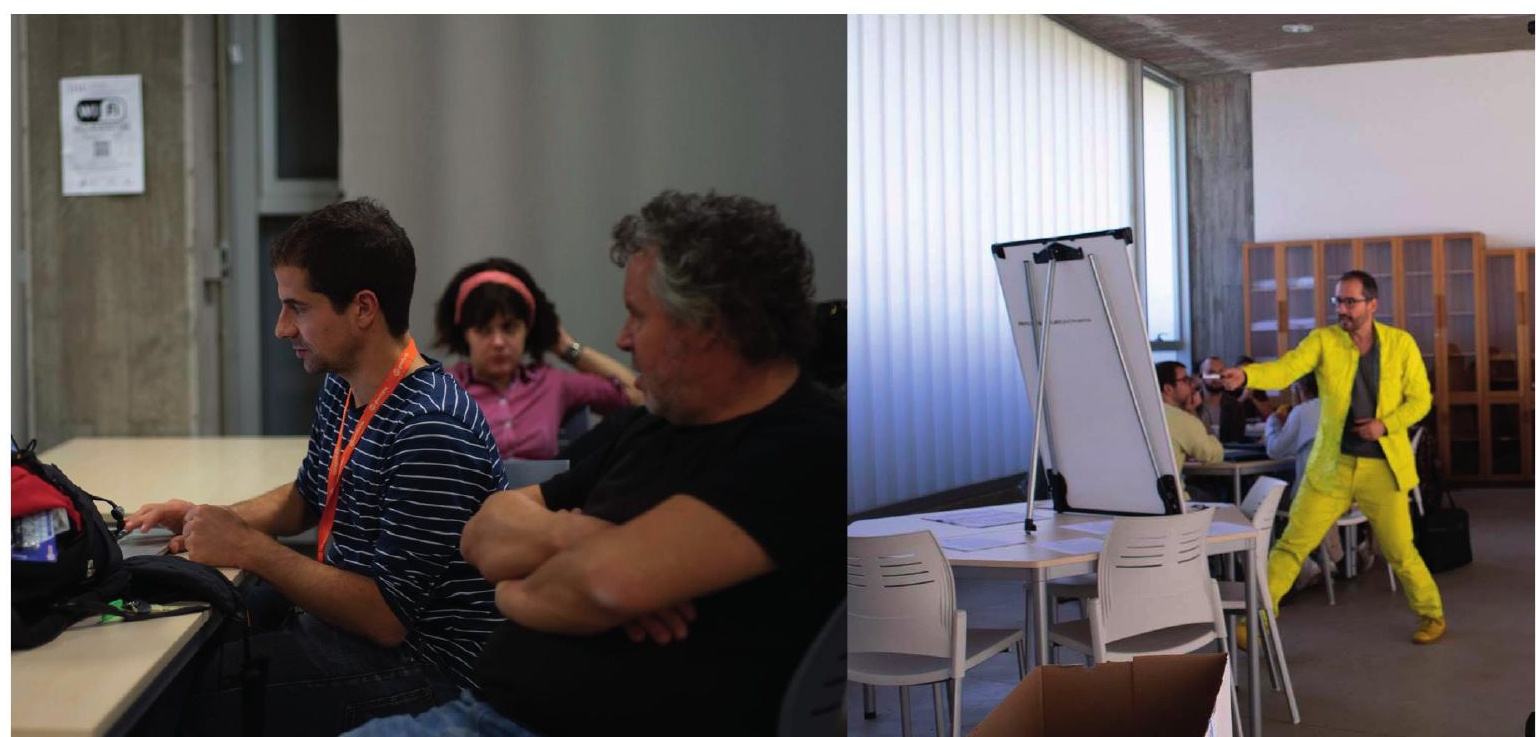


intellectual bond and emotional bond. A number of conclusions can be drawn from the analysis of the resulting diagram, these include: which players empathized the most, which were the most controversial issues, the ones that generating consensus, or the average point where the whole dialogue had been located.

\subsection{Visualizing ethical values in De- sign praxis: the challenge of pro- fessional deontology towards the strengthening of democracy}

Lead by Antoni Mañach

This workshop aimed to explore new meanings on the ethical relationships between design professionals and stakeholders. They tried to improve the designers knowledge about their duties-rights through the following research questions: can we visualize the connection between a complex world and the simplicity of deontological rules? What do we have to look for in ethics codes? Values, principles, functions, rights and duties, stakeholders, types of relationships among them, etc. Is the inductive method the ideal one to transform concrete cases of good or bad professional practices and deontological rules, in the form of duties-rights?

These and others concepts were applied in a real and concrete case study: the creation of the ethic code for di-Ca, the Canarian Designers Association. Data visualization, diagrams and infographics were crucial in this process.

\subsection{Draw me a coffee. A collaborati- ve experience to understand how to design complexity}

Lead by Letizia Bollini

The goal was to approach apparently trivial design problems understanding the complexity of the process, both as individuals and as a collaborative team. In the first phase, the proposed method led designers to look in a closer way to elements and connections among the parts of a whole system or process to generate a deeper understanding of the problem, iterations and the

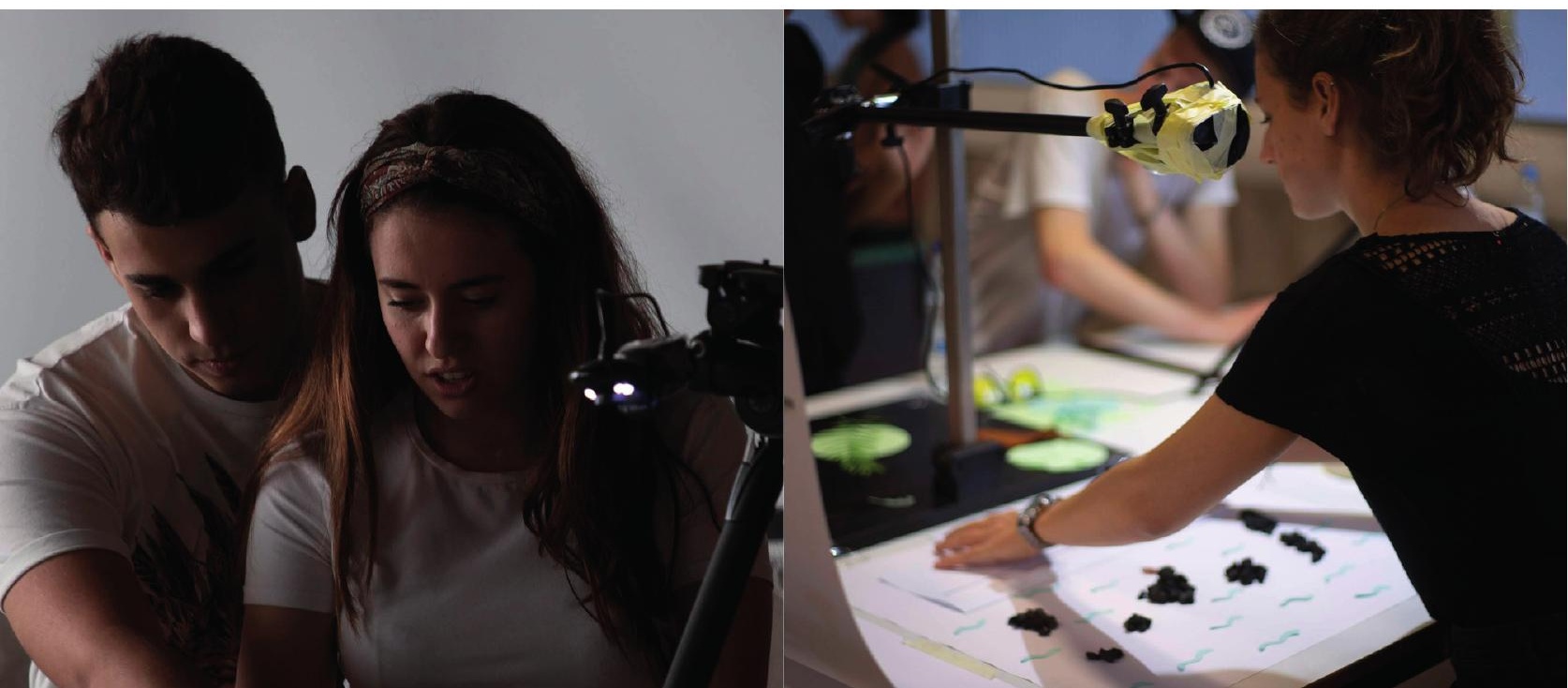


mental models beyond the single object, service or system. In a second moment, participants had to apply the methodology to a (digital) signage project within the local spatial context in which the workshop takes place.

\section{Educational workshops. $16 \mathrm{~h}$ in 2 sessions of 8 h/day}

\subsection{Introduction to Video Scribing}

Lead by Alfonso Ruiz and

Alicia Morales

The workshop was about the making of a video using the technique of video scribing (digital storytelling), or stop motion animation of a drawn narration. Students received a series of basic notions about frame by frame photography and digital postproduction that allowed them to know the basics of this narrative technique, today a standard presentations practice. Although apparently simple, its development implies a solid basic knowledge.

\subsection{Information Design for exhibi- ting complex data}

Lead by Noa Real

This practical workshop was based on the design of informative graphs to explain a process or a series of complex data. Starting with a practical case based on the history of poster design, students made infographic poster proposals that organized the information in a clear and didactic way. Students were introduced to the use of graphic design for complex information communication in an orderly and understandable way. Although students in the Bachelor Degree in Design dominate digital graphic design tools, usual applications consist on illustration or corporate identity projects, while they don't usually face with challenges on graphic organization of data and complex information.

The course provided skills in information architecture, composition and tools to make the presentation of information impactful, easy and comprehensible.

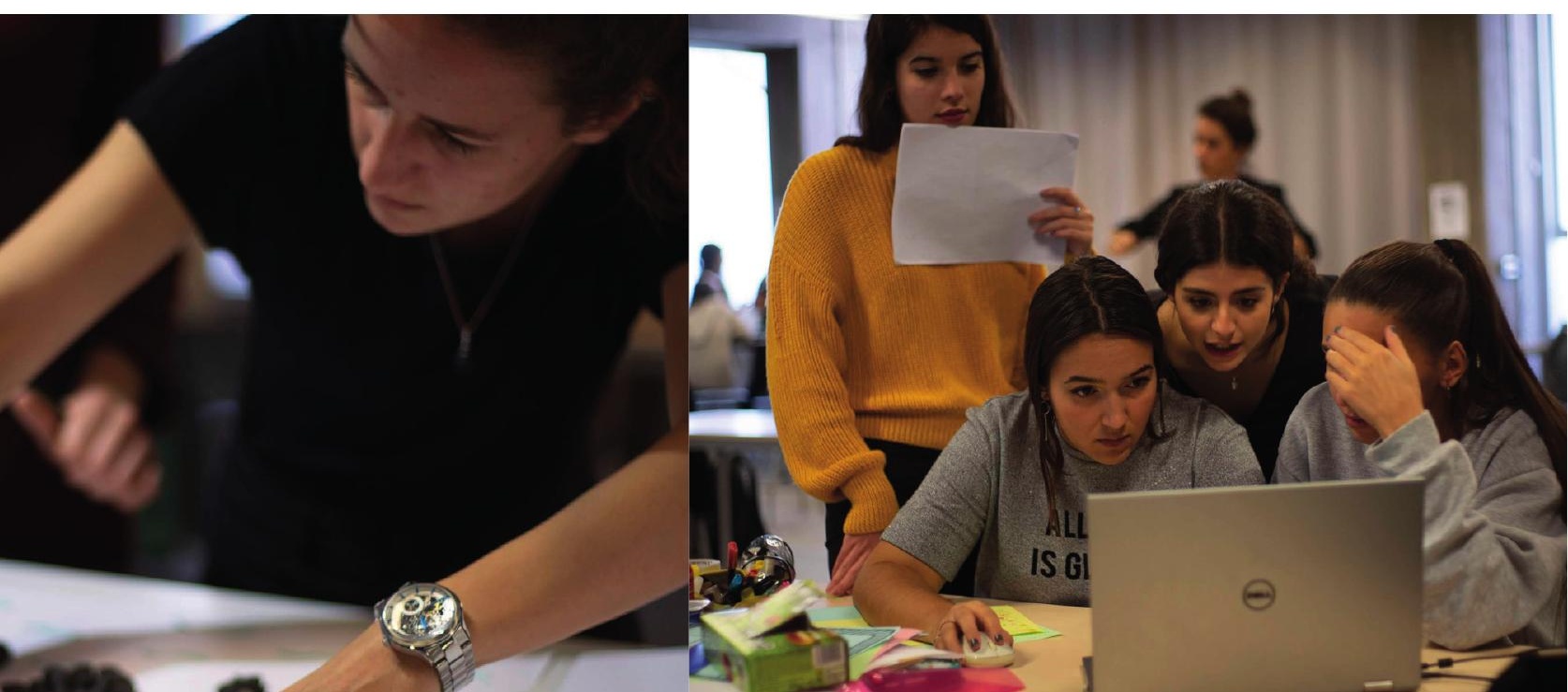




\subsection{Exhibition Design: Structure in space. Space between us}

Lead by Magda Piczyska, Wojciech

Kapela and Carlos Jiménez

The workshop aimed at developing a cross-cultural experimental exhibition space for international and intergenerational dialogue. The chosen topic was the significance of the sign: symbols, signals, images and their application in the construction of an informative environment - an encoding of space. A spatial structure was built using simple mapping techniques. Participants in the workshop learnt to transform narrative information into 3-dimensional space, by using data about the inhabitants of Tenerife as a case study.

\section{Conclusions}

Despite the exhausting organization of eight parallel workshops, the experience was a success on many grounds, and worthy to be considered for future events. Almost two hundred BA,
Master and PhD ULL design students attended the program. Classes were put on stand-by for the week - a first in the history of the School - and replaced by workshops. Swithcing from the usual routine allowed students to face new approaches, dynamics and skills. It was the first time that many of the participants had the opportunity of being somehow involved in an international design conference. Leading the workshops was a chance for their leaders to learn and change their perspectives. The resulting collaborative environment overtook the hierarchies and rigidities of a typical student-teacher relationship, encouraging networking among students, professors and attendees. Although the Faculty of Fine Arts of ULL has a history in design teaching, "communicating complexity" is a relatively new field for its curriculum, if compared to other design branches. We wish therefore to thank the colleagues of DADU-UNISS Alghero for their dedication in giving continuity to the 2CO 2013 conference, giving us the opportunity to celebrate it in Tenerife.

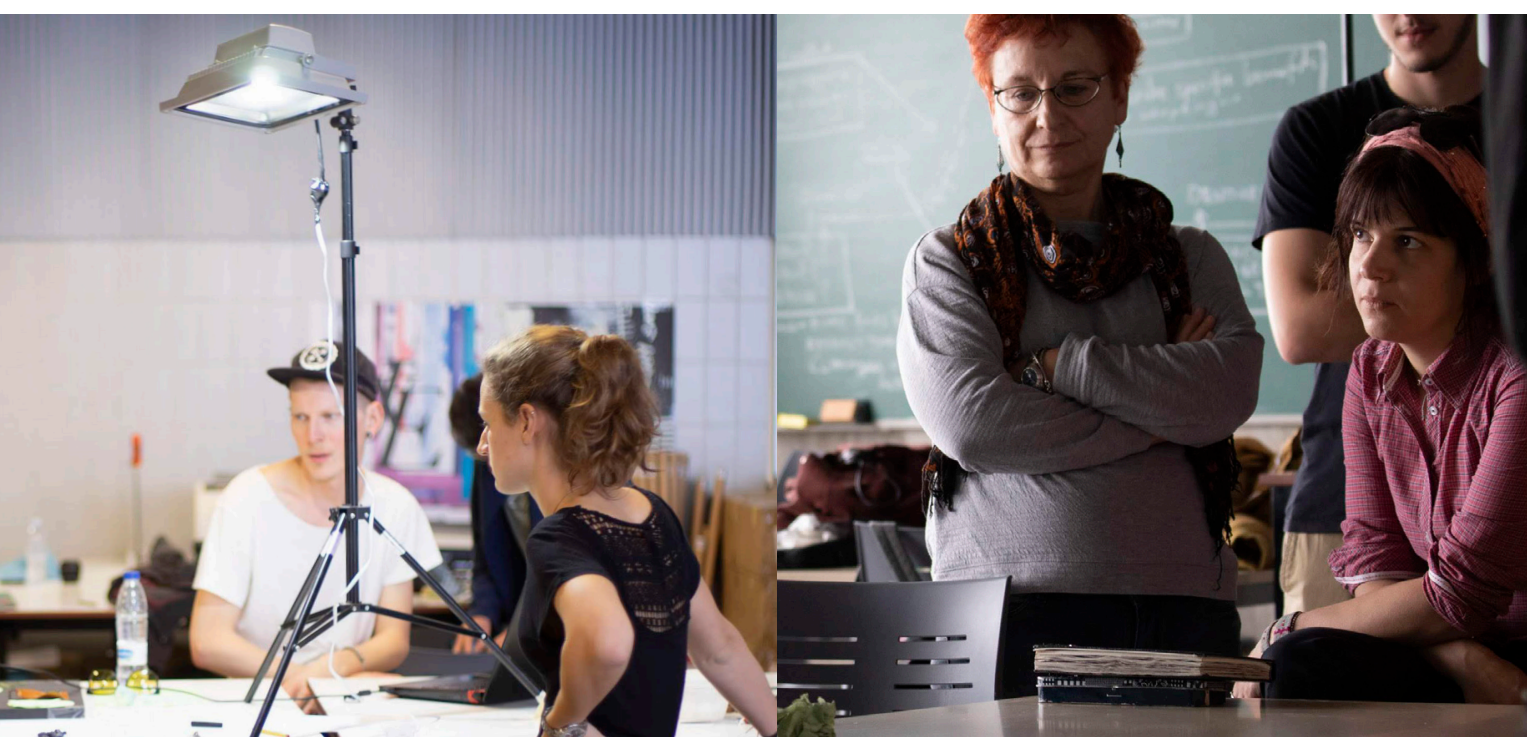




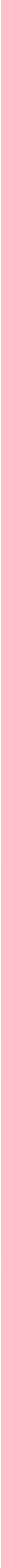




\section{Full papers}

1 : Info-Graphics 


\title{
Information // Message
}

\author{
Lisa Borgenheimer \\ Free University of Bolzano, Faculty of Art and Design, Universitätsplatz 1, Italy \\ info@lisaborgenheimer.com
}

\begin{abstract}
Both elements, the information and the message, are present in information graphics. The information is the translation of the data into visual structures. The message narrates the story the author intended to tell and to point out. Creating meaningful messages within information graphics can lead to more effectiveness in the knowledge transfer, but can also be used to generate propaganda. Therefore the method of visual storytelling can be used to convey informative messages within various settings and contexts. The process is the visual translation of contents into informative and narrative graphics, which can orientate on factual, statistical correctness or on telling emotional stories. Due to that, the information and message are adjusted to the users' needs and interests. In the end, using target-oriented visual storytelling has a higher impact on the knowledge transfer and the users' attention.

Reflecting on existing graphics and visual forms, the following text focuses on the various intentions of telling stories.
\end{abstract}

Keywords: Methodology, Visual Narrative, Storytelling, Semantics

\section{Introduction}

The research started as a master student at the University of Applied Sciences in Augsburg, where I developed a method for analogue and interactive information design as my master thesis. After that, I was mainly interested in the methodology of visual storytelling for information graphics and information design. Therefore I started working between practice and theory. During my time at the Free University of Bolzano, I'm doing research on the discrepancy between the statistical data and the ready-to-sell information graphics, by working on different projects and topics.

The content of information//message is a basic thought of my practice-oriented theory, which is also affecting my outcoming artefacts done with information design or information graphics. In the following text, I would like to point out this theory and relate it to my current practical research on "Communication for participatory democracy - Participatory Budgeting in Mals/Malles (Alta Val Venosta, Italy)". This ongoing project (June 2016 - June 2018) was funded by the Free University of Bolzano and is a collaboration with the municipality of Mals/Malles, POLITis and the Faculty for Education (unibz). 


\section{Information // Message}

The information and the message are always part of information graphics. Therefore the information is based on the dataset and the statistical translation. Whereas the message is the composed result of the content-related semantic elements, which generates particular metaphors.

On the basis of the own constructive perception, the information transfer has interfered and the possible metaphors are the consequences of intended or unintended messages, developed by the author or graphic designer.

The main difference between the information and the message is the method of visual translation. The focus on the statistical correctness or the composition of an emotional narrative is shifting the graphic to an information or message-based visualization. Therefore an information-orientated graphic is displaying the statistical aspect in a factual way. Instead, the message-orientated graphic is showing the emotional narratives.

\subsection{People and Data}

An information graphic is constantly related to a specific target group. Due to that, there is a difference in the complexity, the speaking voice and of course the overall visual appearance.

Creating a graphic means to perceive the (previous) knowledge of the topic, the interests and the possible behaviour of individuals and groups. It is necessary to consider the potential interpretation of the visualisation and the upcoming effect or impact, which can come instantly or later on.

The graphic designer/author/etc. needs to find the important information in the dataset and transforms it into a meaningful message, which can be understood by the related target group. This selected data illustrates an issue and contains meaningful and relevant information, which can be indicated in a message. In the end, this message is directing and narrating the specific issue.

\subsection{Design for Democracy}

As part of my PhD at the Bauhaus-University Weimar (DE) and my research at the Free University of Bolzano (IT), I am concentrating on target-group generated content with information-oriented and also message-oriented information design and graphics. My intention is to find the link between the proposition of the information // message together with a practical and tangible example.

My research project on participatory budgeting, together with the community in Mals/Malles, holds a strong connection to the citizens. Consequently, it was fundamental to create a strategy/method for communicating complex topics for people at the age of $14-99$, with different perception and knowledge of political issues. 
The first step was to determine the information and message based visualisations on the subject of participatory budgeting. Therefore, I analyzed the main issues of the process and the possible interests of the target group.

For sure, the discussion of available money is the most attractive information to mainly concentrate. But there are also other elements of the process, which need to be recognized: e.g. handing-in ideas, the decision-making and also the democratic election of projects, which is showing the acceptance of project-ideas within the community. However, the implicit message of the whole procedure carries the common and individual identity of the involved people and the potential changes within the local area.

\subsection{Communication for Participatory Democracy}

Using the information // message within this project, created a division between factual and emotional storytelling and the outgoing visual knowledge transfer. Therefore the different topics had a higher tendency to focus on the factual information or on emotional messages.

Talking about costs, investments, process planning needed a more reliable and legitimated translation of the datasets to underline the seriousness of the whole procedure. Therefore the visualizations need to show the facts with appropriate graphics, like bar/column charts, line charts, etc. to orientate on the informationtransfer.

Compared to the emotional part, the graphics have higher illustrative characteristics and physical/materialistic references to make the topic more tangible for the citizens. The graphics show the situation of taking part in the political procedure and how to behave in this situation. Therefore all visualizations are more related to the message and the metaphors, which are generating the stories.

\section{Conclusion}

Facts and narratives are connecting different people and identities. Concentrating on the method of information // message, to get the data understood by the citizens with different ages and familiarity, can help to facilitate the general knowledge transferring insights into various visual formats and are enabling to perceive the topic from different perspectives. The method opens more possibilities in style, graphic design, editorial design, etc. and makes the author think and not "just translate" the data into information graphics. Instead, the designer needs to consider the target groups' intentions, surroundings, influences and impacts by using the visual translation, which turns the data into concrete shapes and forms information-based or message-based. 

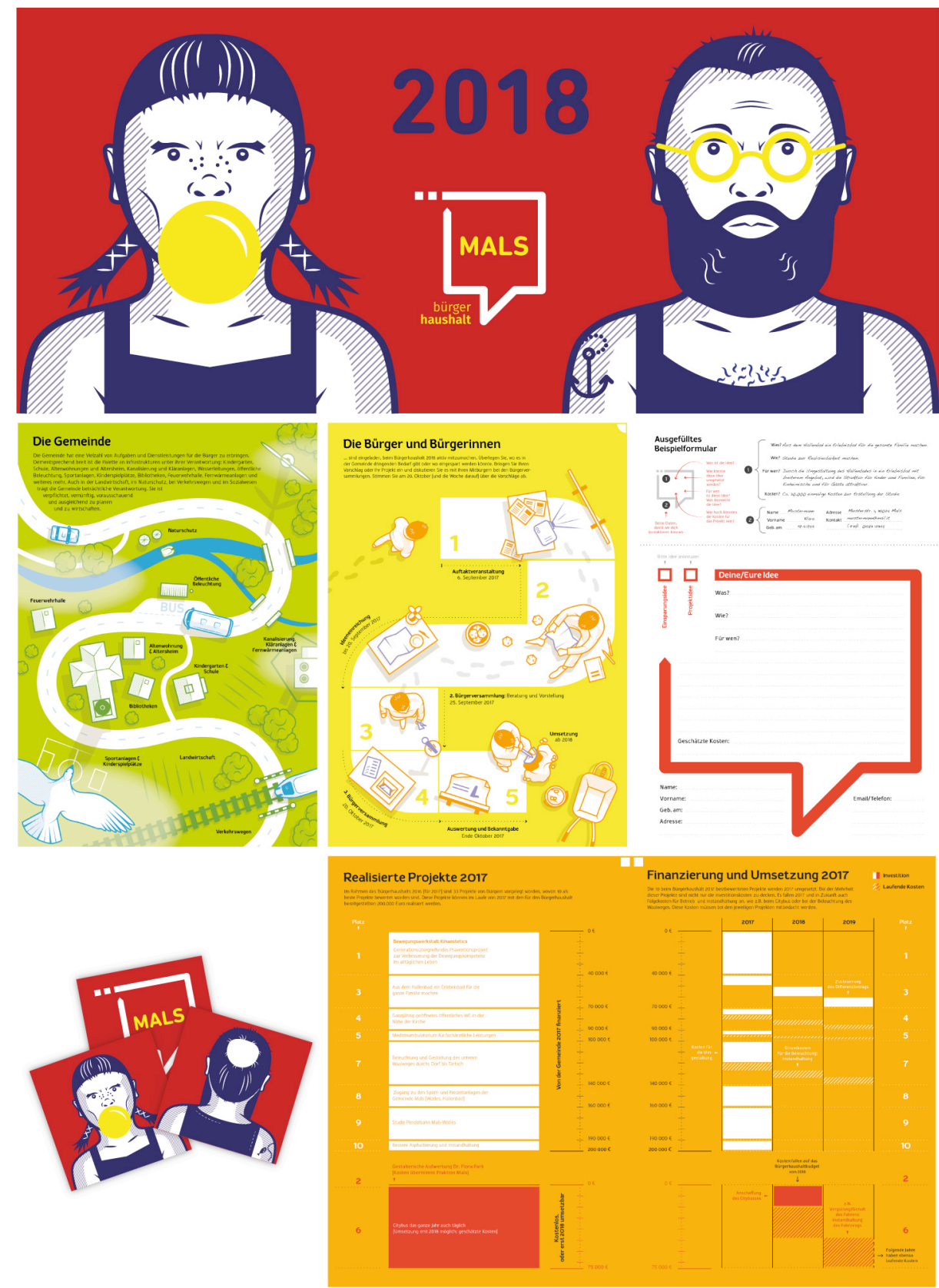

Fig. 1. Borgenheimer, L., Benedikter T., Bernhard A. (2017). Bürgerhaushalt 2017. Marktgemeinde Malles. Italy. Gemeinde Mals/Malles. 


\section{References}

\section{Books}

Benedikter, T. (2013), Die Gemeindefinanzen mitbestimmen - Der Bürgerhaushalt.

Bozen, Italien: POLITiS Bozen

Pörksen, U. (1997), Weltmarkt der Bilder. Stuttgart, Deutschland: Klett-Cotta

Yau, N. (2013), Data Points: Visualization That Means Something. Indianapolis, USA: John Wiley \& Sons Inc.

\section{Magazine}

Borgenheimer, L., Benedikter, T., Bernhard, A. (2016), Bürgerhaushalt 2017. Marktgemeinde Mals/Malles, Italy: Gemeinde Mals

Borgenheimer, L., Benedikter, T., Bernhard, A. (2017), Bürgerhaushalt 2018. Marktgemeinde Mals/Malles, Italy: Gemeinde Mals

\section{Website}

Yau, N. (2017), One Dataset, Visualized in 25 Ways, Retrieved from:

http://flowingdata.com/2017/01/24/one-dataset-visualized-25-ways/ 


\title{
Using pictograms improves the understanding of Stock-Flow Systems
}

\author{
Friederike Brockhaus ${ }^{1}$ and Peter Sedlmeier ${ }^{1}$ \\ ${ }^{1}$ Chemnitz University of Technology, Institut of psychology, \\ 09107 Chemnitz, Germany \\ \{friederike.brockhaus, peter.sedlmeier\}@psychologie.tu-chemnitz.de
}

\begin{abstract}
We examined if we could improve performance in so-called StockFlow Systems (SF-systems). SF-systems are dynamic systems, which consist of a stock and two flows - the inflow and the outflow. The stock changes depending on the flows' patterns. Many persons have problems understanding these systems (Sterman, 2002). Up to now, only one modification of the flows' representation format led to rather strongly enhanced SF-performance: using pictograms instead of line graphs (Brockhaus, Arnold, Schwarz, \& Sedlmeier, 2013). The present experiment analyzed if pictograms led to better performance when the SF-task was somewhat changed; this time, we focused on basic SF-understanding. Additionally, it analyzed, if further modifications of the diagram - emphasizing the distinction of the two flows and emphasizing the calculated difference of inflow minus outflow - could improve SFperformance. Results showed, the effect was smaller, and participants working on pictograms only solved about $50 \%$ or less of the tasks correctly. However, using pictograms improved SF-performance again.
\end{abstract}

Keywords: stock-flow systems / representation format / pictograms

\section{Introduction}

We wanted to find out if modifications of the representation of the flows could improve performance in SF-Systems. SF-Systems consist of an inflow, an outflow and a stock, which changes in dependence of the in- and outflow. Examples for SFSystems may be your bank account with money as the stock or the atmosphere with $\mathrm{CO}_{2}$ concentrations as the stock. In your bank account, the inflow can be your salary, the outflow your expenditures and the stock is the balance, which changes due to the incoming and outgoing money. It is important to understand SF-systems themselves, since they are omnipresent in our personal life, in society, in business, in nature etc. Furthermore, SF-Systems are part of complex dynamic systems, which are very difficult to understand, e.g. the worldwide climate. Often, it was assumed, that these difficulties stem from the high amount of parts or building blocks, complex dynamic systems consist of (Brehmer, 1992). However, the building blocks themselves often are difficult to understand, as exponential growth or SF-systems. 
Therefore, understanding these parts of complex systems is preliminary to understand the systems' complexity. Nevertheless, when people have to understand or manage SF-systems, they often fail even if they are highly educated. They often violate the "principle of accumulation": They do not realize that as long as the inflow is exceeding the outflow, the stock is increasing and vice versa (Cronin, Gonzalez, \& Sterman, 2009).

First authors to analyze SF-Systems were Booth Sweeney and Sterman (2000). In their study about SF-Systems, they created among others a task about a tub of water. In that task, participants received a graph of the in- and outflow (Fig. 1).
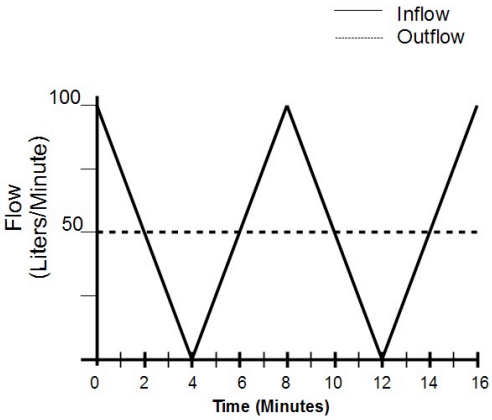

Fig. 1. Triangle task (modified from Booth Sweeney \& Sterman, 2000; taken from (Brockhaus et al., 2013)

Then they were to judge the change of the stock (water in the tub). They had to draw the changes of the stock over time into an empty diagram. In somewhat modified studies, participants had to answer questions about the changes of the stock. Many participants were incapable to solve the SF-tasks correctly. Often $40 \%$ up to $70 \%$ and more of the participants committed errors (Booth Sweeney \& Sterman, 2000; Cronin et al., 2009; Ossimitz, 2002).

Many modifications did not or only slightly improve SF-understanding (Cronin et al., 2009; Roeder, 2017; Schwarz, 2016). Following authors who claim, a graph can be more or less helpfull in dependence of its design (Macdonald-Ross, 1977), (Brockhaus et al., 2013) changed the often used line graphs into a kind of pictorial chart similar to those proposed by (Neurath, 1936). Indeed, the changed representation format of the flow graphs led to better SF-performance: $57 \%$ to $83 \%$ correctly solved the tasks including pictograms whereas in the baseline condition with line graphs only $23 \%$ to $30 \%$ of the participants correctly solved the task. These were large and significant effects. One possible drawback was the fact, that participants calculated the stock for each moment. 


\section{Present study}

In the present study, we changed the tasks wanted to find out if the surprisingly good performance still occurred in the modified tasks. Participants now answered questions instead of drawing the stock. In that way, only basic SF-knowledge is necessary and the participants might be less invited to calculate the stock's behavior for each moment. We designed the tasks so that the participants could easily infer the stock's maximum and minimum in case they understood the principle of accumulation. Furthermore, we modified the pictograms, iconic signs were used that showed directly the difference of in- and outflow (for example birth rates represent the inflow and death rates the outflow, babies and coffins are used instead of stick figures for all). The latter modification referred to ISOTYPE, which can be seen as a picture language and includes advices how to create pictorial charts (Neurath, 1936). We also modified the diagrams, so that the calculated difference of in- and outflow could be seen, that means the conditions including pictograms or iconic signs were presented either with or without emphasizing if the inflow exceeds the outflow or vice versa.

Our main hypothesis was that participants working with pictograms or iconic signs do better than those working with line graphs do. We additionally wanted to find out if iconic signs work better than pictograms and if emphasizing the calculated difference of in- and outflow is helpful.

\subsection{Method}

149 students of Chemnitz University of Technology (mean age = 22 years, $S D=3.8$; range 18 to 24 years; 97 Students of psychology (65\%) and 48 students of Sensors and Cognitive Psychology; 32 male (21\%) and 113 female ${ }^{1}$ ) took part. The participants solved three tasks of different flow patterns (one as in Fig. 1, one as in Fig. 2, and a third as in Fig. 3 ) in different sequences.

\footnotetext{
${ }^{1}$ Some participants did not give that information
} 


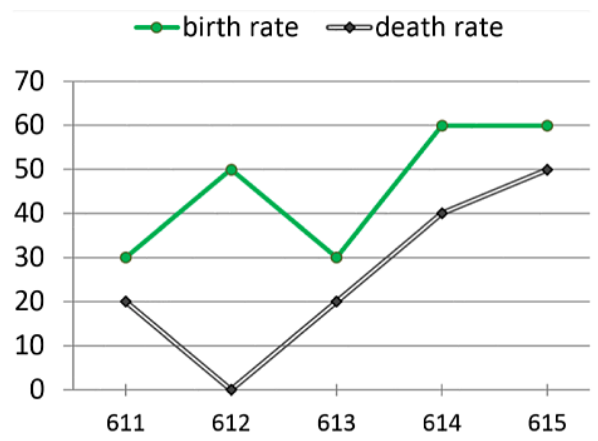

Fig. 2. One SF-task with flows shown as line graph (patterns of flows modified from Cronin et al., 2009).

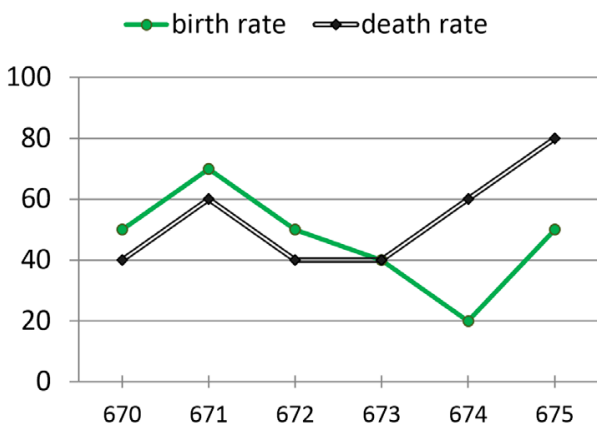

Fig. 3. SF-task with flows shown as line graph (patterns of flows slightly modified from Cronin et al., 2009).

The task's topic was the population of a village, changing in dependence of birth and death rates. Each participant solved all three tasks in one of five different conditions:

(1) baseline with line graphs (Fig. 1 to Fig. 3)

(2) pictograms with identical stick figures for both of the flows and no emphasis of the calculated difference (Fig. 4 (a))

(3) pictograms with emphasis (Fig. 5 (a))

(4) iconic signs with different signs for inflow and outflow and no emphasis (Fig. 4 (b))

(5) iconic signs with emphasis (Fig. 5 (b)).

To solve one task, the participant had to answer two questions: When is the stock maximal and when minimal. The answers were coded as correct ( 1 point) or wrong (0 points). To analyze SF-performance, we calculated the sum of all tasks and questions; it ranged from 0 to 6 points. 


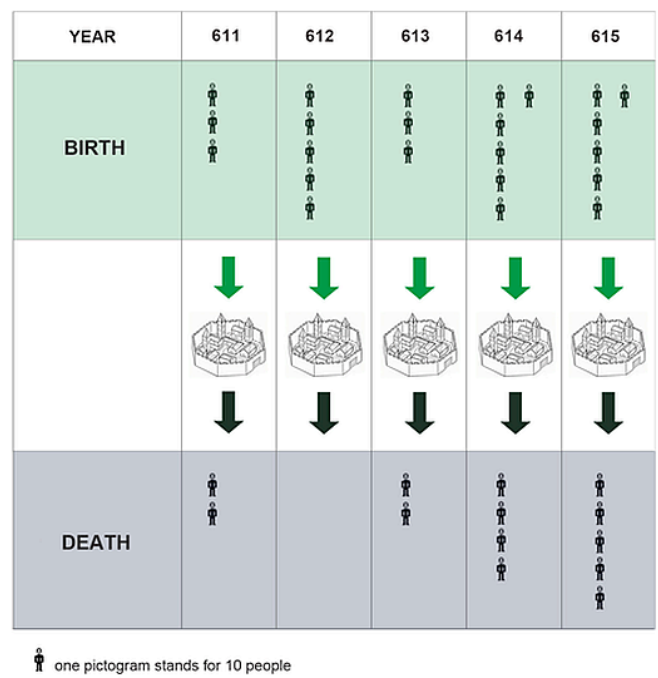

(a)

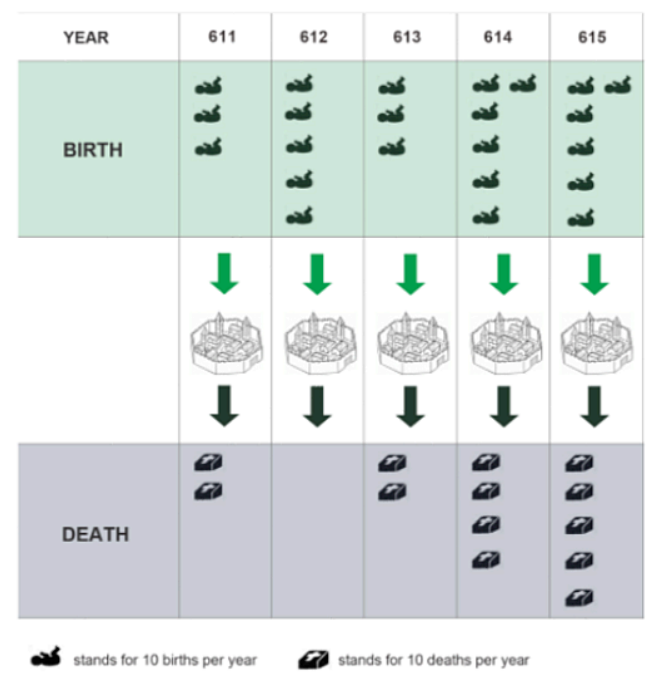

(b)

Fig. 4. Same patterns of flows as in Fig. 2, shown as pictograms (condition (2)) and iconic signs (condition (4)) (Arntz, G. "Pictograms" (Babies and coffins) / (C) VG Bild-Kunst, Bonn 2018) 


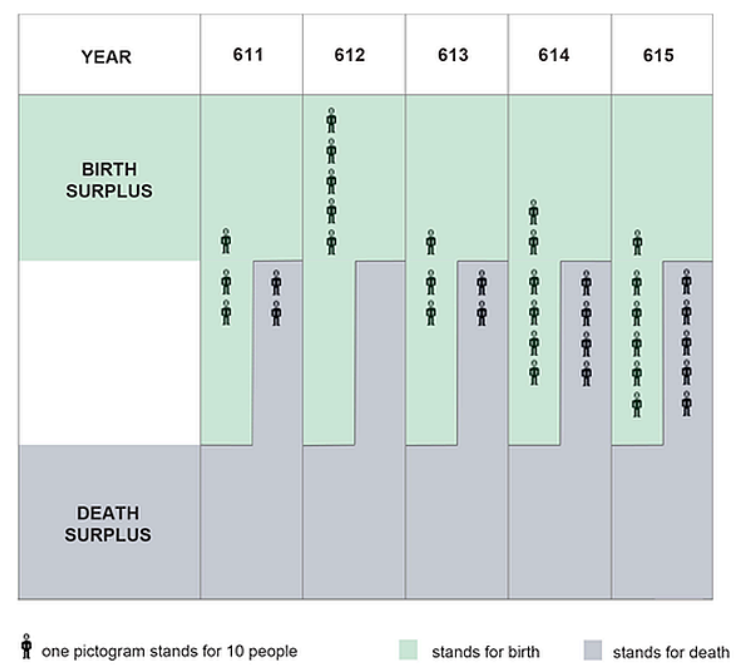

(a)

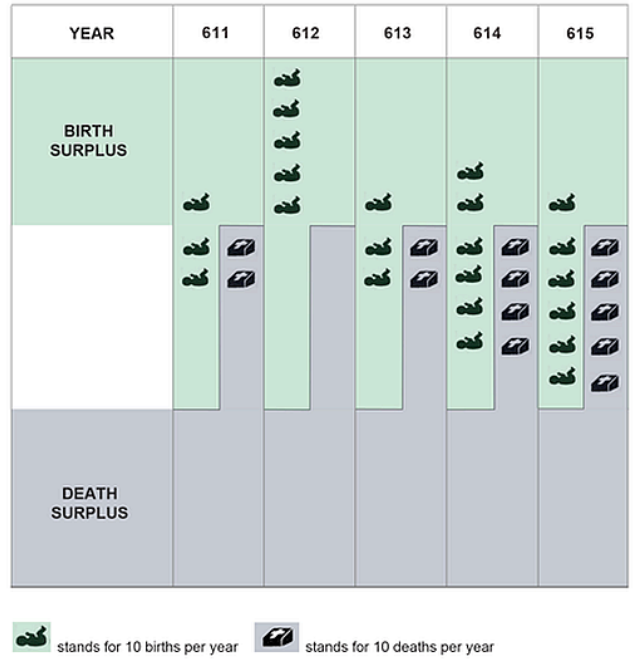

(b)

Fig. 5. Same patterns of flows as in Fig. 2, shown as pictograms and iconic signs (Arntz, G. "Pictograms" (Babies and coffins) / (C) VG Bild-Kunst, Bonn 2018), this time emphasizing the difference of in- and outflow (conditions (3) and (5)).

\subsection{Results}

Indeed, the performance was still better in the conditions with pictograms or iconic signs whereas emphasizing which flow is larger is not helpful. The mean percentage of correct solutions was for baseline $30 \%$, pictograms $48 \%$, pictograms and emphasis 
$41 \%$, iconic signs $53 \%$, iconic signs and emphasis $44 \%$. Fig. 6 shows the means of the sum for all solutions (0 to 6 points).

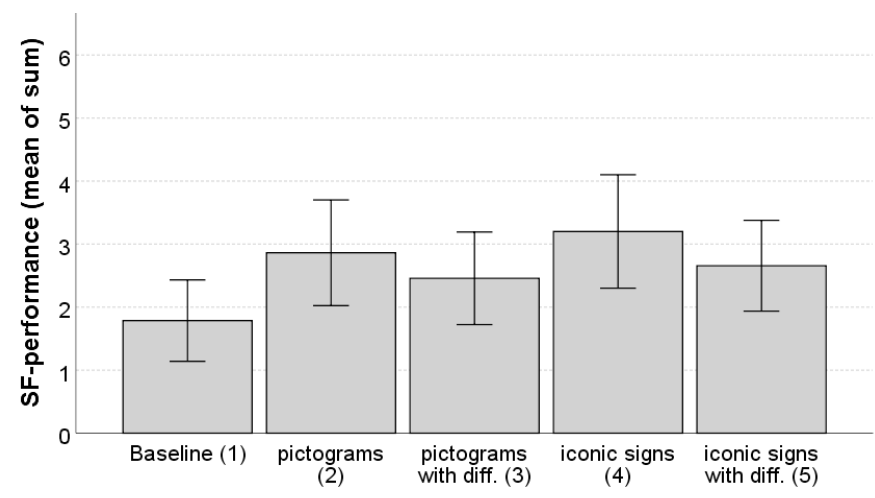

Fig. 6. Mean sum (ranging from 0 to 6 points) for SF-performance in the five conditions with $90 \%$ confidence intervals.

Regression analysis with mean sum as dependent variable and several predictors (conditions and some possible confounding variables) also revealed that SFperformance was still worse when line graphs were used: $R^{2}=.22, F(10,120)=3.424$; $p<.00^{2}$. Baseline being better than all other conditions showed $B=-.20(p=.02)$, which meant baseline significantly led to worse results; iconic signs should lead to better performance than pictograms: $B=.04(p=.33)$; emphasizing difference should lead to better performance: $B=-.08(p=.19)$; both variables did not significantly differ from zero. Further predictors were: sex, subject of study, grade of mathematics, femininity and masculinity (both measured by Bem sex role inventory revisited, (Troche \& Rammsayer, 2011) their interaction and finally a variable if participants had worked on SF-tasks in a former study. The only significant predictors were mathematical grade $(B=.26 ; p<.00$, the better the grade, the better SFperformance) and femininity scale $(B=-.27 ; p=.01$; the higher femininity value the worse SF performance) (for further information (Brockhaus, in press).

\subsection{Discussion}

Again, pictograms and this time used iconic signs led to better SF performance. But using pictograms or iconic signs did not influence SF-performance to the same extent as in the study before (Brockhaus et al., 2013). It seemed that calculating the stock for each moment increased the SF-performance, and the pictograms probably induced the correct calculations. In that study and in the present one, mainly

2 One outlier was excluded from regression analysis 
participants socialized in Germany, and so in a "Western country", and welleducated participants took part. Generalizing the results to other cultural or educational backgrounds is not possible and further studies should analyze that. However, the present study showed that iconic representation of the flows still led to better judgments than line graphs in our sample, so in the moment, the best advice is to use iconic signs when communicating information dealing with SFproblems.

\section{References}

Booth Sweeney, L., \& Sterman, J. D. (2000). Bathtub dynamics: initial results of a systems thinking inventory. System Dynamics Review, 16(4), 249-286.

Brehmer, B. (1992). Dynamic decision making: Human control of complex systems. Acta Psychologica, 81(3), 211-241.

Brockhaus, F. (in press) Von den Flussgroeßen zum Bestand: Lassen sich einfache dynamische Systeme intuitiv verstaendlich darstellen? (Doctoral Thesis). Chemnitz University of Technology, Chemnitz, Germany.

Brockhaus, F., Arnold, J., Schwarz, M., \& Sedlmeier, P. (2013). Does the modification of the representation format affect stock-flow-thinking? Proceedings of the 31st International Conference of the System Dynamics Society in Cambridge, MA, USA.

Cronin, M. A., Gonzalez, C., \& Sterman, J. D. (2009). Why Don't Well-Educated Adults Understand Accumulation? A Challenge to Researchers, Educators, and Citizens. Organizational Behavior and Human Decision Processes, 108(1), 116-130.

Macdonald-Ross, M. (1977). How numbers are shown. Educational Technology Research and Development, 25(4), 359-409.

Neurath, O. (1936). International Picture Language. . London: Kegan Paul. .

Ossimitz, G. (2002). Stock-Flow-Thinking and Reading stock-flow-related Graphs: An Empirical Investigation in Dynamic Thinking Abilities. Paper presented at the International System Dynamics Conference.

Roeder, V. (2017). The Attempt to Boost Stock Flow Performance by Using a General Problem Solving Strategy and a Reappearing Gender Effect. Paper presented at the 35th International Conference of the System Dynamics Society, Cambridge, Massachusetts, USA.

Schwarz, M. A. (2016). Vom stockenden Verständnis fließender Zusammenhänge. Darstellungs- und personenbezogene Einflussfaktoren auf das basale Verständnis einfacher dynamischer Systeme. (Doctoral Thesis). Chemnitz University of Technology, Chemnitz, Germany.

Sterman, J. D. (2002). All Models are Wrong: Reflections on Becoming a Systems Scientist. System Dynamics Review, 18, 501-531.

Troche, S., \& Rammsayer, T. H. (2011). Eine Revision des deutschsprachigen Bem Sex-Role Inventory. Klinische Diagnostik und Evaluation, 4, 262-283. 


\title{
Beyond visual literacy: Communication design as a cultural mediation process
}

\author{
Alfredo Calosci \\ Università degli Studi di Sassari, Dipartimento di Architettura Design \\ e Urbanistica, Alghero, Italia \\ \{alfredoc\}@negot.net
}

\begin{abstract}
This paper will present a modest theoretical contribution, from an historical perspective, trying to underline the fact that our knowledge on visual communication has deep roots in fields that reside under the domain of others non visual disciplines. By doing so, we hope that this short jump into the past may result useful to face contemporary communication challenges.
\end{abstract}

Keywords: Rhetoric / Perception / Ancient Schematic Representations / Cognition / Transmedia

\section{A multidisciplinary scenario}

One of the reason why we visualize is because we believe an image can stand for a thousand words. As matter of facts we all know that the relations between words and images - as well as diagrams, notations, monograms and all kind of forms of marks are much more complex as they constantly interacts in our communication systems (Ong 2002, Perondi 2012).

Diagrams - as well as others spatial configuration of signs - have proved to be incredibly efficient due to their ability to create memorable mental images of complex systems. For this reason they have been widely adopted to convey knowledge, no matter if based on "scientific evidences" rather than "facts" or "faith".

As visually literate people most communication designers are familiar with ancient schematic representations (Anceschi 1992) as trees, wheels, stairs and even with more complex visual metaphors like the "tower of knowledge", the "lignum vitae" or the "six winged seraph".

This paper will present a modest theoretical contribution, from an historical perspective, trying to underline the fact that our knowledge on visual communication has deep roots in fields that reside under the domain of others non visual disciplines. By doing so, we hope that this short jump into the past may result useful to face contemporary communication challenges.

Data visualization is not just about images - as proof of facts many of the historical (and more recent) contributions to this specific form of communication 
have been introduced by unorthodox designers. Most of the manuals on data visualization mentions historical examples likes the 1854 (Physician) John Snow London cholera map or (Nurse) Florence Nightingale's Diagram of the Causes of Mortality in the Army of the East, as well as (Civil Engineer) Charles Joseph Minard's work or (Geographer) Jacques Bertin contributions.

This multidisciplinary scenario is not just about professionals from different fields occasionally producing images; as the Isotype experience demonstrates, data visualisation is often part of a much more complex transmedia strategy where the visual abilities may have a prominent, but not necessary leading, role. As Marie Neurath and Robin Kinross pointed out (Neurath, Kinross 2009) the Isotype method was much more than a simple matter of symbols and pictograms, it represented a multidisciplinary approach for transforming information into a visual form. The graphic work of Gerard Arntz, Marie Neurath and others visual designers became the basis of a versatile syntax, that included also verbal elements, in order to produce visual explanations for a wide range of audience through publications, exhibit design and even a few motion graphics.

\section{A web of images}

The starting point of this contribution is about public speeches that includes also some visual elements and is based on an essay written by a professor of Italian Literature at the Scuola Normale Superiore in Pisa. By studying the beginning of vernacular preaching, Lina Bolzoni (2004) shows the use of a wide web of images as part of what we may call today a transmedia strategy of communication from the early XIV century. Thanks to her knowledge of rhetoric, and the role of images in several mnemonic techniques, the author unveils a dense network of meaning as it was supposed to be perceived at the time of their creation. Because, even for visually literate people, there are images we are no longer able to see, although we look at them.

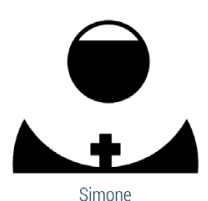

Simone

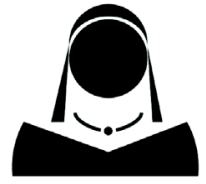

Caterina

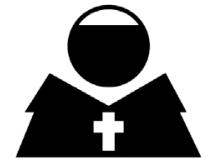

the young friar

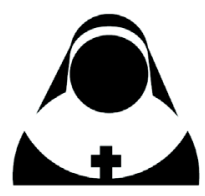

young nun

Fig. 1. Colloquio Spirituale: the four characters.

Part of this particular journey across the vernacular preaching, from its origins to St. Bernardino da Siena, is dedicated to the "Colloquio Spirituale" (spiritual conversation), a sermon written by Simone da Cascina by the end of the XIV century. The text is a dialog among four characters - two males and two females, two young 
and two old - each one absolving a precise narrative role. The two main characters are, from one side, Simone: the theologist, the main teacher, the one who knows and is trying to explain all the deep meaning of the liturgy - and, on the other side, Caterina: the religious woman who is willing to know and the one who arise questions. Along the conversation they are joined, in first place, by a young friar and shortly later by a young noun. The four together covers all the main functions that rhetoric prescribes for an effective and compelling discourse: to teach, to amuse and to move (docere, delectare, movere) and, in a way, they represent them in a kind of teatral allegory.

Simone and Caterina are in charge of the docere part of the discourse in a sequence of questions and answers interrupted, every once y a while, by the interventions of the young friar - who rephrases Simone's answers in visual metaphors. Most of the these allegories represents spaces and building - and others kind of locis - amusing the reader and offering him places to hang concepts in memory. While doing so the young friar get an immediate enthusiastic feedback from the young noun who get enlightened by the metaphors and moved by the acquired knowledge.

Shaped in this way, the conversation can stimulates the intellect, the will and the memory of the reader by offering him simultaneously allegoria, exemplum and locis.

Another vivid example of the many different uses of visual metaphors is presented in the chapter dedicated to San Bernardino da Siena's public speeches. Bernardino of Siena was a Franciscan friar who lived in Italy between 1380 and 1444. His popular preaching made him famous during his own lifetime, although it was frequently directed against, sorcery, gambling, infanticide, usury, and others more sensible issues likes witchcraft, sodomy, homosexuality and judaism. Besides its moral authority, Bernardino is often described as a skilled kind of showman, aware of all the tricks used to capture and hold people's attention while competing for audience in a public square.

Lina Bolzoni suggests a classification for Bernardino's use of visual metaphors. Images were frequently used as an implicit or explicit index for the different arguments used along a preach or for the different topics covered in a cycle of speeches. For instance, images like trees, wheals or a a six-winged seraphim where regularly used as a starting point for diagrams that enumerates, and allows to recall, long list of items like christian theological virtues or deadly sins. So it was quite common, in a Bernardino's speech, to listen the equivalent of a table of contents slide, in a contemporary power point presentation, as a description of a familiar form labeled with the main presentation's index.

Another common use was to adopt an image as an illustrations, by evoking some of the (not so abundant) items belonging to the social visual repertory, mostly made by paintings and frescos exposed nearby in public spaces.

Bernardino was also especially talented in creating new visual metaphors by suggesting unconventional synesthetic associations. One of them allows him to use a rook (Corvus frugilegus) as a symbol for procrastination by associating the cry of the 
bird: "Cra Cra Cra ..." with the latin expression for tomorrow "Cras" (as in the english etymology of "pro-cras-tination").

As a mix of the two previous categories, by creating new unorthodox interpretations of existing and recognized images Bernardino has pioneered what we may define today as culture jamming.

And finally, he creates a new iconography - acting as a sort of art director - by reintroducing an updated version of the "JHS" monogram, as support for an ars combinatoria of variable meanings. Bernardino biography is still associated with this christogram, later adopted by religious congregation of the "Society of Jesus" (Jesuits), that becomes part of his own iconography as a Saint.

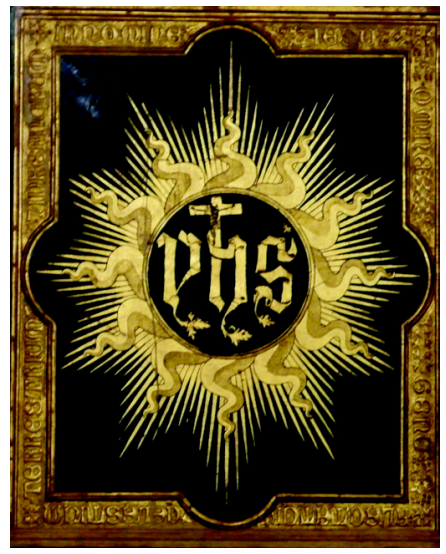

Fig. 2. The YHS monogram Di Laboratorio sf - Opera propria, CC BY-SA 4.0,

The iota-eta-sigma monogram IH $\Sigma$ (from greek IH $\Sigma O Y \Sigma$ : Jesus) was already in use

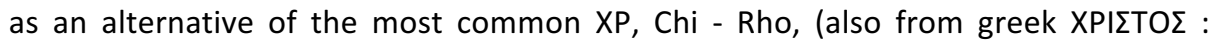
Christus) symbol. IHS, JHS or YHS are all different latin translations for IH $\Sigma$ - most of them can also be read as an acronymous i.e. Jesus Hominum Salvator, or In Hoc Signo, among many others possible meanings. Bernardino's version presents the monogram on the top of a golden blazing sun - with 12 mayor sunbeams and others 144 smaller ones - over a blue background.

This kind of new heraldic-like visual identity for the christian community was also intended as a possible alternative to displace both popular pagan symbols and seals of political factions, like the Guelphs and Ghibellines, from public spaces.

If for one side the YHS monogram can be used, as a whole, as a sign for christianity - on the other side, every single elements offers Bernardino a huge repository of visual references for a limitless combinations of meanings. Consider for instance the letter " $h$ " - drawn in the monogram with an added horizontal stroke as in a cross - in one of his speech, Bernardino invite his audience to associate the letter with the "Holy Spirit" - being "yhs" the trinity - because its curved shapes refers to a pregnant woman (who get pregnant by the HS), because its a silent letter 
and its pronounced just by a breath of air ... because is the 8th letter of the alphabet ... and so on. Bernardino mixed up text and images and used without distinction letters as shapes - and viceversa - in its descriptions that leads to new cultural conventions.

Observed from our point of view, he was able to pack several layers of moral and religious meanings into every single item of the web of images he call forth during its public preaches.

\section{Evolving concepts}

Both, scientists and mystics, shares a common ability for understanding something even before being able to see it.

Our task, as communication designers, is different; most of the times we are asked to convey a message about topics that are already acknowledged. In order to do so, we also pack layers of informations and meaning into visual devices and we expect our audience to be able to move from perception to cognition, without any other external help, and to create by themselves new associations in the network of their ideas and to fix them in a memorable form.

Sometimes this schematic representation behave almost like a real model, as in the periodic table of the chemical elements devised by Dmitri Mendeleev in 1869, that contemplates correctly the position, and therefore the properties, of still unknown elements. Most of the time what we outline are just visual metaphors of the real process.

Visual literacy consists in a set of representation skills, mainly built on empirical knowledge and observation, that has been recently enhanced by several contributions from others disciplines, both from social and natural science.

What we discovered about the physiology of perception mostly confirmed what was previously empirically observed. We have always been aware of optical illusions and, generally speaking, we know that our five senses sometimes lead to weird perceptions. But since we know how represent spaces using perspective, we are also able to produce astonishing anamorphic effects, as in "The Ambassadors" by Hans Holbein the Younger (1533). The same happens with the "Hermann Grid", an optical illusion, noticed by Ludimar Hermann in 1870, we can now explore and easily recreate thanks to what we know about saccade and eye movements. 

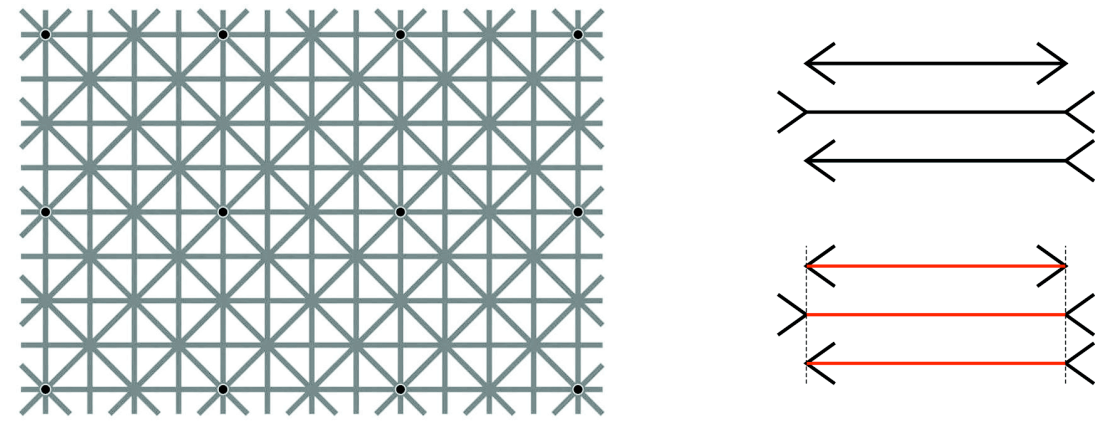

Fig. 3. The Hermann Grid and other optical illusion,

Behind our eyes, even our brain sometime gives us some false impressions. Nowadays, thanks to the "Dual process" theories of cognition (DPT), we're also aware of the existence of cognitive illusions. DPT have been around for a long time but they become popular only recently, thanks to Daniel Kahneman's best seller "Thinking fast and slow".

According to this theory, our cognitive processes are managed by two systems. System 1 produces the fast, intuitive reactions and instantaneous decisions that govern most of our lives while System 2 is the deliberate type of thinking involved in focus, deliberation, reasoning or analysis - such as calculating a complex math problem, exercising self-control, or performing a demanding physical task.

From this perspective, the path from perception to cognition rely on our ability to create compelling sensible images, suitable to be stored by System 2 in order to be easily retrieved by System 1 when needed - as Simone da Cascina and Bernardino da Siena empirically observed.

Even intuitions are not naturals ideas, they are heavily influenced by our cultural conventions and by the authors we familiar with. Carlo Rovelli (2017) gives us a very clear example of this process comparing our natural perception of "time" with the evolution of this concept in contemporary physics.

Time is frequently represented as a uniform linear variable on diagrams and timelines. This linear metaphor is what we have been told at school and is still the way time is conceived in classical mechanics. Now, if you think about our personal perception of time its everything but uniform. We live minutes that lasts for hours, days that rush and never ending seasons.

Physicist told us that time was linear and now they are almost sure that it is not longer true - at leat at certain scales of the matter. At the same time they invite us to understand the world by studying changes rather than things.

As in the past, communication it's essentially a matter of arranging clusters of ideas, in a way they can be easily retrieved, along a transmedia narrative; it requires a solid conceptual background and cultural mediation abilities, as well as our specific visual empirical knowledge. 


\section{References}

Anceschi, G. (1992). L'oggetto della raffigurazione. Milano: Etaslibri.

Bolzoni, L. (2004). The web of images: Vernacular preaching from its origins to St Bernardino da Siena. Aldershot: Ashgate.

Kahneman, D. (2015). Thinking, fast and slow. New York: Farrar, Straus and Giroux.

Neurath, M., \& Kinross, R. (2009). The transformer: Principles of making isotype charts. London: Hyphen.

Ong, W. J., \& Hartley, J. (2002 - 2013). Orality and literacy: The technologizing of the word. London: Routledge, Taylor \& Francis Group.

Perondi, L. (2012). Sinsemie: Scritture nello spazio. Viterbo: Stampa alternativa/ Nuovi equilibri.

Rovelli, C. (2017). L'ordine del tempo. Milano: Adelphi. 


\title{
When Everything goes wrong Make a Diagram
}

\author{
Maria Rosaria Digregorio \\ De Montfort University, Leicester Media School, Faculty of Technology, \\ The Gateway, Leicester, LE1 9BH, United Kingdom \\ Maria.Digregorio@dmu.ac.uk
}

\begin{abstract}
Looking at historical examples, this research explores the power of diagrams and visual reasoning. It focuses on their ability to make knowledge more accessible, train critical thinking and trigger a form of intellectual resistance in a post-truth world; it encourages a deeper integration between diagrams and writing, and the diffusion of information design approaches outside the design realm.
\end{abstract}

Keywords: post-truth / diagrammatic reasoning / non-linear writing / visual rhetoric

\section{Introduction}

In 2016 Oxford Dictionaries declared 'post-truth' word of the year. The adjective is defined as 'relating to or denoting circumstances in which objective facts are less influential in shaping public opinion than appeals to emotion and personal belief'. The choice acknowledged a spike in frequency in the context of the EU referendum in the United Kingdom and the presidential election in the United States. Since then, the word became even more mainstream, extending its meaning from an isolated quality of particular assertions to a general characteristic of the current age. One year later the winning word for Collins Dictionary was 'fake news', defined as 'false, often sensational, information disseminated under the guise of news reporting', reinforcing the perception of a dismal context.

This trend seems to suggest that when dealing with the challenging task of communicating complexity, presenting information in a clear and accessible way is not a common practice because is not perceived as an effective strategy - it works better confusing and encouraging irrationality.

Political interests have often preferred propaganda to actual facts, but the recent developments have aroused the doubt that this is a lot bigger than just the political sphere: there is too much information out there, it is very easy to spread fake news and it is very hard for people discerning what is true and what is not - it becomes easier opting for slogans rather than composite facts.

How can information designers - and the whole humankind - cope with such a scenario, where making the effort of understanding and communicating complexity seems overwhelming and almost useless? A possible answer is making diagrams - 
focusing on visualising reasoning and trying to reclaim the power of logical thinking and good argumentation. It might feel a small action, but diagrams are actually really powerful.

\section{The Power of Diagrams}

Visual inferences. In math and geometry, visual configurations are used as proper inferences to demonstrate the validity of reasoning - for instance in the case of the Pythagoras's Theorem and the binomial theorem. Despite written words or notations can also be used to visually represent theorems, the diagram is able to show at glance the reasons behind the rule (Perondi, 2012).
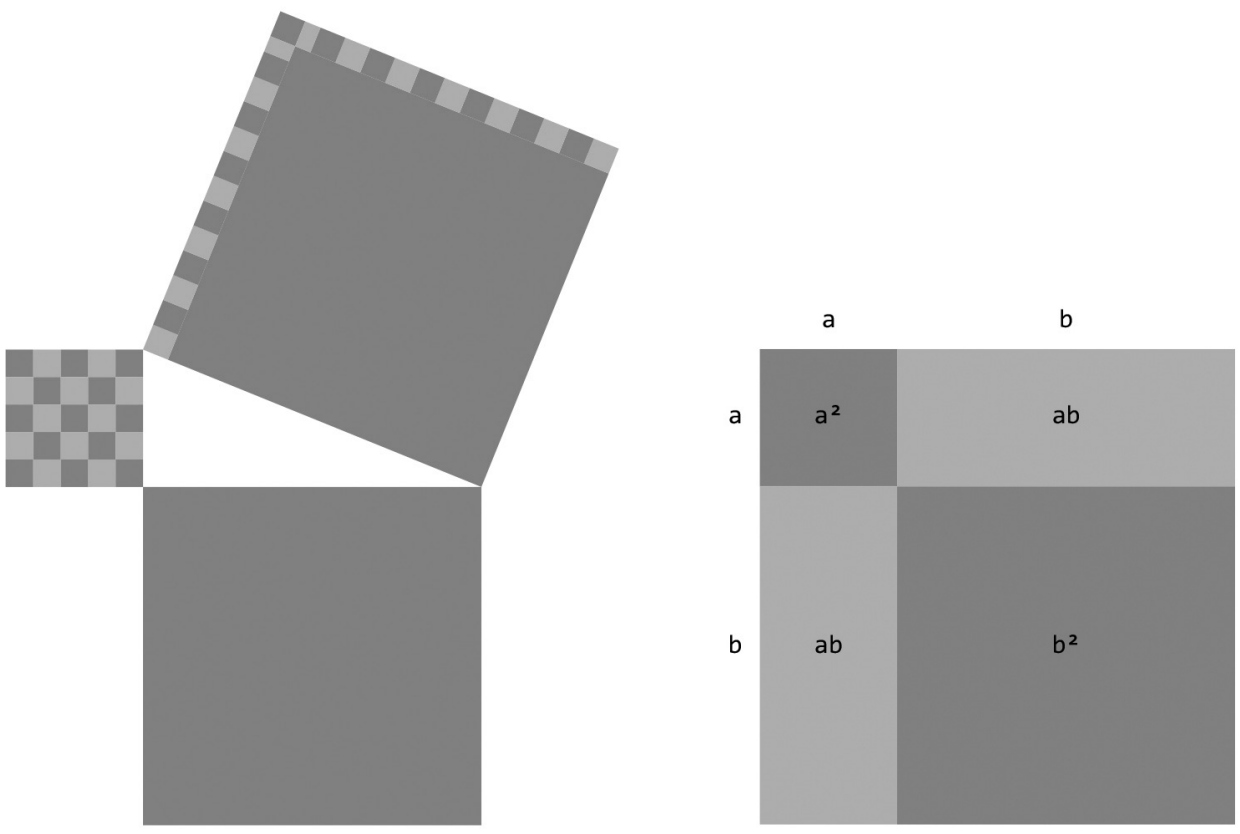

Fig. 1. Pythagoras's Theorem. The square of the hypotenuse is equal to the sum of the squares of the other two sides $\left[a^{2}+b^{2}=c^{2}\right]$. In Digregorio, M. R. (2010), Tipografia delle relazioni logiche. Rappresentazione tipografica della struttura del ragionamento. Master Thesis, Università IUAV di Venezia, Venice, Italy, p. 16.

Fig. 2. Binomial Theorem. A squared binomial is equal to the square of the first term, plus the double of the product of the first by the second plus the square of the second term $\left[(a+b)^{2}=\right.$ $\left.a^{2}+2 a b+b^{2}\right]$. In Digregorio, M. R. (2010), Tipografia delle relazioni logiche. Rappresentazione tipografica della struttura del ragionamento. Master Thesis, Università IUAV di Venezia, Venice, Italy, p. 16. 
Following the same principle, Oliver Byrne designed a version of The Elements of Euclid 'in which coloured diagrams and symbols are used instead of letters for the greater ease of learners' as stated in the subtitle. Words, notation and diagrams are hybridised in a non-linear configuration in which reasoning is demonstrated through visual deduction.

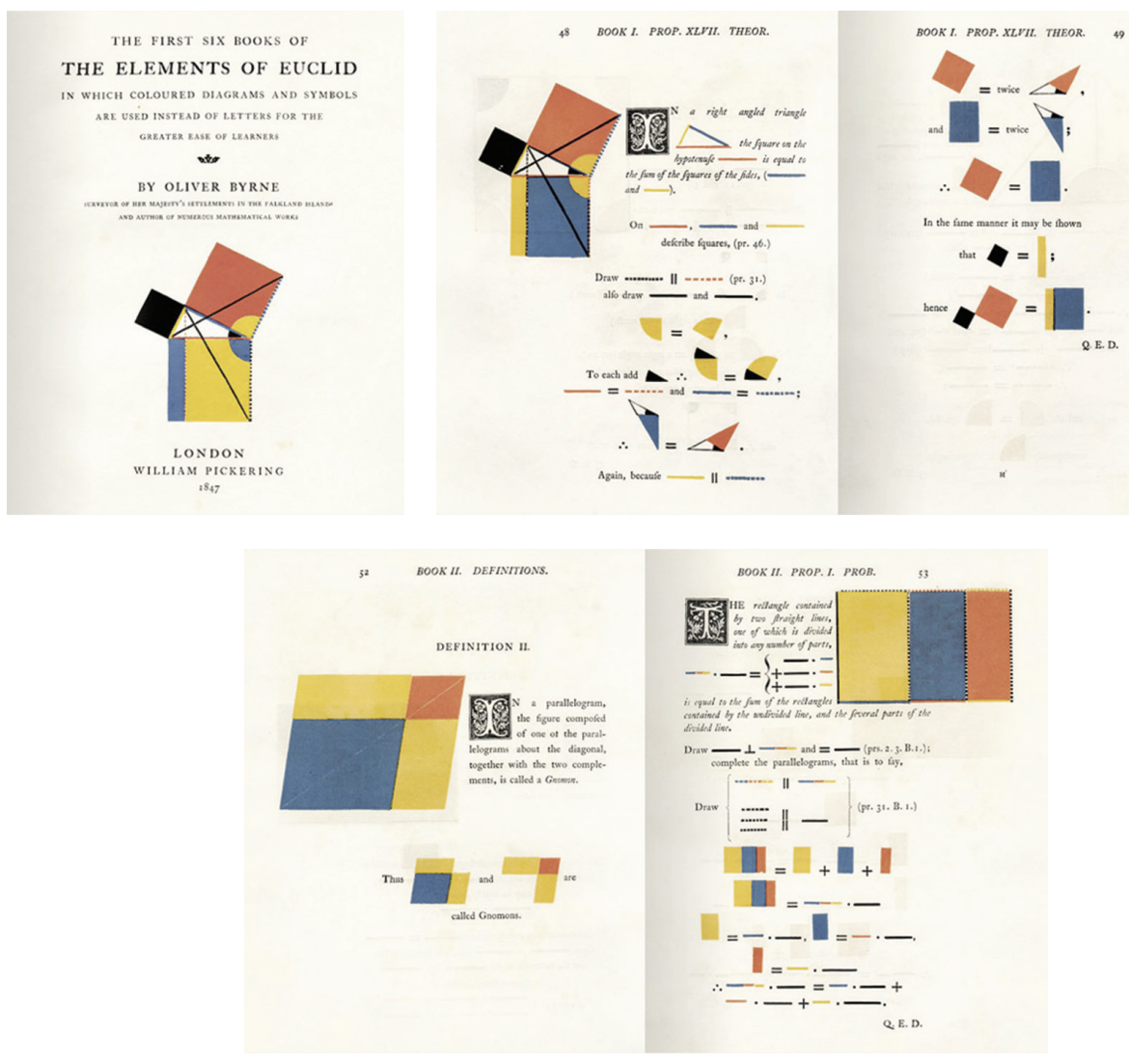

Fig. 3. Byrne, O. (1847), The First Six Books of the Elements of Euclid, in which coloured diagrams and symbols are used instead of letters for the greater ease of learners. London, United Kingdom: William Pickering, title page, pp. 48-49 and pp. 52-53.

In logic, diagrams have been used since Aristotle to visualise the argumentative structure of reasoning, both with analytic and didactic intents - like in the case of Euler diagrams, the closed shapes used to visualise syllogisms. According to their famous inventor, Leonard Euler, these diagrams are extremely useful to facilitate reflection as they allow to make implicit relationships visible (Bagni, 2007). 

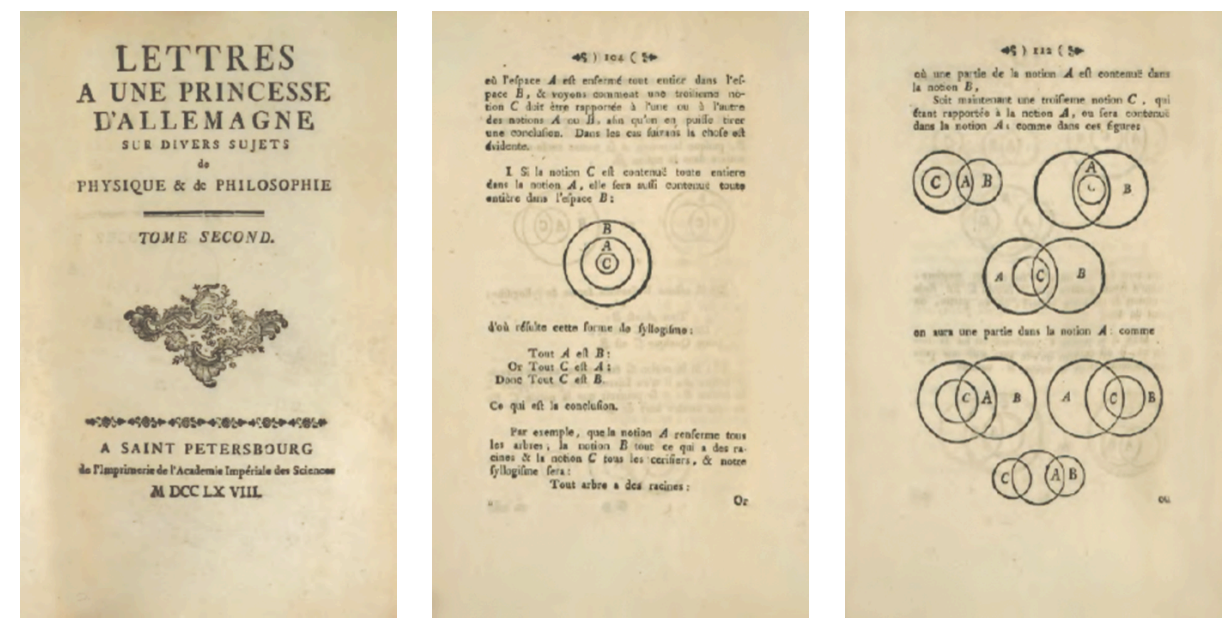

Fig. 4. Euler, L. (1768). Lettres a une princesse d'Allemagne sur divers sujets de physique \& de philosophie. Saint Petersburg, Russia: Académie Impériale des Sciences, title page, p 104 and p.112.

With a similar intent, renowned author of Alice in Wonderland, Lewis Carroll, designed a diagram-based game to teach children the fundamentals of logic. Premises and conclusions are displayed on two related matrices by correctly positioning the coloured tokens, showing immediately which are the valid conclusions given specific premises.
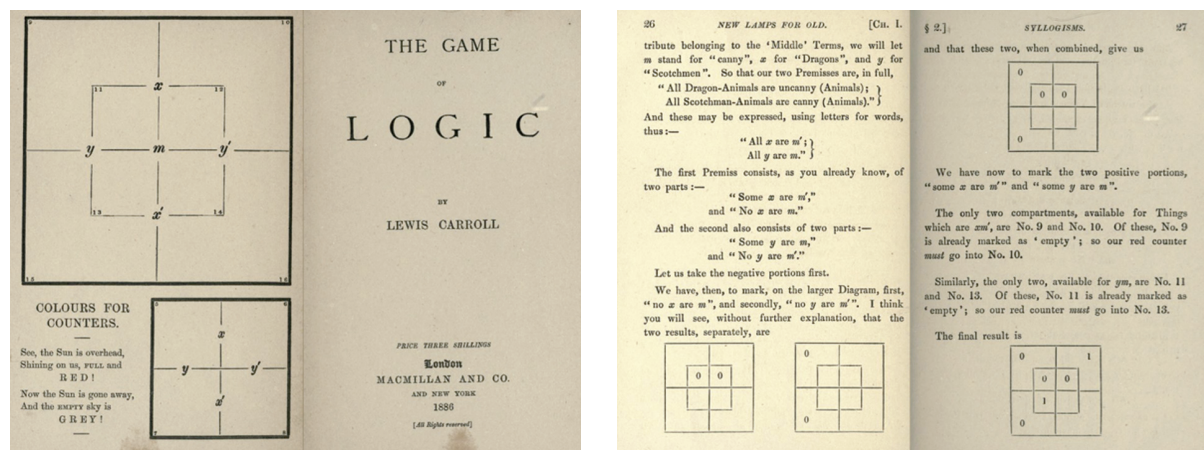

Fig. 5. Carroll, L. (1886), The Game of Logic. London, United Kingdom and New York, United States: Macmillan, title page with diagrams and pp. 26-27. 
Visual analogies. In science, the attribution of a particular configuration to a specific phenomenon is comparable to a real discovery - the hexagonal structure of organic compounds, the double helix of DNA, the inverted tree of evolution, or the concentric circles of the solar system (Anceschi, 1992).

Greek and Roman speakers, instead, used a diagram-based technique to better remember reasoning. Known as the method of loci (loci being Latin for 'places') or memory palace, this 'mnemotechnic' would create a correspondence between the shape of architectural structures and the sequence of arguments in a speech (Yates, 1966).
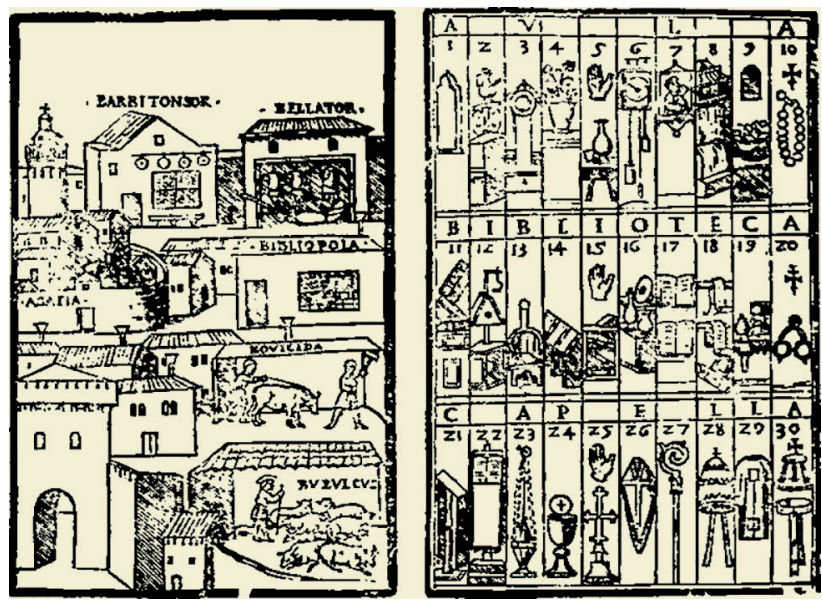

Fig. 6. Abbey Memory System (left) and images to be used in the Abbey Memory System (right) from Johannes Romberch, Congestorium Artificiose Memorie (1533). In: Yates, F. (1966), The Art of Memory. London, United Kingdom \& New York, United States: Routledge and Kegan Paul, p. 112.

Non-linear Writing. Even the written word - which is almost always regarded as a mere reference for visual representations, like the spoken word - when articulated in a non-linear and visually meaningful way, can work as a diagram and be able to represent directly the structure of reasoning (Lussu, 2007). Handwritten notes, postit boards, mind maps, are all examples of the diagrammatic nature of writing and how it offers a practical support to organise thoughts and make decisions.

Diagrammatic Reasoning. According to philosopher and logician Charles Sanders Peirce, good reasoning is related to strong visual images. Peirce considered diagrams not only a tool to divide reasoning into small parts and facilitate logical analysis, but above all a strategy to make mental experiments on thoughts like if they were concrete things, facilitating manipulation and discovery (1980). He elaborated the concept of 'diagrammatic reasoning', a thinking that is made of visual structures, ultimately affirming that there is no reasoning that does not have the nature of the diagrammatic reasoning (2005). 
Peirce's position remarks once more that diagrams provide at different degrees the advantages of making reasoning easier to analyse, manipulate and remember. They allow to anchor the reflection to a concrete support and examine all logical implications in a more rigorous and systematic way than abstract speculation. They allow to access knowledge through their ability to simplify complexity and unfold hidden connections. It is for all these reasons that they are one of most powerful tools to defuse post-truth.

\section{The Rhetoric of Neutrality}

Focusing on visualising reasoning and taking advantage of the diagrams' ability to communicate complexity can be a strategy for designers to navigate the intricacy of an information overloaded world. Nevertheless, pure information is just an abstraction and every representation embeds a rhetoric intent which starts with the design process, even when the intention of the designer is to be as objective as possible (Bonsiepe, 1999).

In his essay The Rhetoric of Neutrality, design critic Robin Kinross (1999) invites to avoid the simplistic distinction between design for information (information design) and design for persuasion (advertising or propaganda) and argues that even the most 'functional' typographic choices are never neutral, they always communicate something else about the designer, the client, the context and, in conjunction with all the other visual variables, they work as 'rhetoric devices'.

Type designer Gerard Unger (2007) goes even further suggesting to think about typography as a 'rhetoric toolkit' that should be part of everyone's learning in order to become more aware of how to visualise reasoning effectively through writing. If also diagrams and non-linear writing approaches were considered part of the same learning pack, it would be possible to shape an infographic toolkit able to enrich everyone's visual vocabulary and increase exponentially the ability to read and conceive complex visualisations, blurring the boundaries between writing and information design.

\section{Conclusion}

The power of diagrams relies on their ability to make complexity more accessible and accustom to logical reasoning, which makes them a crucial tool for design and education. However, even the best intentions of social commitment cannot avoid rhetorical infiltration. Therefore, aiming at communicating complexity is not enough for designers. In order to ensure a more autonomous access to knowledge, it is also necessary to spread the means to visualise information outside the realm of design. Only by encouraging the direct use of diagrams and the personal interpretations of 
information, it will be possible to trigger an intellectual resistance to the loss of trust in good reasoning and, hopefully, welcome a new wave of critical thinking.

\section{References}

Anceschi, G. (1992). L'oggetto della raffigurazione. Milan, Italy: Etas.

Bagni, G. T. (2007). Rappresentare la matematica. Rome, Italy: Aracne.

Bonsiepe, G. (1999). Visual/Verbal Rhetoric. In Bierut, M., Helfand, J., Heller, S., \& Poynor, R. (Eds.), Looking closer 3. Classic writings on graphic design. New York, United States: Allworth Communications.

Digregorio, M. R. (2011), Gli Elementi di Byrne e il ruolo del diagramma nella didattica della matematica. In Progetto Grafico, volume 20, Milan, Italy: AIAP.

Kinross, R. (1989), The Rhetoric of Neutrality. In Margolin, V. (Ed.), Design Discourse. Chicago, United States: University of Chicago Press.

Lussu, G. (2007), Tipografia e oltre. In V. Bucchetti (Ed.), Culture visive. Contributi per il design della comunicazione. Milan, Italy: Poli.design.

Peirce, C. S. (2005), Pensiero e scrittura, MS 956. In Marietti, S. (Ed.) Un passo inedito dai quaderni del filosofo circa il rapporto tra pensiero e scrittura. Riproduzione del manoscritto, testo inglese, traduzione italiana e introduzione, Rivista di filologia cognitiva, volume 3. Retrieved from: http://filologiacognitiva.let.uniroma1.it/peircei.html

Peirce, C. S. (1980), Semiotica. Torino, Italy: Einaudi.

Perondi, L. (2012), Sinsemie. Scritture nello spazio. Rome, Italy: Stampa alternativa e Graffiti.

The Collins Word of the Year 2017 is... (2017, November).

Retrieved from: http://www.collinsdictionary.com/woty

Unger, G. (2007), Typography as (Vehicle of) Science. Amsterdam, Netherlands: De Buitenkant. Word of the Year 2016 is... (2016, November).

Retrieved from: http://en.oxforddictionaries.com/word-of-the-year/word-of-the-year-2016

Yates, F. (1966), The Art of Memory. London, United Kingdom \& New York, United States: Routledge and Kegan Paul. 


\title{
Principles for Designing Systems of Screen Icons
}

\author{
Elena González-Miranda ${ }^{1}$ and Tania Quindós ${ }^{1}$ \\ ${ }^{1}$ Universidad del País Vasco/Euskal Herriko Unibertsitatea (UPV/EHU), \\ Departamento de Dibujo (Diseño), Facultad de Bellas Artes. Apdo.1397. 48080 \\ Bilbao. Bizkaia. Spain. \\ \{elena.gonzalezmiranda, tania.quindos\}@ehu.eus
}

\begin{abstract}
The basic principles of design are the essential guidelines that need to be considered at the beginning and during the stages of the Design Process. The principles related to icon systems are inferred from and defined through experience and daily practice. In this paper, we make a contribution to basic research by proposing ten principles for designing System Icons for the Graphic User Interface. These premises, applied with wise criteria and flexibility, allow to produce harmonic, consistent and effective signs for our electronic devices.
\end{abstract}

Keywords: Icons, User Interface Icons, Design Principles, Pictograms.

\section{Introduction}

In the last decades, a substantial change has taken place in the professional profile of the graphic designers out of the need of adapting our knowledge to new digital media. By changing the medium in order to organize the messages, we also deal with new projects with perceptual, conceptual and methodological challenges, such as the design of icons for the User Interface. In the 21st century, we are living a real enhancement of these small signs that are used intensively and daily in our electronic devices.

In the 1980s, designer Susan Kare made an important contribution to the study of these icons, when she designed the typographic and iconographic signs for Apple. This designer had to transform a small grid of pixels, into a family of symbols "in order to make it simple for people to use the computer" (Abdullah and Hübner, 2006).

Since then, with the same purpose of developing accessible interfaces, static icons have been designed to indicate tools or actions in computer programs; other examples are dynamic and interactive icons such as video display, scroll bar, sound icon or the different cursors to mark the position on the screen. In the last years, applications developed to be executed through smart mobile devices have also appeared. These apps use these signs as a hyperlink to access to the complexity of their contents. In these new projects, designers apply their knowledge of the design of pictograms to the design of families of screen icons. 
On the other hand, we know that basic principles are an essential knowledge in many disciplines. These guidelines allow us to begin and validate the work, with the certainty that we are on the right track.

The renowned designer Dieter Rams defined 10 principles that answer the question "Is my design good design?" For him a good design should be innovative, useful, aesthetic, understandable, honest, unobtrusive, long-lived, consistent, and environmentally friendly. "Last but not least, good design is as little design as possible (less but better)" (Dieter Rams; in Fairs, 2004).

These commandments, which recommend eliminating all unnecessary elements, can be found in the Isotype project in 1924, or in the pictograms system for the Munich Olympic Games of 1972, designed by Otl Aicher. Another significant example is the standardized pictograms of many airports in the world, developed by the American Institute of Graphic Arts (AIGA and DOT) (AIGA, 1981).

Other authors such as Abdullah and Hübner (2002), Costa (2007) or Norberto Chaves (2009), listed general principles and other recommendations to be considered when designing an iconic sign.

Within this theoretical framework, we have deemed pertinent to specify the basic rules to be taken into account at the beginning and during the Design Process of a system of icons for digital media. Icons of interactive contexts, specifically designed for this contribution, illustrate these principles.

\section{The 10 Principles for Designing Systems of Screen Icons}

\section{Articulate accurate and relevant messages}

First of all, we must carry out an inventory of the items that are really necessary and relevant to most users of the sign system. An accurate utterance will provide us with the right guidelines and will avoid errors of approach at the beginning of the design process, since the wording conditions the graphic result. (Figures 1 and 2)

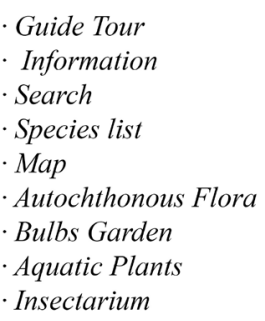

Fig. 1. Inventory for an app about a Botanical Garden.

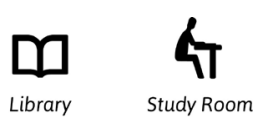

Fig. 2. At a university, the 'Study Room' does not fulfill the same function as a 'Library' and the sign on the digital signage map must reflect that difference. 


\section{Choose the appropriate iconographic referent}

Once the messages have been defined, we must select the appropriate and meaningful referent ${ }^{1}$ that will ease the interpretation and decoding of the message (Figures 3 and 4)

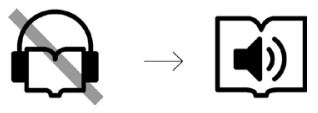

Fig. 3. In the 'audiobook' icon, it is not appropriate to represent headphones since these books can be listened without them. Speaker icon may be more meaningful.

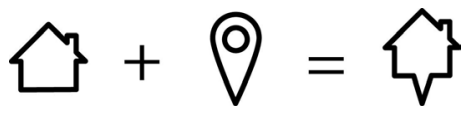

Fig. 4. In some cases, several referents can be joined resulting in composite icons. Message: I select this house on a map.

\section{Shape the sign respecting the logical physiognomic form}

The referent must have a form that corresponds to its constitution and logical structure so that the receiver identifies the object represented. (Figures 5 and 6 )
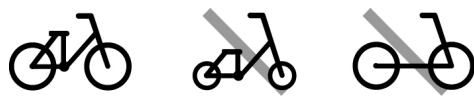

Fig. 5. Logical physiognomic form of a bicycle for a cycling route app. In the second icon, there is an obvious disproportion in some of the elements. The third sign is missing some essential features and confuses the receiver.

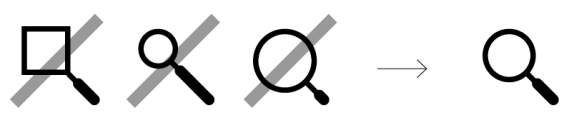

Fig. 6. Logical physiognomic shape of a magnifying glass.

\section{Adapt the referent to the context of the receiver}

By choosing current models adapted to the cultural and geographical context of the user, the understanding of the iconographic sign is facilitated. (Figures 7 and 8)

\footnotetext{
${ }^{1}$ The etymological meaning of the word "referent" is that it refers to or relates to something. In semiological terms it is the real object to which the sign alludes.
} 


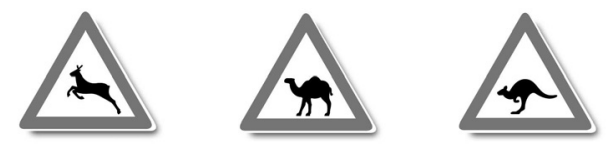

Fig. 7. As in traffic signals, on a GPS device interface, the warning message for 'Caution, wild animals' will have to be adapted to different geographic areas.

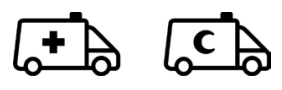

Fig. 8. On a health emergency application, 'Request an ambulance' will be represented by a cross or by the crescent, according to the country.

\section{Design by using widespread, conventional forms}

When the referent shows formal and/or stylistic variety, we will have to design a conventional and widespread form, which is found in the collective imaginary of the receiver. (Figure 9)
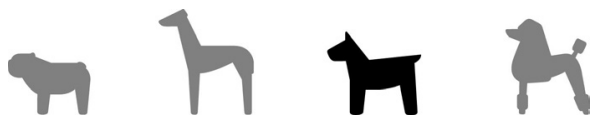

Fig. 9. On an app to know where dogs are allowed, the graphic solution should represent all dogs, regardless of race or size.

\section{Synthesize and refine the referent: Graphic sobriety}

The shape of each pictogram must be refined and reduced to its essential features. This avoids excessive and irrelevant visual information. "The sign must be saturated, that is, lacking of zones deprived of meaning. If when eliminating an element nothing is lost, is because that element was unnecessary". ${ }^{2}$ (Figure 10).

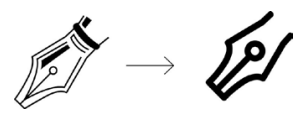

Fig. 10. The nib is reduced to its significant features.

\section{Ensure that the sign is easily learned}

The learning of a new sign must be immediate or it must occur in a very short time.

\footnotetext{
${ }^{2}$ In Chaves, Norberto (2015) Ten principles of graphic design. Foroalfa. Published on 04/15/2015. Accessed on 09/20/2017, retrieved from: https://foroalfa.org/articulos/tenprinciples-of-graphic-design
} 
Nowadays - as in the evolution of species or language - signs that conform an 'iconographic dialect' emerge or die in the continuous evolution of our contemporary culture. (Figure 11)

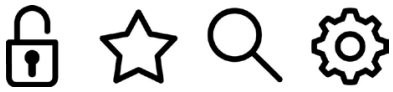

Fig. 11. Metaphors we have learned from using social networks: Privacy (padlock), Favorites (star), Search engine (magnifying glass) or Settings (cogwheel).

\section{Avoid linguistic signs}

The interpretation of alphabetic characters is conditioned by the specific language of the receiver. For this reason, we should avoid as far as possible the use of letters in a sign.

However, in some signs, the obvious referent is a number or letter and then its use is unavoidable. (Figure 12)

\section{Á̀ (i) ?}

Fig. 12. Alphabet referents to choose the size of the letter, to obtain information or to ask for help.

\section{Systematize visual constants: Formal consistency}

A system of pictograms will be perceived as a harmonic visual unit if all the elements that comprise it have a common structure or grid that guarantees its formal consistency. (Figures 13 and 14). In these visual constants, it is also necessary to establish appropriate chromatic or formal criteria to indicate the selected contents. (Figure 15)
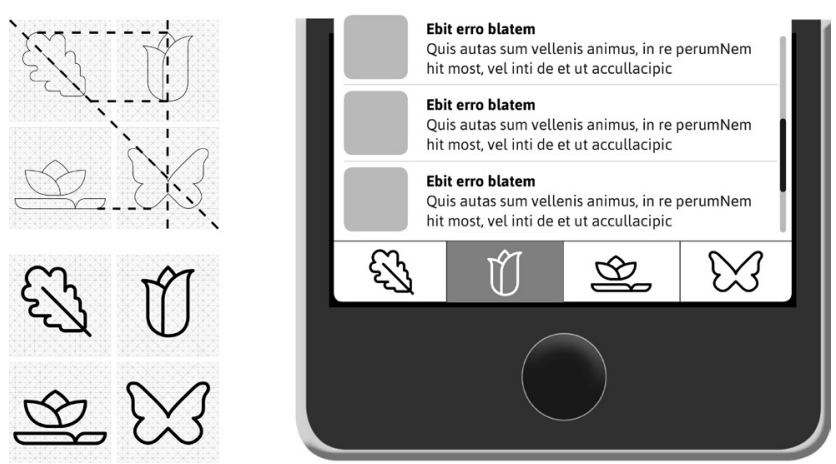

Fig. 13. The items Autochthonous Flora, Garden of Bulbs, Aquatic Plants and Insectarium of a Botanical Garden App, have been adjusted to the grid. Similar parameters have been intentionally sought in height, width or angle. 


\section{ÁABCDEFGHIJKLMN NOPORSTUWWXYZ abcolefghijklmn ñopqrstuvwxyz

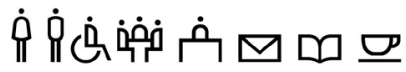 1234567890

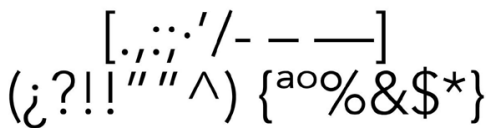

Fig. 14. Consistency and syntactic compatibility with the typographical signs of visual identity are sometimes required. In pictograms of typographic origin for the Avenir font, a recognizable visual vocabulary is established with the following characteristics: elimination of superfluous features, number of details reduced to a minimum, assignment of font proportions, lines of similar thickness in the characters, tendency to symmetry and finally, formal similarity of certain structures-like the dot with the head of the person.

\section{仓Q $\mathrm{A} Q \mathrm{Q}$}

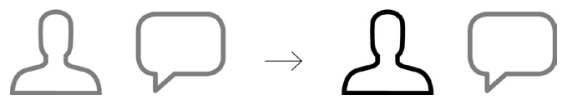

Fig. 15. The section selected on the application is represented by a filled-in shape or by a different line color.

\section{Optimize the signs for the screen}

As when designing web typographies, pictograms too have to be created so that they are optimally perceived on electronic devices' screens. On the one hand, it is necessary to make some optical adjustments so that the human eye perceives each sign in harmony within the system as a whole. It may be necessary to adjust the shape when pictograms are to be displayed in smaller sized devices. We must also adjust the vertical and horizontal strokes or check the visual weight of the connections between strokes, among other optical corrections. ${ }^{3}$ (Figures 16 y 17)

\footnotetext{
${ }^{3}$ Further information on optical adjustments on González-Miranda, E. and Quindós T. (2015) Diseño de iconos y pictogramas. Pp. 139-145.
} 
On the other hand, a smoothing process must be carried out by applying halftones on the contours of the forms. This process aims to make staggered edges uniform on monitors. (Figure 18)
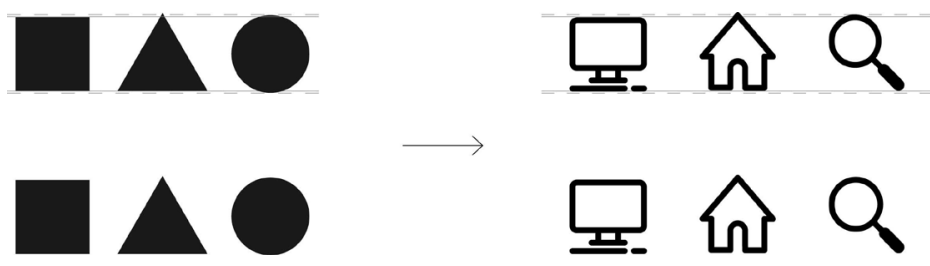

Fig. 16. Optical adjustments in a family of signs.

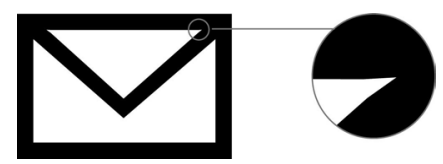

Fig. 17. Connections between strokes.

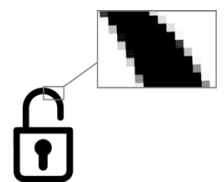

Anti-aliasing ON

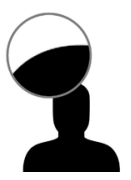

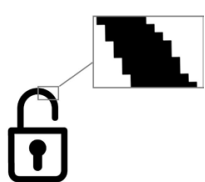

Anti-aliasing OFF

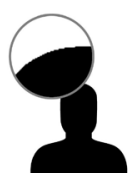

Fig. 18. Anti-aliasing process.

\section{Concluding remark}

We can summarize these ten tips in the following diagram. (Figure 19).

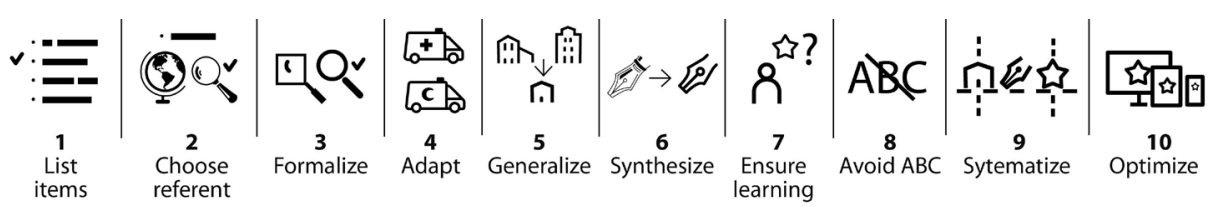

Fig. 19. Figure representing the points previously explained. 
We have to clarify that the designer has to take these principles into account throughout the design process but should not be dogmatic in the practical application of them. Designers have to be flexible enough to adapt these recommendations to the specificity of the project in hand, in order to ensure the communicative effectiveness of each sign and the consistency of the system.

\section{Acknowledgements}

This contribution has been financed in part by University of the Basque Country, UPV/EHU. Tania Quindós was granted by UPV / EHU for her Doctoral Thesis project on Pictograms and Typography.

\section{References}

Abdullah, R. and Hübner. R. (2002) Pictograms, Icons \& Signs. A guide to information Graphics. London: Ed. Thames \& Hudson Ltd.

Aicher, O. and Krampen, M. (1979) Sistemas de signos en la comunicación visual. Barcelona: Gustavo Gili SA.

American Institute of Graphic Arts, AIGA (1984) Símbolos de señalización. (Symbol Signs). Barcelona: Editorial Gustavo Gili SA.

Costa, J. (2007) Señalética corporativa. Barcelona: Costa Punto Com.

Chaves, N. (2009) Ten principles of Graphics design. 3/08/2009. Retrieved from: https://foroalfa.org/articulos/ten-principles-of-graphic-design

González-Miranda, E. and Quindós T. (2015) Diseño de iconos y pictogramas. Valencia: Campgràfic.

Fairs, M. (2004) Dieter Rams interview. Icon Magazine 10: February 2004. Retrieved from: http://web.archive.org/web/20070310142422/http://www.iconmagazine.co.uk/issues/010/rams_text.htm.

Morris, C.W. (1985) Fundamentos de la teoría de los signos (Foundations of the Theory of Signs). Barcelona: Paidós Comunicación.

Pierce, T. (1996) The International Pictograms Standard. USA: Design Pacifica Int. LLC.

Smitshuijzen, E. (2007) Signage Design Manual. Baden: Lars Müller Publishers. 


\title{
Please Contribute
}

\author{
Jonathan Spencer ${ }^{1}$ and Chris Jackson ${ }^{1}$ \\ 1 \\ Liverpool John Moores University, Graphic Design and Illustration, John Lennon Art \\ and Design Building, 2 Duckinfield St, Liverpool L3 5RD, UK \\ \{j.spencer, c.s.jackson\}@ljmu.ac.uk
}

\begin{abstract}
Please Contribute' is a participatory collective manifesto born in response to the socio-political trend towards oversimplifying the communication of complex concepts. The project chooses to confront this trend and present the complex as complex - to wilfully celebrate complexity itself whilst remaining accessible. Combining elements of indexing and manifesto writing, 'Please Contribute' seeks to engage the reader in a conversation about the society they live in and their relationship to it. This paper documents and explains the genesis, structure and manifestations of the project and considers questions around formats of publication and their implications on audience engagement.
\end{abstract}

Keywords: Manifesto / Participatory / Publication

\section{Introduction}

'Please Contribute' is a participatory collective manifesto born in response to the socio-political trend towards oversimplifying the communication of complex concepts. The project chooses to confront this trend and present the complex as complex - to wilfully celebrate complexity itself whilst remaining accessible.

In the run up to, and in the wake of the Brexit referendum, and with the subsequent UK General Election, we felt we saw a reduction in the quality of social and political debate. Popular dailies such as The Sun, Mail and Express continued their long term eurosceptic and anti-immigration messages. Highly emotive visuals and simplified messages played on age-old fears of the outsider - 'The Other', often employing language and rhetoric that harked back to earlier historical anti-immigration campaigns. False claims such as the now infamous "Let's give our NHS the $£ 350$ million the EU takes every week"[1] on the Brexit Bus were not held to account and left uncontested by the national broadcaster[2].

The referendum ballot paper offered a simple choice to the question "Should the United Kingdom remain a member of the European Union or leave the European 
Union?" The electorate could then cross a box for either "Remain a member of the European Union", or "Leave the European Union".

The question is of course, given the nature of a ballot, a simplistic representation of the choice being given. If we unpack the implications of the question we see that the UK's relationship with the EU impacts on a huge number of areas of our society. Including, but not limited to; immigration, asylum seekers and refugees, economic migrants, trade deals with the EU, trade deals with the rest of the world, security, privacy, law enforcement, sovereignty, jam, pig semen, light bulbs, straight bananas, keeping beaches clean, the air we breathe, animal welfare, saving the bees, health treatment, dealing with pandemics, road safety, offshore tax, corporation tax, firearms, rules on tobacco[3]. Given this level of complexity, perhaps the ballot paper should have instead looked like:
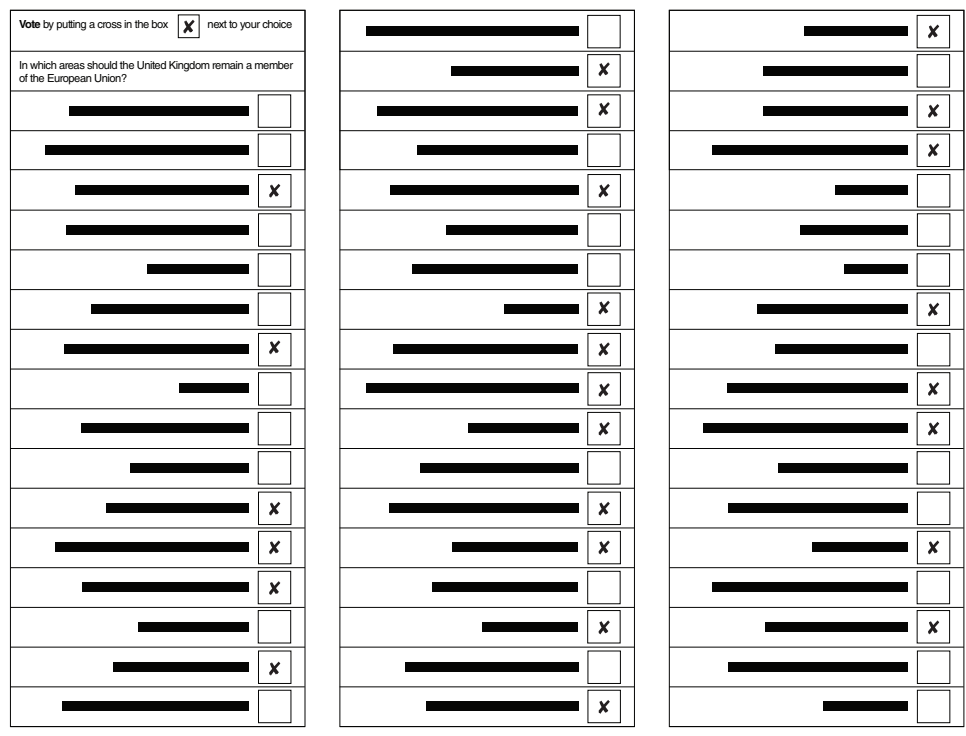

Fig. 1. Proposed EU Referendum ballot.

Rather than a simple yes / no choice it could present a record of preferences, a personal manifesto of sorts. "Yes, I am for straight carrots, but no health regulation or pension provision for expats". An unrealistic proposition, of course, but this is what we felt was missing from the conversation, a sense of the nuanced complexity of these issues.

We were angered at this and concerned with the question of how graphic design might be used to provide a counterpoint to this; to provoke or prompt people into considering their relationship to the society they are a part of? How might we start to explore this? 


\section{The List}

The solution that we arrived at combines two well established processes; indexing, or list making, and the manifesto. There is a long history of manifesto writing, particularly within the political, social and creative spheres. Creating one demands a particular engagement and level of reflective self-analysis with regard to the external world.

The act of list making can be a powerful tool. Whether Samuel Johnson's A Dictionary of the English Language or a simple To-Do list, the process of investigating, selecting, cataloguing, sequencing and publishing provides a methodology to allow us to understand and make sense of the subject matter, imparting a level of control. It creates a positive feedback loop in which the act of creating the index in turn spurs further investigation and analysis. Essentially we, in collaboration with readers of the work, are indexing and presenting a nonhierarchical taxonomy of contemporary society.

\subsection{The Basic Unit}

The premise underpinning the structure is a set of four reflective questions which ask the reader / respondents to assess their own relationship towards a given subject. These were first conceived while Jonathan was studying letterpress under Alan Kitching at the RCA. Seeking an efficient approach to the process, a simple, easily typeset, structure was created which could be repeated to form a larger piece.

The questions deliberately place the reader at the center of the piece starting with a simple binary declaration I am for or I am not for. The option is there to select either, both or neither of these but this is, from our perspective, not important (though it can be revealing), what is important is that the reader considers their relationship to the subject.

The following statements ask the reader to question why they are for or against it; for I am or for I am not. Is it because it impacts or affects their lives, or because it does not? The hope being that the contemplation might prompt further consideration of the importance of this to them.

The audience is asked to redact the statements in order to bring their own voices to the Manifesto. These contributions form strata of information - a record of preferences, concerns and interests. They may be one, or many, layers in depth, and bring a new discourse to the original piece. This collective discussion is also evident in the interactions between the contributors in front of the document itself.

The resulting palimpsestic record provides an insight into the collective mindset of the audience, not just their values but also their interests and understanding 
(including via the reference points not amended). The main aim of the piece is to introduce the audience to a broader range of reference points for consideration and to prompt further debate or investigation.

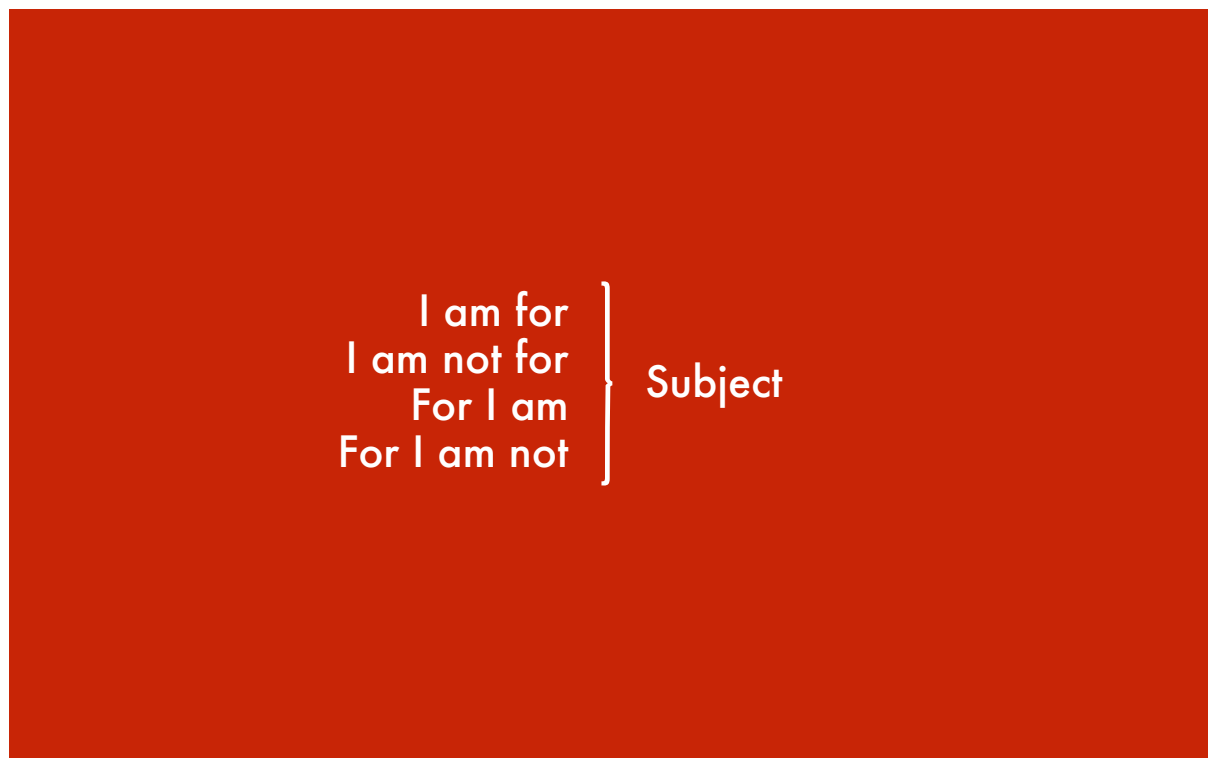

Fig. 2. The Please Contribute Basic Unit.

\subsection{The Structure}

Simple elements, repeated, can yield complexity. The list deliberately repeats the form of the basic unit until it becomes complex, large, and somewhat overwhelming and disorientating. By this it gives the impression that interacting with it will require work. It presents a challenge to the reader while allowing them to revel in the complexity through the process of navigating it.

Although it may initially seem random or disparately arranged, there is an underlying rationale to the order and placement of the units, a deliberate and purposeful structure across the piece.

Firstly, the start is always the same. "ME".

This places the individual at the heart of the experience. Although the project is partly about challenging a movement towards individualism (and away from the collective good), this strategy uses this selfish imperative to prompt introspection. 
This is further reinforced by the redactable statements I am for, For I am, I am not for, For I am not, rather than WE are for, For WE are, WE are not for, For WE are not. This is a deliberate move to place the reader; their relationships with others, their society, and the context of the modern world, as central to the experience.

We then introduce the notion of another:

YOU

followed by THEM, US, WE, encouraging the reader to reflect on their position in relation to others. These are the basic relationships we want to the reader to consider and the building blocks for the rest of the list.

The list moves through various proposals of social order, their implications and structure before introducing forms of governance - the "ocracy" stage. Although this section can change in response to current events, it tends to remain as is from iteration to iteration. The list then presents the reader a larger, more popular culture-centric, continuation of the aggregation, which itself contains discrete structural phases and rhythms. This section is more transient as it concerns itself with contemporary reference points which, by definition, exist in a state of flux.

The intent here is to focus the reader on a basic idea of society, along with a myriad of structural models. Some of these are known, some may not be known but can be understood through research. The aim is to encourage a deeper thinking about the political and social context before exploring the more popular, and recognised, section of the list.

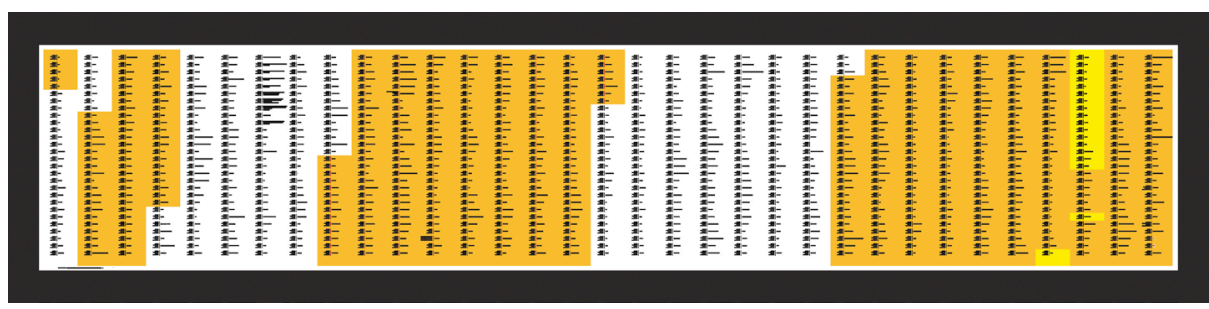

Fig. 3. Highlighted sections in the list.

\subsection{The Format}

Please Contribute exists in a number of formats and acts as a driver for our investigations into methods of publishing and their effect on audience engagement. The core version takes the form of a scroll with other iterations spanning more contemporary forms of publications and installations. 
The scroll was chosen for number of reasons. As one the first easily editable and portable forms of writing they were commonly used to record economic, industrial, religious or cultural information. The nature of this information as well as the historical precedents created by commercial, state and religious institutions lends the format an authority and permanence that others lack. The scale of the scroll, combined with the ability to, at any particular moment, gain an overview of the entirety of the content was also an important consideration. Partitioning the list into the discreet pages of a book introduces unwanted punctuation, structures and associations while diminishing the sense of an overwhelming complexity of information.

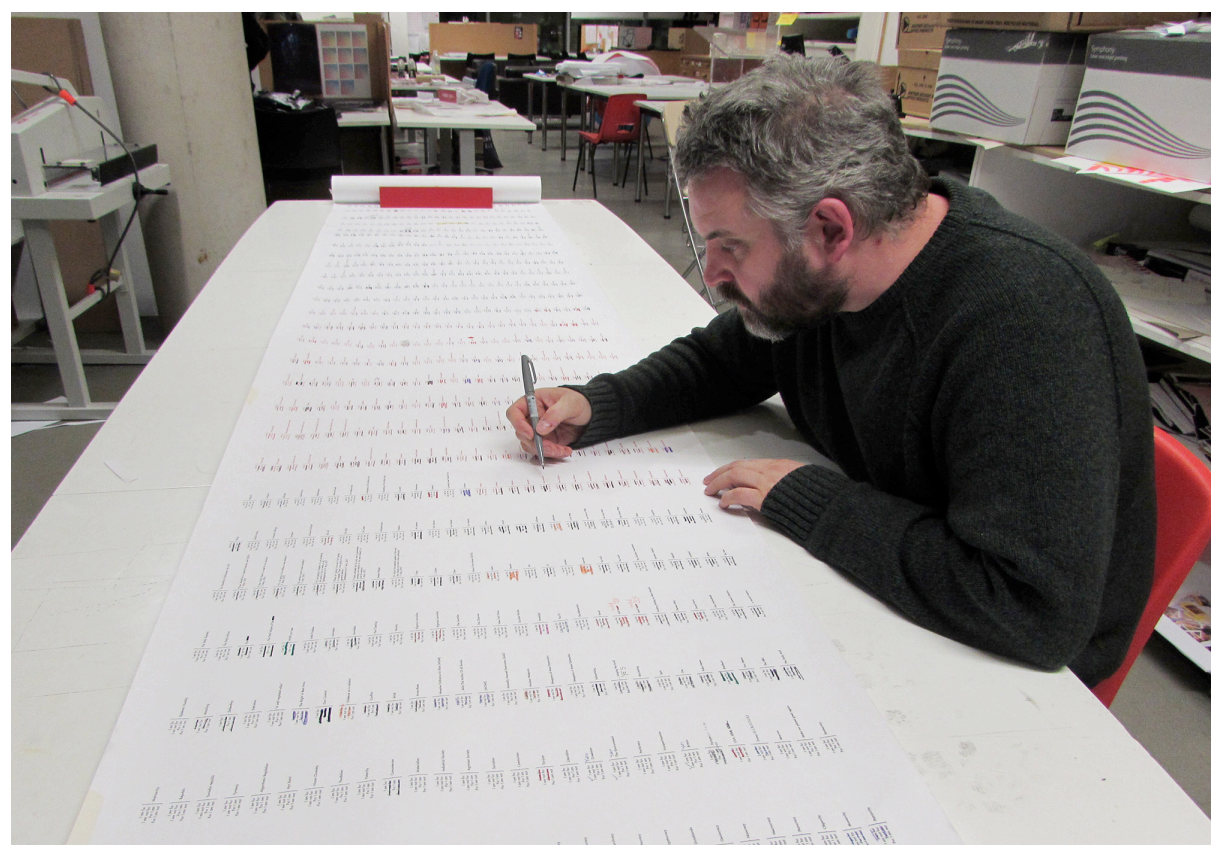

Fig. 4. Jonathan examining the Please Contribute: Kendal scroll.

\section{Please Contribute Iterations}

\subsection{Kendal - 2017}

Presented at a four-day field school exploring potential future directions for arts education with our Graphic Design and Illustration students. The format of this version of the list was a single 3.5-meter scroll with a bespoke education section; the whole totaling 924 defined, and 112 blank user-definable single units. The scroll was visible and accessible throughout the duration. Participation was high with the 
majority of units interacted with at least once. The scroll revealed some unexpected interactions, both with the list as well as between the participants. Issues were debated on the list itself, forming a palimpsestic record of the debate. Some of these were more contentious than others; Coldplay proving particularly divisive.

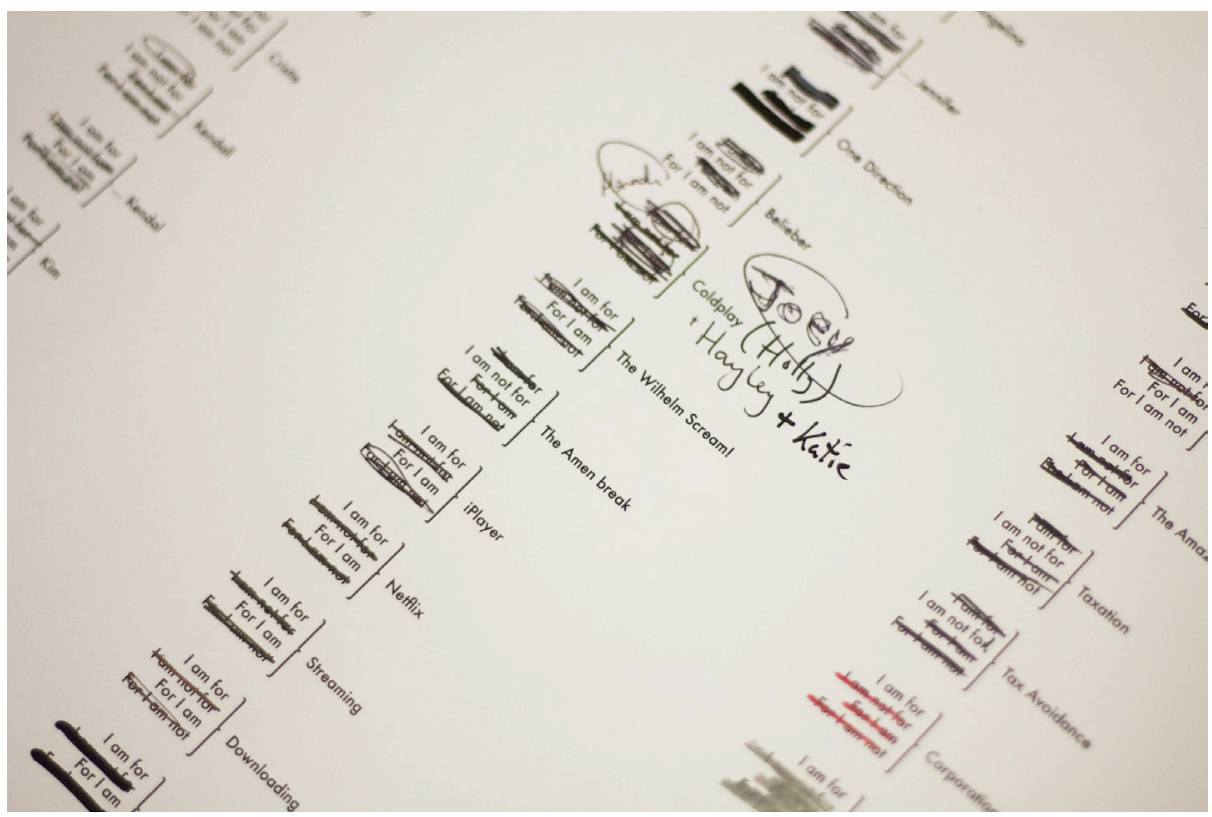

Fig. 5. Please Contribute: Kendal Coldplay debate.

\subsection{Ride Your Pony, Islington Mill / JLADA - 2017/18}

Rather than responding to a list, this version asked the audience to contribute words / units prompted by a single word, 'Britain'. The response to this was mixed, with majority of the respondents submitting fairly frivolous suggestions which offered little to the debate and were often personal jokes. What was interesting though was the creative way in which some of the answers were given. A number of responses used the dotted lines as a divider to suggest paired or opposing units e.g. Traveling $v$ Boundaries. 


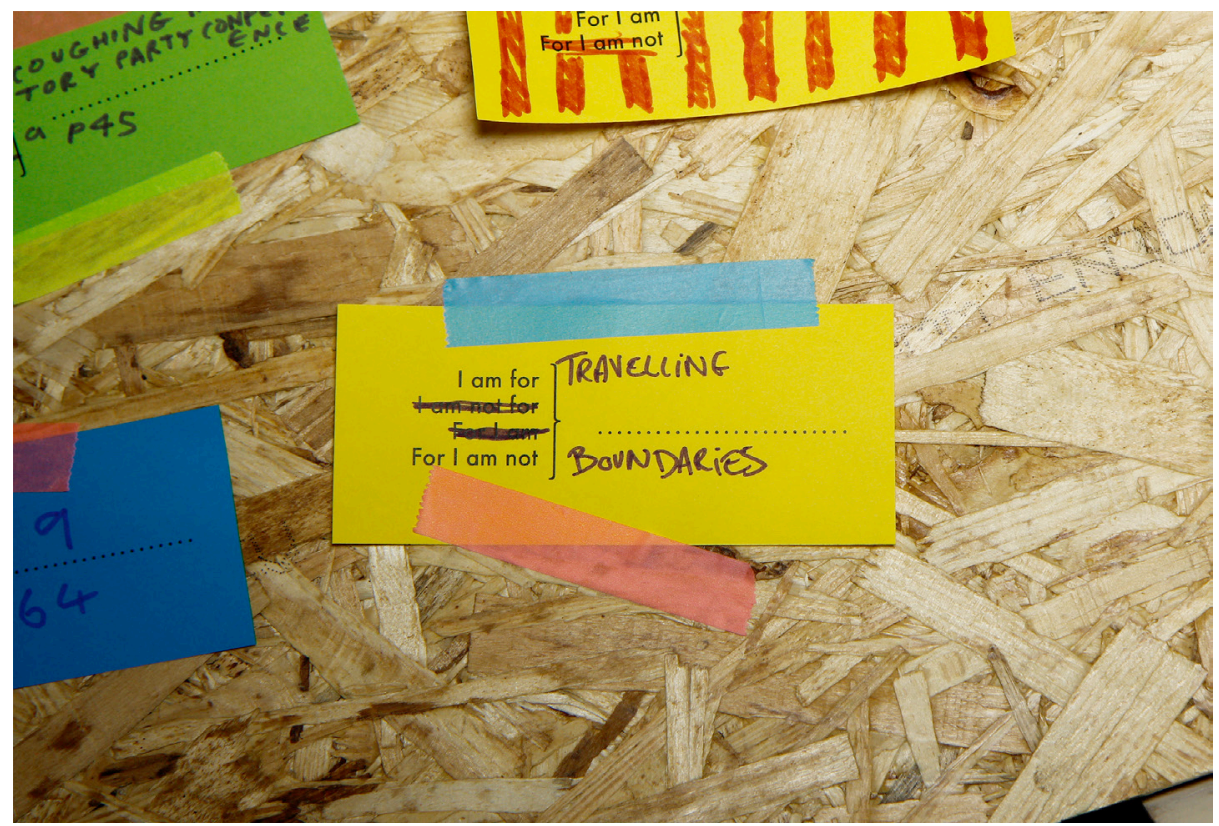

Fig. 6. Submissions at the Ride Your Pony exhibition, Islington Mill, Manchester.

\subsection{CO_two Conference - 2017}

Anticipating that the audience was likely to share a common interest, this iteration took the form of a booklet containing a reduced list themed around the subject of the conference, 'Complexity'. The booklet contained 97 defined units, followed by 36 blank units and from 50 booklets handed out, 12 were completed and returned. As in previous iterations, the nature and format of the responses revealed new ways that people chose to interact with the list. In contrast to previous versions, the section where the reader was invited to contribute their own list was far more considered and coherent. Of the returned booklets, 1 filled all 36 blank units and added 7 additional units in the endpaper, 4 filled all 36, 1 filled 27, 1 filled 11, 1 filled 10, 1 filled 2 and 3 filled no units. It was also encouraging to see the publication prompting delegates of the conference to discuss the various nuances of the list and what they would choose to add to it. 


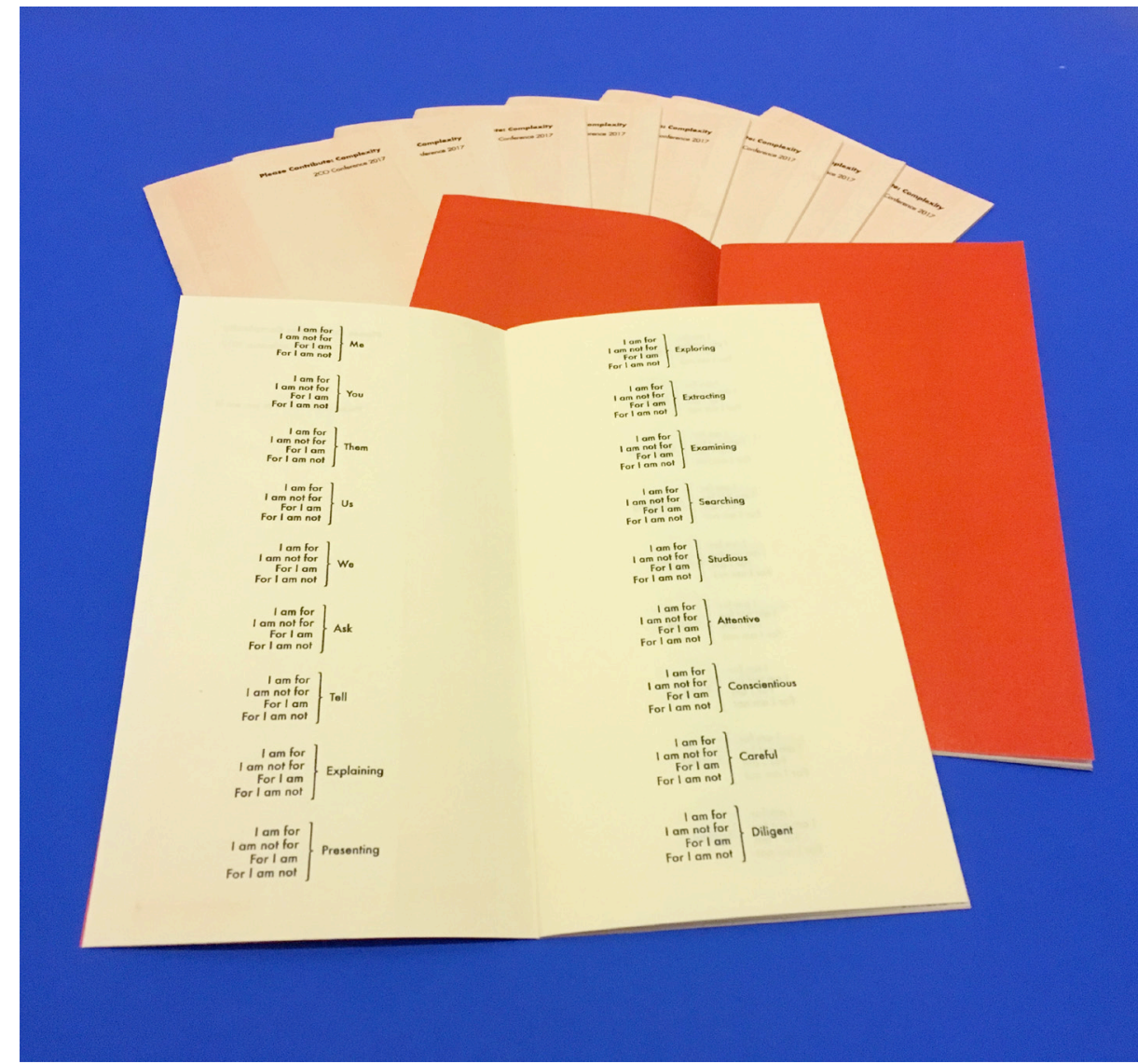

Fig. 7. The Please Contribute: Complexity booklet. Distributed at 2CO_two Conference, Tenerife 2017.

\section{Conclusion}

Please Contribute is proving to be revealing, not just in terms of people's responses to the list, but also in how they choose to interact with it. They are offering new ways to respond and are clearly taking the list seriously. Some of the more obscure words are obviously not being interacted with to any great degree but this itself is not a concern as the idea is not to gather responses on each individual unit but to prompt thought. The better response rates are seen in the redactions and additions to the list itself, as opposed to in the areas for the reader to add their own additional units. While audience, and the context in which the project is encountered affect these rates, it is interesting to note how the method of presenting the information to the reader can influence the quality of response. The booklet format, with its two 
stage approach of presenting units of the list for contemplation, making the reader to take a stance, followed by a request for the reader to construct their own list based on subject areas important to them, seems to be the most effective so far.

Moving forwards, we will continue to explore the relationship between these ongoing iterations and the core list. We will be investigating how we might develop an online implementation, with the concomitant implications for presenting large amounts of information and encouraging user engagement in a digital space. An exhibition "Of Rights and Resistance" at the International Slavery Museum in Liverpool sees another iteration which asks the reader to respond to the articles of the Universal Declaration of Human Rights of 1948 and also to propose their own articles, giving a voice in the creation of their own personal declaration. Please Contribute will continue to present the complexities of the modern age, encourage socially engaged graphic design and challenge the reader to question their role in society and the context in which they live.

\section{References}

[1] Smith, M. (29 March, 2017). Theresa May admits $£ 350$ million pledged to NHS by Brexit campaign isn't going to happen. Mirror. Retrieved from https://www.mirror.co.uk/news/politics/theresa-admits-350-million-pledged10124021

[2] Van Reenen, J. (2016, August). The aftermath of the Brexit vote - the verdict from a derided expert. Retrieved from: http://blogs.Ise.ac.uk/politicsandpolicy/theaftermath-of-the-brexit-vote-a-verdict-from-those-of-those-experts-were-notsupposed-to-listen-to/

[3] Fox, K. Vonberg, J. Dewan, A. (Mar 29, 2017). Brexit: 50 things the UK needs to do after triggering Article 50. CNN. Retrieved from: https://edition.cnn.com/2017/03/29/europe/brexit-article-50-to-dolist/index.html 


\title{
Infographics: Absent Without Leave
}

\author{
Ian Mitchell \\ Liverpool John Moores University, School of Art and Design, Liverpool, UK \\ i.mitchell@ljmu.ac.uk
}

\begin{abstract}
It is widely regarded by cultural commentators that we are in a period of unprecedented political uncertainty, in which there is a desire for simple explanations to the complex sociopolitical challenges of 21st Century. It might be argued that in this climate a mode of communication such as infographics would have considerable currency - especially within the context of interpreting and understanding the competing and contradictory political views that often reference complex data and statistics. Infographics have always attempted to make the visualisation of information easy and accessible to ordinary people whilst maintaining an objectivity and factual accuracy, articulated in the work of the Isotope Movement and the celebrated examples by William Playfair, Florence Nightingale and Thomas Clarkson. Other examples such as The Daily Express newspaper's Expressographs of the mid 1950s promoted the political bias of its owner and were little more than news propaganda masquerading as informative graphics. Whether it's objective explanation, communicating a sociopolitical cause or belief, or outright deception and propaganda, infographics have been a central communication tool for many years. However this research finds an almost complete absence of infographics used during the 2017 UK General Election across a variety of communication media channels. This paper questions whether infographics have a place anymore in communicating political ideas and beliefs and whether this represents an emerging irrelevance (or death) of one of graphic design's most significant visual languages. Are we entering a post-truth, post-facts, post-infographics era? This research will focus on an analysis of communication content published during the 2017 UK General Election, ranging from traditional printed newspapers and official political party publications to unofficial online and social media output. The results presented will determine the extent of infographics diminishing value and relevance and offer some possible reasons for this phenomenon.
\end{abstract}

Keywords: Infographics / political graphics / propaganda

\section{Introduction}

In Spring 2017 a general election was called in the UK bringing into sharp focus the practice of communicating complex "social and economic matters to ordinary people". [1] It was hoped that the period of election campaigning would offer a 
defined sample of politically and socially motivated infographics to analyse. This analysis would aim to measure the quantity and quality of infographics. From preliminary research examples of infographics appeared hard to find. Does this indicate an emerging irrelevance of one of graphic design's most significant visual languages in communicating political ideas and beliefs?

\section{Methodology}

This research employs one main methodology: the analysis of communication content published during the UK General Election campaign, ranging from traditional newspapers, their online versions, official Political Party manifestos, and their twitter feeds, and finally what could be found across other less official social media. This broad and varied approach was taken to acknowledge the recent and ongoing shifts in how news and political debate is published, consumed and shared. For each communication channel the type of visual content was counted and the use of infographics reviewed.

Printed newspapers. Three daily newspapers and their Sunday equivalents from across the political spectrum were surveyed the weekend preceding the election to give an initial snapshot of traditional printed news. The Guardian and Observer from the broadsheet left, the Mirror from the tabloid left, the Express from the tabloid right, and the specialist economic broadsheet the Financial Times. This was by no means an extensive sample, however it was hoped that this cross section of newspapers would return some examples of infographics. The Guardian is well known for its use of infographics and data journalism, [2] whilst the Express has a history of using infographics know as "Expressographics" for propaganda purposes in the 1950s. [3]

Online newspapers. A survey of the printed newspapers' online versions allowed for analysis across a longer period of time. Each newspapers' General Election sections were reviewed for articles available in the seven days preceding the election.

Manifestos. Political party manifestos were analysed as the official published declaration of the ideas, beliefs and policies of the six main parties; The Conservative Party, Labour, Liberal Democrats, The Green Party, SNP (Scottish National Party) and UKIP (UK Independence Party).

Twitter. A survey of the six main parties' official twitter feeds extended the analysis of official party communication into the less formal and more immediate channel of social media and how infographics may be used in response to unfolding campaign events. Twitter's built-in Advanced Search facility allowed an analysis of each party's twitter feed for the entire duration of the campaign - from $19^{\text {th }}$ April 2017 when the election was called until $7^{\text {th }}$ June 2017 when campaigning stopped. 
Other social media. The influence of social media on election campaigning is well documented now, even if its extent and influence is still being debated. Recent allegations place Cambridge Analytica and Facebook at the centre of a scandal in which political organisations targeted voters with personalised political advertisements during the Brexit campaign by harvesting 50 million Facebook profiles without permission. [4] However, defining a sample to analyse for a social media channel such as Facebook is complicated. A key feature of Facebook is that it feeds us what we are already interested in, making it hard to analyse it with any sure objectivity. The analysis of election related posts in the week preceding the election was inevitably trapped in the researcher's bubble. A general Facebook Posts search for "UK General Election 2017 infographics" was made in the hope of returning a broader and more objective sample to analyse.

\section{Coding Units}

The following coding units were identified: the articles, posts or pages; photographic images; videos; graphics; infographics and info-animations. For the purpose of this analysis the following define the less explicit coding units:

Graphics. Designed images, typically featuring a combination of photography, graphics and/or typography.

Infographics. Designed images featuring elements associated with traditional infographics such as pictograms, charts, diagrams and displays of data.

Info-animations. Videos or moving images that contains some elements of infographics.

Similar coding units were identified for the analysis of each communication channel.

\section{Findings}

To summarise, less than $4 \%$ of all the content analysed could be coded as infographics or info-animation. Figure 1 shows the breakdown across media channels: Printed newspapers $0.5 \%$, online newspapers $16 \%$, Party manifestos $0 \%$, Party twitter feeds $1.6 \%$ and Facebook $6 \%$. 


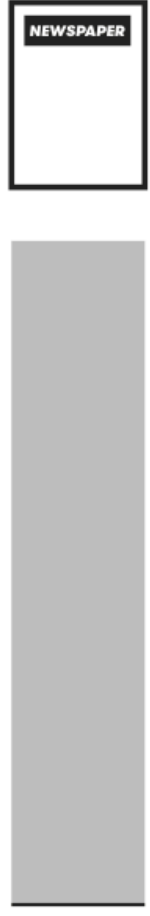

$0.5 \%$
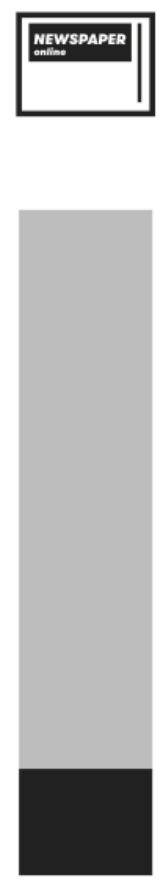

$16 \%$
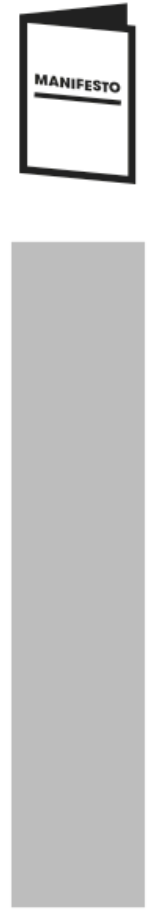

$0 \%$
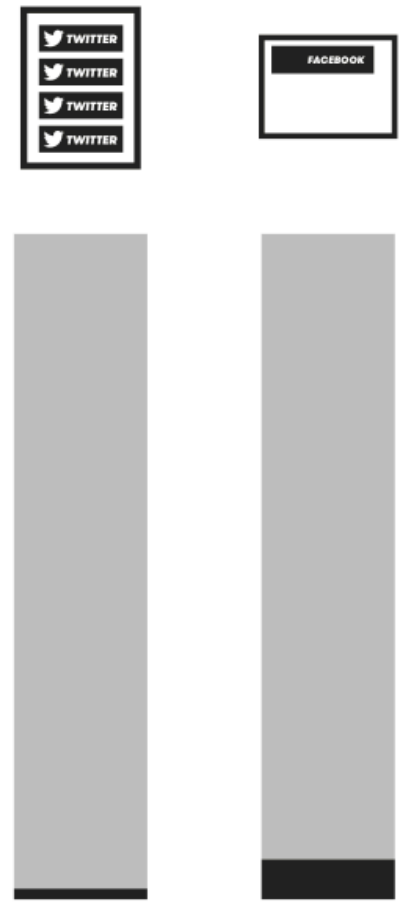

$1.6 \%$

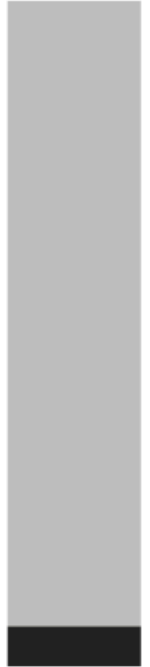

$6 \%$

Fig. 1. Chart showing the percentage of info-graphics counted across media channels.

The almost complete absence of infographics in the printed newspapers was a surprise, and did prompt the broadening of research to other media. There were just eleven uses of infographics across the seven newspapers, and only one example that could be considered to have anything to do with the election; a poll of polls and political map from the Observer.

The online newspapers featured infographics more significantly. Express online and Guardian online had the highest proportion of infographics. The examples of the Guardian graphics were neat, tidy and workmanlike but somewhat disappointing for a newspaper that is renowned for its use of infographics. However they did contain genuine information that could help interpret policy. Although Express online featured the highest proportion of infographics, almost all were about the polls and all were originated by other sources such as YouGov, IPSOS More, ICM, britainelects.com. The closest they came to presenting something more editorial was the reposting of a BBC report, which contained unnecessary contextualization that reduced the piece to a satirical parody of news graphics, or "chart-junk". [5] The Financial Times clearly placed the greatest emphasis on a design led approach to their online articles with a variety of illustrative work and adventurous data 
visualisation. However, like Express online, these tended to focus on explanation of the polls and the political system, not on policy. For example, one nicely produced info-animation explained the political system rather than issues or debates. The tone of the content felt a little patronising considering the likely extent of the audience's political engagement. The FT online requires a subscription for example, which possibly accounts for the richly designed content on the site.

Infographics were conspicuous by their complete absence in the party manifesto documents. Not one was featured. Instead, a variety of well-worn visual clichés were used to illustrate or signify each party's policies and beliefs. Ironically many of these signifiers were shared across the political spectrum.

The twitter feeds of the parties did register some use of infographics, although quite insignificant in terms of the proportion of overall tweets (see figure 2), especially considering the generous interpretation of the definitions of infographics and info-animations being used to identify the coding units. Many of the examples coded as info-animations featured superficial infographics used for decoration rather than visual explanation. At best the style (or language) of infographics was being used as possible shorthand for facts, where very little data or information was being presented.
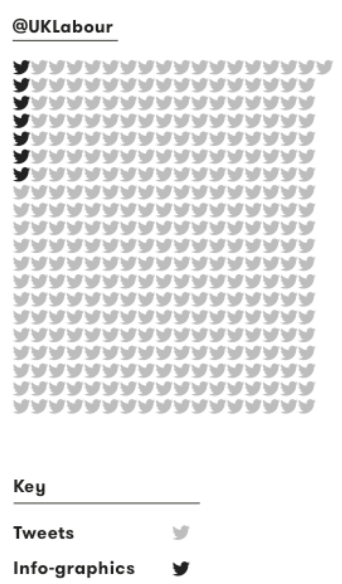
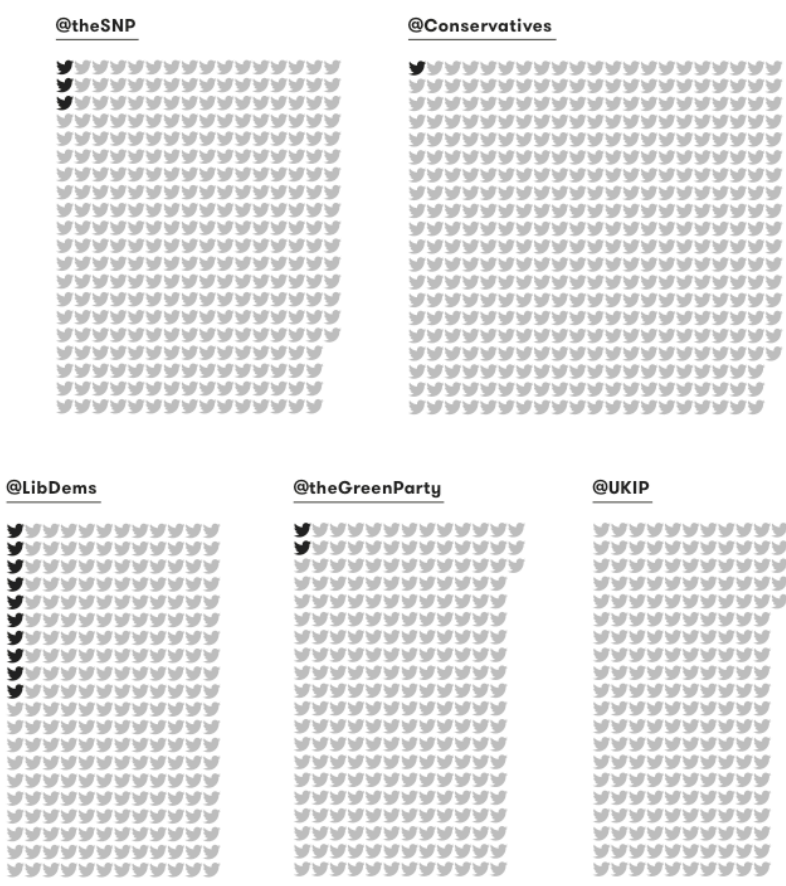

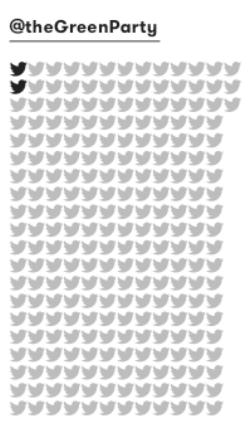

Fig. 2. Chart showing the proportion of info-graphics counted across Party Twitter feeds. 
From the analysis of the researcher's Facebook newsfeed, the Alt-Left online media publication Another Angry Voice was particularly evident. Its Facebook site, styled on an old-fashioned blog, reaches millions of people with a "combination of endearingly homemade memes, Facebook-friendly headlines, and a regular output of relentlessly anti-Conservative takes on the news". [6] Out of 243 posts during the election campaign the majority featured either graphics or video, of which 15 (6\%) could be coded as infographics. "What's striking is the extent to which the new alt-left sites can appear remarkably similar in tone and approach to their arch-enemies... using the same tabloid tactics to reach the maximum number of people and putting a heavy spin on quotes and statistics." [7] The three most shared posts featuring infographics use a no frills anti-design approach which has become a part of Another Angry Voice's authentic brand.

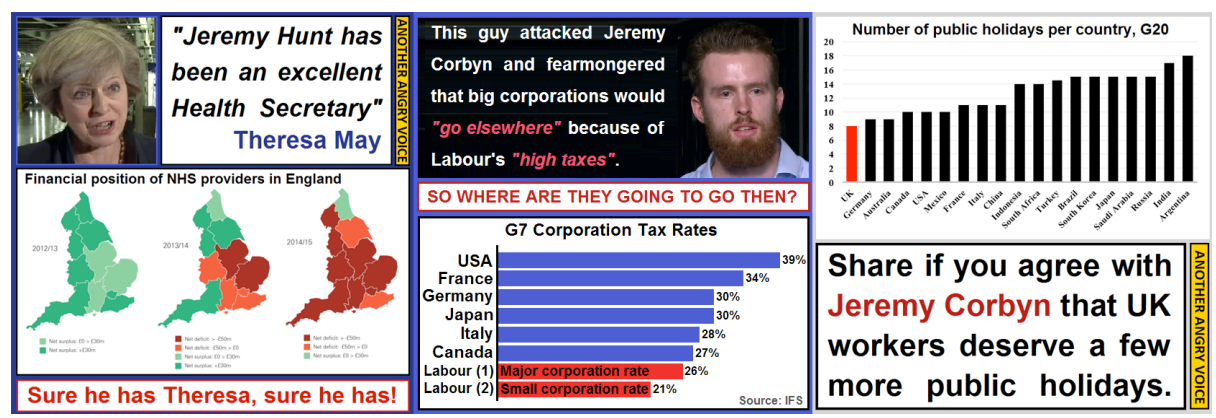

Fig. 3. Images from: https://www.facebook.com/Another-Angry-Voice-185180654855189. Another Angry Voice.

Although the general Facebook Posts search for "UK General Election 2017 infographics" produced few results it did uncover one notable example by a recent design graduate Daniel Britton. The info-animation for Momentum (the grassroots campaigning movement for Labour's left-wing) illustrates the direction the UK has taken over the past 7 years, presenting 10 facts using a minimal modernist design aesthetic with a level of sophistication between form and content that was hard to find in the rest of this research. 


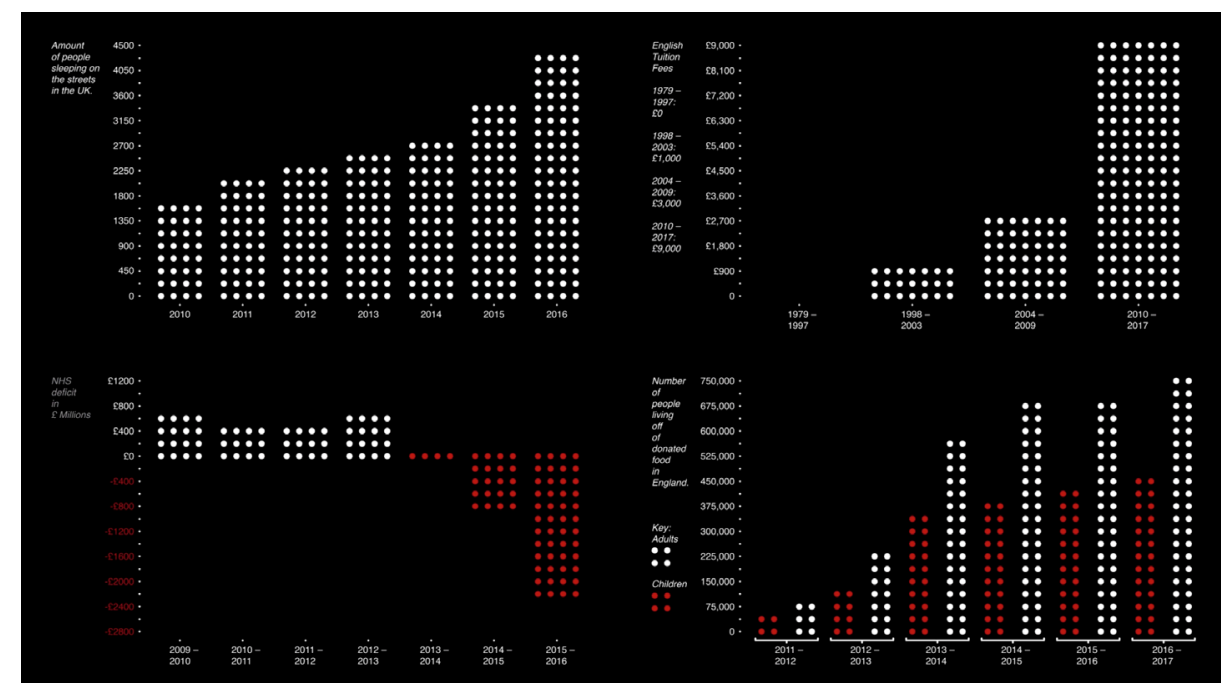

Fig. 4. Frames from 'UK General Election 2017 infographics'. Daniel Britton.

Daniel Britton was questioned about the authorship of the work (Britton, personal communication, October 27, 2017):

"So what happened with the project is that I had so much passion for creating awareness about the current political climate I produced the info-graphic off my own back. I created a narrative and once I had the story I wanted to tell I sourced the information (all from government websites or respected charities) and once I designed it I then contacted anyone that would of been interested to listen and begged for them to look it over. Of course because I am a small name designer $99 \%$ of people will ignore you but Momentum were open to the idea and in a few places even assisted me with the research. Once Momentum posted the piece it got 50,000 views in 2 days and the design gained a new weight."

\section{Discussion}

Is $4 \%$ a good or appropriate amount of content analysed to be considered infographics or info-animation? It's hard to say without comparing these results with a different sample - a previous general election campaign or a campaign from another country for instance.

Infographics are in evidence but primarily online. Although this may be an indicator of the pre-eminence of this media now, the dearth of infographics in printed newspapers is disappointing considering that print offers the time for a reader to slow down and properly interrogate an infographic. This criticism can also 
be levelled at the party manifestos. These long form documents, dense with policy data and factual evidence would all surely benefit from visual explanations in the form of infographics. However, across the manifestos or social media, very few parties valued a design led graphic approach let alone a sophisticated or creative use of infographics.

Why is it that there weren't more examples like Daniel Britton's infographic? Looking beyond the parameters of the election there are impressive examples of contemporary socio-political infographics, such as Antti Lipponen's The Temperature Circle (2017). His info-animation posted and shared across Twitter shows the rhythm of global warming for countries around the world, from Afghanistan to Zimbabwe. It unequivocally presents the argument that global warming is a very real and urgent problem. Lipponen said he made the animation because he wanted a "nice looking, clear, and informative" [8] way to convey that information in a way people can understand.

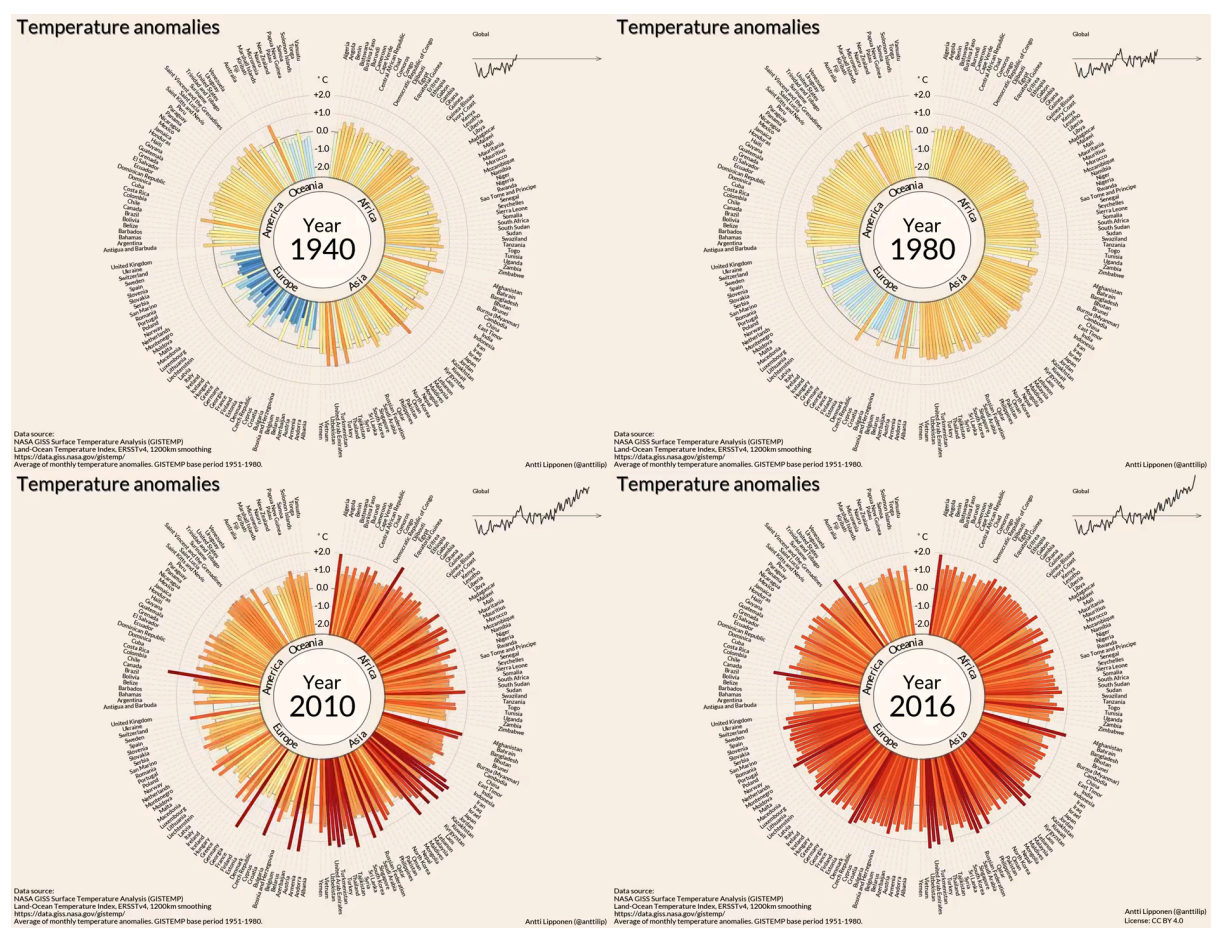

Fig. 5. Frames from 'The Temperature Cycle'. Antti Lipponen.

Lipponen is a physicist at the Finnish Meteorological Institute. Perhaps this is a clue to the absence of quality infographics found in this research. Who are the authors of the graphics - hired hands? Do they really have personal interest in the issues? Are they personally motivated to convey information in an understandable way? 
Lipponen isn't a graphic designer or an information designer, yet he's taken of Isotype's role of the "transformer" [9] to turn data into a persuasive graphic because he had wanted to explain something. Similarly Daniel Britton's animations were made "off his own back". He had a story to tell, sourced the information and then self-published the infographic which was then picked-up by an official channel.

\section{Conclusion}

Is it a surprise that an election campaign featured a dearth of quality infographics? Election campaigns rarely produce quality political debate in other communication formats, whether it's news reporting or party political broadcast, so why should infographics be any different.

This research unashamedly focused on the UK and in most cases official sources, which is certainly a limitation. Hopefully, if repeated in another country it might produce very different results. If not, we may have a crisis for one of graphic design's most significant visual languages to reflect the current political crises.

\section{References}

1 Kindel, E and Walker, S. (2010). Isotype Revisited. Retrieved from: http://isotyperevisited.org/2010/09/isotype-revisited.html assessed 2017

2 Rogers, S. (2011). Facts Are Sacred: The Power of Data. London, UK: Guardian Books.

3 Dick, M. (2015). Just Fancy That. Journalism Studies, 16:2, 152-174. Oxford: Routledge. DOI: 10.1080/1461670X.2013.872415

4 Greenfield, P, (2017, March). The Cambridge Analytica files; the story so far. Retrieved from: https://www.theguardian.com/news/2018/mar/26/the-cambridge-analytica-filesthe-story-so-far theguardian.com

5 Tufte, E. (2001). The Visual Display of Quantitative Information. Connecticut, USA: Graphics Press.

6 Waterson, J. (2017, May). The Rise Of The Alt-Left British Media. Retrieved from: https://www.buzzfeed.com/jimwaterson/the-rise-of-the-altleft?utm_term=.cbQMzY310j\#.stQldxkyWB

7 ibid

8 Lipponen, A. as cited in Kahn, B. (2017, August). A Century of Global Warming, in Just 35 Seconds. Retrieved from: https://www.scientificamerican.com/article/a-century-of-globalwarming-in-just-35seconds $/$ ?utm_source=twitter\&utm_medium=social\&utm_campaign=sa-editorialsocial\&utm_content $=\& u t m \_t e r m=\&$ sf104473521 $=1$

9 Kinross, K. (2009). The Transformer - Principles of Making Isotype Charts. London, UK: Hyphen Press. 


\title{
Communicating the complexity of children's needs and aspirations to the designers of info-graphics
}

\author{
Anne-Marie Moore \\ ${ }^{1}$ Liverpool School of Art and Design, Liverpool John Moores University, UK \\ A.Moore@LJMU.ac.uk
}

\begin{abstract}
Info-graphics are designed to make complex information accessible. They are visual representations of data designed to convey information in a succinct and efficient way [1] (Newsom and Haynes, 2004; Smiciklas, 2012). An example may be a pictogram or public safety sign designed to warn people of a hazard. Such communication devices are currently developed through designercentered, adult-led processes. While many adults are able to interpret public signs correctly, [2] Siu et al. (2014) question whether children understand them, even when they are exposed to public signs in child-friendly spaces such as playgrounds or schools.
\end{abstract}

In a bid to enhance sign design and improve children's understanding of infographics, [3] Siu et al. (2017) make a case for including children in their design, as children's drawings can give new insights. However, the challenges of engaging children as co-designers in infographic research are yet to be addressed. In this paper, the author reflects on her involvement in the Together through Play project [4] (Holt et al., 2014), a three-year, Leverhulme Trust funded project aimed at developing understanding of children's needs and aspirations through the process of co-design.

With the intention of addressing the power imbalance between adults and children in co-design research, the researcher employed and adapted methods of cooperative inquiry, an approach to creating new designs for children, with children [5] (Druin, 1999). This paper focuses specifically on the participatory approaches, strategies and methodologies employed to encourage designers to truly listen to the voices of children, and their relevance to visual design research.

Twenty-two children aged 7 to 11 were recruited to participate in the study from four UK-based mainstream Primary Schools. At least one child participant from each school had a recognised physical impairment and at least one of their coparticipants did not. Six disabled children and their non-disabled peers took part in the study, with four of these children having physical impairments relating to cerebral palsy. One child had dyspraxia and one child had a hearing impairment.

Undergraduate students from Product Design and Engineering programmes at the University of Leeds were recruited to work alongside the children as codesigners. Their involvement included realising the children's design ideas as prototypes and producing a series of critical artefacts as tools for discussion. 
Through semi-structured interviews with the researcher, the students reflected upon their experience and involvement in the study.

Where focus groups with children have traditionally been used as a means of verifying design solutions, this project aimed to actively engage children in the design process from conception to completion. Rather than focusing on the end product, feedback and interaction with prototypes was used to develop understanding of the barriers encountered by children and their aspirations for inclusive play. It was anticipated that this dialogue would be more insightful than straightforward interviewing alone [6] (Holt et al., 2012).

Previous attempts to include children in research, particularly in the area of childhood studies, have emphasised the pre-existing power differentials between adults and children that lead to the silencing of children's voices [7] (Kay and Tisdall, 2012). However, the Together through Play project identified that many other factors can contribute to the silencing of children's voices in design research, with the attitudes of other children identified as one of the most significant barriers.

In this paper, reflections on the methods employed in the Together through Play project are used to inform a set of guidelines for designers of infographics seeking to work collaboratively with disabled and non-disabled children in the future. It addresses the communication barriers identified that warrant the attention of infographic designers. It also highlights scope for infographics to be used to bring a greater balance of power to co-design projects with children.

Keywords: Infographics/co-design/children 


\section{Introduction to the Problem}

The UN Convention on the Rights of the Child [8] (2005) recognises the right for children to have voice on issues affecting them and to have their views heard. Kay and Tisdall (2012) [7] argue that too little research puts forward the viewpoints of children and values their contributions. Moreover, the term 'children's voice' has distinct disadvantages and exclusionary aspects that frequently act as a camouflage for what actually happens in research.

One dilemma researchers face is that children are considered vulnerable [9] (Mclntosh, 2000), and that any degree of harm may, therefore, affect children more than deeply than adults. The imbalance of power between adults and children are well documented, with adult assumptions about childhood contributing to children's marginalised position in society [10] (Punch, 2002). There is a common assumption that children cannot be 'fully informed', therefore they cannot give full consent to participation in research [11] (Posch and Fitzpatrick, 2012). Parents and carers have often been consulted about their children's experiences by proxy, and as a result, children's views have been undervalued and supressed [12] (Garth and Aroni, 2003). Further, adults may overlook the value and potential of children's ideas in design research as their imagination and creativity is often more limited than children's [13] (Almqvist, 1996).

Children are still treated unequally in comparison to adult research participants in research. For example, whereas adults are often remunerated for their participation in research, children are not [7] (Kay and Tisdall, 2012). Moreover, in the development of products aimed at children, children's ideas are not always granted the same respect as those of adult users [14] (Druin and Solomon, 1996). [15] Read and Fredrikson (2011) have focused on the ethics of children's participation in design research and the importance of children being given full information about the designs towards which they contribute. Read et al. (2014) [16] also draw attention to a lack of democracy in research with children, identifying a study undertaken by Iversen and Smith (2012) [17] as the first of its kind to deliberately place democratic processes at the forefront.

One of the benefits of engaging children as design partners in research is their ability to offer 'bluntly honest views of their world' (Druin, et al., 1997, p.1) [18]. However, young children in particular have difficulty verbalising their thoughts (Druin, 2002) [19]. Thus, alternative modes of communication need to be explored in research projects involving children. As children will tend to try to please adult researchers and respond positively when engaging in more favourable activities (Read et al., 2006) [20], strategies employed for working with children as co-designers must also address power imbalances and bring greater equality to the process. 
Regarding the involvement of disabled children in research - in childhood studies and disability studies, there has been a tendency for disabled children's experiences to be ignored (Priestley, 1998) [21]. Critics argue that disability research in general is adultcentric and gives little consideration to disabled children (Connors and Stalker, 2007) [22]. For James (2007) [23], rhetoric about 'giving voice to children' masks a number of important problems, since there is a tendency for researcher to avoid asking difficult questions (Badham, 2002) [24]. Not only have the views of disabled children been excluded from existing research, so too has the analysis of their social experiences (Davis, 2005) [25]. Moreover, 'voice' may reproduce understandings that marginalise children, i.e. assuming that the voice as the property of a rational, articulate, knowledgeable individual, capable of speaking for herself (Tisdall et al., 2009) [26].

In the UK, there are currently government guidelines on designing for users with additional needs (Home Office Digital, 2014) [27] (see figure 1). However, organisations such as CHANGE, the UK-based human rights charity, advocate working with disabled people in the development of accessible information and easy read resources (see figure 2) [28]. Regarding disabled children's engagement in design research, guidance exists on the issue of designing specifically for disabled children (Endicott et al., 2010) [29]. However, this research has focused on special adaptations and access provision for disabled children rather than being inclusive of disabled and non-disabled children's needs. 


\section{Designing for users with low vision}

\section{Do...}

use good colour contrasts and a readable font size

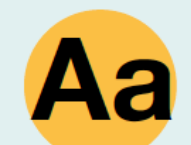

publish all information on web pages

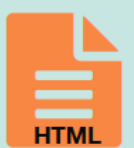

use a combination of colour, shapes and text

\section{Start}

$200 \%$ magnification

follow a linear, logical layout

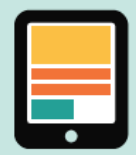

put buttons and notifications in context

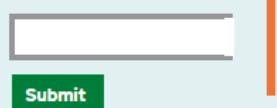

\section{Don't...}

use low colour contrasts and small font size

bury information

in downloads

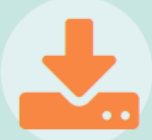

only use colour to convey meaning

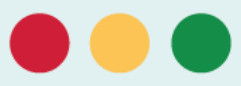

$200 \%$ magnification

spread content all over a page

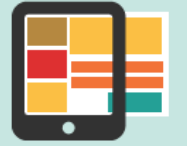

separate actions from their context

芦 ofice access@digital.homeoffice.gov.uk

Fig. 1. Home Office Digital, 2014 'Designing for Users with Low Vision' (https://accessibility.blog.gov.uk/2016/09/02/dos-and-donts-on-designing-for-accessibility/). 

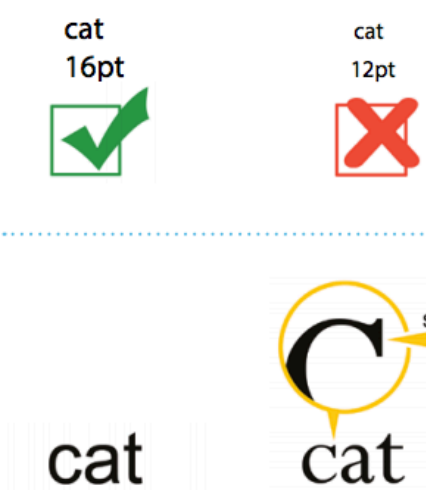

font without serifs

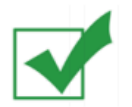

cat

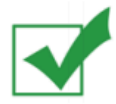

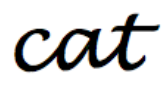

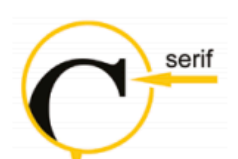

cat

font with serifs
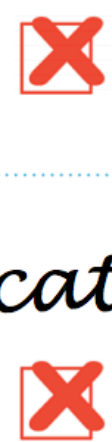

- Use a clear, easy to read font and make it at least 14pt in size. If you can, try to make the font $16 \mathrm{pt}$ or even bigger.

- It is important that your font is clear and easy to read. It should not have any serifs or complicated letter shapes.
- Most people will find fonts that are made to look like hand writing harder to read than printed fonts.

\section{Arial Tahoma \\ Verdana Myriad \\ Helvetica Calibri \\ Candara Corbel \\ Segoe Gill Sans}

- A good font to use is Arial or something that looks similarly plain. Examples of good fonts include: Tahoma, Verdana, Myriad, Helvetica, Calibri, Candara, Corbel, Segoe, and Gill Sans amongst many others.

Fig. 2. CHANGE 'Making Information Accessible' Guidelines.

In the field of infographics, designers are responding to children's need for access to information. Infographics in children's books such as those designed by Rogers and Grundy (see figure 3) [30] enable children to access information rather than fictional 
stories. It is important for children to be considered in infographic design. As noted by Rogers (2014) [31]:

Information belongs to everyone. The world's stories are being told through numbers and facts. But while we treat this as something that only applies to adults, it belongs to everyone. And the younger it starts, the better.

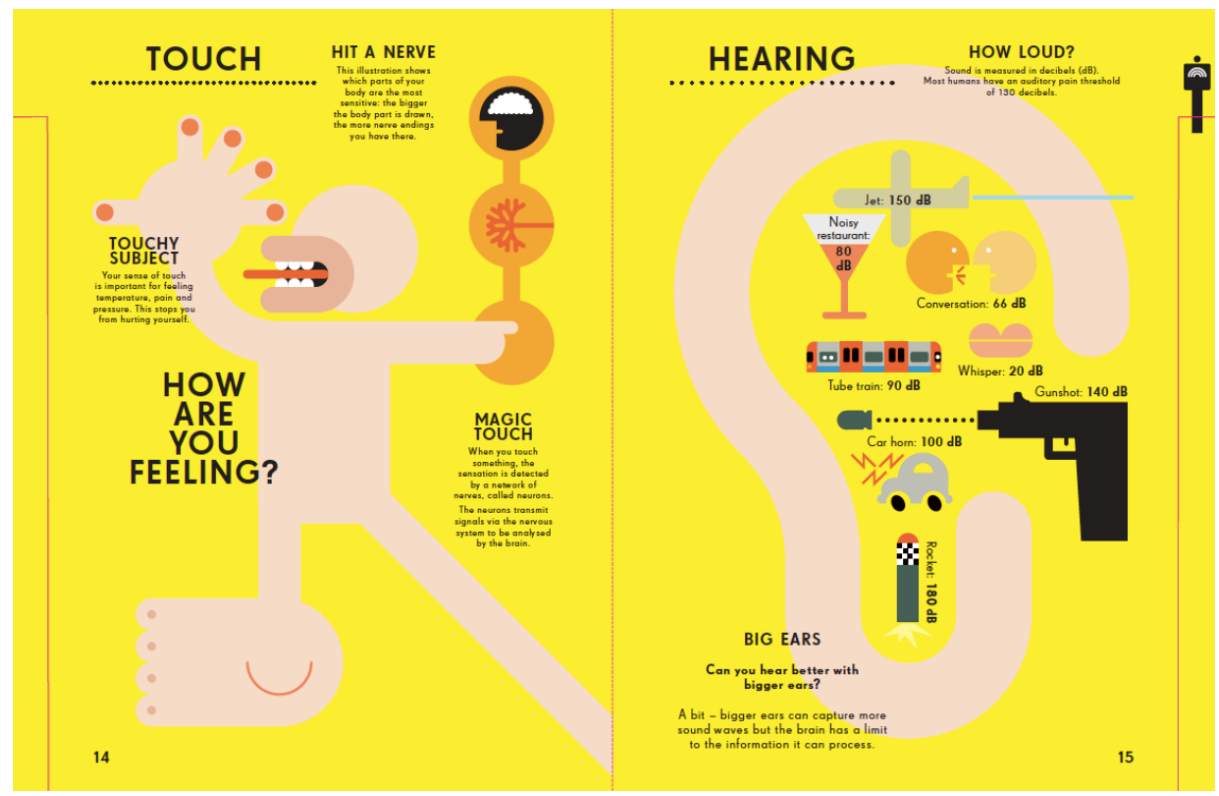

Fig. 3. Infographics: Human Body (Rogers and Grundy, 2014).

Siu et al. (2015) [3] make a case for the inclusion of children in the design of infographics. However, the aim of their research is to enable infographic designers to produce signs for children rather than supporting children's ongoing contribution to, and participation in, this process. The Together through Play project was the first of its kind to examine the process of designing with disabled and non-disabled children. There is also scope for investigation into special considerations for the inclusion of children with physical or sensory impairments in infographic research. 


\section{The Together through Play project}

In a bid to engage disabled children in the design process, the Together through Play project was an investigation into methods of cooperative inquiry (Druin, 1999) [5] an approach to participatory research with children as a means of gaining insight to their experiences and exploring their views. It involved a series of iterative cycles, including the following:

1. Observations of children at participating schools;

2. Focus group discussions with children about their experience of play;

3. Co-design activities with children;

4. The development of conceptual games and lo-fidelity prototypes at the University of Leeds, for children's review;

5. The development of hi-fidelity prototypes at the University of Leeds, based on children's feedback;

6. Semi-structured interviews and focus groups with teachers, parents and carers;

7. The selection and refinement of two preferred concepts, for final evaluation

The researcher also sought to examine methods employed by product design teams when attempting to engage disabled and non-disabled children in the process of user-centred design. Therefore, the following iterative cycles were undertaken:

1. A second, more in-depth analysis of the qualitative data collated through the project;

2. Semi-structured interviews and focus groups with undergraduate students responsible for the development of prototype toys and games at the University of Leeds (Moore, 2016) [32].

The theoretical framework for this study was underpinned by sociological methods drawing on the sociology of childhood (James and Prout, 2015) [33] and disability studies perspectives (Barnes, Barton and Oliver, 2002) [34]. Two common themes unify these perspectives - both seek to transform the position of children and disabled people from objects to subjects of study, and both seek to present children and disabled people as active agents, through a commitment to concepts of rights and participation (Watson, 2012) [35]. The social studies of childhood (Alderson, 1993; Beresford, 1997; Watson et al., 1999 and Connors and Stalker, 2003; 2007) [36], [37], [38], [39], [22], informed the design of this project - in particular, participatory methodologies designed to ensure the voices of disabled children themselves were represented in the research. 
Four UK-based mainstream Primary Schools participated in this study. At the discretion of each school, twenty-two children aged 7 to 11 were recruited for participation. There was no restriction on group size, however, the minimum requirement was that at least one child participant had a recognised physical impairment and at least one co-participant did not. Six disabled children and their non-disabled class peers took part in the study, with four of these children having physical impairments relating to cerebral palsy.

The scope of this project was limited to children with physical impairments. The aim was to conduct exploratory research into the views of a specific group of children, rather than conducting a systematic and representative study and to provide insight to the specific play experiences of the disabled and non-disabled children participants. Five undergraduate students from Product Design and Engineering programmes were recruited to participate in the study as co-designers. During semi-structured interviews and focus groups with the researcher, the students reflected on their involvement in the project.

This study employed a research by design approach (Frayling, 1993) [40]. Research by design is a form of action research through which the process of designing and evaluating a product for a situation becomes a vehicle for understanding that situation. An interpretive approach was employed in this study due to its flexible, and inductive nature (Braun \& Clarke, 2006) [41]. Inductive analyses primarily have a descriptive and exploratory orientation, which provide insight to individual experiences and allow researchers to develop understanding of issues as they emerge.

\section{Findings}

Although each of the children found ways in which to participate in the research activities, some encountered social, physical, or psychological barriers to participation, resulting in the silencing of their voices. For disabled children, social barriers were most prominent, particularly in relation to the negative views and behaviours of their non-disabled peers and others. In the worst case, two children experienced name calling and bullying at the hands of their non-disabled coparticipants.

Children with upper limb and motor impairments found written tasks difficult and some topics were too sensitive for others to discuss in a focus group scenario. Nondisabled children also encountered barriers to participation in focus group discussions and mind mapping activities, due to concentration-loss; disengagement with written tasks and limited time or resources. 
The disabled children gained voice when they were able to express themselves through self-initiated research methods and participate in the research in more nuanced ways. They developed their own techniques for evaluating toys and games and at times, deviated from the research schedule, in order to discuss topics of significance to them. For example, in addition to verbalising their views on the prototype toys and games, some chose to act out their gameplay suggestions (see figure 4).

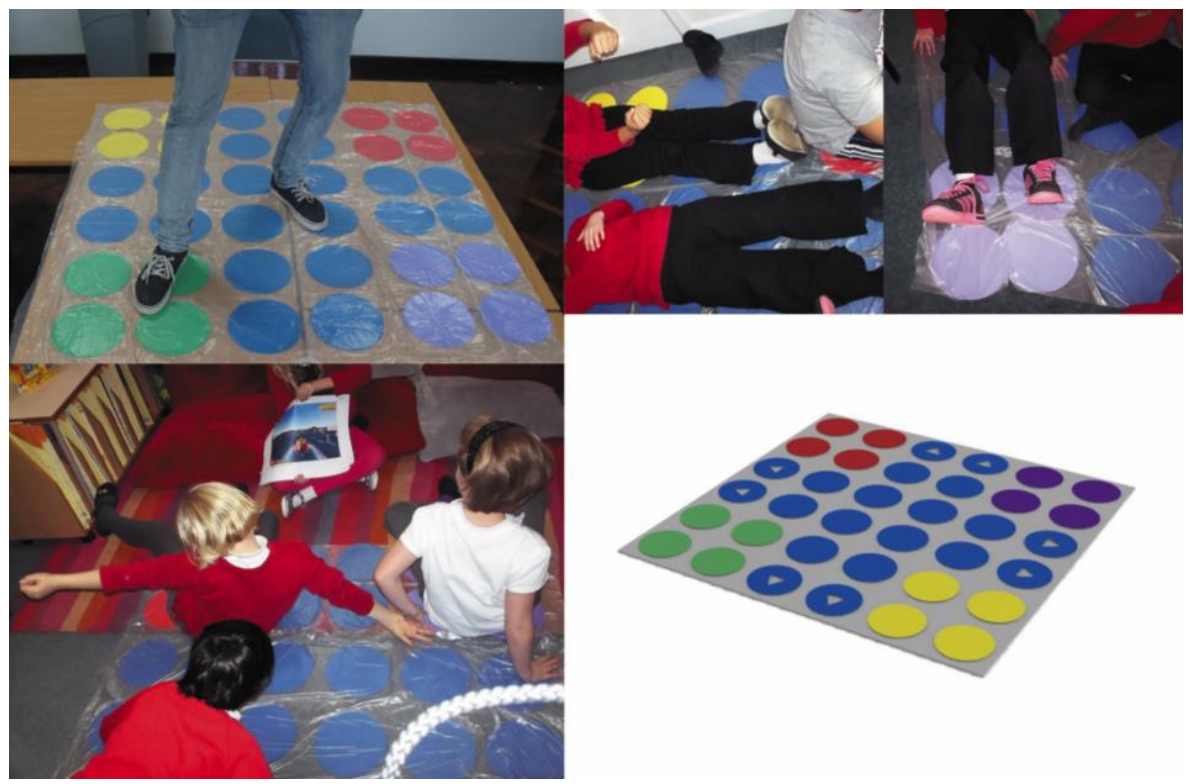

Fig. 4. Prototype evaluation session at school participating in the Together through Play project.

Some children used infographics to express their views and experiences (see figure 5). When emphasising the importance of inclusion, some felt that signs should be used to reinforce key messages, particularly in relation to bullying. However, self-initiated research methods were not applied consistently, nor were these methods shared between groups. Children at each participating school also expressed the need for a greater sense of autonomy over, and participation in, the design process. Some were also keen to find out how their ideas had been used to inform the design of the prototypes - highlighting the need for more transparency in the process of participatory design research with children. 


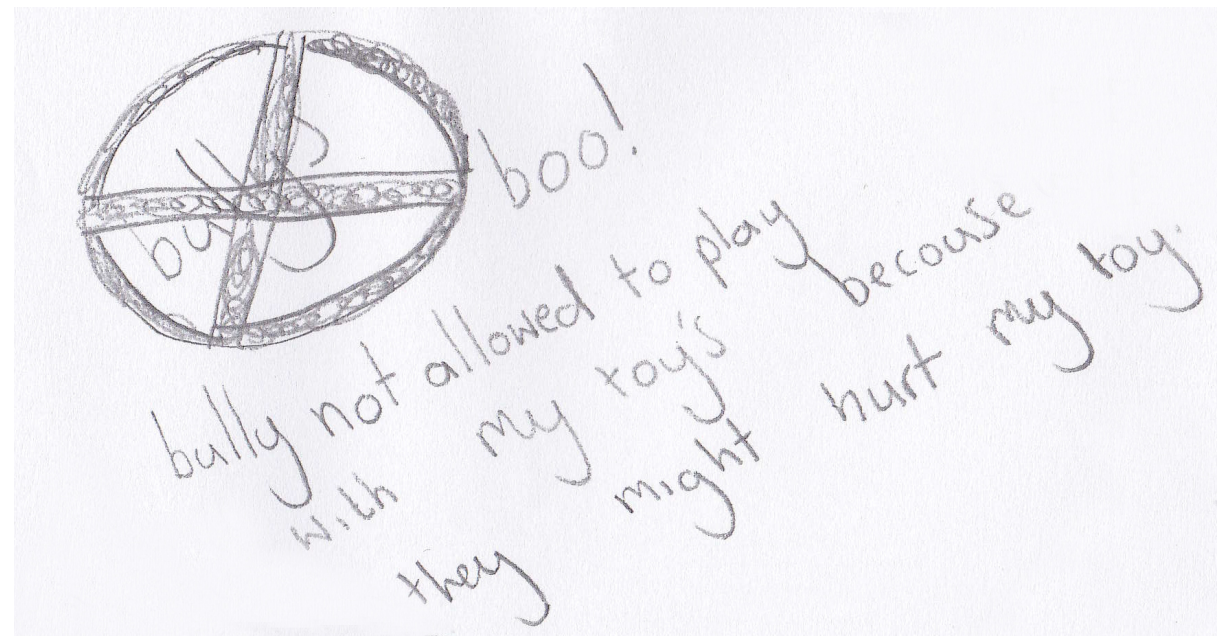

Fig. 5. Info-graphic developed by child participant engaged in the Together through Play project.

In their review of existing games and prototype games developed through the project, the communication of information was identified as one of the most significant barriers to play for child participants. A number of children expressed a preference for autonomous play and opportunities to learn or develop new skills through play. Suggested improvements included access to information, the communication of instructions, rule setting and guidance on how to play games. Each of these aspects could potentially benefit from the contribution of infographics designers. During observations, game rules tended to be communicated verbally between the children - a factor that was particularly exclusionary for the child participating with a hearing impairment.

Undergraduate students developed visual examples for some of their design concepts and incorporated the design of logos, symbols and colour coding into the design of some of the games. However, as children tended to take the visuals literally, some elements needed further development and refinement (e.g. an image of a player standing was taken as instruction to stand in order to play the game, and any errors in colour coding were noted by the children). 


\section{Student experience of the co-design process}

One of the challenges encountered by the undergraduate students included managing and filtering the vast amount of qualitative data generated through the project, without losing its richness. As the children expressed such a variety of preferences in their feedback, the students found the data overwhelming. Furthermore, the students had to be critical about some of the suggestions made by the children. Not all of the children's suggestions would support inclusion. For example, reliance on verbal instructions in a game, as suggested by one of the non-disabled children would exclude children with hearing impairments. Some of the children's views and suggestions conflicted - for example, there were disagreements on timings, levels of difficulty, themes, plus there was a tension between their desire for inclusivity as well as exclusivity. As the students were unable to observe the children interacting with the prototypes, due to safeguarding measures set by the University, and participating schools, they felt that they did not gain enough detailed feedback. Furthermore, the limited availability of participating schools meant that the iterative process was slow and that many of the students' questions went unanswered - highlighting the need for tools to enable quick idea iteration.

\section{Discussion and Conclusions}

The Together through Play project was the first of its kind to examine co-design with groups of children including children with additional needs. Having established the barriers to engagement with co-design processes for adult design researchers and children, there is scope for investigation into ways in which designers of infographics might aid the research process and address some of the barriers identified. Moreover, addressing issues of inclusion in co-design research is beneficial to disabled and nondisabled children. From this study, we can conclude that all children are unique, and it is important for design researchers to tailor research methods to children's individual needs.

\section{Guidelines for designers of infographics seeking to work collaboratively with disabled and non-disabled children in the future}

\section{Skills sharing}

This project highlighted the need to equip both children and adults with the relevant skills and experience to participate in co-design teams. In order to support children's involvement in co-design, adult design intervention may be required, in the form of technical demonstrations, scaffolded design tasks or divergent thinking strategies to help children overcome barriers to creativity. Collaborative work between designers and children towards defining inclusion is also recommended. As undergraduate 
students involved in this study had a tendency to focus on issues of accessibility for disabled children, rather than the interactions that made play meaningful to the child participants, their understanding of inclusion required further development. This paper encourages teams of adult and child co-designers to establish shared values, in order to bring a greater balance of power to future collaborative design projects.

\section{Transparency}

As discussed in section 1, Read and Fredrikson (2011) [15] emphasise the ethics of children's participation in design research, making a case for children being given full information about the potential use of designs towards which they contribute. As undergraduate students involved in the Together through Play project found their methods 'wishy-washy' and 'intuitive', there is scope to bring greater transparency to the process by using info-graphics to chart decision-making processes and evidence where children's ideas and feedback are used. Arguably, such resources could be used to enable or support member checks with children, ultimately giving children voice in the verification of design decisions.

\section{Communication barriers identified that warrant the attention of infographic designers}

In focus group discussion transcripts from disabled and non-disabled children, negative attitudes towards disabled people were identified as a significant barrier to engagement for disabled children. As infographic design projects can be used to develop children's critical-thinking skills (Krauss, 2012) [42], there is the potential for infographics to be used to challenge negative assumptions about disabled children and their role in design research.

\section{Research tools}

This study emphasised the need to enable children to contribute to the development of research tools used in co-design projects. As some of the child participants used self-initiated research methods to express their views and experiences, there is scope for info-graphics to be used to help realise and organise self-initiated research methods and alternative forms of expression for children.

Focusing on voice alone favours comprehendible verbal utterances over alternative communication forms, which can potentially exclude children who communicate with few or no words through speech (Komulainen, 2007) [43] or those who stay silent or respond to a researcher's questions with laughter (Lewis, 2010; Nairn et al., 2005) [44], [45]. Focusing on verbal communication can restrict the use of other 
communication methods, ranging from drawing to role-play - established methods for engaging with a diversity of children (Kay and Tisdall, 2012) [7].

Meeting children's individual needs through accessible infographics could potentially include the provision of easy read documents or visual flash cards. This project also highlighted the need for research into quick iterative techniques amongst co-design teams, in order to enable more meaningful dialogue. The field of infographics has the potential to make a positive contribution to this area in the future - for example, through the development of more effective evaluation tools.

\section{Communication of research aims and findings}

As verbal and written research proposals given at the point of ethical consent did not complete the children's understanding of the research, there is scope for investigation into ways in which child-friendly infographics such as the diagram featured below might develop children's understanding of the research process. Children involved in this study expressed a desire for access to information - such as finding out more about the undergraduate designers, children at other participating schools and the origin of some of the design ideas. Infographics are often used in research for publication and dissemination purposes. Arguably, infographics such as figure 6 could be used to help inform children and designers about their fellow co-designers in ways that are more accessible to them. Similarly, as the undergraduate students found much of the qualitative data overwhelming, infographics such as this one may also have been used to help them grasp a better understanding of the children involved in the project. Infographics can be a highly efficient and effective way to convey large amounts of information in a visual manner (Majoon et al., 2017) [46]. However, striking the balance between making data accessible and manageable, whilst avoiding diluting the rich information collated or stereotyping is a potential challenge for infographic designers.

This project highlighted the need for designers to consider ways in which research data might be communicated to be more inclusive of users with different needs, for example, with the inclusion of multi-sensory elements. There is scope for investigation into ways in which infographics might be used to support the needs of children and people with sensory impairments through the process of co-design. As highlighted by Barratt (2014) [47], information design has the potential to cross boundaries of experience design and art, bringing participants together in more nuanced ways (see figure 7). 


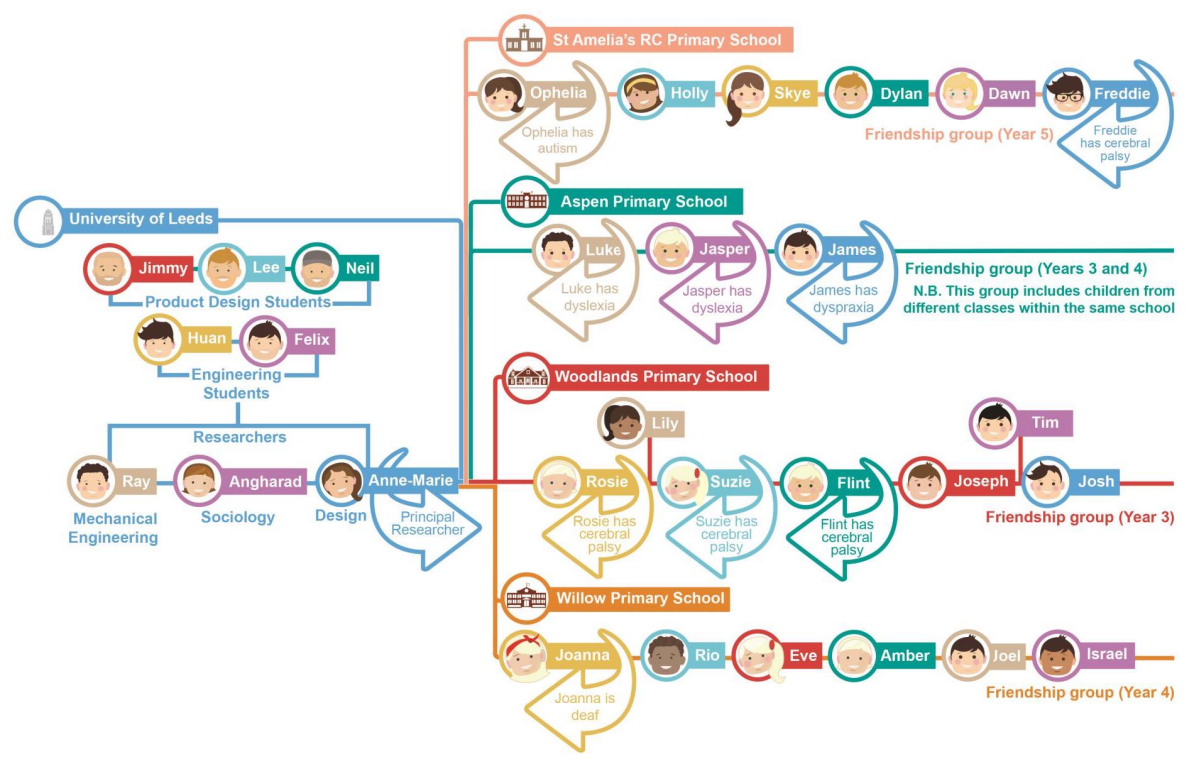

Fig. 6. Participant information diagram - Together through Play project.

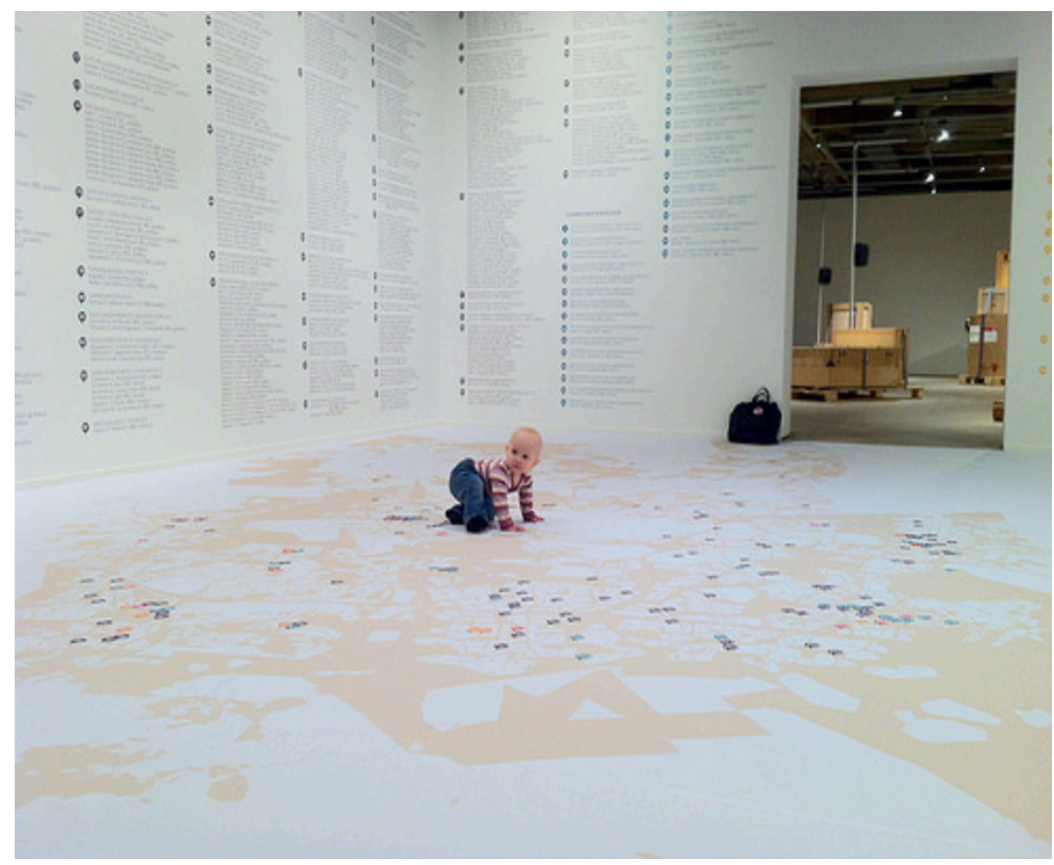

Fig. 7. Guide to the distributed collection of the Easpoo Museum of Modern Art. Courtesy of Stefania Passera [47]. 


\section{References}

[1] Newsom, D., \& Haynes, J. (2007). Public relations writing: Form \& style. Cengage Learning.

[2] Siu, K. W. M., Wong, Y. L., Lam, M. S., \& Ng, A. W. (2014). Children's misinterpretation of today's designs: a case study of how children interpret registered safety signs. The International Journal of Creativity and Problem Solving, 24(2), 61-74.

[3] Siu, K. W. M., Lam, M. S., \& Wong, Y. L. (2015). Designing signs for children: a study of children's drawings for safety signs. Communication Design, 3(2), 106-123.

[4] Holt, R. J., Moore, A. M., \& Beckett, A. E. (2014). Together through play: Facilitating inclusive play through participatory design. In Inclusive Designing (pp. 245-255). Springer Publishing.

[5] Druin, A. (1999, May). Cooperative inquiry: developing new technologies for children with children. In Proceedings of the SIGCHI conference on Human Factors in Computing Systems (pp. 592-599). ACM.

[6] Holt, R., Moore, A. -M., Beckett, A., 'Together Through Play: Facilitating Meaningful Play for Disabled \& Non-Disabled Children through Participatory Design' 11th International Conference on Interaction Design and Children, Bremen, Germany (12/06/2012 15/06/2012). Repository URL: http://eprints.whiterose.ac.uk/93102/.

[7] Tisdall, E. K. M. (2012). The challenge and challenging of childhood studies? Learning from disability studies and research with disabled children. Children \& society, 26(3), 181-191.

[8] Van Gils, J. (2007). The UN Convention on the Rights of the Child and the evolution of children's Play. In ICCP Conference in Brno/online/. Retrieved on February (Vol. 15, p. 2013).

[9] McIntosh, N., 2000. Guidelines for the ethical conduct of medical research involving children. Archives of Disease in Childhood. 82(2), 177-182.

[10] Punch, S. (2002). Research with children: The same or different from research with adults? Childhood, 9(3), 321-341.

[11] Posch, I., \& Fitzpatrick, G. (2012, November). First steps in the FabLab: experiences engaging children. In Proceedings of the 24th Australian Computer-Human Interaction Conference (pp. 497-500). ACM.

[12] Garth, B., \& Aroni, R. (2003). 'I Value What You have to Say'. Seeking the Perspective of Children with a Disability, Not Just their Parents. Disability \& Society, 18(5), 561-576.

[13] Almquist, J., \& Lupton, J. (2010). Affording meaning: Design-oriented research from the humanities and social sciences. Design Issues, 26(1), 3-14.

[14] Druin, A., \& Solomon, C. (1996). Designing Multimedia Environments for Children: Computers, Creativity, and Kids. Wiley Computer Publishing, John Wiley and Sons, Inc., One Wiley Drive, Somerset, NJ 08875.

[15] Read, J. C., \& Fredrikson, M. (2011). What do we take? What do we keep? What do we tell? Ethical concerns in the design of inclusive socially connected technology for children. The Social Impact of Social Computing, 392.

[16] Read, J. C., Fitton, D., \& Horton, M. (2014, June). Giving ideas an equal chance: inclusion and representation in participatory design with children. In Proceedings of the 2014 conference on Interaction design and children (pp. 105-114). ACM. 
[17] Iversen, O. S., \& Smith, R. C. (2012, June). Scandinavian participatory design: dialogic curation with teenagers. In Proceedings of the 11th International Conference on Interaction Design and Children (pp. 106-115). ACM.

[18] Druin, A., Stewart, J., Proft, D., Bederson, B., \& Hollan, J. (1997, March). KidPad: a design collaboration between children, technologists, and educators. In Proceedings of the ACM SIGCHI Conference on Human factors in computing systems (pp. 463-470). ACM.

[19] Druin, A. (1999). The Role of Children in the Design Technology.

[20] Read, J. C., \& MacFarlane, S. (2006, June). Using the fun toolkit and other survey methods to gather opinions in child computer interaction. In Proceedings of the 2006 conference on Interaction design and children (pp. 81-88). ACM.

[21] Priestley, M. (1998). Childhood disability and disabled childhoods: Agendas for research. Childhood, 5(2), 207-223.

[22] Connors, C., \& Stalker, K. (2007). Children's experiences of disability: Pointers to a social model of childhood disability. Disability \& Society, 22(1), 19-33.

[23] James, A. 2007. Giving voice to children's voices: Practices and problems, pitfalls and potentials. American anthropologist. 109(2), 261-272.

[24] Badham, B., 2002. So What's Changed? An Evaluation of the External Impact of Ask Us! London: The Children's Society and the Joseph Rowntree Foundation. Available from: http://www.billb@nya.org.uk [Accessed 15 June 2014].

[25] Davis, J., Watson, N., Corker, M., \& Shakespeare, T. (2003). 12 Reconstructing disability, childhood and social policy in the UK. Hearing the voices of children: Social policy for a new century, 192.

[26] Tisdall, K., Davis, J. M., \& Gallagher, M. (2008). Researching with children and young people: Research design, methods and analysis. Sage.

[27] Home Office Digital, 2014.

[28] CHANGE (2017). Making Information Accessible.

[29] Endicott, S., Mullick, A., Kar, G., \& Topping, M. (2010, September). Development of the inclusive indoor play design guidelines. In Proceedings of the Human Factors and Ergonomics Society Annual Meeting (Vol. 54, No. 20, pp. 1822-1826). Sage CA: Los Angeles, CA: SAGE Publications.

[30] Smiciklas, M. (2012). The power of infographics: Using pictures to communicate and connect with your audiences. Que Publishing.

[31] Rogers, S. (2014). Infographics for children: what they can learn from data visualisations. The Guardian. URL https://www. theguardian. com/news/datablog/2014/mar/07/infographics-forchildren-can-learn-from-data-visualisations (accessed 9.15. 16).

[32] Moore (2016). The Role of the Designer in the Facilitation of Meaningful Play through Participatory Design.

[33] James, A., \& Prout, A. (Eds.). (2015). Constructing and reconstructing childhood: Contemporary issues in the sociological study of childhood. Routledge.

[34] Barnes, C., Barton, L., \& Oliver, M. (Eds.). (2002). Disability studies today. Polity.

[35] Watson, N. (2012). Theorising the lives of disabled children: How can disability theory help? Children \& Society, 26(3), 192-202. 
[36] Alderson, P. (2000). 12 Children as Researchers The Effects of Participation Rights on Research Methodology. Research with children: Perspectives and practices, 241.

[37] Beresford, B. (1997). Personal accounts: Involving disabled children in research.

[38] Watson, N., Shakespeare, T., Cunningham-Burley, S., Barnes, C., Davis, J., Corker, M., Priestley, M., 1999. Life as a Disabled Child: A Qualitative Study of Young People's Experiences and Perspectives _ [Online]. Available from: http://www.leeds.ac.uk [Accessed 22 June 2010].

[39] Stalker, K., \& Connors, C. (2003). Communicating with disabled children. Adoption \& Fostering, 27(1), 26-35.

[40] Frayling, C. (1994). Research in Art and Design (Royal College of Art Research Papers, Vol 1, No 1, 1993/4).

[41] Braun, V., \& Clarke, V. (2006). Using thematic analysis in psychology. Qualitative research in psychology, 3(2), 77-101.

[42] Krauss, J. (2012). Infographics: More than words can say. Learning \& leading with Technology, 39(5), 10-14.

[43] Komulainen, S. (2007). The ambiguity of the child's 'voice' in social research. Childhood, 14(1), 11-28.

[44] Lewis, A. (2010). Silence in the context of 'child voice'. Children \& Society, 24(1), 14-23.

[45] Nairn, K., Munro, J. \& Smith, A. B., 2005. A counter-narrative of a failed interview. Qualitative Research. 5, 221-244.

[46] Majooni, A., Masood, M., \& Akhavan, A. (2017). An eye-tracking study on the effect of infographic structures on viewer's comprehension and cognitive load. Information Visualization, 1473871617701971.

[47] Barratt (2014). Eye Magazine: the Promise of Information Blogpost. URL: http://www.eyemagazine.com/blog/post/the-promise-of-information (accessed 9.15. 16) 


\title{
A dictionary of visual analogies
}

\author{
Luciano Perondi ${ }^{1}$, Marco Ferrari ${ }^{2}$ and Donato Ricci ${ }^{3}$ \\ 1,2 \\ ISIA Urbino, via Santa Chiara 36, 36100 Urbino, Italy \\ \{luciano.perondi, marco.ferrari\}@isiaurbino.net \\ 3 \\ SciencesPo|médialab, Paris, France \\ donato.ricci@sciencespo.fr
}

\begin{abstract}
This paper discusses a theoretical framework for a research aimed to produce a dictionary of visual analogies used for the explanation of scientific theories, collected both from historical and contemporary sources. The artifacts will be indexed through a set of criteria and tags that will allow to navigate the contents and map correlations across time, scientific domains and types of publication. The archive will grow as an open-ended accumulation of examples, adapting the methodology for the selection and organisation of the analogies based on the new entries. A set of visualisations will be used in order to navigate the archive and make emerging patterns legible. The initial method of classification will be based on the faceted system envisioned by Luca Rosati (Rosati, 2015), in which artifacts are tagged and tags are organised according to a faceted classification. Tags will not be mutually exclusive, but they'll act like attributes: each entry may have multiple tags, the number of which can grow without any limit or predetermined direction.
\end{abstract}

Keywords: Analogy / Information Design / Scientific Representation

\section{A Definition of Analogy}

In order to understand if analogies can be considered a valuable tool to provide legibility into complex domains of information, we need first to define what kind of analogies we consider in our enquiry. As an initial reference, we introduce the discrimination between two different definitions of analogy, as proposed by Gelfert (2016):

"The term 'analogy', which derives from the Greek expression for 'proportion', itself has multiple uses, depending on whether one considers its use as a rhetorical device or as a tool for scientific understanding."

Given these two intents, the one that is of interest here is the second one, and specifically the one that defines analogy as the resemblance between relations in two different domains: the relation $(a-b)$ in domain-1 is like the relation $(c-d)$ in domain2 (Bailer-Jones, 2002; Gelfert 2016). 
"Its general form is that of 'pointing to a resemblance between relations in two different domains, i.e. $A$ is related to $B$ like $C$ is related to $D^{\prime \prime \prime}$ (Bailer-Jones, 2002, p. 110).

According to Pierre Duhem, who criticised the excessive use of mechanical models for the visualisation of physical processes in scientific literature:

"Analogies consist in bringing together two abstract systems; either one of them already known serves to help us guess the form of the other not yet known, or both being formulated, they clarify the other." (Duhem, 1914/1954)

We can visually express the inference at the basis of this particular type of analogy with the sketch of fig. 1 :

\section{domain-1 domain-2}

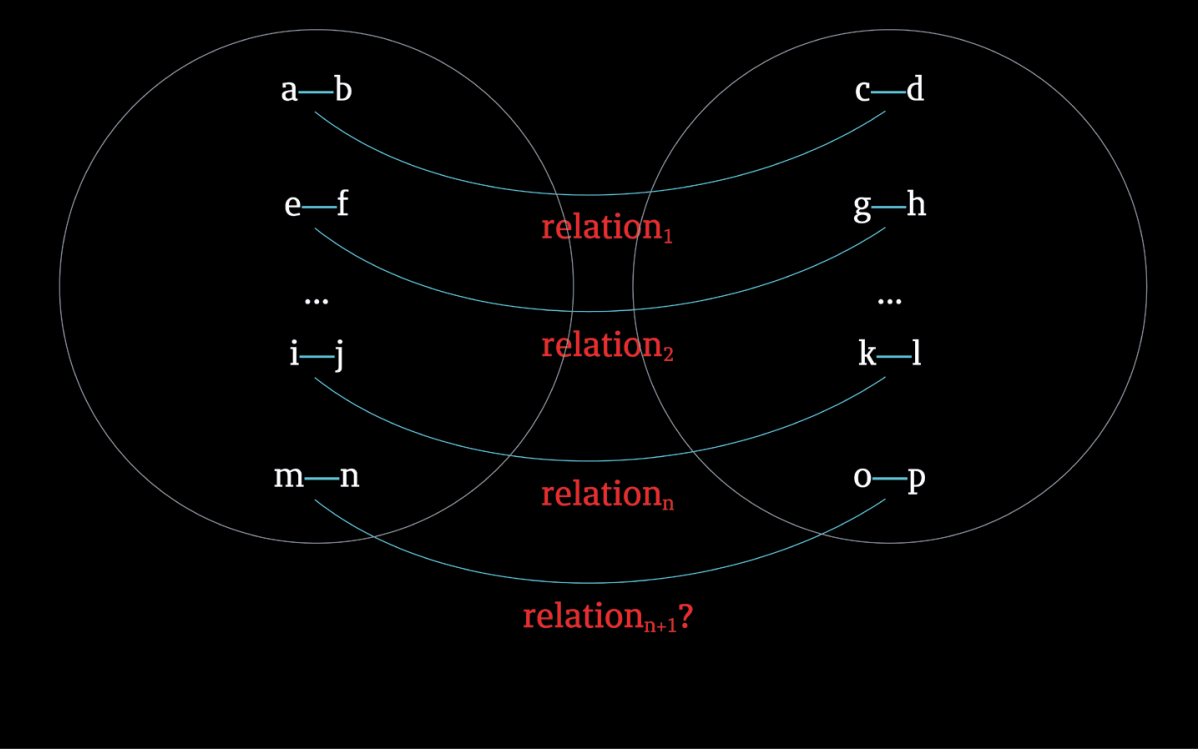

Fig. 1. If $\mathrm{n}$ properties in domain-1 match with the ones in domain-2, we can conclude that also the property^ $n+1$ institutes a valid relation between the two domains.

In real-life examples, it's a common situation that just some of all of the possible relations are used to establish a valid analogy, and we don't know if there is a not- 
matching relation until we find it. Even in the case of a non-complete correspondence between two different domains, though, this condition does not jeopardise the legitimacy of analogy as a tool for understanding. Analogies do not necessarily imply structural identity, but help to find patterns and similarities between two apparently distant domains.

\section{domain-1 domain-2}

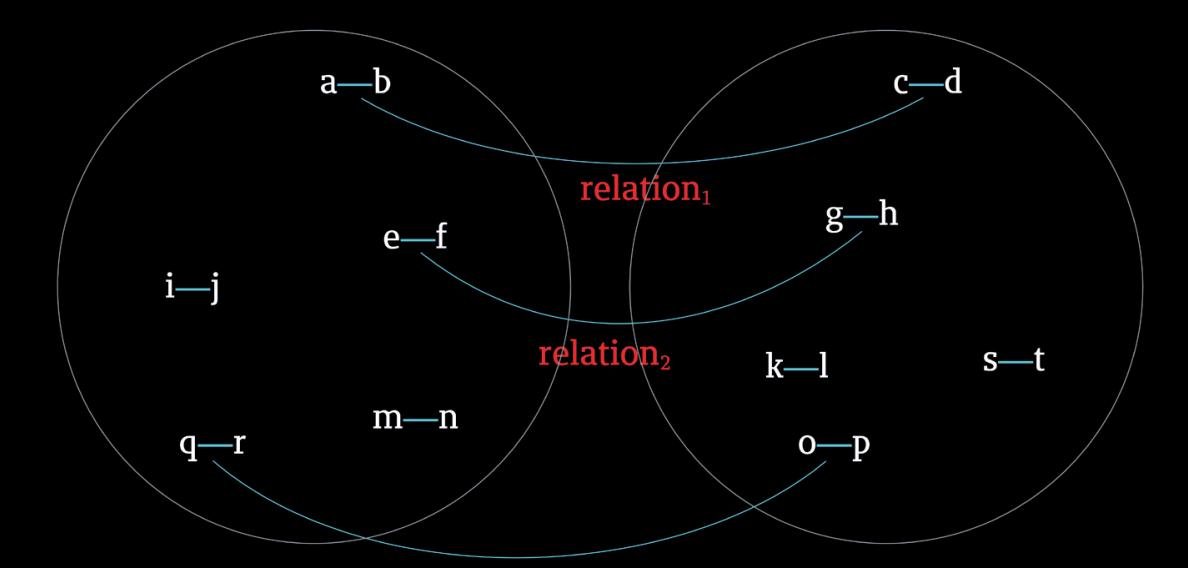

relation $_{3}$

Fig. 2. Despite the apparent limitation of a partial correspondence between features in two different domains, analogies can be used anyway as an effective tool for understanding: finding relations that do not match is also a knowledge-building process. Non-matching relationships can also be negative analogies.

It's interesting to note that analogies are often created between non-compatible domains. This means that inference per se is not enough to explain the process through which an analogy is established. Analogies-like scientific discoveries-are the product of creative imagination (Hesse, 1953), and are actively constructed.

As an example, let's consider the analogy used by Christiaan Huygens to explain the behaviour of sound waves and light waves... (Gelfert, 2016). 
Another, well-known example is the analogy between the Bohr model of the atom and a planetary system. This analogy constitutes a hybrid comparison, since the behaviour of electrons that jump continuously between different orbits cannot be explained by the Saturnian model initially adopted by Rutherford. On the other hand, the fact that the electrons revolve around the central core is explained through the mechanical model of the solar system (Arabatzis and loannidou, 2015). Therefore, the evolution of the Borh model has been based both on a positive and a negative analogy: the contradictory behaviour of the electrons compared to the model allowed to find an alternative theory.

Both these analogies include incongrous features, but they've been fundamental for the study of their corresponding phaenomena.

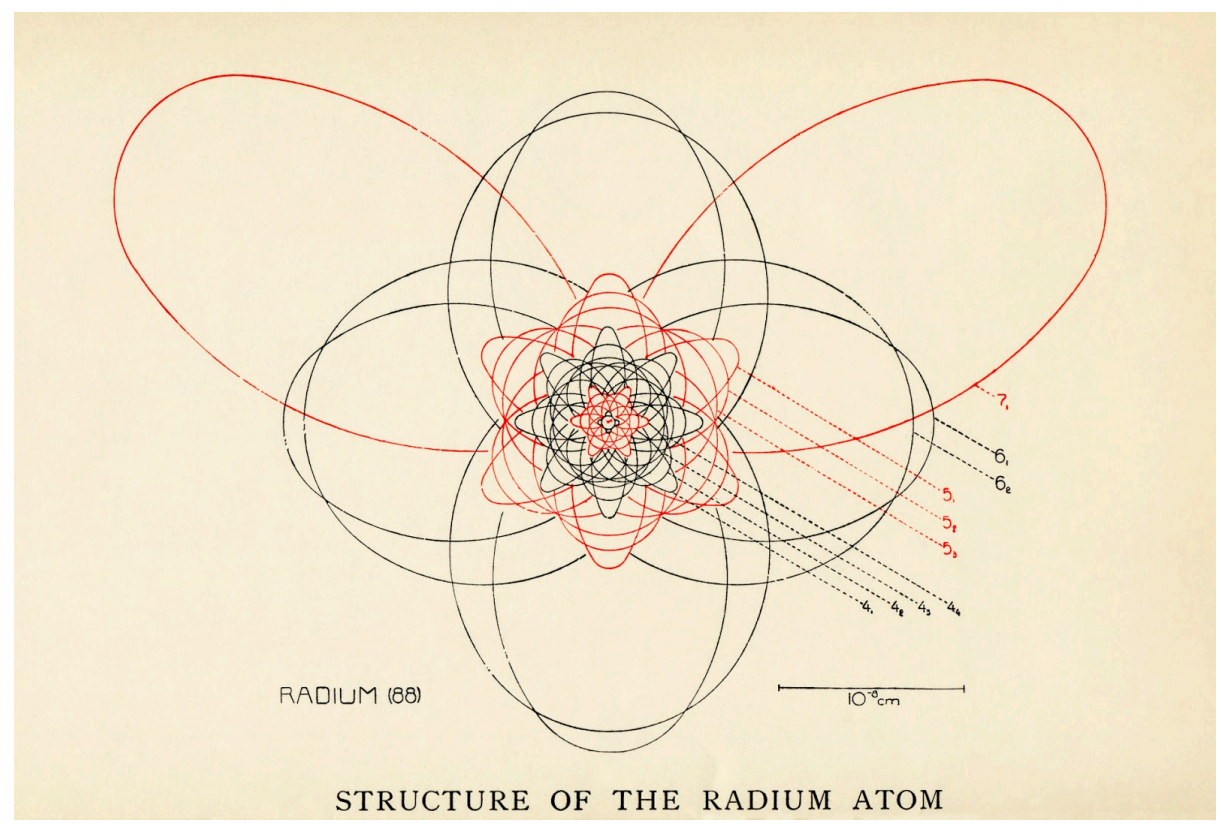

Fig. 3. The structure of the Radium atom according to Bohr's theory. Image from The atom and the Bohr theory of its structure. An elementary presentation, by Hendrik Anthony Kramers and Helge Holst (1923).

The use of analogy as a tool for the production of knowledge is not limited to the scientific domain, but it's common in many other fields. Let's consider as an example the kennings for Old Norse poetry, or the late Middle Age preaching based on an analogic process of building images (Bolzoni, 2002). We suppose that analogy is structural in human thinking, and thus it can be found in amy different fields as a way to articulate complex thoughts or elaborate knowledge. 
Metaphors share the same assumptions that we introduced for the definition of analogy, which means that they need to satisfy the following requisite: "a similarity between two different domains, where the features of domain-1 are structured as one-to-one relationships with the ones in domain-2".

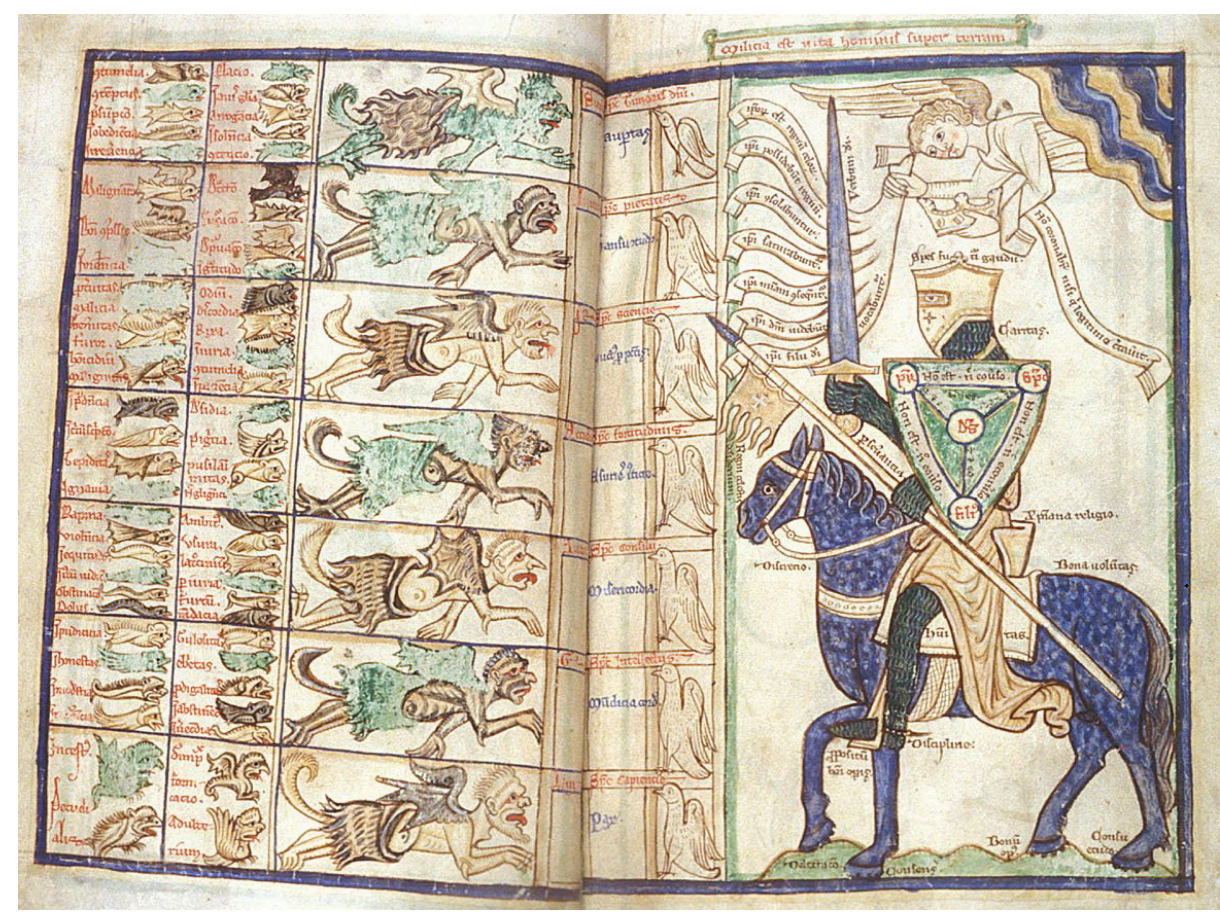

Fig. 4. Anonymous, Guilelmus Peraldus, Summa de virtutibus et vitiis, second half of XII century. Pigments on vellum. Harleian ms. 3244, folios 27v-28r.

\section{Structural Knowledge}

The second concept that we use to build our own model of analogy is the one of 'structural knowledge' as proposed by Jonassen (2000) in the field of problem-solving theories:

Analogies allow to make the first step to get a structural knowledge of a domain. According to Jonassen: "Structural knowledge [...] connects declarative and procedural knowledge. Structural knowledge is knowledge of how the ideas within a domain are integrated and interrelated" (Jonassen, 2000). 
The gap between declarative and procedural knowledge is bridged by analogies.

Structural knowledge is the knowledge of the relations within a domain, while analogy encompasses the similarities between relations within two different domains.

If we consider all the above points, referring to the definition of analogy and the concept of structural knowledge, we can state that analogies are a legitimate tool for accessing knowledge, and have been widely used over history to assemble scientific knowledge. C

We consider a definition of analogy in the widest possible sense: one that includes any kind of resemblance or likeness between domains. As stated before, the fundamental requisite is a correspondence or a partial similarity, for the purpose of explanation or clarification.

The reasons behind our interests in visual analogies are:

1. Analogies have always been part of the human understanding both of the physical world and abstract thought, but they are increasingly relevant and widespread today, where the visibility of technologies, systems and processes is being highly reduced by their exponential complexity and miniaturisation.

2. We want to trace an evolutionary history of analogies, and map how similar images have been used over time to define different concepts. The life of analogies often exceeds the one of the theories they represent and explain, in order to influence the subsequent evolution of scientific theories.

\section{A Charted History of Analogies}

The primary field of investigation will be limited to static and graphic representations used in scientific manuals published between the XIX and XX century. The analysis will be pointed only to visual and graphic artifacts (illustrations, diagrams, photos and photographic collages used for the explanation and divulgation of scientific theories), in order to limit the complexity of the methodological approach. The visual domain is the one we know better, and it will allow for a quicker processing of the images through visual analysis. The images will be sourced from publications present in the Internet Archive, a "non-profit, digital library of Internet sites and other cultural artifacts in digital form." (https://archive.org/about/). The Internet Archive provides free online access to a wide selection of manuals and publications from different scientific domains. In particular, the initial selection of images will be focused on scientific manuals. 
An initial corpus of images will be assembled in order to test the classification methodology and build a wide-enough database of contents that will then serve as a basis and reference for next step of the project, where the users of the dictionary will be able to suggest new entries. The aim is to build an open platform for the collection and classification of the images, an expanding database of visual analogies that will help to visualise the evolution of scientific theories throughout history.

Once this metholodgy will be tested and expanded with a suitable set of tags, it will then potentially be applied to other types of publication: encyclopedias, scientific papers, atlases, school textbooks, etc. We decided to initially focus on the manual because manuals have been the primary tool for the dissemination and affirmation of scientific theories throughout the XIX and XX century within peers. Other, more divulgative texts would weaken the analogies and their power to embody and steer scientific discoveries, as they would be seen just a mean for the spread of top-down knowledge.

Visual analogies found in manuals will be compared to similar ones in the same publication, besides looking for similar graphic artifacts outside the perimeter of the domain (snowball sampling).

The aim is to develop a web platform where the collection of the visual samples that constitute the database will be sorted and displayed, according to the following organisation. This tool that will serve as a way to cross-reference and investigate different analogies across time and disciplines, helping to map their relevance, cultural relevance, impact on the scientific discourse and mutual influence.

The initial method of classification will be based on the faceted system envisioned by Luca Rosati (Rosati, 2015), in which artifacts are tagged and tags are organised according to a faceted classification. Tags will not be mutually exclusive, but they'll act like attributes: each entry may have multiple tags, the number of which can grow without any limit or predetermined direction. We will thus be able to maintain the advantages of the tag classification-namely the possibility to introduce more attributes for each example and to introduce new attributes at every given momentplus the advantages of the faceted classification, used for the organisation of the attributes. 


\section{References}

Arabatzis, T., \& loannidou, D. (2015). The role of models and analogies in the Bohr atom. In F. Aaserud and H. Kragh (eds.), One Hundred Years of the Bohr Atom (pp. 360-376). Copenhagen: The Royal Danish Academy of Sciences and Letters.

D. Bailer-Jones, Models, Metaphors and Analogies, in The Blackwell Guide to the Philosophy of Science, ed. by P. Machamer, M. Silberstein (Blackwell, Oxford, 2002), pp. 108-127

Bolzoni, L. (2009). La rete delle immagini: predicazione in volgare dalle origini a Bernardino da Siena. Piccola biblioteca Einaudi. Einaudi. Retrieved from:

https://books.google.it/books?id=sHVnQAAACAAJ

Duhem, P. M. M., Wiener, P. P., Vuillemin, J., \& de Broglie, L. (1991). The Aim and Structure of Physical Theory. Atheneum paperbacks. Princeton University Press. Retrieved from https://books.google.it/books?id=5mVPK7QBdTkC

Gelfert, A. (2015). How to Do Science with Models: A Philosophical Primer. SpringerBriefs in Philosophy. Springer International Publishing. Retrieved from:

https://books.google.it/books?id=KVFECWAAQBAJ

Hesse, M. (1953). Models in Physics. The British Journal for the Philosophy of Science, 4(15), 198-214. Retrieved from http://www.jstor.org/stable/685897

Jonassen, D. H. (2000). Computers as Mindtools for Schools: Engaging Critical Thinking. Merrill. Retrieved from https://books.google.it/books?id=IW3uAAAAMAAJ

Kramers, H. A. (2015). The Atom and the Bohr Theory of Its Structure, an Elementary Presentation. Fb\\&c Limited. Retrieved from:

https://books.google.it/books?id=oXKltAEACAAJ

Rosati, L. (2015). Combinare tag e classificazione a faccette per migliorare la trovabilità. Retrieved from https://www.lucarosati.it/blog/tag-e-faccette 


\title{
Sinsemia as a tool for designing interactive artifacts for teaching.
}

\section{The case study of The topography of Dante's Inferno and the detailed definition of reference frame}

\author{
Giulia Bonora , Giampiero Dalai , Daniele De Rosa , Adelaide Imperato ${ }^{1}$, \\ Berta Martini ${ }^{2}$ and Luciano Perondi ${ }^{1}$ \\ 1 \\ Alpaca Società Cooperativa, via G. Garibaldi 5, 44121 Ferrara FE, Italy \\ \{giulia.bonora, giampiero.dalai, daniele.derosa, adelaide.imperato, \\ luciano.perondi\}@alpacaprojects.com \\ 2 \\ Università degli studi di Urbino, Dipartimento di studi umanistici, \\ Via Bramante, 17, 61029 Urbino PU, Italy \\ berta.martini@uniurb.it
}

\begin{abstract}
The Topography of Dante's Inferno" is a synsemic interactive artifact which is designed for 11-14 years old students. The design process has been based on the fundamental concepts of synsemia, which lead to an artifact that includes and combines different didactic mediators; in particular, in this article is described more in detail the fundamental concept of reference frame. The reference frame can be described as the frame (consisting of graphic elements) which allows to contextualize the graphic elements of a synsemic text.

The artifact has been qualitatively evaluated in two focus groups (one with 12 teachers in training and one with 12 teachers in service), in which some reflections emerged, like some misinterpretations due to a more or less correct design of the reference frame and the didactic mediators.
\end{abstract}

Keywords: Synsemia, Didactic mediation, Context

\section{Introduction}

The project "The Topography of Dante's Inferno" is a synsemic interactive artifact which is designed specifically for 11-14 years old students. After a research process, the website went under a first iteration of redesign and error-fixing.

As we described in two previous papers (Bonora et. al, 2017; Bonora et. al., in press), the project originated from the idea that there is no distinction between infographics, images and writing, which is the fundament of the theory of synsemia, which has a background in findings by Elkins, Goodman, Harris, Lussu (as discussed in Perondi, 2012). 
The design of the artifact is based on the elaboration of the fundamental concepts of the synsemic writing (hereinafter described as the synsemic quatrefoil), as previously described in Bonora et al. (2017) and Bonora et. al. (in press). These four concepts are:

1. Visual variables

2. Dissociative variables (which define the visual hierarchy)

3. Associative variables (which define the aggregates of graphic elements)

4. Reference frame

In this article we describe further the concept of reference frame, which has its background in neuroscience theories, perception, cognition, learning, and the theory of affordances (Gibson, 2015, p.119; Kandel et al., 2013).

\section{The Context. Background.}

Starting from this definition we state that, in our perspective, the concept of reference frame is strictly related to the concept of "context". As Johnson (2014, p. 9) synthesize, "the pattern of neural activity that corresponds to recognizing a letter, a word, a face, or any object includes input from neural activity stimulated by the context. This context includes other nearby perceived objects and events, and even reactivated memories of previously perceived objects and events."

Therefore, we consider the context as a complex integration of numerous elements (e.g. perception, memories, actions) which constitute a visual scene, a situation, a state of the memory, and this integration influences the perception and the analysis of an artifact and it contributes to assign meaning to the stimuli.

As already discussed by Perondi (2012, pp. 194-201) in an earlier stage, the context is created by the accumulus of memories and interaction with the artifacts and the environment. The recognition of an object implies the integration of the beholder with the environment in which the object lies (Gibson, 2015). As Kandel et al. (pp. 602-603) describe, the way in which a visual feature is perceived depends on everything that surrounds that feature and the response of a neuron in the visual cortex is context-dependent (e.g. the perception of a point or a line depends on how that object is perceptually linked to other visual features).

This form of embodied cognition (Varela et al., 1991, pp. 147-184) highlights how there is not a clear separation between vision and action, but rather there is a neural substrate which puts in relation the world with our possibility to act inside it. Indeed, Kandel (p. 557) explains how "In vision as in other cognitive operations, various features-motion, depth, form, and color-occur together in a unified percept. This unity is achieved not by one hierarchical neural system but by multiple areas in the brain that are fed by at least two major interacting neural pathways."

Indeed, the identification mechanism supported by the mirror-neuron system can be seen as a process aimed to understand the context, in which a subject 
understands how to act and projects his/her actions in the environment (see for example Fogassi \& Ferrari, 2007; Rizzolatti \& Craighero 2004).

\section{The Reference Frame as a Portable Context}

All these reflections about the context can be applied to the synsemic writing, since the reference frame acts as an "activator" of neural pathways aimed to reenact the context. The reference frames, which can be described as compressed contexts, are designed to be degraded in a systematic way with the goal of becoming "portable" - this hypothesis has been formulated and discussed by Luciano Perondi and Leonardo Fogassi during a personal interview (Fogassi, L., personal communication, June 27, 2017).

Creating a reference frame implies abstracting the context. The designer reduces the number of explicit relations within the elements of the context, stripping the context of its accessory references which are part of its complexity. This way, the designer compresses the context, making it become "portable" by reducing its informational "weight".

The mode for creating a context is, in our opinion, similar to the one described by Weber for Ideal-Types (Swedberg \& Agevall, 2016, pp. 156-158), for which the concepts are not made for copying the reality, but rather to highlight the connections which seems more relevant to the researcher. In this sense, the reference frame is the scheme which explicits the aspects that are considered more relevant by the author and the graphic compositor of the text. The readers also project a sort of "ideal type" on graphical artifacts, which is based on their expectations and previous experiences.

We hypothesize that neural pathways are activated by the reference frames though the process described as follows:

1. the set of visual elements, which are organized according to the synsemic quatrefoil, stimulate the reader's elaboration of the context.

2. This context consist of a a set of relations between graphical elements aimed to highlight one or more specific aspects, which the author of the text considers relevant.

3. The set of relations stimulates in the reader the creation of the context which allows the interpretation of the artifact.

The design of the artifact through the usage of the synsemic quatrefoil-done by the author and the graphic compositor-as well as the interpretation of the quatrefoil-done by the reader-are not serial. The four components of the synsemic quatrefoil are to be designed and interpreted as parts of a single process. Therefore, 
in the design of synsemic artifacts there is not a sequence of four distinct design actions, but a single process consisting of the integration of the four fundamental concepts.

When we refer to the reference frame, we do not refer to a cartesian grid-which is a particular case of reference frame-, but to a set of graphical-visual relations, and also proprioceptive, more or less regular, which allow to activate the elaboration of a more complex context.

The combination of the number of explicit relations within the reference frame and the degree of compatibility with the readers' "ideal-type" generates a perceived context. As consequence, the reference frame can be identified within a matrix scheme as follows:

Table 1. Description of reference frame types.

\begin{tabular}{c|c|c} 
& $\begin{array}{c}\text { High compatibility } \\
\text { with the readers" } \\
\text { "ideal-type" }\end{array}$ & $\begin{array}{c}\text { Low compatibility } \\
\text { with the readers" } \\
\text { "ideal-type" }\end{array}$ \\
\hline $\begin{array}{c}\text { High number } \\
\text { of explicit relations } \\
\text { within the reference } \\
\text { frame }\end{array}$ & Depictive & $\begin{array}{c}\text { Impossible to } \\
\text { disambiguate, } \\
\text { inscrutable }\end{array}$ \\
\hline $\begin{array}{c}\text { Low number of explicit } \\
\text { relations within the } \\
\text { reference frame }\end{array}$ & Abstract & Hermetic
\end{tabular}

If the reference frame is depictive (high number of relations, high compatibility), the process of re-enactment (and decompression) of the context will be less subjective (more regular) and more immediate (less resource demanding).

If the reference frame is abstract (low number of relations, high compatibility), the process of reconstruction (and decompression) of the context will be more subjective (less regular) and more difficult to interpret (more resource demanding).

In case of low compatibility with the readers' ideal type, it can possibly happen that the reference frame results to be ineffective: the elements which are supposed to activate reconstruction (and decompression) of the context are not available to the reader.

Anyway, a synsemic text, even the more depictive, is a set of more or less complex relations, which are selected and ordered rather than being a copy of the reality.

Here it follows a series of examples which could help to better understand the concept of reference frame. 


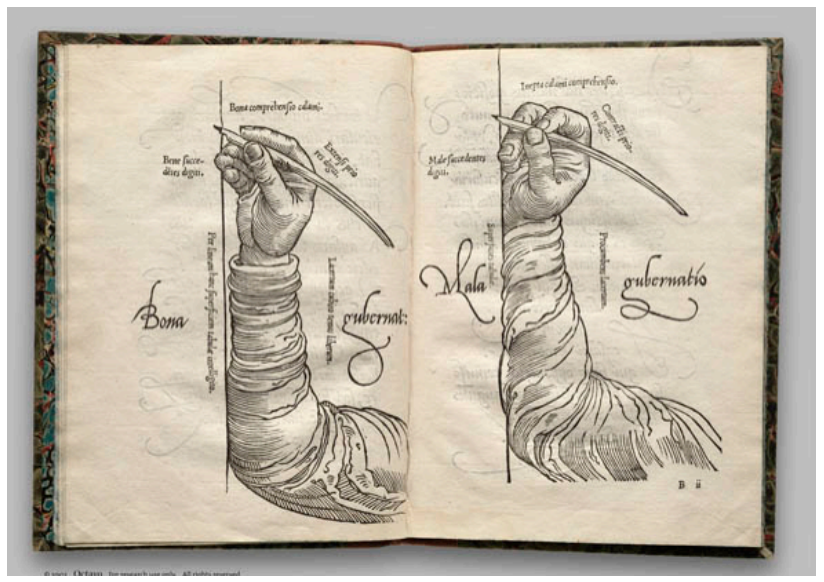

Fig. 1. Mercator, Literarum latinarum, quas Italicas, cursoriasque vocat, scribendarum ratio, Lovanio: Rutgerus Rescius, 1540.

Image retrieved from: http://www.rarebookroom.org/Control/mcrlit/

In this text from Mercator, the depiction of the arm acts as the main reference frame in order to explain the various aspects of "bona" and "mala gubernatio". In this case the reference frame is based on a tridimensional representation, which helps the reader to elaborate the context of Mercator's explanations. The typographical elements are activated and acquire meaning thanks to the reference frame "arm depiction", which in turn becomes polarized and contextualized by the presence of alphabetic writings.

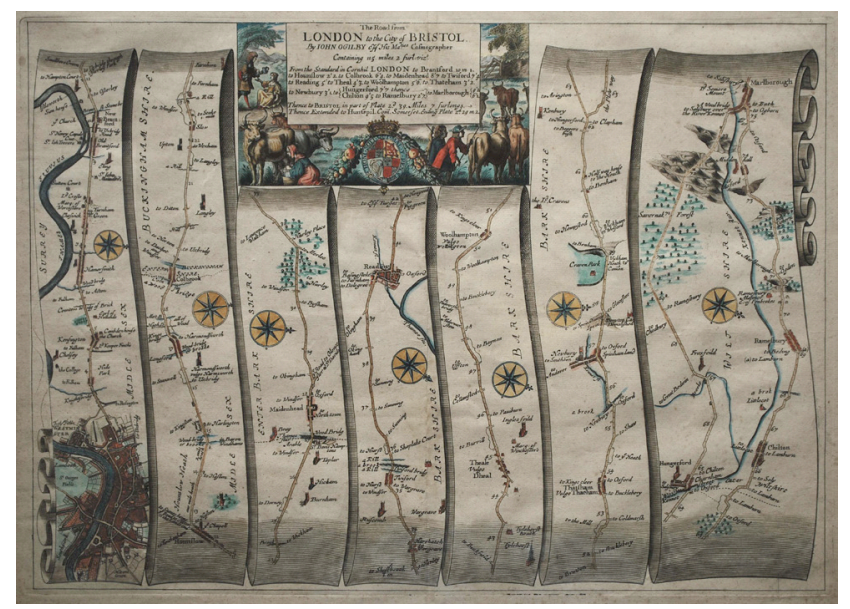

Fig. 2. John Ogilby, Strip map from the 1675 Britannia Atlas, showing the route from London to Bristol. Image retrieved from https://commons.wikimedia.org/wiki/File:John_Ogilby__The_Road_from_London_to_the_City_of_Bristol_(1675).jpg 
In this text from John Ogilby, the cartographic representation is distributed on a tridimensional paper strip, which is unfolded and weaves through the page. This expedient is aimed to elicit a context of continuous spatial representation, otherwise impossible since one ot the geographic dimensions clearly prevails on the others. In this case, the tridimensional elements of the text provide the connections useful for contextualizing the various parts of the geographic map.

The paper strip is not colored, while the cartography is colored, and this allows to clearly distinguish the two main aggregates (paper strip and cartography). The tridimensional component (visual variable "orientation") intensify this distinction.

The compass roses, which are aggregated by the variables "shape", "color" and "size", are distinguished from each other by the variable "orientation", which allows to contextualize the geographical relations in the various parts of the cartographic representation.

From this example, it is evident that more reference frames (paper strip, compass roses...) can coexist and that those reference frames interact and attribute meaning to the elements of a synsemic texts.

In this article we report and discuss unpublished results from the previous research by Bonora et al. (2017). The aim of that previous study was to assess the potential effects of the usage of interactive synsemic artifacts in didactics. In particular, the results we present and discuss in this article are related to focus groups held with teachers in training and in service. The aim of this research was to investigate on the effectiveness of the design based on the synsemic quatrefoil and the recognizability of the used reference frames (e.g. the stratified funnel shape) from the teachers' point of view. The discussion was developed around the website "The topography of Dante's Inferno". ${ }^{1}$

During the focus groups, the moderator asked to the teachers to express their opinions about the artifact in relation to its possible didactic usage.

\section{Methodology}

Here it follows a synthesis of the methodology used for the focus groups (which is described in more detail in the original article): two focus groups were held. One with 12 teachers in training, one with 12 teachers in service, both groups belonging to Department of Humanities at the University of Urbino. The website Topography of Dante's inferno was freely accessible to the teachers during the focus group. The teachers in training were prompted to discuss about the didactic features of the website and how they thought to use it in a school setting.

\footnotetext{
${ }^{1}$ The English version of the website is available at www.alpacaprojects.com/inferno/en/
} 
The teachers in service were prompted to discuss about the purpose of the artifact, its possible didactic use and the usage and the role of educational mediators (regarding in particular the aspects of synsemic writing of the text). The focus groups were audio recorded and transcribed, coding the relevant conversational units and sub-units.

The documents containing the coded transcriptions are available (in Italian language) at:

1. Focus group teachers in training: https://drive.google.com/open?id=0B9XpaKxrMRP4SjZSUTZtTOdqbms

2. Focus group teachers in service: https://drive.google.com/open?id=0B9XpaKxrMRP4RGZBZm5KaFZ4TVk

\section{Results}

\subsection{Results of Focus-Group Teachers in Training}

The transcription of the focus-group with the teachers in training consists of 15 conversational units, for a total of 68 sub-units. From here the numeric references in parentheses denote units and sub-units of conversation.

From data analysis emerges that student reflections mainly focus on three topics: contents, didactic mediators, and knowledge adaptation.

The contents. Students (Teacher in training) show that they are interested to known content $(1.1 ; 1.2 ; 3.3 ; 3.5)$. This interest is however "negative": they seem worried from the lack of expected content (the traditional scholastic contents, linked to the meaning of the poetic text, which they studied when they were at school). This could happen for two reasons. The first is a spontaneous adherence of the students to a "pedagogy of the content" (Develay, 1992). According to this concept, the pupil learns only through the perfect knowledge of the content by the teacher; the second is the students' acceptance of the "didactic contract", which is implicitly established in the didactic situation (Brousseau, 1998): within the didactic system, future teachers take the pose of students and feel obliged to demonstrate to the coordinator and members of the group their own knowledge of the Dante's poem. Concerns disappear when they realize that the artifact is intended to provide a representation of Dante's Inferno since. In this case, they should consider that the artifact can support the figurative and operational cognitive processes of students: understanding $(2.4 ; 3.2 ; 5.6 ; 9.3 ; 9.6)$ and intuition $(3.7 ; 4.2)$.

Didactic mediators. Students attribute specific importance to iconic mediators, linked to the use of figuration $(5.7 ; 6.2 ;)$; and active mediators, linked to the possibility of interaction with the artifact $(5.6 ; 7.2)$. Instead, observations about the use of symbolic mediators, mainly linked to the use of alphanumeric text, are limited. 
The adaptation of knowledge. Among the didactic transposition criteria, the criterion of "reduction to essential points is identified".

The criterion is related to the selection of the scholastic contents which the educator aims to teach. The elements are "essential" if they structure the expert knowledge and if, at the same time, they constitute the points through which the educational path passes (Martini, 2011) (9.1, 9.3, 9.5, 14.3). Everyone agrees that the site allows for flexible teaching. The flexibility concerns both the kind of training courses (more or less linear) (11.2-11.7) and the type of student's approach, in relation to their interests and characteristics $(7.4 ; 10.2)$.

\subsection{Results of Focus-Group Teachers in Service}

The transcript of the focus-group with the teachers in service consists of 13 conversational units, for a total of 19 sub-units.

From data analysis emerges that teachers consider the topographic representation to be effective $(1.1 ; 4.1 ; 7.1)$. In particular, the triangular/conical shape supports the understanding of the structure of the work as it allows to define and differentiate the various levels. The teachers also discuss the representation of the characters. Some are doubtful about the ability to recognize the characters because the images that represent them are not connotated enough. Others consider this aspect an advantage. Less detailed images could easily raise an otherworldly reality and provide a representation of punishments more suitable for boys aged $11-13$ (3.1; 3.2; $9.1 ; 10.01 ; 11.1)$.

A teacher observed that there is no good balance between poetic text and images (8.1): "the image does not help to decode the linguistic construct". These words suggest that he considers the image as a tool supporting the decoding of the individual line of poetry, like an illustrated paraphrase, and not as a graphic element integrated with others for understanding. In our opinion, this expectation could constitute an obstacle to teachers' understanding of the concept of synsemia. The psychological function of images as learning support is well-known (Clark and Lyons, 2010). However teachers have little awareness of how different graphic elements interact with each other. They often think that the effects produced by more didactic mediators (alphanumeric text and images) coincide with the sum of the effects of individual mediators rather than with their combination.

Many teachers discuss about the didactic use of the artifact. They appreciate its flexibility to construct different didactic paths $(1.1 ; 2.1)$ for the whole class $(6.1)$. Finally, teachers believe that the artifact is effective in stimulating students' curiosity and interest $(4.1 ; 5.1)$. 


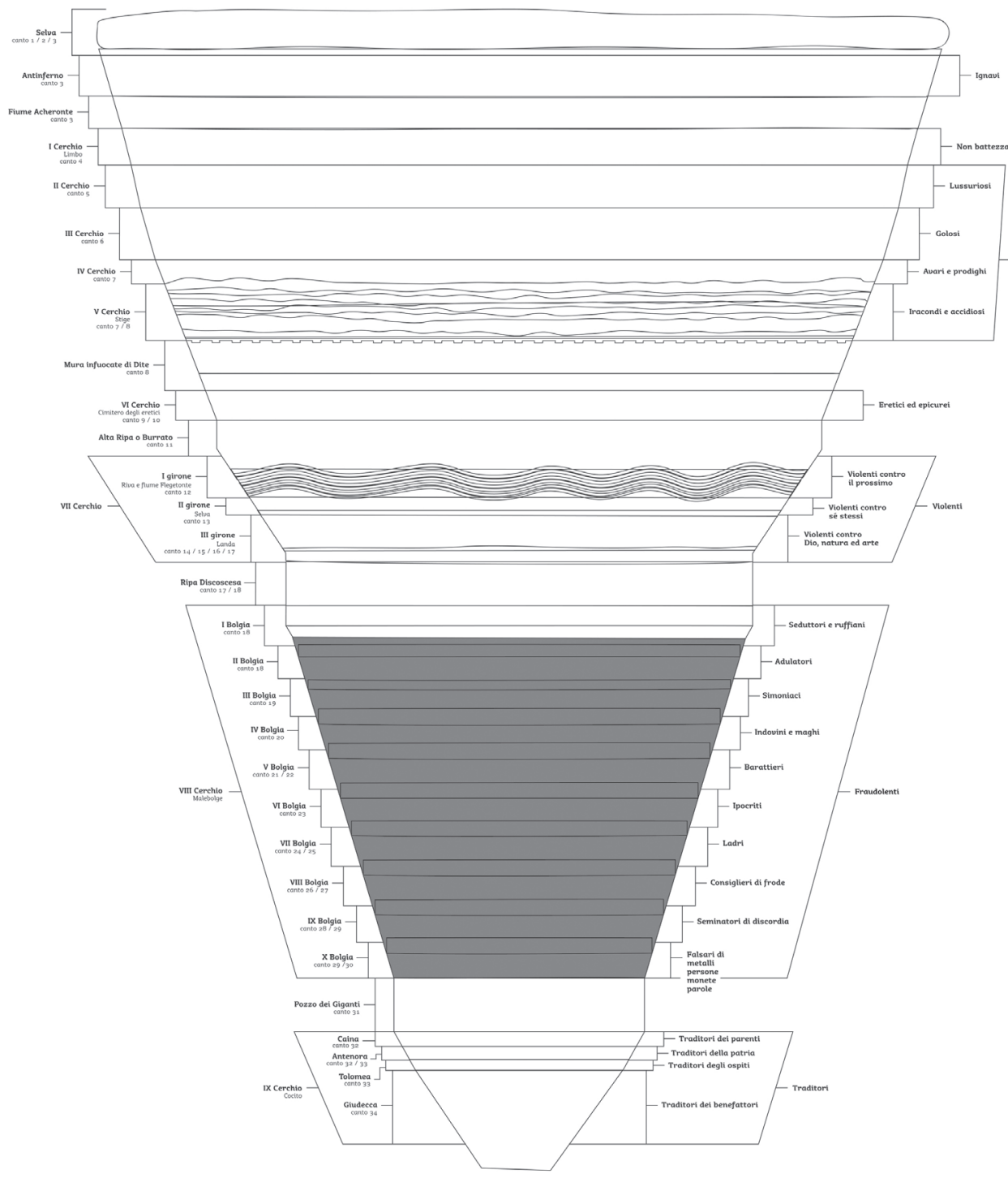

Fig. 3. The scheme of the funnel-shaped reference frame of the Topography of Dante's Inferno 


\section{Discussion}

From the information collected during the focus groups, some reflections emerge:

1. Also in adults (and not only for the target young students) the presence of iconic mediators influences their perception of the hierarchical levels in the artifact: the funnel shape is an effective reference frame, which is understood, at least from the teachers.

2. While designing and using an iconic mediator or a reference frame, the designer needs to take into account the following bias: generating in the reader the expectation of an accurate and detailed transposition of the contents.

The readers create a context by means of the graphical artifact: what they see in the representation acquires a particular "truth value", for which they expect that all the elements in the artifact are planned and strictly consistent with the "contents". This is not possible obviously, but the writer (author and graphic compositor) needs to keep into account this readers' expectation, since every inconsistency in the composition through the synsemic quatrefoil can be interpreted as intentional by the reader: an artifact makes use of a reference frame, which activates a context, which in turn generates a sort of "expectation", which if it is not met it can generate confusion or suspiciousness about the usefulness of the artifact itself.

For these reasons, consistency and systematicity, or better the regularity (Greimas \& Courtés, 2007, p. 280), are fundamental principles of the design of synsemic artifacts.

3. The teachers think that the process of the creation of knowledge originates from the sum of the didactic mediators used and not from their combination. This shows the preconceived belief that this process is linear (resulting from the sum of the mediators) and not non-linear (resulting from the combination of the mediators). This represents a didactic problem, since this belief suggests that the more the number of mediators, the broader is the comprehension, while an inappropriate combination of the mediators could generate a distortion in the comprehension and confusion.

\section{Acknowledgements}

We would like to thank Monica Tombolato, from the University of Urbino, for her insights about Weber's theories. We would also like to thank Silvia Tulli, from ISTICNR of Pisa, for her insights about neuroscience theories. 


\section{References}

Bonora, G., D’Ugo, R., Dalai, G., Rosa, D. D., Imperato, A., Martini, B., \& Perondi, L. (2017). The Project Interactive Topography of Dante's Inferno. Transfer of Knowledge and Design of Didactic Tools. Proceedings, 1(9), 875. https://doi.org/10.3390/proceedings 1090875

Bonora, G., Dalai, G., Rosa, D. D., Imperato, A., \& Perondi, L. (in press). Dante's Inferno. In Proceedings of the IDXVII conference, IIID VisionPlus. Riga: International Institute for Information Design (IIID).

Brousseau, G. (1998). Théorie des situation didactiques. Grenoble: La Pensée Sauvage.

Clark, R. C., \& Lyons, C. (2010). Graphics for Learning: Proven Guidelines for Planning, Designing and Evaluating Visual inTraining Materials. San Francisco, CA: Pfeiffer.

Develay, M. (1992). De L'apprentissage à L'enseignement. Paris: ESF.

Fogassi, L., \& Ferrari, P. F. (2007). Mirror Neurons and the Evolution of Embodied Language. Current Directions in Psychological Science, 16(3), 136-141. https://doi.org/10.1111/j.1467

Gibson, J. J. (2015). The Ecological Approach to Visual Perception: Classic Edition. New York, NY: Psychology Press.

Greimas, A. J., \& Courtés, J. (2007). Ricorrimento. In Semiotica: dizionario ragionato della teoria del linguaggio. (P. Fabbri, A. Fabbri, R. Giovannoli, \& I. Pezzini, P. Fabbri, A. Fabbri, R. Giovannoli, \& I. Pezzini, Eds.). Milano: Bruno Mondadori.

Johnson, J. (2014). Designing with the Mind in Mind: Simple Guide to Understanding User Interface Design Guidelines (2nd ed.). Waltham, MA: Elsevier Science.

Kandel, E. R., Schwartz, J. H., Jessell, T. M., Siegelbaum, S. A., \& Hudspeth, A. J. (Eds.). (2013). Principles of Neural Science (5th ed.). New York, NY: The McGraw-Hill Companies.

Martini, B. (2011). Pedagogia dei saperi: problemi, luoghi e pratiche per l'educazione. Milano: Franco Angeli Editore.

Mongardini, C. (2001). La conoscenza sociologica. Concetti fondamentali. Genova: ECIG.

Perondi, L. (2012). Sinsemie, Scrittura nello spazio. Viterbo: Nuovi Equilibri.

Rizzolatti, G., \& Craighero, L. (2004). The Mirror-Neuron System. Annual Review of Neuroscience, 27(1), 169-192. https://doi.org/10.1146/annurev.neuro.27.070203.144230

Swedberg, R., \& Agevall, O. (2016). The Max Weber Dictionary: Key Words and Central Concepts (2nd ed.). Stanford, CA: Stanford Social Sciences.

Varela, F. J., Rosch, E., \& Thompson, E. (1991). The Embodied Mind: Cognitive Science and Human Experience. Cambridge, MA: MIT Press. 


\section{Full papers}

2 : Interactive Data Visualization 


\title{
A user-centered Perspective on Interactive Data Visualization. A digital flâneries into the documentation of the Historical Italian Mind Science Archive.
}

\author{
Letizia Bollini \\ University of Milano-Bicocca, Department of Psychology, Milano, Italy \\ letizia.bollini@unimib.it
}

\begin{abstract}
The data visualization debate is often polarized between the two dominant position of communication design and data science. A human-centered approach can introduce a third perspective putting people who'll use the information in a prominent role in the design process. According to user research methods, user personas and task-based testing, and co-design activities, the paper presents a case study developed for the Historical Italian Mind Science Archive (Aspi). The project has been focused on the experience of the users when surfing the hierarchical structure of the Aspi website looking for biographical information about the protagonists or searching for primary and original documents - such as correspondence, writings, notes - inside the digitized archives and their inventory. Interactive data visualization, on one hand, and human-centered design, on the other, are the two drivers chosen to make links and connections - otherwise embedded in the historical knowledge of experts in the field - explicit or, better to say, visible. The results are different conceptual and visual displays of the archives and curated contents of the website offering dynamic and interactive insights according to three different selected criteria: time, space, people. Activities of expert walk-through and user-testing, used in the research phase of the process have been used to evaluate the final results to understand and assess the overall experience of users and to validate the initial design hypothesis to extend the approach beyond the proposed case study.
\end{abstract}

Keywords: Interactive data visualization / digital archives interfaces and interactions / user-centered design

\section{Introduction}

The discussion - both academical and professional - on how to let people navigate information has raised in the last four decades. The massive diffusion of computers and their capabilities in generating, and analyzing data have opened the info to wider targets. 
Nevertheless, the ambition to have a system or an intelligent machine able to catalog and connect every single fragment of knowledge is older. We already find intriguing examples in the work of Aby Warburg: the Mnemosyne Bilderatlas introduced in 1929 [1], or in the Shiyali Ramamrita Ranganathan faceted Colon Classification system [2].

In the contemporary debate, it has progressively polarized according to different disciplinary perspectives.

Firstly information architecture - the term has been introduced by Wurman in 1997 [3] - includes the problem both of information organization and of its visualization. The attention is driven not just by the conceptual structure, but also on the users' mental model [4], the cognitive map [5], and how it can be represented [6].

A year later, in the milestone book Information Architecture [7], Morville and Rosenfeld stated the aim and the role of IA: "Learn how to merge aesthetics and mechanics to design Web sites that 'work'. This book shows how to apply principles of architecture and library science to design cohesive Web sites and intranets that are easy to use, manage, and expand. Covers building complex sites, hierarchy design and organization, and techniques to make your site easier to search." On the other hand, authors such as Tufte [8] emphasized the visual structure displayed information as a method to understand and create meaning: the process itself in which data make sense.

Finally - but not in chronological order - visual semiotics [9] and the information graphics manipulation studies [10] started by Bertin in the late '60s tries to give scientific guidelines - cognitive [11], qualitative [12] and quantitative [13] - to data visualization disciplines.

\section{Divers vs. flâneurs}

Since the introduction of hyper-text and the web design era graphical user interfaces have been the tool to let people interact with digital artifacts. Metaphors, allegories and other figures of speech [14] - in this case - visual rhetoric figures have been adopted to let people build their mental model of a navigation system or a data structure.

In the early years two models have revealed creating what we now call the hierarchy model and the hub one $[7,15,16]$.

\subsection{The hierarchical model}

The first pattern established in digital navigation systems - the hierarchical or waterfall model - has a very organized shape, often compared to a tree's structure. The main trunk, the different branches, and single leaves are the metaphor adopted to draw and visually represent the nested level of information. According to this approach, peoples' navigation starts from the top - the homepage - and proceeds in a 
vertical descent. As the user proceeds, information become more in-depth, complete and specialized.

As underlined already by Rosenfeld and Morville, the structural model below the hierarchical navigation has a very determined organization. On the one hand, information architects approach to the tree definition adopting a top-down a decisional process in which every path have been already designed and determined.

"While a well-designed hierarchical organization scheme will reduce the likelihood that users will become lost, a complementary navigation system is often needed to provide context and to allow for greater flexibility of movement within site.

Navigation systems can be designed to support associative learning by featuring resources that are related to the content currently being displayed" [17]. Therefore, to bypass this limitation, other navigation systems are offered other than global navigation: local and contextual ones. Then the hierarchical models seems to perform well when the user already has a mental model of the whole structure, good knowledge on the field and already and an idea of the information he/she is looking for. In this case, the top-down structure is very efficient in letting people retrieving data and information in an effortless and fast way.

\subsection{The explorative model}

The hub structure offers a second perspective on how to move across a digital hypertext. Nodes are interconnected, but ideally at the same hierarchy level, to draw a map where all information is disposable at the same time.

Links can be explored according to a meaning associative relation, where all the opportunities are presented and exposed.

The user can move through the information in a horizontal direction- rather than vertical - discovering associations not thought before losing him/herself in a sort of cognitive labyrinth. The apparent loss of structure and control opens up, instead, to the serendipity of discovering unpredictable associations or unknown connections. Navigation itself suggests new paths and offers new insight and perspectives as masterfully told by Borges [18] creating a random discovery experience that enriches and broadened the user knowledge.

\subsection{Complex digital information visualization}

Furthermore, if referred to a complex information and material system - such as the exhibit or digital archive field - the hub opens big opportunities that change the nature itself of logical and physical connections: "The natural evolution of web hypertextual space has allowed the real deconstruction, not only of the physical unit of the archive [...] the conceptual space of the collection and its belonging. The works become primordial cells, atoms of culture and of memory, which aggregate, disassociate and recompose in different associations with respect to the static nature of an exhibition, or their belonging to a collection corpus. The objects become nomads 
and transversal, they intertwine in a continuous movement which stratifies their reading, relations and contaminations." [19]

Although the two models refer mainly information architecture e and cognitive navigation strategies they have deeply connected also with specific patterns of visual representation.

The first hierarchical one often adopts the graphical structure of the list - a logical form - the second one prefers spatial structure as maps [20].

Consequently, hierarchy representation tends to utilize ordered navigation steps based on the sequence: home > list > card, from general to particular, mainly displaying information according to an editorial grid system where images, texts, and contextual links are placed side by side in columns.

On the other hand hub and maps are based on a synoptic structure - both in a temporal and spatial sense - and a bi- or tridimensional visualization of the date and their connections.

If this second model has already been a field of experimentation for data visualization practices - see Thinkmap Visual Thesaurus [21] by Plum design based on semantic connections implemented back in 1998 to see how powerful the visual approach is - it is not always clear how to evaluate and asses the efficacy of such an approach.

However promising the adoption of the visual language, by its very nature unstable and polysemic is likely to introduce a further complexity, instead of supporting the user experience [22].

\section{A human-centered approach to complex data visualization}

According to a recent adoption of a usability methods also in the field of graphic design [23], an experimental project has been developed aimed to evaluate the users experience when navigating inside a complex ecosystem [24] offering both a hierarchical and an explorative navigation pattern.

The selected case study is the Aspi The historical Italian Mind Science Archive (aspi.unimib.it), established in 2004 at the University of Milano-Bicocca. The digital archive portal is part of the PAST the Historical Archive Center, and between 2014 and 2016, two funded projects has been developed to offer a dynamic data visualization aimed to present the connections among the three archives pillars: people, places and time [25]. The mission of the research center is to map and study the history of Italian mind science since XIX century, and nowadays the website presents 196 curated bios of the Italian protagonist, 23 digitized archives, and 111 registered archives. Historians and archivists, psychologist mind scientists and scholars, Ux a UI designer, computer scientists and software developers have been involved in a transdisciplinary redesign activity along with the users [26]. 


\subsection{Method}

To evaluate the different system an experimental activity has been conducted in a two phases. In an early stage, the existing hierarchical interface has been evaluated with expert users - historians, archivists, and scholars - to understand the interaction dynamics and the research strategies. Then subject has been interviewed: the analysis was focused on how experts can transfer their cultural knowledge to enable a broader audience guaranteeing cognitive accessibility to historical documentation [27]. The role of experts emerges above all in the ability to connect the protagonists just looking at a names' list, to contextualize documents - letters, manuscripts, written notes - and to read the connection between people and places - research institutes or mental hospitals - in an historical framework.

In a second phase, according to user-test task-based/personas-based method both the navigation models have been evaluated with users.

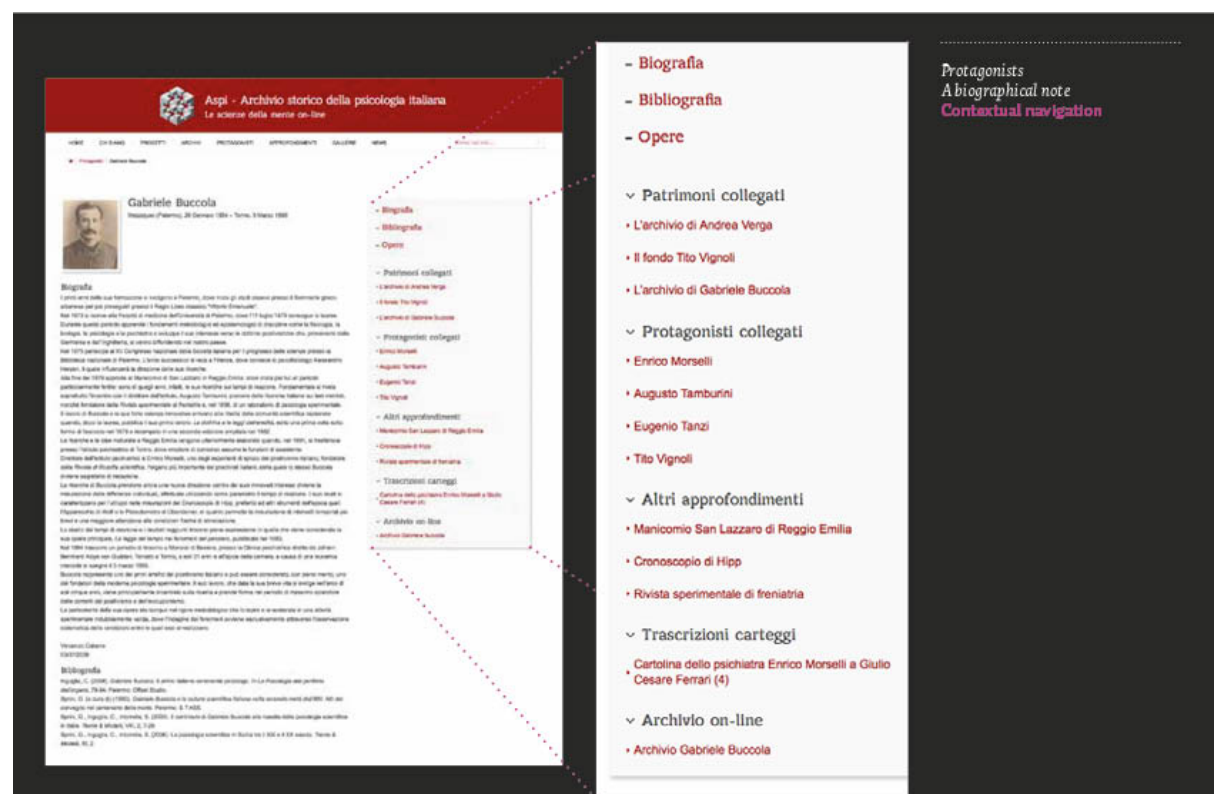

Fig. 1. Aspi: hierarchical navigation modality. Biographical card and contextual navigation system. 


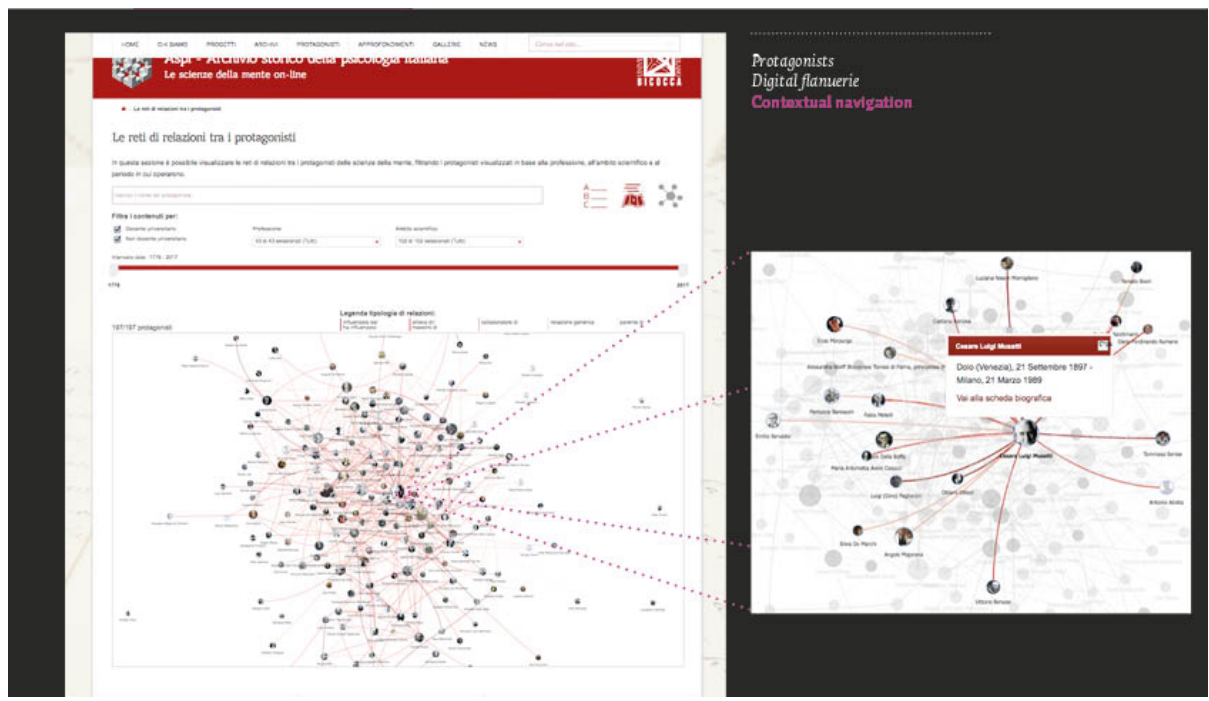

Fig. 2. Aspi: explorative navigation modality. Protagonists and associative navigation system.

The new target audience was composed of psychology students, fine arts, art history and architecture scholars and professionals.

The 25 participants according to literature - were split into two groups of respectively 5,5 and 15 subjects and were asked to complete five tasks. One group approach firstly the hierarchical navigation model, the second the explorative one. Other subjects were free to choose which way they want to start with, and then they must complete the same tasks starting from the other modality.

They stacks were: 1) final a biography 2) find the correspondence between two protagonists 3 ) find an archive 4) find a place 5) find if a place was active in a specific period. Results were evaluated according three parameters: a) efficiency: execution time b) efficiency: errors or completed tasks c) satisfaction evaluated with a qualitative interview.

\subsection{Results}

Outcomes of the users' test have been clustered and prioritized according to the Norman's Design Principles: a) visibility b) feed-back c) constraints d) mapping e) consistency, and f) affordance.

Results have been divided and compared between the two navigation systems. The hierarchical model seems to fails mainly in the local navigation affordance of the contextual menu. A second emerged issue is the conceptual model of the place's alphabetical order organization. The exploration model has a lack of a) feedback for things and events happening under the folder, that means under the visible area of the display b) action trigger to activate the search and filter query (see fig.4) c) of visibility in the vertical scrolling of the timeline visualization. 


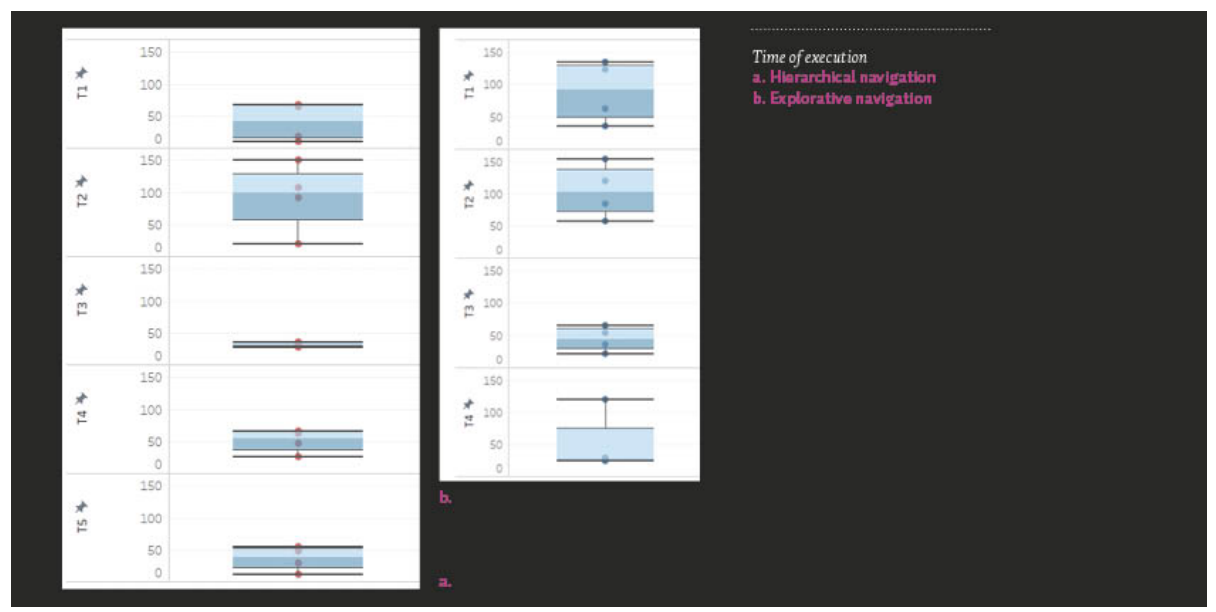

Fig. 3. Efficiency: time of execution a) the hierarchical b) explorative model.

\subsection{Discussion}

From the qualitative interviews emerge, probably the most interesting aspects of the two models comparison.

It seems that experts prefer the hierarchical navigation: they are able to manage historical documents so they directly dive inside the digital archive able to locate and contextualize the retrieved informations. On the other hand, generic public prefers to be guided by the visual system and the cloud of connections that offers an associative navigation when the scope or the destination is not yet known or clear.

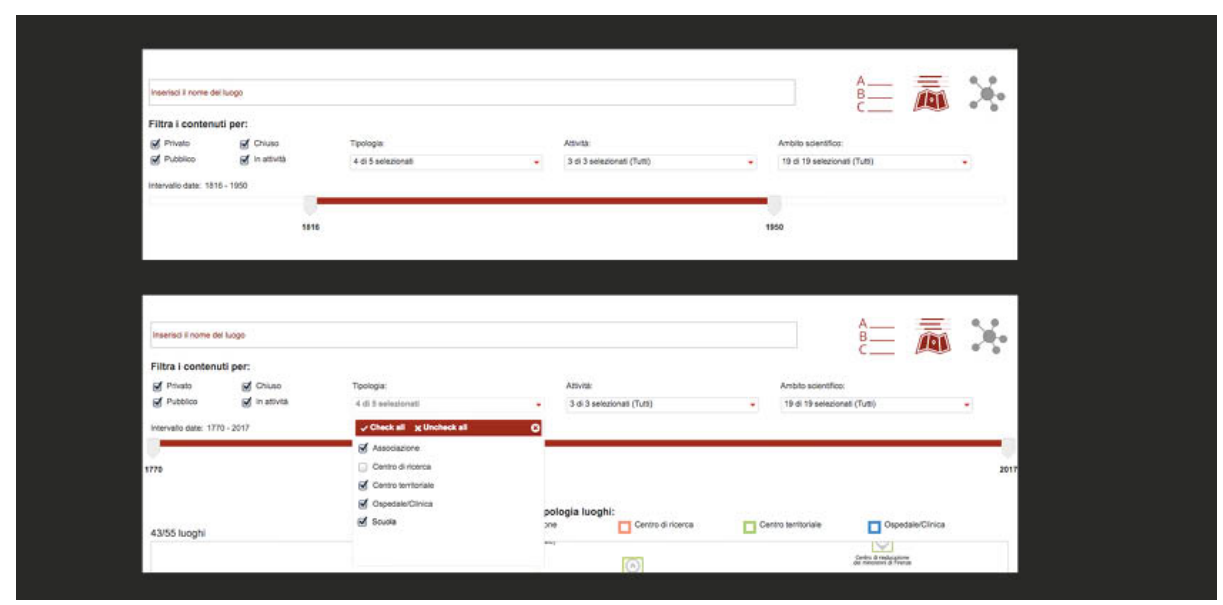

Fig. 4. Efficacy: filter and search action triggers. 


\section{Conclusions}

The lesson learned in this experimental approach to a data visualization digital dynamic system seems to be that visualization facilitate accessibility both to data and embedded knowledge.

The graphical form of the interface - as happened since the introduction of GUI in 1984 - is a way to enable and empower users in complex information ecosystems. Furthermore, the visual language, the spatial and synchronic representation of data is a way to create and communicate context and to visualize significant connections.

The results of this first experimental phase could be developed in further design activities such as an iterative cycle to redesign and test again the problematic issues emerged by the study.

Furthermore a topic to be foster understand and implemented is a possible integration between the two models trying to offer a more connected and rich user experience mainly for non-experts.

\section{References}

[1] Warburg, A. (1929). Bilderatlas Mnemosyne. Einleitung.

Retrieved from: http://www.engramma.it/eOS/index.php?id_articolo=2334

[2] Garfield, E. (1984, February). A Tribute to S. R. Ranganathan, the father of Indian library science. Essays of an Information Scientist, 7, 37-44.

[3] Wurman, R. S. (1997). Information Architects. New York: Graphis Inc

[4] Bollini, L., \& Palma, G. (2004). Cognitive maps: New paradigms in information architecture and interface design for the web. The Opsis identifier descriptive model for web information architecture based on cognitive maps: Designing-x a case study. In A. J. Canas, J. D. Novak \& F. M. Gonzalez (Eds.), Concept maps: Theory, methodology, technology. (2), pp. 95-98. Navarra: Nova Text

[5] Bollini, L., \& Palma, G. (2003). Web interface design based on cognitive maps: Generative dynamics in information architecture. In C. Soddu (Ed.), 6th Generative Art, Conference Proceedings (pp. 66-71). Milano: Politecnico di Milano

[6] Bollini, L., \& Palma, G. (2006). Un approccio visivo all'architettura dell'informazione per il web: Le mappe cognitive. Progetto Grafico(7), 48-55

[7] Rosenfeld, L.; Morville, P. \& Arango, J. (2015). Information Architecture: For the Web and Beyond. 4th Ed. Sebastopol: CA: O'Reilly Media

[8] Tufte E. R. (1990). Envisioning information. Cheshire, CT: Graphic Press

[9] Bertin , J. (1967). Sémiologie graphique. Les diagrammes, les réseaux, les cartes. Paris: La Haye, Mouton, Gauthier-Villars 
[10] Bertin , J. \& S. Bonin (1977). La graphique et le traitement graphique de l'information. Paris: Flammarion

[11] Blackwell A. F., Britton C., Cox A., Green T. R. G., Gurr C., Kadoda G., Young R. M. (2001). Cognitive dimensions of notations: Design tools for cognitive technology. In Beynon M., Nehaniv C. L., Dautenhahn K. (Eds.), Cognitive technology (pp. 325-341). Berlin, Germany: Springer.

[12] Ware C. (2004). Information visualization . San Francisco CA: Morgan Kaufmann

[13] Tufte E. R. (1997). Visual Explanations: Images and Quantities, Evidence and Narrative. Birmingham: Graphics Pr.

[14] Eppler M. (2006). A comparison between concept maps, mind maps, conceptual diagrams, and visual metaphors as complementary tools for knowledge construction and sharing. Information Visualization, 5, 202-210

[15]Resmini, A. \& Rosati, L. (2011). Pervasive Information Architecture. Designing Cross-Channel User Experiences. Morgan Kaufman

[16] Bollini, L. (2004). Registica multimodale: Il design dei new media. Milano: CLUP

[17] Rosenfeld, L.; Morville, P. (1998, February 20). Designing Navigation Systems https://people.apache.org/ jim/NewArchitect/webrevu/1998/02_20/webauthors/02_20 _98_10.html

[18] Borges, JL. (1964). Labyrinths. Selected Stories \& Other Writings. New York: New Directions.

[19] Bollini, L. (2013). Lo spazio digitale del sapere: dalla forma archivio alle knowledge-base culturali. Aggregazioni, narrazioni e migrazioni. In R. Trocchianesi \& E. Lupo (Eds.), Progetto e memoria del temporaneo (Vol. 3, pp. 53-67). Milano: Electa

[20] Bollini, L., \& Cerletti, V. (2009). Knowledge sharing and management for local community: Logical and visual georeferenced information access. In B. Granville, Z. Majkic \& L. Chunping (Eds.), EISWT-09 conference proceedings (pp. 92-99). Orlando: IRST

[21] www.visualthesaurus.com

[22] Karjaluoto E. (2014). The design Method, A philosophy and process for functional visual communication. San Francisco: New Riders

[23] Schlatter T., Levinson D. (2013). Visual Usability: Principles and Practices for Designing Digital Applications. San Francisco: Morgan Kaufmann

[24] Bollini, L. (2016). Large, small, medium. Progettare la comunicazione nell'ecosistema digitale. Rimini: Maggioli

[25] Bollini, L.; De Santis, D.; Radice, S. \& Zocchi, P. (2016). Le trame invisibili. Nuove modalità di esplorazione online dell'Archivio storico della psicologia italiana. Umanistica Digitale, $1(1)$, pp.59-84

[26] Bollini, L. (2009). From paper to bytes: Digital knowledge sharing. A multi-level approach to document digitalization. A case history in Italian historical studies. In Filipe, J; Cordeiro, J. (Eds.), Proceedings of the fifth international conference on Web Information Systems and Technologies (pp. 567-571). Lisbona

[27] Bollini, L. (2016). The open heritage of digital archives. Preservation, sustainability and accessibility of historical documentation to map the field of Italian Mind Science (pp. 773782). In R. Amoêda, S. Lira \& C. Pinheiro (Eds.). HERITAGE 2016. Lisbona: Green Lines Institute 


\title{
Visual Monitoring of Complex Algorithms
}

\author{
Michele Invernizzi ${ }^{1}$, Michele Mauri ${ }^{1}$ and Paolo Ciuccarelli ${ }^{1}$ \\ Politecnico di Milano, Department of Design, \\ Via Durando 38/A - 20158 Milano, Italy \\ \{michele.invernizzi, michele.mauri, paolo.ciuccarelli\}@polimi.it
}

\begin{abstract}
Purchases, conversations, access to information, music and movies: more and more of our online life is mediated by complex algorithms that are designed to make the experience of the Web customized and more "personal". These algorithms can process an amount of heterogeneous data that would take enormous resources for the human mind to cope with, and find valuable patterns in it. Their use is not limited to our online experience as similar algorithms have been also implemented, for example, to inform policymakers: suggesting where to deploy police forces around the urban context, assessing criminality risk scores of offenders, or allocating high school students to the most suited school.

While the consequences of the decisions made by algorithms have a great impact on people's lives, the way they are built and designed makes them de facto "black boxes": a series of legal and technical barriers prevents from accessing and understanding how a certain input influences a given output. Overseeing their decision processes becomes then of the utmost importance.

This paper argues that visualizations can become a powerful tool to monitor algorithms and make their complexity accessible and usable by visually showing the relation between the inputs and the outputs in a manner that mimics an observational study approach. The paper analyzes a case study developed as an experiment to test opportunities and criticalities in using visualization to represent the presence and the activity of algorithms.

This represents a shift from the main purpose of visualizations and Data Visualization in general: since its strong suit is to support human decisionmaking processes by transforming data into knowledge, the substitution of people by machines in this activity seems to make visualizations obsolete. A computer doesn't need to "see" the data to make a decision - or at least not in the same way as people do - no matter how multidimensional and heterogeneous the data is. With the diffusion of algorithms, the need to inspect their accountability and performance will simply move visualizations at a later stage. From a decision-making tool visualization becomes a monitoring and awareness tool.
\end{abstract}

Keywords: Data Visualization / Algorithmic Accountability / Visualizing complexity 


\section{Introduction}

It has become almost formulaic to say: "We now live in a hyperconnected, online world", and yet it still is a phrase that is worth saying because every year, or better every day, a bigger portion of our daily interactions with entities different than ourselves could potentially be moved entirely online. Supplies are bought on Amazon, vacations are booked on Airbnb, news are read on Facebook, etc. For every need and desire there is a platform for that. Moreover, the shift to the digital has been so powerful also because most of these interactions are tailored just for us, to the point where no person sees a given website in the same way and no website is seen in the same way twice. This has become possible since every action performed online leaves digital traces, that can be collected, processed and later disseminated [1] as a personalized service by firms whose central core is built around this ability of analyzing data [2].

Managing such massive inflow of multidimensional and heterogeneous data would be impossible without the help of powerful algorithms that can cope with and find valuable patterns in the complexity of the data. These algorithms are designed to be dynamic [3], in the sense that they adapt to the ever-changing data, and self-taught as they make decisions without the need by their programmers to hardcode all the possibilities when facing these decisions [4]. Fed by the data we produce daily they mediate, invisible and undetected [5], most of our Web interactions: search engine results, photos and texts on social networks, movies or products suggestions are all managed by a set of computer programs that are most commonly known as machinelearning algorithms.

The use of these tools is not only confined to the online realm, as similar algorithms are beginning to be employed to inform policymakers in the public sector or affect us in our offline life. Examples are predictive policing algorithms that are used to deploy effectively police forces around the city ${ }^{1}$, assessment algorithms that are used by judges to inform their decision by providing a criminality risk score to the offender ${ }^{2}$, or data processing algorithms that control self-driving cars. Especially when we consider the latter examples, a set of questions arise: how do we evaluate the decision of the algorithm? How can we understand the logics followed by the algorithm in choosing a particular solution?

As soon as we start to think in terms of algorithmic accountability [3], what makes these computer programs so powerful and flexible turns out to be also their greatest pitfall. In fact, in order to make decisions based on provided data, a machine-learning algorithm creates an internal layer that is not understandable even by the programmers that wrote that algorithm [6]. So, even if the data and the code written by the engineers are comprehensible, the way the algorithm "learns" from the data and later makes decisions is not: this combination of algorithm and data [7] is where its complexity, and opacity, resides. Moreover, all the code behind the proprietary

\footnotetext{
${ }^{1}$ http://www.predpol.com

${ }^{2}$ http://www.equivant.com
} 
software is jealously protected by intellectual property patents and away from possible public scrutiny. It thus becomes a black box [8] that is hard to evaluate and tools are needed to make sure that there is control or at least transparency over risks of fault or, worse, discrimination done by the algorithm.

\section{Exposing algorithms through visualization}

We argue that one of the tools that could be used to expose these algorithms and engage publics in a fruitful discussion of the issue comes from information design, namely information visualization. With it we are able to trace the origins and presence of an issue, in this case the presence of an algorithm, and communicate it, make it known [9].

In this paper we present a case study where visualization was aimed at investigating the News Feed algorithm of Facebook. This content curation algorithm is particularly interesting because its use is widespread and relevant, as it decides what should be shown to 2.13 billion monthly active Facebook users ${ }^{3}$; at the same time its presence is invisible, as many users are not aware of its existence at all [10].

The project was the result of a collaboration with a group of digital activists, led by Claudio Agosti, who are developing tools with the goal of increasing transparency and awareness behind personalization algorithms. They developed a browser extension called facebook.tracking.exposed ${ }^{4}$ that collects data about the posts seen whenever using Facebook: namely the time of creation of the post, its type and its order of appearance in the user's feed. In order to make this data readable and comparable we created an interactive visualization trough which users can see their interaction with Facebook from a different perspective, exposing how the News Feed algorithm rearrange results compared to their temporal flow. Since it's technically and legally impossible to reverse-engineer the algorithm or understand its internal structure, in this case study information visualization plays a key role in revealing the algorithm presence and highlight its outputs, thus creating a way to open the black box [11].

\footnotetext{
${ }^{3}$ Data taken from https://newsroom.fb.com/company-info, updated April $4{ }^{\text {th }} 2018$

${ }^{4}$ https://facebook.tracking.exposed. At the time of the collaboration the project was still in its alpha phase and it is now much evolved since then.
} 

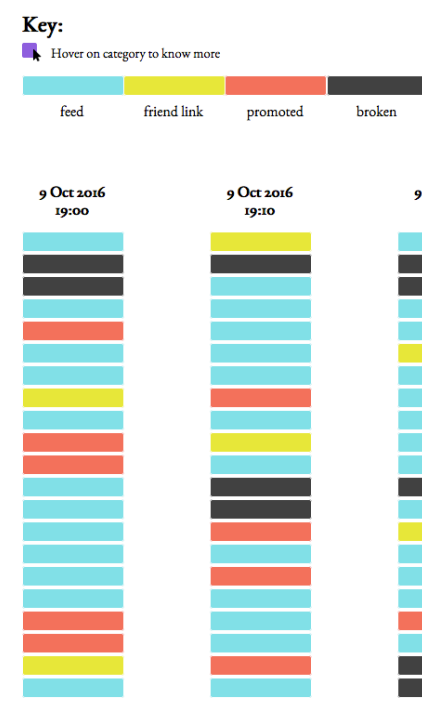
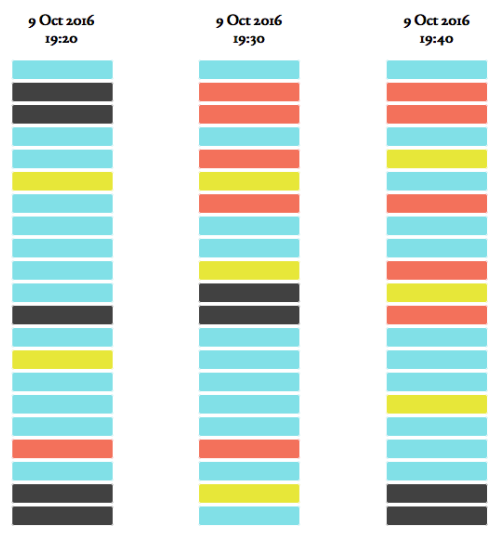

Sort by type

Sort by actual creation time

Show allinfo

Fig. 1. Screenshot of the interface showing the posts grouped in columns (representing the moments in time when the user went on Facebook).

\section{Interface and use case}

After installing the extension, every time the user opens Facebook, the order and type of posts is recorded. In any moment the user can insert her Facebook Id in the interface in order to load the visualization with her own data. The interface presents every visit to the social network as a column, sorted in chronological order. Each column is composed by seen posts, color coded by the type of post (Fig. 1). The user could then sort the posts based on different criteria, in a way overwriting the curation of the algorithm: they can be sorted by type or by actual creation time. Hovering on a post would highlight it through time, letting the user see the relevance given to it by the algorithm in different moments (Fig. 2). By letting the users play with the order of Facebook posts, we are both creating awareness of the existence of the algorithm as well as engaging them in thinking about the consequences of the curation mechanism. Taking as example Fig. 1, we can see that the user has been on Facebook on October $9^{\text {th }} 2016$ six times, once every ten minutes. Leaving aside posts colored in black ${ }^{5}$, we can notice that there are quite a lot of promoted posts (advertising paid by companies), especially in the last three columns where they are even among the first posts to be shown. Another thing we could see is that friend links, meaning posts made by friends of friends that Facebook thinks could be relevant to us, are sporadic but quite evenly spread out.

\footnotetext{
${ }^{5}$ These would be broken posts, or posts that the browser extension was not able to retrieve.
} 

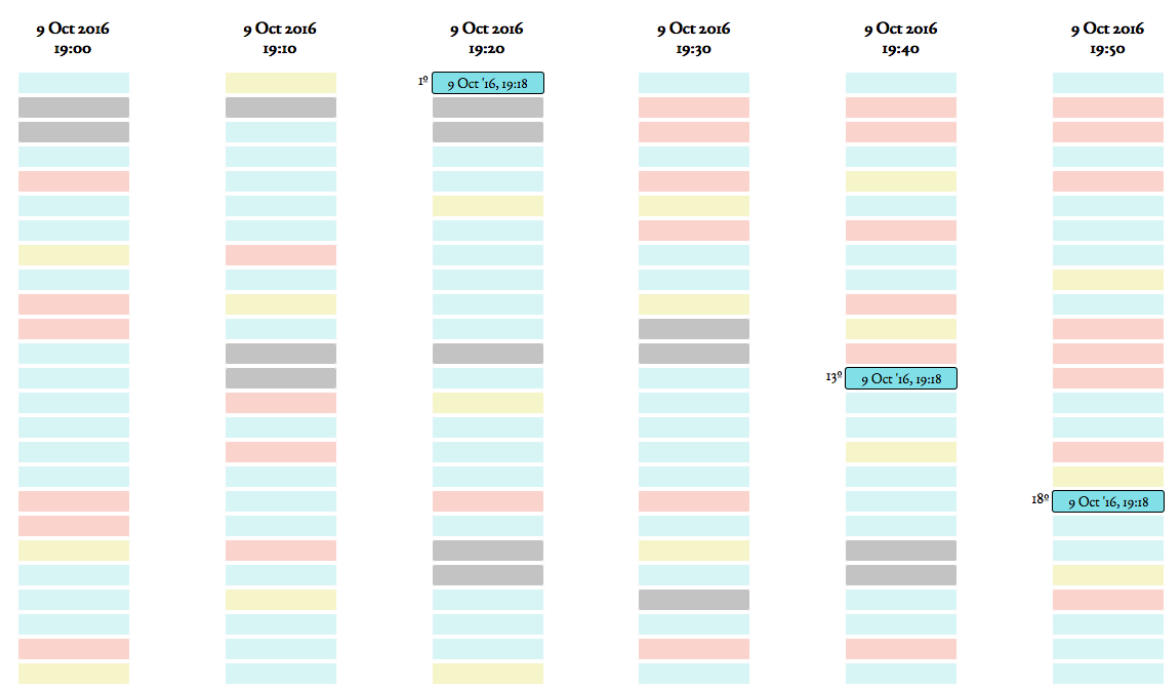

Fig. 2. Screenshot of the interface showing the same post highlighted in different columns.

\section{Discussion}

With this case study, we've seen how we can use information visualization to expose an invisible algorithm. During the unfolding of the project, a series of limitations and prompts for future development have emerged and are worth discussing.

First of all, it's important to keep in mind that this case study had some ethical implications: by using Facebook data we were not complying with its Terms of Service, even more since we were using data collected automatically by a program. At this point we had to make a calculation of the trade-offs between this violation and the benefits of studying a potential harmful discrimination. That said, the other relevant limitation is in terms of scale of the data. What it means is that our ability of exposing the algorithm is of course strictly related to how much information we can gather about it. If we could have accessed not only the order of the posts seen by the user and their type but also for example, the total number of friends that the user had, we could have calculated how many friends the algorithm was deciding to show, or which friend was considered the most relevant by it. Overall though, this first attempt opened the way to a series of future experiments where we will also need to set up an evaluation process. At the same time, the project revealed an interesting new way of thinking about the purpose of visualization. While we think of it as a good way to make sense of complex data to inform the process of decision-making, this purpose would seem at first glance to lose meaning the moment we start to delegate every decision to computer programs: they now decide what is more relevant, more coherent, more suited to our needs. Visualization would nevertheless still be useful, moving from a decision-making to a monitoring and awareness tool. 


\section{References}

[1] D. J. Solove, "A taxonomy of privacy," U. Pa. L. Rev., vol. 154, p. 477, 2005.

[2] N. Srnicek, Platform capitalism, John Wiley \& Sons, 2017

[3] N. Diakopoulos, "Algorithmic accountability: Journalistic investigation of computational power structures," Digital Journalism, vol. 3(3), pp. 398-415, 2015.

[4] J. Burrell, "How the machine 'thinks': Understanding opacity in machine learning algorithms," Big Data |\& Society, vol. 3(1), 2016.

[5] K. Hamilton, K. Karahalios, C. Sandvig and M. Eslami, "A path to understanding the effects of algorithm awareness," in CHI'14 Extended Abstracts on Human Factors in Computing Systems, 2014.

[6] T. Gillespie, "The relevance of algorithms," Media technologies: Essays on communication, materiality, and society, p. 167, 2014.

[7] C. Sandvig, K. Hamilton, K. Karahalios and C. Langbort, "Auditing algorithms: Research methods for detecting discrimination on internet platforms," Data and discrimination: converting critical concerns into productive inquiry, pp. 1-23, 2014.

[8] F. Pasquale, The black box society: The secret algorithms that control money and information, Harvard University Press, 2015.

[9] C. DiSalvo, "Design and the Construction of Publics," Design issues, vol. 25, no. 1, pp. 4863, 2009.

[10] M. Eslami, A. Rickman, K. Vaccaro, A. Aleyasen, A. Vuong, K. Karahalios, K. Hamilton and C. Sandvig, "I always assumed that I wasn't really that close to [her]: Reasoning about Invisible Algorithms in News Feeds," in Proceedings of the 33rd annual ACM conference on human factors in computing systems, 2015.

[11] B. Latour, Science in action: How to follow scientists and engineers through society, Harvard university press, 1987. 


\title{
Visualising open communities. Guidelines from three case studies
}

\author{
Massimo Menichinelli ${ }^{1}$, Giovanni Profeta ${ }^{2}$ and Serena Cangiano ${ }^{3}$ \\ ${ }^{1}$ IAAC, Fab City Research Lab, Pujades 10208005 Barcelona, Spain \\ massimo@fablabbcn.org \\ ${ }^{2}$ University of Applied Sciences and Arts of Southern Switzerland SUPSI, Department for \\ Environment Constructions and Design, Campus Trevano via Trevano 6952 Canobbio, \\ Switzerland \\ giovanni.profeta@supsi.ch \\ ${ }^{3}$ University of Applied Sciences and Arts of Southern Switzerland SUPSI, Department for \\ Environment Constructions and Design, Campus Trevano via Trevano 6952 Canobbio, \\ Switzerland \\ serena.cangiano@supsi.ch
}

\begin{abstract}
One of the most interesting and promising phenomena of the last years is the emergence of social innovation initiatives, a loose and world-wide movement of people, projects and organisations that are addressing social challenges in fields like healthcare, education, employment, democratic participation, migration and the environment. We especially consider to be very promising those initiatives that are based around communities that adopts digital platforms, develop digital solutions and are open in their processes and results. The importance of online open communities in developing and scaling social innovations could then lead to an improved and broader understanding of the dynamics of social innovations and online platforms. The article aims at improving the knowledge about the use of graphical visualisations for understanding open communities, which data sources and formats are available and which ones are missing for this task, which are the main design requirements and strategies for this task, and which are the common elements in existing ongoing experiences in visualising open communities.
\end{abstract}

Keywords: Open community / Digital platforms / Data visualisation

\section{Introduction}

One of the most interesting and promising phenomena of the last years is the emergence of social innovation initiatives, a loose and world-wide movement of people, projects and organisations that are addressing social challenges in fields like healthcare, education, employment, democratic participation, migration and the environment. These initiatives have been developed with multiple approaches, 
structures, goals and cultures rather than a one-size-fits-all modality. We especially consider to be very promising those initiatives that are based around communities that adopts digital platforms, develop digital solutions and are open in their processes and results. The topics of social innovation and of citizens' participation in processes have been increasingly relevant in the design research and practice in the last years, which has also partially shifted its focus from artifacts to territories, from companies to platforms and ecosystems, from single users to local and online communities, from isolated projects to whole complex systems. Digital social innovation initiatives are very interesting in these directions, and the analysis and visualisation of its open communities is a potential strategy for improving our understanding of them and of the visualisation of complex social systems with a research through design approach.

The importance of online open communities in developing and scaling social innovations render their understanding relevant not just related to the dynamics of specific cases, but also more generically for improving the understanding of the dynamics of social innovations and online platforms. The article aims at improving the knowledge about the use of visualisations for understanding open communities with the research question: which are the main design requirements, common elements and strategies for this task emerging from ongoing experiences? We explored three case studies and we identified key guidelines and limitations for visualising the geographic distribution, history and social dynamics of open communities.

\section{Case Studies}

We analysed three case studies in order to propose guidelines and requirements for the design of visualisations systems of open communities: 2.1) Maker initiatives and their impact, 2.2 ) the Wikipedia community, 2.3) digital social innovations.

\subsection{Fab City Dashboard}

The Maker Movement [1] is a global community interested in designing, making, repairing physical objects with digital fabrication tools in distributed laboratories like Fab Labs and Makerspaces [2]. Its impact is however rarely measured, the MAKE-IT ${ }^{1}$ project investigated several Social Impact Assessment methods for this [3] and, with this case, the potential of platforms for measuring this impact over city resilience with the the Fab City perspective [4]. The Fab City Dashboard ${ }^{2}$ is a web-based prototype developed in a 9-days hackathon at Medialab Prado, Madrid, during

\footnotetext{
${ }^{1}$ http://make-it.io/

${ }^{2}$ http://dashboard.fab.city/
} 
Visualizar' $16^{3}$. It lets user explore the resilience of cities, regions and countries based on wellbeing indexes from OECD $[5,6]$, and has a simplified simulation of the impact of a Maker project over them. The limited datasets available rendered this only a research-through-design exploration of the impact of Makers, providing the space for reflecting about a potential model.

\section{Barcelona}

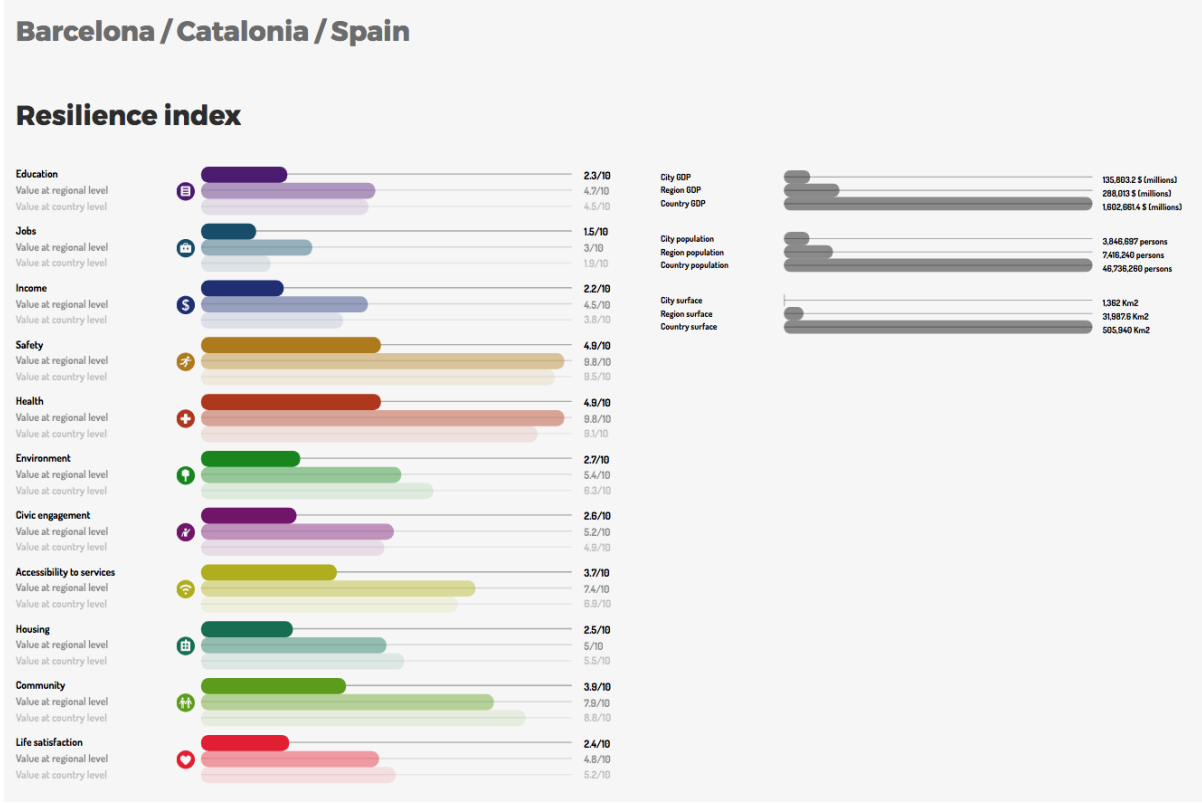

Fig. 1. A screenshot of the Fab City Dashboard showing resilience as wellbeing of cities, regions and countries.

\footnotetext{
${ }^{3}$ https://www.medialab-prado.es/en/news/visualizar16-call-projects
} 


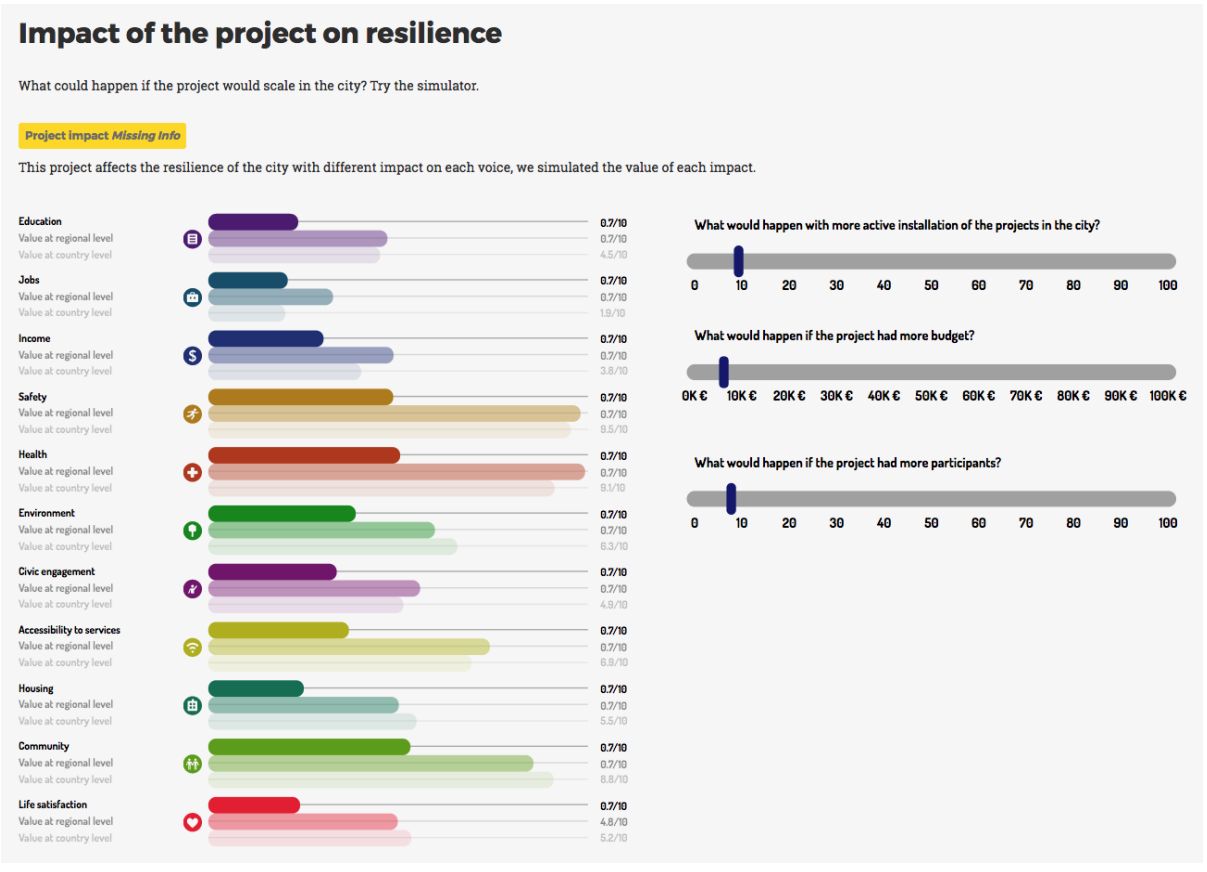

Fig. 2. A screenshot of the Fab City Dashboard simulating the impact of a Maker project over resilience of cities, regions and countries.

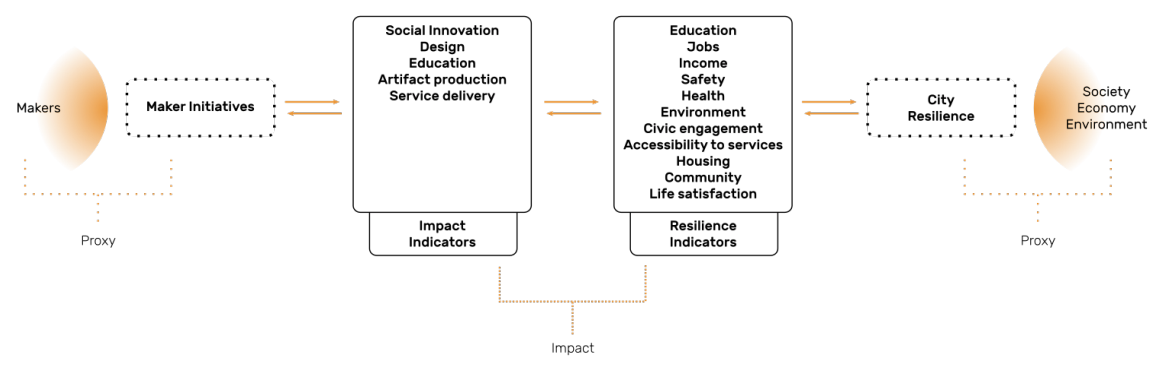

Fig. 3. A conceptual model for understanding the impact of Maker projects over resilience of cities, regions and countries, elaborated from the Fab City Dashboard prototype. 


\subsection{Wikipedia}

The Wikipedia community consists of more than one hundred thousand active users (wikipedians). The Wikipedia Primary School research project ${ }^{4}$ [7] was developed by the University of Applied Sciences and Arts of Southern Switzerland and by the University of Cape Town. The project aims in developing and evaluating a system to assess Wikipedia articles for primary education through the use of multiple strategies (edit-a-thons, review by domain experts etc.) and seeks to involve a wide network of wikipedians and scholars in their production. The focus was on the primary school in South Africa.

The main goals of the visualisation ${ }^{5}$ are: understanding the status of the articles (in quantitative terms) and to evaluate the impact of the strategies. The visualizations take into consideration multiple parameters, such as: connections between articles, user edits and integration of further resources (references, notes and images etc.).

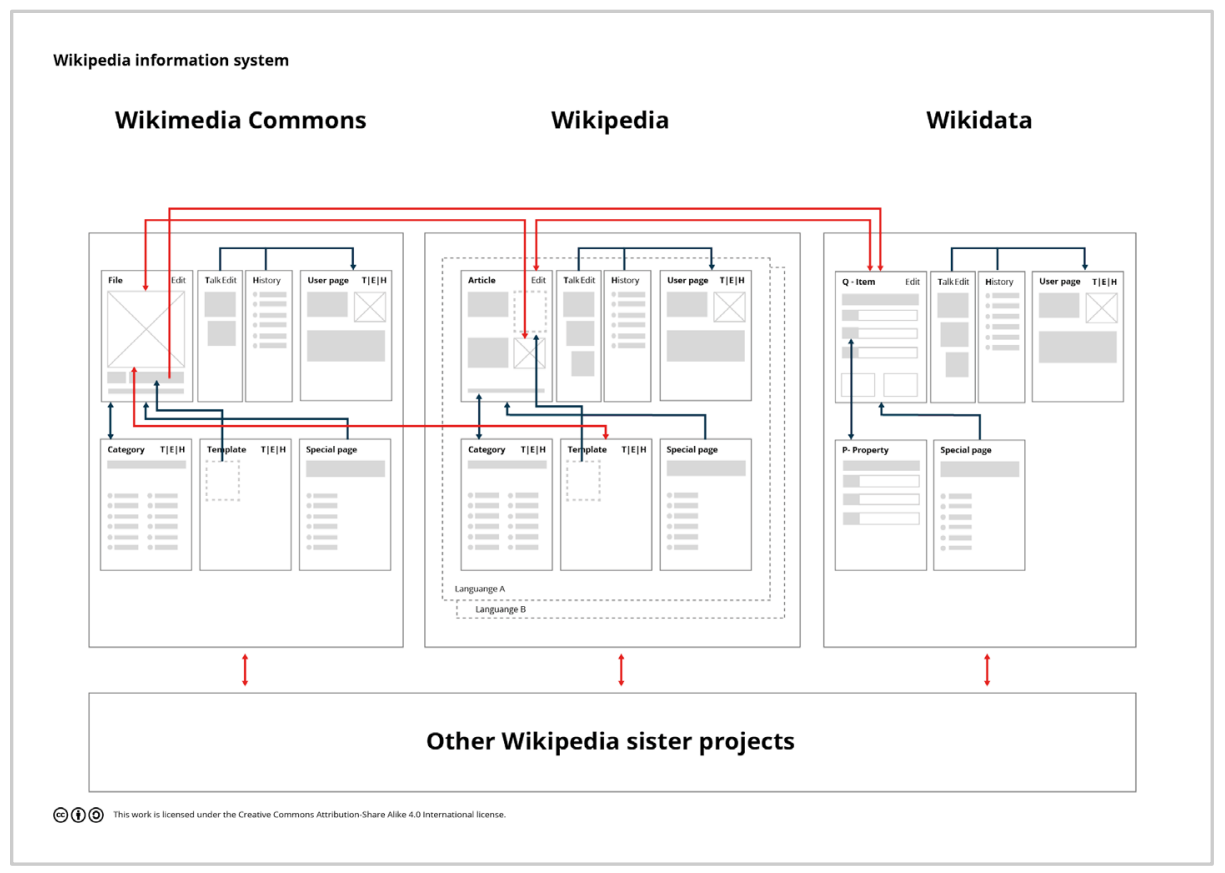

Fig. 4. Wikipedia information system. Laboratorio cultura visiva SUPSI. Lugano.

\footnotetext{
${ }^{4}$ https://meta.wikimedia.org/wiki/Wikipedia_Primary_School

${ }^{5}$ https://meta.wikimedia.org/wiki/Research:Wikipedia_Primary_School_SSAJRP_programme/ Evaluation
} 


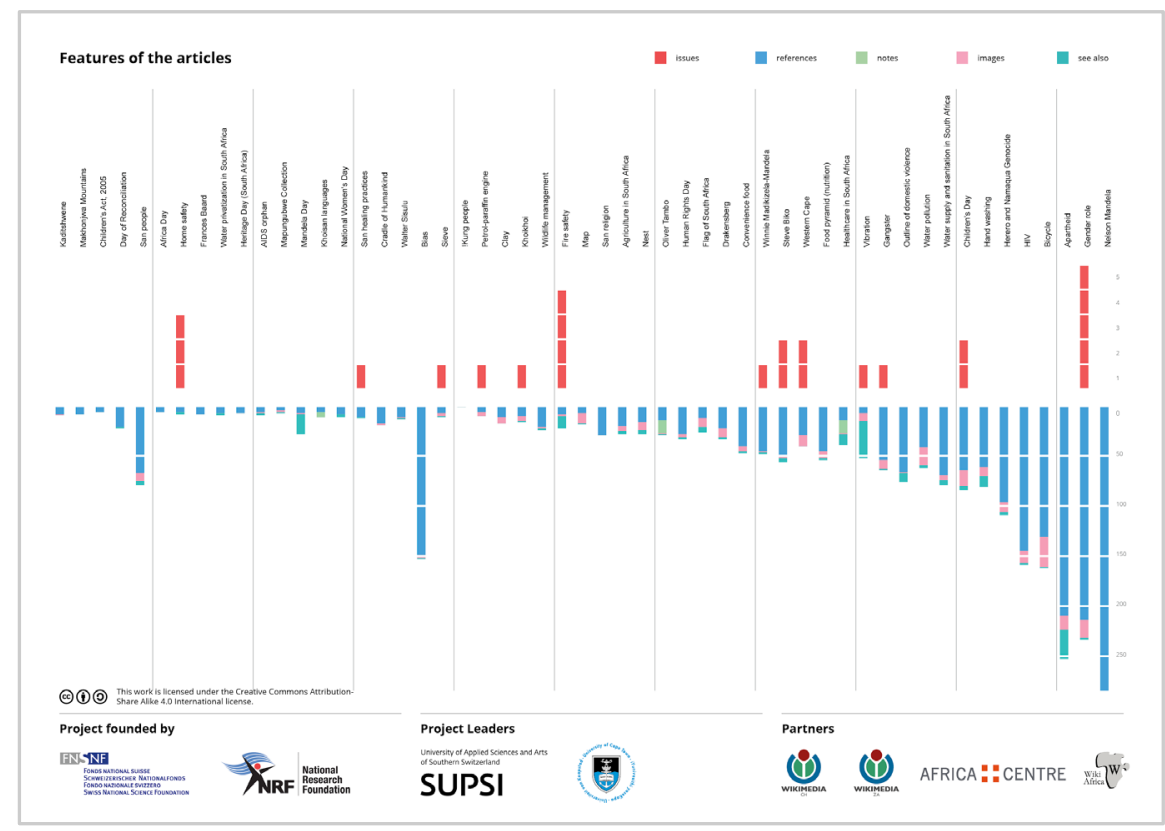

Fig. 5. Visualization of articles' features: issues, images, etc. Laboratorio cultura visiva SUPSI. Lugano.

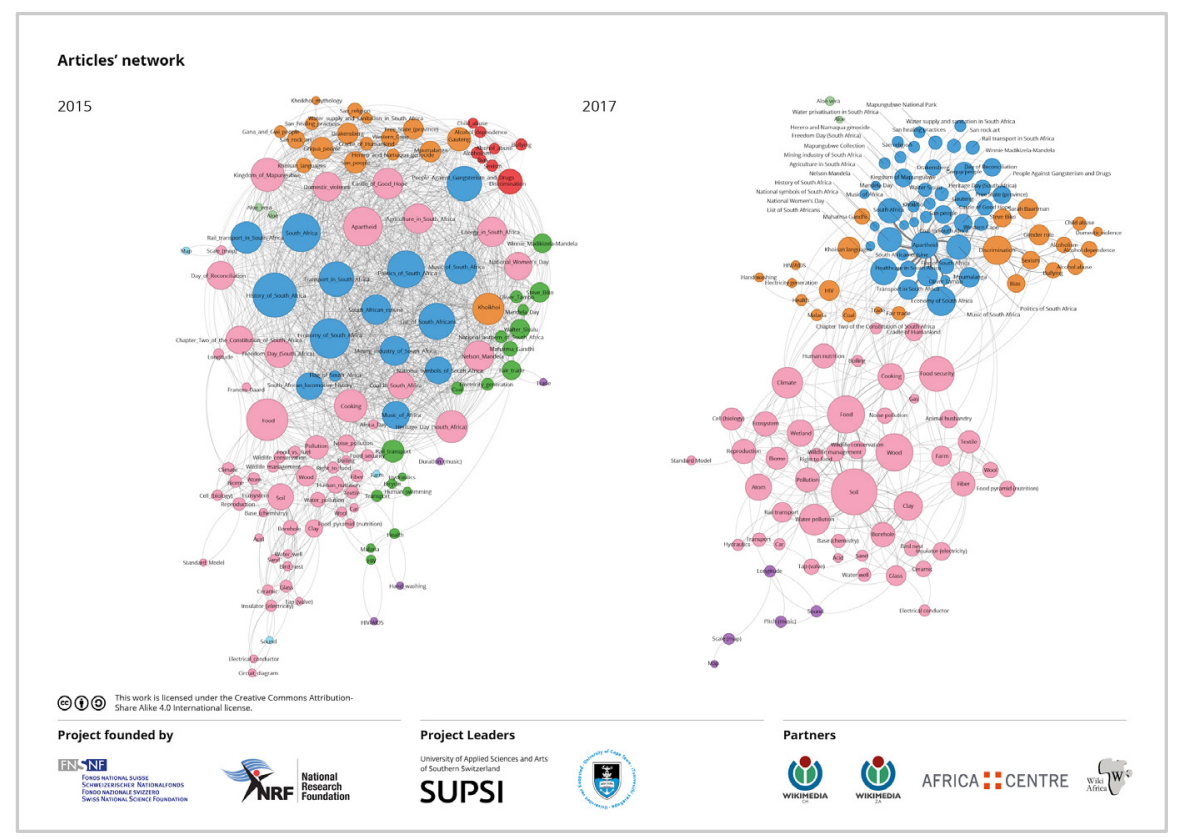

Fig. 6. Comparison of articles' networks. Laboratorio cultura visiva SUPSI. Lugano. 


\subsection{Digital Social Innovation for Europe}

Digitasocial.eu is the web hub of the DSI4EU, an EU funded project that aims to support a growing network of projects and organizations providing a bottom-up approach to tech development. Across Europe digital social innovators are developing inspiring digital solutions to social challenges by using technology, such as the open source software and hardware and open data, crowdsourcing and Internet of Things (IoT). The hub is a network of networks and its interactive visualization reflects the complexity of analysing communities that shares common values but deliver social impact in fields as diverse as healthcare, education, democracy, environment, transport and housing. The visualisation ${ }^{6}$ proposes three views: map, network, projects [8].

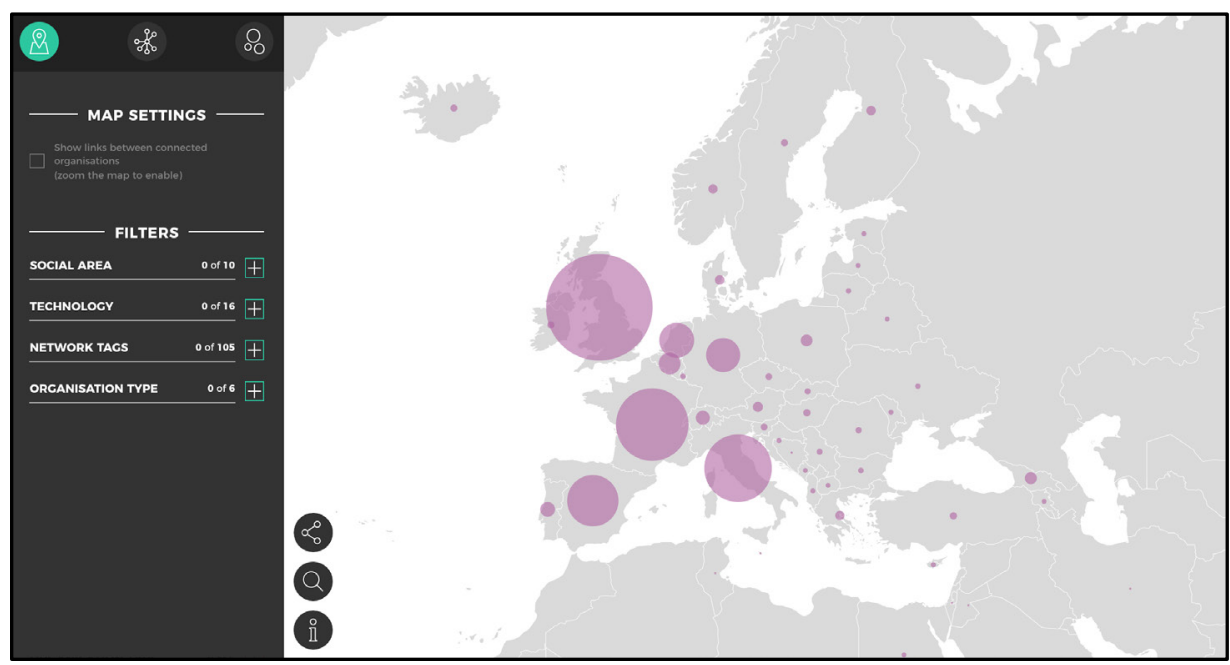

Fig. 7. View from 'Digitalsocial.eu'. DSI4EU Interactive visualization - Map view.

\footnotetext{
${ }^{6}$ https://digitalsocial.eu/viz/
} 


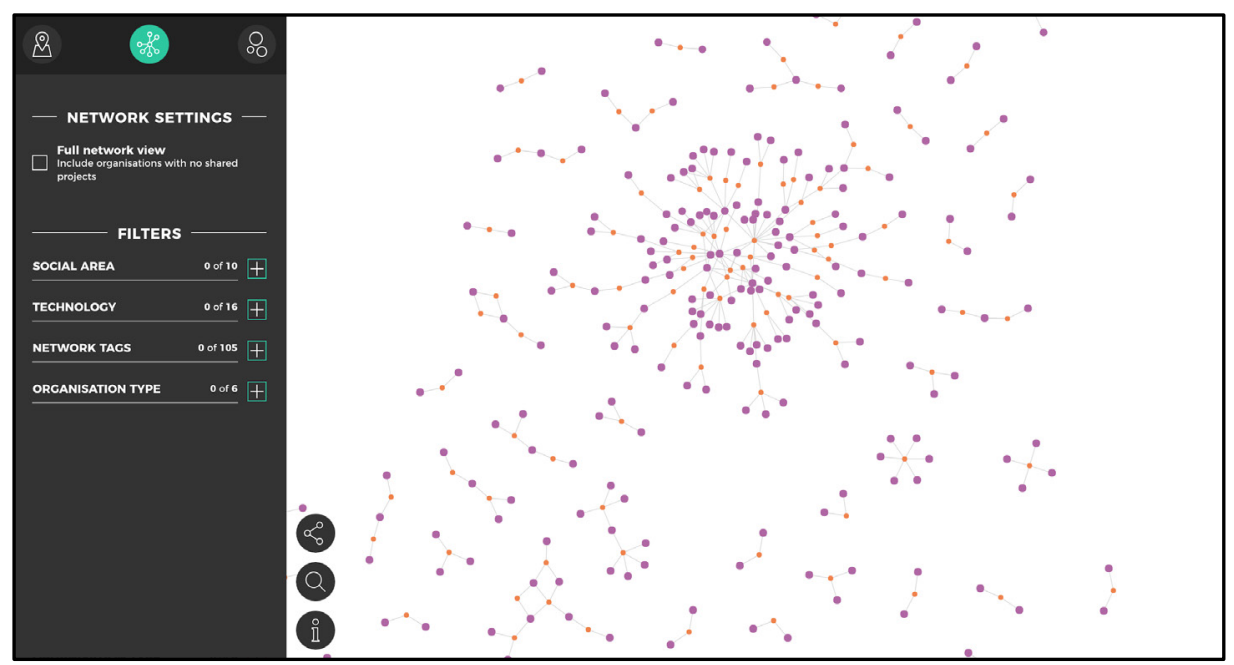

Fig. 8. View from 'Digitalsocial.eu'. DSI4EU Interactive visualization - Network view.

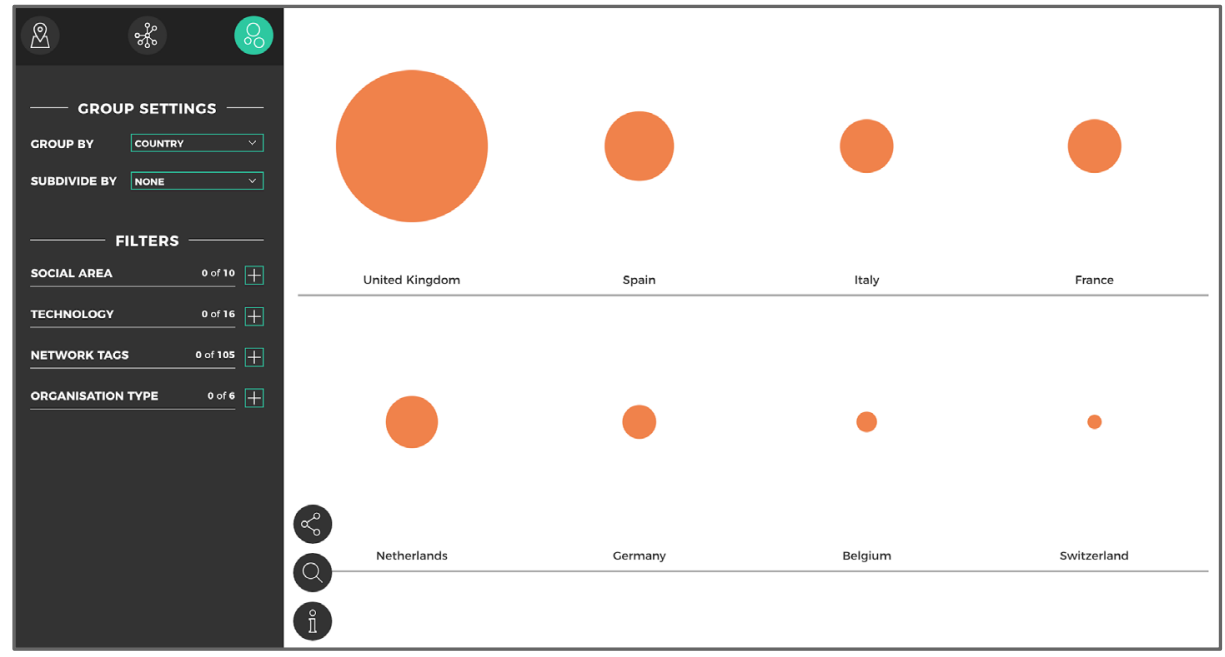

Fig. 9. View from 'Digitalsocial.eu'. DSI4EU Interactive visualization - Project view.

\section{Discussion}

We compared these cases in order to understand their similarities, differences, and common elements in the visualisation of open communities in terms of dimensions 
(geographic, systemic, historical), focus (impact, processes, size and distribution) and strategy (data source, scale, approach) (Table 1).

Table 1. Comparison of the three case studies

\begin{tabular}{|c|c|c|c|}
\hline Case Studies & Fab City Dashboard & Wikipedia & $\begin{array}{l}\text { Digital Social } \\
\text { Innovation }\end{array}$ \\
\hline \multicolumn{4}{|l|}{ Dimensions } \\
\hline $\begin{array}{l}\text { Geographic } \\
\text { (place) }\end{array}$ & $x$ & & $\mathrm{x}$ \\
\hline $\begin{array}{l}\text { Systemic } \\
\text { (network) }\end{array}$ & WIP & $x$ & $x$ \\
\hline Historical (time) & & $x$ & \\
\hline \multicolumn{4}{|l|}{ Focus } \\
\hline Impact & $x$ & & \\
\hline Processes & WIP & $x$ & \\
\hline $\begin{array}{l}\text { Size and } \\
\text { distribution }\end{array}$ & & & $x$ \\
\hline \multicolumn{4}{|l|}{ Strategy } \\
\hline Data source & External, explored & External, analysed & Own \\
\hline Scale & $\begin{array}{c}\text { Global, selected cities and } \\
\text { regions }\end{array}$ & Global, online & Europe \\
\hline Approach & $\begin{array}{l}\text { Research through design, } \\
\text { Exploratory Simulation }\end{array}$ & $\begin{array}{l}\text { Data-driven } \\
\text { analysis }\end{array}$ & $\begin{array}{c}\text { Crowdsourced } \\
\text { mapping }\end{array}$ \\
\hline
\end{tabular}

From the comparison of the three cases we elaborate these preliminary research guidelines for the visualisation of open communities:

- Manage and visualise ambiguity of cases that can be hardly checked in a coherent way since they are distributed.

- Manage and visualise missing or not completely coherent datasets.

- Manage and visualise user participation in providing datasets, and the consequent quality issues.

- Define metrics in collaboration with domain experts.

- Integrate multiple perspectives with different visualisations instead of one single visualisation.

- Develop simple visualisations and models instead of complex ones, but able to evolve in the future.

- Add in-depth textual explanations to main (complex) concepts. 
- Provide a global and comprehensive overview, but ability to focus on individual elements.

- Start with exploratory analysis with available datasets, refine and then test with stakeholders.

- Aim at finding datasets and elaborate models that can compare cases.

\section{Conclusions}

While the enthusiasms in the positive influence of digital technologies on society has been greatly reduced in the past years, the hopes in digital social innovation initiatives are still high especially thanks to their ability to scale up and engage people in their processes. This article proposes the analysis of three case studies of visualisations focusing on community-based digital social innovation initiatives and elaborated few guidelines. However, we consider the research here presented to have certain limitations:

\section{Case 1:}

- Missing datasets regarding cities, regions, and Maker initiatives.

- Rough model of impact, to be improved.

\section{Case 2:}

- Continuous evolution of Wikipedia content and structure.

- Missing worldwide recognised metrics.

Case 3:

- Cannot support the impact of each organisation because the number of projects cannot demonstrate their effectiveness.

- Cannot compare amongst the organisations and projects.

Considering these limitations, we suggest these directions for future research:

\section{Case 1:}

- Develop a model of impact of Maker initiatives over cities and regions based on easily accessible and scalable datasets, and develop tools accordingly.

- Integrate with analysis and visualisation of processes.

\section{Case 2:}

- Apply the research approach to other countries and education systems.

- Foster the Wikipedia community to adopt visual models to evaluate articles.

Case 3:

- Visualise qualitative data regarding the sustainable scalability of the projects. 
Generally, we suggest that future research should focus on a coherent framework for understanding and visualising open communities by integrating these three perspectives and test it and the cases with stakeholders and domain experts.

\section{Acknowledgements}

This research received funding from:

1. the Horizon 2020 Programme of the European Union within the MAKE-IT project under grant agreement $n^{\circ} 688241$.

2. the Swiss National Science Foundation, the National Research Foundation of South Africa, in partnership with Wikimedia $\mathrm{CH}$, Wikimedia $\mathrm{ZH}$, Africa Centre and Wiki Africa.

3. the Horizon 2020 Programme of the European Union within the DSI4EU project under grant agreement $n^{\circ} 688192$.

This publication reflects only the authors' views and the European Union is not liable for any use that may be made of the information contained therein.

\section{References}

[1] Anderson, C. (2012). Makers: The New Industrial Revolution. New York: Crown Business.

[2] Menichinelli, M. (2016). Mapping the structure of the global maker laboratories community through Twitter connections. In C. Levallois, M. Marchand, T. Mata, \& A. Panisson (Eds.), Twitter for Research Handbook 2015 - 2016 (pp. 47-62). Lyon: EMLYON Press. Retrieved from http://dx.doi.org/10.5281/zenodo.44882

[3] Sbeih, J., Pelka, B., Zirngiebl, M., Millard, J., Unterfrauner, E., Langley, D., ... Cuypers, M. (2017). D6.2 Societal Impact Analysis and Sustainability Scenarios (MAKE-IT No. D6.2). Retrieved from http://make-it.io/deliverables/

[4] Diez, T. (2016, June). Fab City Whitepaper. IAAC Bits, 6(4.3). Retrieved from https://issuu.com/iaacbits/docs/6.4.3_white_paper_fab_lab

[5] OECD. (2011). How's Life? Measuring well-being. OECD Publishing. https://doi.org/10.1787/9789264121164-en

[6] OECD. (2014). How's Life in Your Region? Measuring Regional and Local Well-being for Policy Making. OECD Publishing. https://doi.org/10.1787/9789264217416-en

[7] Cangiano, S., Profeta, G., Lurati, M., Elsharbaty, S., Pensa, I.\& Devouard, F. (2017) Community Digest: Using data to visualize Wikipedia knowledge gaps; news in brief. Wikimedia Foundation Blog. Retrieved from: https://blog.wikimedia.org/2017/02/23/digest-data-visualization.

[8] Cangiano, S., Romano, Z., \& Loglio, M. (2017). The growth of digital social innovation in Europe. An Open Design approach to support innovation for the societal good. The Design Journal, 20 (sup1), S3546-S3559. https://doi.org/10.1080/14606925.2017.1352857 


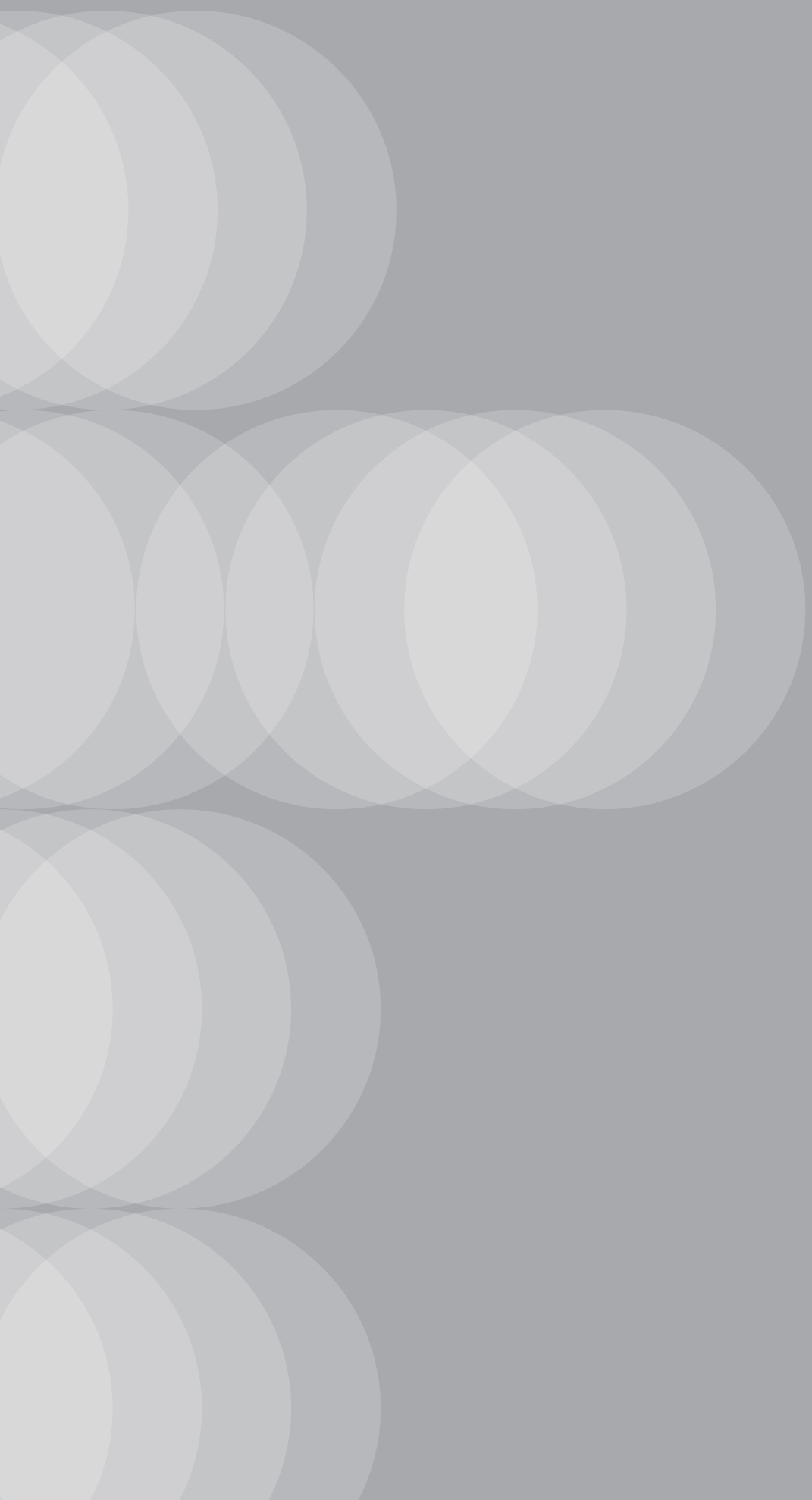




\section{Full papers}

3 : Informative Animation 


\title{
Picturing $\mathbf{7 0 0}$ years of history Charting political and social relationships from the Statuti Sassaresi, a XIV century manuscript statute-book
}

\author{
Nicolò Ceccarelli ${ }^{1}$, Alfredo Calosci ${ }^{1}$ and Marco Sironi ${ }^{1}$ \\ 1 Laboratorio AnimazioneDesign, DADU, Università di Sassari, Italy \\ nceccare@uniss.it, alfredoc@negot.net, marcosironi@elitradesign.it
}

\begin{abstract}
In 1316 the town-republic of Sassari issued its 'Statuti', a collection of regulations describing the city's legal and administrative matters. Although the contents of the document vividly present many traits of the city's XIV century's life, the original form in which it came to us - in Latin and vernacular Sardinian - make it very inaccessible to the general public. In the 700's anniversary of the Statuti the local Historic Archives started a vast dissemination project involving us on the grounds of our expertise in communication design.

Over the following year our research unit was engaged in the production of an experimental informative platform in which various artifacts - three animated short films, an illustrated booklet, and a website, among the others - explore ways to enhance the degree of accessibility of such an important historical account to the general public.
\end{abstract}

A key step along this process was the understanding that as different users have varying abilities in processing the available information, to provide actual access to it implies varying degrees of interpretation of the text per se, which clearly raises questions of historical accuracy.

This brought to the development of a model in which a series of artifacts based on various degrees of 'proximity' - and therefore of interpretation - to the original text, can represent different access points for the understanding of an otherwise very inaccessible text.

Keywords: Info-graphics, isotype, cultural heritage, pictogram design 


\section{Introduction}

In 1316 the town-republic of Sassari, in Sardinia (Italy), issued its 'Statuti', a collection of regulations describing the city's legal and administrative matters. In the emerging frame of north and central Italian "Communal" culture autonomy, the appearence of similar statute-books can be considered a tenet of the movement that lead to the end of the feudal world.

Although similar to many contemporary city's legislations, the Sassari statutes are in a way unique. They combine in fact a body of justice deriving both from the Roman and the Barbaric Laws with ancient local customary practices peculiar to the history of insular Sardinia (

The document, that came to us as a large volume in parchment in two versions, one in Latin, the other in ancient logodurese (a form of ancient vernacular Sardinian), vividly represents various traits of the city's XIV century's life (Mattone 1986). Among these, its political structure, the way justice was implemented, the administrative system, building regulations, health and safety issues, presenting a lively fresco of the social structure of a city in Italy's Communal times.

In the event of the 700's anniversary of its issuing, in 2016, the local Historic Archives started a project for disseminating this extraordinary document through a series of cultural events and presentations. One important step of this effort was the high resolution digitalization of the original document, followed by its on-line publication (http://archiviostorico.comune.sassari.it/statuti/).

\section{A dissemination effort}

Beautiful in their elegant handwritten text, the volumes are hardly accessible to the general public. A first practical reason is connected with the uniqueness of the document itself, which for obvious preservation purposes needs to be stored and handled with extreme care. Moreover, beyond the scarce legibility of the XIV Century hand-writing itself and the ancient parchment's not always optimal state of conservation, the document's contents themselves are far from being of easy interpretation. Both the Latin and ancient Sardinian versions are written in archaic form. The language is technical and very specific and, as it was then customary, specific textual formulas and abbreviations are widely used throughout the text. The passing of time also ought to be taken in consideration. Although many of the general issues the Statuti deal with are still present in today's life, society as a whole has gone through significant changes. Time has taken its toll on other grounds too: many landmarks of medieval Sassari's mentioned in the Statuti - buildings, churches, squares and streets - are today hard to spot out, even for the historian: other simply no longer exist or have changed in name and function.

Other subtler elements make the dissemination effort even more challenging. Despite containing an incredible amount of useful informations to the expert, the 
volumes don't present to our contemporary eyes an obvious and comprehensive picture of Sassari's life in the XVI century.

A medieval statute was neither a chronicle or a touristic guide: it was rather a collection of regulations - often assembled quite randomly - dealing with various aspects of the local political, social, legal and economic life. As for many other similar documents of the time, their entries would not necessarily encompass much of what can be perceived useful, relevant, even of general use, to our contemporary eyes. Many of these issues, apart from offering a lively testimony of the city life of their time, often focused on very specific and practical issues. Despite being possibly considered pressing and sensible to those who lived there at the time, may appear irrelevant today. It must also be kept in mind that at the time of the Statuti many mundane matters would have possibly been dealt with through customary - often orally transmitted - set of habits. Such daily practices would have then made unnecessary to transcribe something which - being widely accepted - did not need to be made explicit, and therefore transmitted to us.

Finally, it is not necessarily true that the degree of attention devoted to specific issues - building standards, the private exploitation of public space, public health measures, for instance - automatically indicates their relevance. Issues covered with less depth through the documents may well be not necessarily less important, but maybe only less 'problematic', hence not requiring constant efforts and/or specific ruling.

As this overview of the many questions associated with the dissemination of a document like the Sassari Statuti outlines, the praise-worthy digital publication of the document by the Historical Archive's website does offer an improvement of the available access opportunities, but clearly does not per se suffice in bringing this extraordinary heritage to full light. Dissemination implies information to be put in context, read 'in between the lines', and this clearly requires interpretation and guidance.

\section{Contact: a dissemination journey}

The contact between the Historical Archives of Sassari's Municipality and our research unit was generated by a common interest in exploring ways in which a system of 'visual explanations' (Tufte 1998) can improve the dissemination of a unique resource of local heritage and history.

As we started working at this task, a rather stimulating design trajectory was offered by the America And Britain series of three volumes published in the 1940's (and today available on-line). The volumes, presumably intended to help bringing the people of the two main war allied closer, uses an effective combination of text, photographs and original informative charts (designed for the scope by the Isotype Foundation) to present a thorough comparative view on the two country's social, economic and political features. 
A specific section of one of the volumes, Our Two Democracies At Work (Smellie 1944), which presents two comparative charts of the two nation's formal structures of political and administrative power, particularly caught our attention.
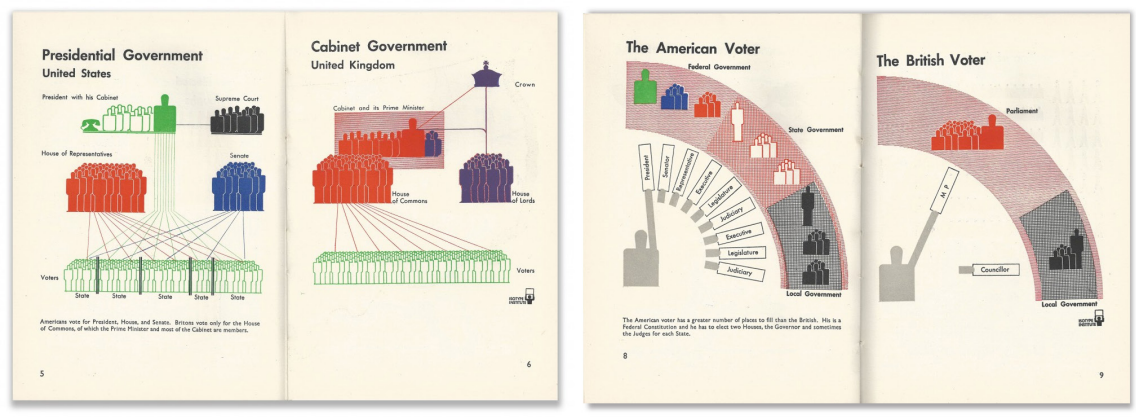

Fig. 1 Isotype comparative charts presenting parallel views of the political structures in the UK and the USA in the Our Two Democracies At Work volume.

Meant as offering a comparative perspective, the charts are structured as couples. The first one, Cabinet Government (UK)/Presidential Government (USA), based on a classic hierarchical diagram, depicts the two countries' political forms. A second pair: The British Voter/The American Voter presents the same structure and information from the subjective point of view of a citizen/voter in terms of its 'electoral potential'.

Apart from Isotype's usual spotless design and composition clarity, what we found particularly inspiring in the comparative arrangement of these charts was their effectiveness in naturally encompassing two totally different ways to 'tell the story'. While the first diagram is structured on an isometric-like point of observation - one giving to all components a same visual weight whilst hierarchically ordering them - the second chart illustrates the voter's position through an 'internal' conceptual arrangement, allowing to present the facts from a subjective specific point of view.

In reference to the history of graphic representation, we may highlight here the presence of a subtle visual arrangement. On the track of Erwin Panofsky's notorious reflections on Perspective as Symbolic Form, it is interesting to argue how in this specific metaphorical composition the image places the observer in the center of the scene. Although, geometrically speaking, the composition isn't strictly built as a perspective projection, it does present a conceptual 'perspective-like' point of view. Similarly to what happened with Renaissance painting, Panofsky's interpretation of the perspective projection as a symbolic device, the rhetorical solution of placing us in the centre of the scheme, offers a stimulating point of observation, contributing in bringing to light relationships that would otherwise remain distant and very abstract.

Through this elementary, and yet sophisticated, comparative conceptual device, the Isotype chart succeeds in connecting the abstractness of the political and administrative formal power structure - masterly depicted throughout a fine example of its 'in-house' isometric presentation style - with its 'reality' in terms of the network 
of interactions among the people that shape a community. It is a comparison within the comparison: almost a bi-directional magnifying glass, presenting in a concise, efficient and very convincing way, the two sides of a same coin.

\section{Early implementations}

On the track of this promising direction, our first step was developing a series of charts that, on the grounds of Isotype's classic methodology (Neurath, 1936, Kinross, 2009), present the social framework and distribution of power in 1300's Sassari.

This exploration was carried out within the first year design studio 'Comunicazione di Progetto' (Design Communication) at our school. Under our supervision, our students developed a series of basic charts and schemes visualizing information extracted from the analysis of the actual Statutes' text. The charts included various synoptic representations. Among these, graphs on the city's political structure at the time of the Statuti, as well as stylistic 'Isotype-like' representations (Frutiger 1989) of the key features of various figures mentioned in the text, developed on the grounds of their occupation and/or social status.
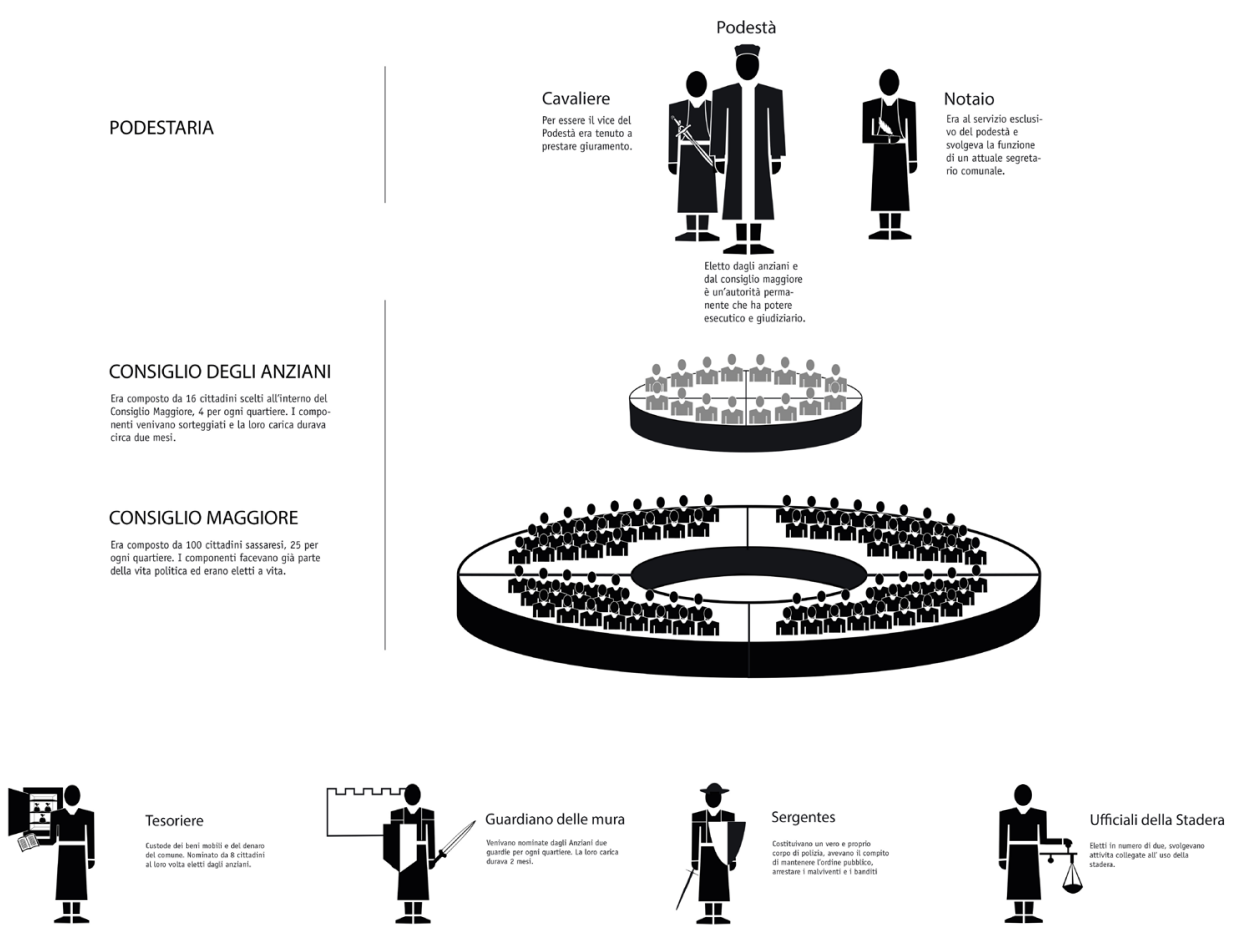

Fig. 2, 3 Two charts presenting a synoptic view of Sassari's formal power structure, as they are described in the text. Students: Giovanni Battista Asara, Chiara Muzzu, Ilaria Mundula, Alessia Rassu, Pasquale Messina. 


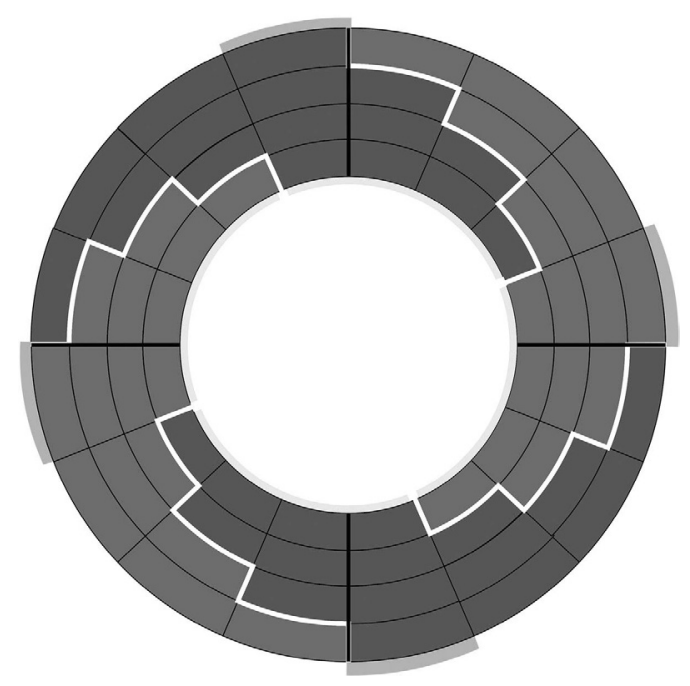

Fig. 4 Schematic chronologic representation of the ways in which Sassari Elder's council was elected. Students: Maria Laura Porqueddu, Fabrizio Palitta.

We readily acknowledged the potential of this approach for the visual development our project.

Although being based on the interpretation of a set of very elementary original information, the the representation of people (Abdullah and Hubner 2006) who actually lived in Sassari at the time of the Statuti, and the development of diagrams presenting the network of general responsibilities shared by a community and the related interactions, could allows us to bring to light, or at least to present, by analogy, actual relationships between real people living in 1300's Sassari.

Despite these early rather convincing results, we realized that developing a double comparative chart for Sassari in the XIV Century of the kind of the one in Our Two Democracies At Work would have been arduous. Further scrutiny of the available information highlighted in fact various difficulties and inconsistencies. Although technically possible, forcing the available facts into a comparative chart would correspond to twisting the historical facts, resulting in an inaccurate, or in an even incorrect, representation of the reality.

In order to achieve what we thought the America and Britain's charts provided best: a variety of different personalized perspectives, we needed to change strategy, redirecting our efforts to other ways to incorporate this element in our presentation. We hence started focusing on the elements that we thought made the Isotype institute's comparative pairs so effective: the combination between presenting information in a multi-scalar way and the adoption of an 'internal' point of view. The next step along this track was to find ways of connecting today's Sassari inhabitants with their 1300's peers. 


\section{Identities}

There can be little doubt about the fact that the over than 700 hundred years-old Sassari Statutes are, on many grounds, a powerful - although partially underrepresented - element of local identity. In this perspective, conveying to the actual inhabitants elements of such cultural and historical legacy becomes even more meaningful and relevant.

A first promising path in this direction has to do with what we may describe as 'geo-referencing'. Despite the many physical transformations that the city's structure went through over the past seven centuries, similarly to many other Italian towns of medium and small size, Sassari has retained a series of rather tangible spatial connections with its historical legacy. Landmarks mentioned in the Statuti can still be spotted within the city's actual form and built environment: in large still existing traits of the medieval walls and towers as well as in minor architectural elements such as corner-stones, columns, window-frames, plaques and inscriptions. Although not any more in place, historic sites such as the 'Carra Manna' and 'Carra Pizzinna' - specialized spaces that, according to the Statuti, where at medieval times used for weighting (for taxing purposes, in fact) goods entering the city - can still be traced through their toponyms. Similarly, the remains of the majestic gothic stone arcades in the 'Corso', in the heart of old Sassari, still provide a solid testimony of the existance of the Platha de Cothinas, the medieval city's high street (the only street to be paved at the time) along which all main public activities took place at the Statuti times.

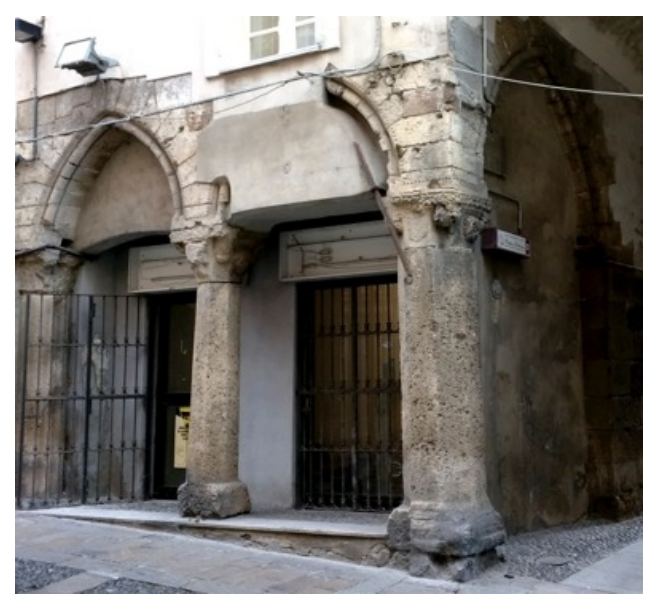

Fig. 5 Gothic portico remains in Sassari's old Platha de Cothinas

Although the full awareness of this legacy is lost in today's Sassari, once appropriately revisited and presented, these elements can play a powerful role in terms of reinforcing the local identity and a feeling of belonging. 
Another subtler, intangible and yet meaningful, level of connection lies in the parallel between the political status of the Sassari's Statuti and some current emerging trends in our society.

Over the last few years, developments in digital technologies and networking have triggered interest on ideas associated with the 'commons' movement and in its impact in social and cultural terms within increasingly aware communities. At the same time, a generalized loss of trust towards traditional forms of political representation has recently sparked in various countries (and this I certainly the case for Italy) a new attitude towards the idea of politics, which nowadays is more and more perceived as a shared responsibility involving certain forms of direct representation. It is not difficult to see connections between these trends and the ideals that drove to the Communal era.

It is easy to see that in such a perspective the Statuti text may today look unexpectedly modern and is bound to become increasingly interesting to broader public than that of the historians.

Having appraised the potential contribution of these components in the development of our project we went back to work looking for ways to spark an active interest within our public - the actual citizens of Sassari - beyond the acknowledgment of the existence of the Statuti documents per se.

\section{Establishing connections}

As finding ways to engage an audience is a key step for effectively communicating and transmitting information, we resolved to explore some classic approaches.

Being able to connect with the audience's direct experience is a valuable approach for reducing the apparent distance - and complexity - of a problem, making it easier to understand. Over time, classical rhetoric approaches have pursued a series of different strategies. Devices such as analogies, metaphors, allegories, are part of this toolbox, and well-known facts have become exempla, easy to grasp exemplary stories that can ease the adaptation of new information with patterns we already are familiar with (Zorzetti, 1980). This can be easily understood in cognitive terms, as it offers the advantage of presenting a framework for interpreting new information: a reference system for gauging the value of an otherwise unintelligible set of facts. Finally, the idea itself of associating, through some form of 'personalization', a new fact with existing knowledge and experience, contributes in making it more appealing.

As in Frances Yates' pivotal study on the art of Memory (Yates 1966), focused on classical rhetoric spatial-based techniques for structuring spatial mnemonic systems, and on more recent work by Lina Bolzoni (Bolzoni, 2002) on how images have been used to structure meaning in in late Medieval times, allegorical associations with 
buildings - palace, a tower - or other physical devices, a ladder to ascend to heaven, have been common through centuries to present complex information or, as Bolzoni highlights, to win over the common people.

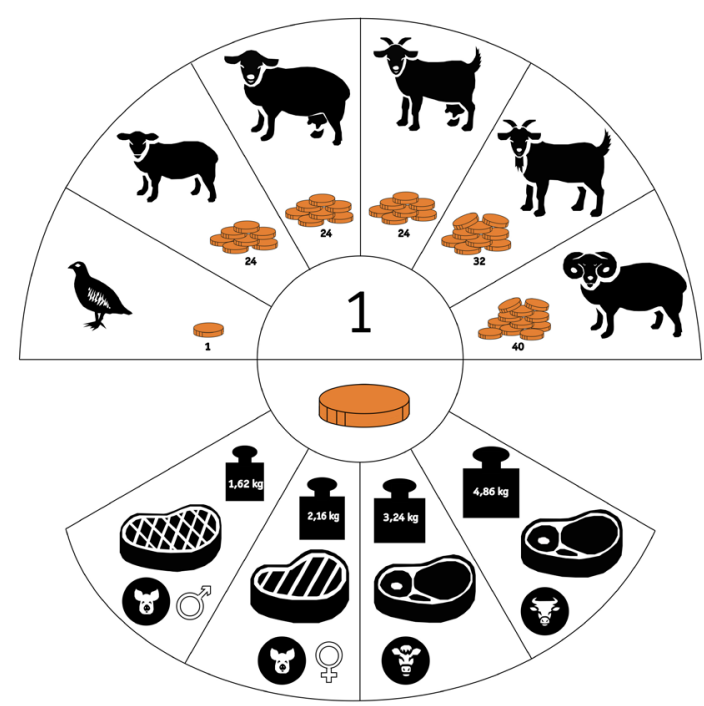

Potere d'acquisto: tre professioni

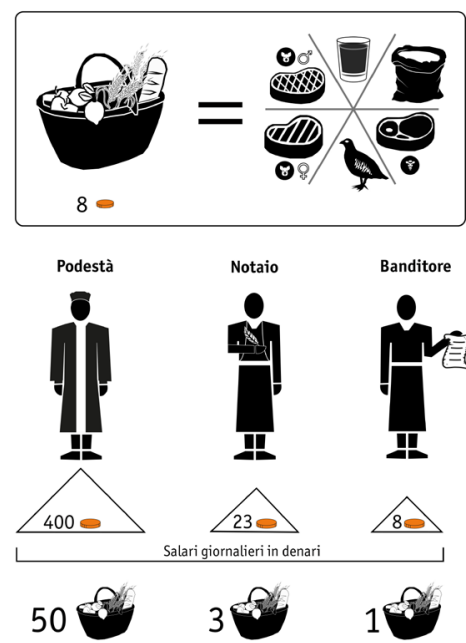

Fig.6 Visualization of meat prices (per unit and in weight) as they are listed in the Statuti, and food basket and comparative chart showing the spending power of different Sassari's 1300 city officers, based on available data on the average stipends. Students: Noemi Ena, Simona Piras, Daniela Tiana.

The idea of triggering an identification process between our audience and the people living at the Statuti time was instrumental to one of the most successful charts we developed with our students in the first phase of our research. The chart presents the prices of some foodstuffs, as specified in the Statuti, by visualizing them in as an ideal daily food basket of an average citizen of 1300's Sassari.

Combining information on the salaries of different people mentioned in the actual text, with an hypothetic basket of their families' respective daily allowances, has allowed us to depict the distribution of wealth across the city's social ladder at the time of the Statuti. This not only has made possible to present the existing differences in spending power between actual people - from the Mayor himself, yearly earning 600 Genoa Liras, to the humble "town crier" - but creates a powerful connection through time and space. Despite the many transformations occurred through time, and the obvious modifications in shopping habits, many Sassari inhabitants still visit regularly the city's central market to buy goods. Beyond being undisputedly exciting, the idea of being able to peep into a typical day's food basket of a fellow citizen who lived more than 700 years ago allows an ideal, and yet tangible, connection. 
Back to our project, one of main issues we were confronting with was how could we "tell our story" being able to spark interest beyond the circles of the learned historians and of the occasional curious. How could we achieve empathy among the actual 'Sassaresi' and their forefathers of more than seven centuries ago on the grounds of a few set of random and loosely related facts?

The direction we resolved to take was to focus on the balance between contextualizing information and actual varying informative demands of different potential users.

\section{Mise en scene}

Although the Statuti is an amazing source of information on a variety of different grounds, culling information from a document of this kind is not an easy task. Although often confusedly dispersed over the whole text, single facts and apparently fragmented units of information can, if re-organized within a broader picture, be turned into a significant reference base. But of course, such a re-organization of existing facts implies some form of information orchestration, which inevitably raises questions of historical accuracy.

Let's take as an example the market square, a fundamental public space in the life of any medieval town.

Although no direct description of Sassari's main market is to be found in the Statuti, the text presents text presents plenty of valid information to sketch what could have taken place there on a typical day.

We can be quite sure, for instance, that the city's centre attracted greengrocers (at the time mainly women, who carried to town the products of the many vegetable gardens located in the city's fertile surroundings). We know this indirectly, as a specific article in the Statuti expressly forbids them to card wool while selling their ware, supposedly in order to prevent any loose grains or fibers to end up in the goods.

From the Municipal procedures for taxing incoming goods, accurately listed in the text, we can instead learn about medieval customary units of weight and volume. The text also precisely describes how cheese, fish or leather, as well as many other goods, were to be sold. The cost for different meat cuts (used as a reference base in the food basket comparative chart we discussed earlier) is also prescribed in the Statuti, which among many other useful information also records the kind of fabrics or cloth one could expect to find on sale. We know the market's location (in Sassari today's 'corso', the city's Main Street) and that, in order to safeguard the decorum of its city core, the Statuti banished selling foodstuffs within a specific section of the corso itself.

As these examples make clear, the Statuti cover a multitude of on different areas of the social, economic, political life of the city life. And despite being often scattered within the entire text, many existing small snippets of information offer, once seen in their entirety, a rather comprehensive and vivid picture of Sassari's life at medieval times. From the point of view of anyone wishing to disseminate a 
document such as the Statuti, it isn't possible not to perceive these elements (places, people, things) as discrete informative building blocks, that once recombined with others through an accurate mise en scene process really can help addressing the varying needs and backgrounds of the document's public at large.

A grant from the Department for Education and Cultural Heritage of Sardinia's Regional Government in the area of research in audiovisual languages, offered our research team the opportunity to explore widely this idea over almost one year of very intensive work. The injection of fresh energy and resources provided to our project an even more stimulating perspective, allowing us to pursue a double, parallel, strategy.

Beyond achieving the more straightforward, and 'internal', objectives of our investigation - exploring the audiovisual medium's adaptability in treating different informative tasks - we realized in fact that our project could largely benefit by adopting a wider point of view. The original idea: developing a series of short films to test different informative patterns, would result significantly empowered if these were considered not per se, but as the components of a more comprehensive and integrated system. We then resolved on developing an informative environment that, by revolving around this audiovisual core, could provide multiple access points, offering an easier, less formal - and possibly more engaging - approach to the exploration of the Statuti.

\section{Framing contents.}

An important issue connected with the dissemination of any document has to do with the degree of interpretation it takes to make it meaningful to the general public. If we look at the Statuti as a 'raw' original material base this must necessarily be linked with the actual abilities of the potential recipients in receiving it as a source of information.

A scholar with extensive familiarity with ancient manuscripts and a good understanding of the political structure of Medieval communal cities (the kind of specialized 'visitor' one can find browsing through city historical archives throughout Italy), may have no problems in extracting information from the direct source. And in fact, a high-resolution digital version of the Statuti is available, on request, for scholarly purposes.

At the other side of the spectrum though, despite being possibly intrigued by the opportunity of browsing the newly-published on-line facsimile of the document, an average user will be mostly unable to obtain much useful information from it.

So, whereas we can expect the first type of user favor the digital facsimile's unfiltered information, the lack of background and skills will make that same source of information almost totally useless for the latter (as well as for ourselves, in fact). 
Whenever the goal is an effective dissemination of the document, some sort of compromise between these two extremes must then be sought after. Making information interesting and understandable to a public of non-experts implies adding context, which in turn leads to introducing varying degrees of interpretation to the original information. This obviously implies issues of historical accuracy: the idea of extracting bits of facts from an original context to re-combine them otherwise often horrifies historians. Any re-contextualization of historic facts is prone to be controversial, beyond any degree of rigor with which the selection of the single bits has been carried out - in our case in strict cooperation with the responsible of the local Historic Archive.

On the other side, what a waste for a document as extraordinary as the Sassari Statuti, to having survived over seven centuries of wars, famine, fires and riots, for the solitary pleasures a few knowledgeable experts.

The angle we resolved to take to approach this issue was to respond to the demands of different potential users by developing a series of specific informative artifacts, framed in a wider, comprehensive, informative system. The scheme presented in the below illustration, illustrates how the various artifacts we devised are intended to convey information to audiences with different backgrounds, combining narrative orchestration with proximity to the actual text (or, in other terms, their historic accuracy in strict terms).

The model is based on increasing degrees of interpretation, from left to right, of the original Statuti text.
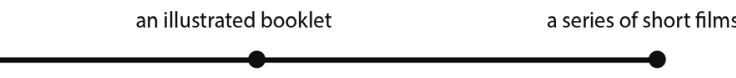

- degree of 'interpretation'

Fig. 7 The accuracy/interpretation scheme on which we have modeled our experimentations

Four distinct steps in this relationship where considered for the development of our research.

On the left side of the scheme is what already exists: the on-line digital facsimile of the Statuti books. Available for interactive browsing through the website of the Municipal Historical Archive (http://archiviostorico.comune.sassari.it/statuti/). Already on-line at the time of our involvement in the project, this is possibly the most unfiltered artifact available to the general public as it presents no, or very little, degree of interpretation.

On the opposite side of the scheme are the three audiovisual artifacts we developed in the course of our investigation. As we will discuss later on, by exploring 
different approaches to the original source in terms of language, tone and visual development, the short films themselves establish different degrees of proximity / interpretation with the text per se.

Between these two extremes, the reference model is completed by two intermediate steps.

Moving from left to right is an annotated version of the Statuti. This artifact, which we have only sketched as a prototype, can be thought as an extension - a hyperfacsimile, enriched by a system of cross-references - of the actual on-line digital version. Based on the actual text - here transcribed, and presented in the original (either in latin or ancient vulgar) versions as well as translated in Italian - this would present interactive explanations and contextualizations of the original text. Developed in the shape of a wiki-document, the relatively low degree of interpretation from the original source would be enhanced by a web of internal connections within the document contents. These may include a system of visual 'notes', in form of icons and other visual aids, to suggest cross-references and links to thematic areas of interest, linking to short textual integrative explanations and contextualizations, as well as to other and similar entries in the text.
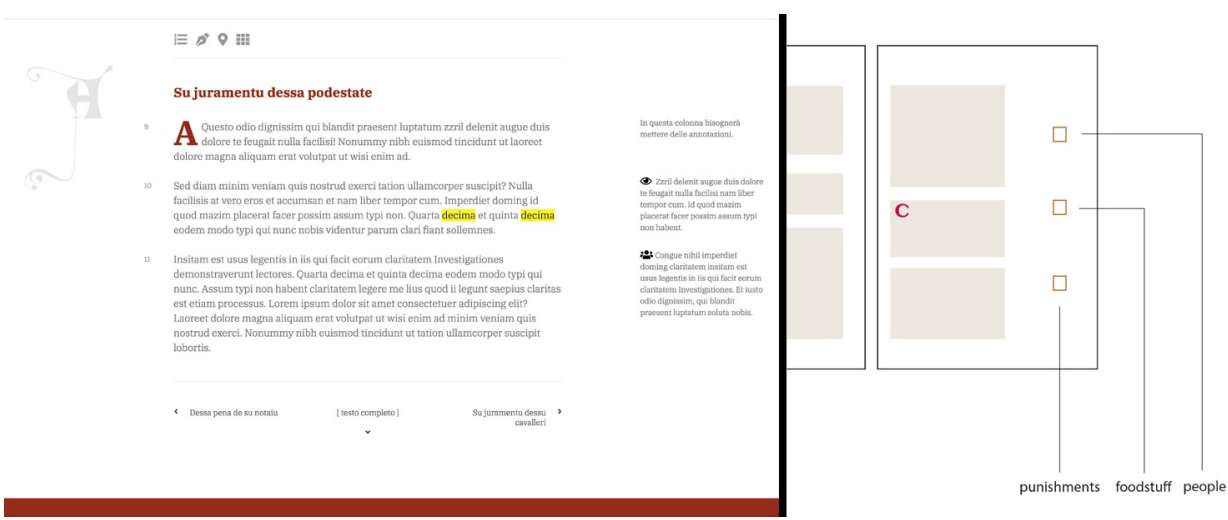

Fig. 8 Sketch for a prototype digital annotated version of the Statuti text. The original, transcribed, text is enriched by annotations, as in a hyper-document. Small iconic side labels may indicate that a specific piece of text can be used as a reference, possibly linking to similar ones, hence allowing the hyper-exploration of the whole text.

The following intermediate step in our reference model takes the form of an illustrated booklet, a light introductory guide to the Statuti, to be handed out to the visitors of the Municipal Archives, distributed in local schools and made available for free on-line download. 
The booklet - that we designed, illustrated, composed and printed - is a visual introduction to the Statuti and providing a general contextualization of the Communal era through focusing on some of its key social, political and economical traits. The booklet combines samples of the info-graphic charts developed by our students with a few illustrative full-page spreads. The spreads, which remind of 'living tableaux' reenact some specific moments of Sassari's life at the time of the Statuti. Each tableau presents plausible information - people, places, specific events and so on - which are combined through an intentional mise en scene process. Just as well as the selected elements, the already mentioned informative 'snippets', are extracted from the original text, these are presented with a direct reference, (a tag, in fact, coded in roman numerals) to the corresponding entry in the original text. Whereas possible, the contextualization has been reinforced spatially by referencing to architectural details still recognizable in today's city fabric.

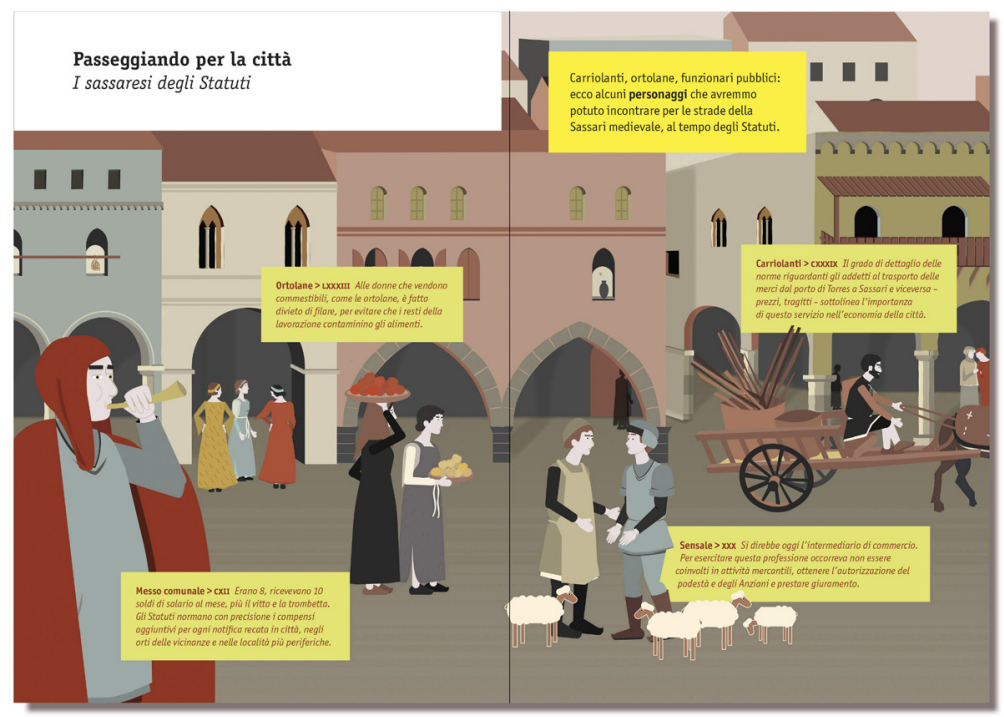

Fig. 9 Full-page spread from our illustrated introductory booklet. Thought as a sort of visual index, each spread combines various sets of informations about people, places and things, into a single comprehensive tableau.

Finally, as anticipated, the platform is completed by three animated short films - the subject of the funding we were granted by Sardinia's Regional Government for our 'Animating History' research project. The main focus of this part of the project is to explore the 'internal' capacity of the language of animation to address different informative tasks. Still, the intentional re-combination, in the films, of a series of units of raw information (extracted from the original Statuti text) into narrative 


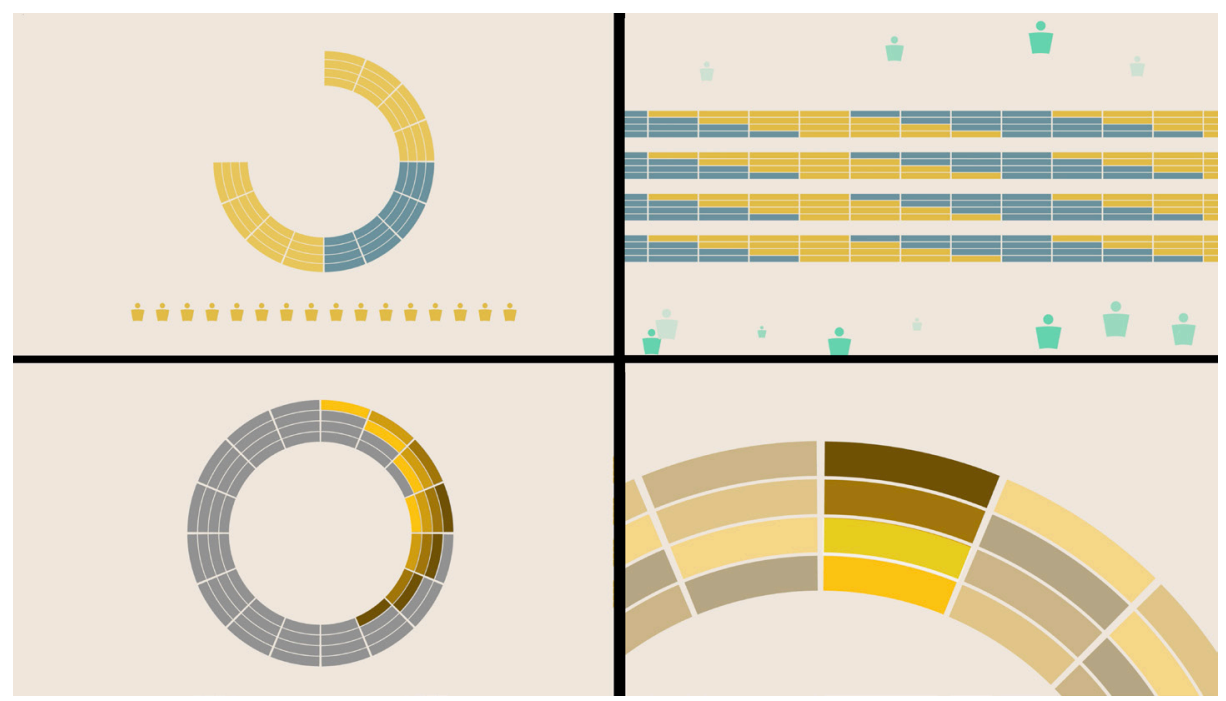

Fig. 10 Our first film, which presents the structure of Sassari's Elders Council, exploits a neutral-like general tone - based on an abstract info-graphics and a detached voiceover - to suggest the 'objective' interpretation of its workings and technicalities.

patterns, offers varying contextual degrees of interpretation, presenting interesting insights on the relationships between historical accuracy and accessibility.

The first of our short films The Elders Council presents the structure and the workings of one of the key political structures of Sassari's local government in the XIV century, focusing on its composition and on the duration of the counsellor's office. The piece has been developed as a distinctly abstract info-graphic presentation. The film's schematic visual treatment is reinforced by a neutral voiceover to convey the idea of an 'objective' interpretation of the presented facts.

Our second short The Sassari Statutes. An introduction, presents the specific circumstances of the Sassari Statuti within a general overview of the Communal age in Italy and Europe. The film is based on a series of descriptive scenes, arranged in the style of an illustration book. A detached voiceover comments what is being shown. The information is presented either directly or through the use of visual metaphors. Sound effects and camera moves are used to enhance the narration. The general atmosphere is deliberately that of the slightly pedantic pitch characteristic of many classic informative documentaries.

The goal of our third and final film $A$ day at the Market, is instead to engage the audience through an immersive dramatization of the Platha de Cotinas, Sassari's 1300 


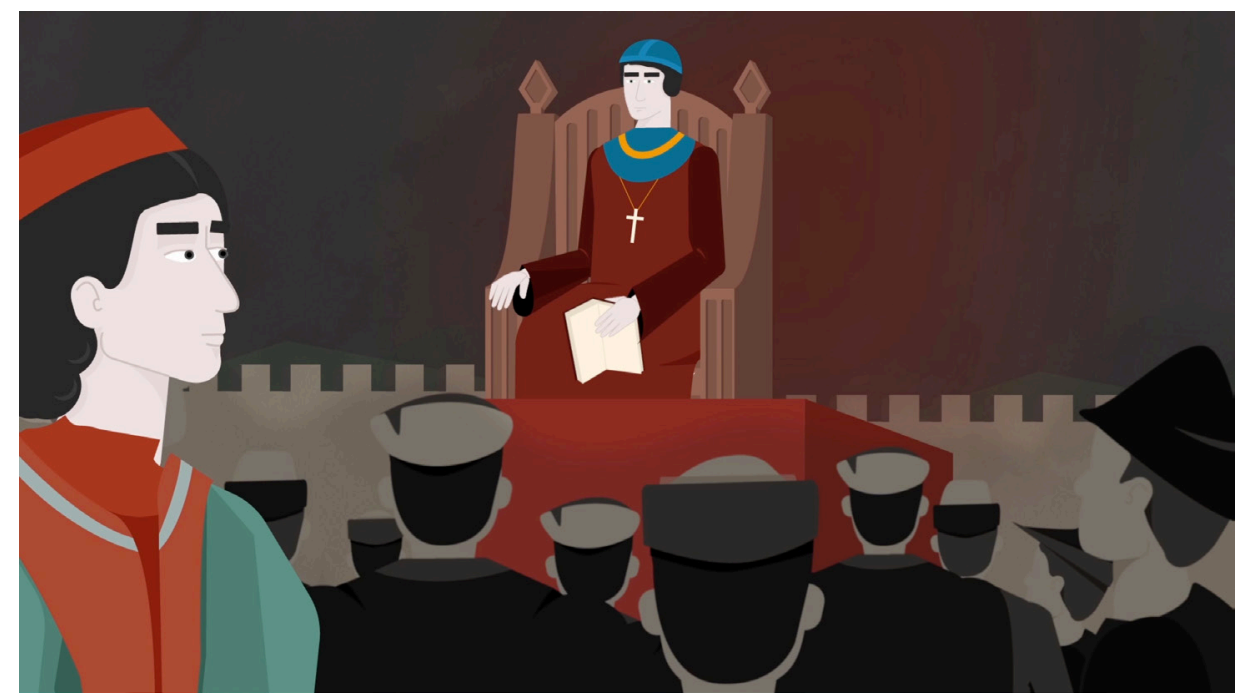

Fig. 11 One frame from our introductory animated film. The general tone of this specific piece is consciously modeled on the pedantic pitch characteristic of many informative documentaries.

central market. Several narrative artifices were put into place to recreate the atmosphere of a typical day in a medieval town. The film is intentionally composed as a unique long shot, aimed at suggesting the crossing of the market on a busy day.

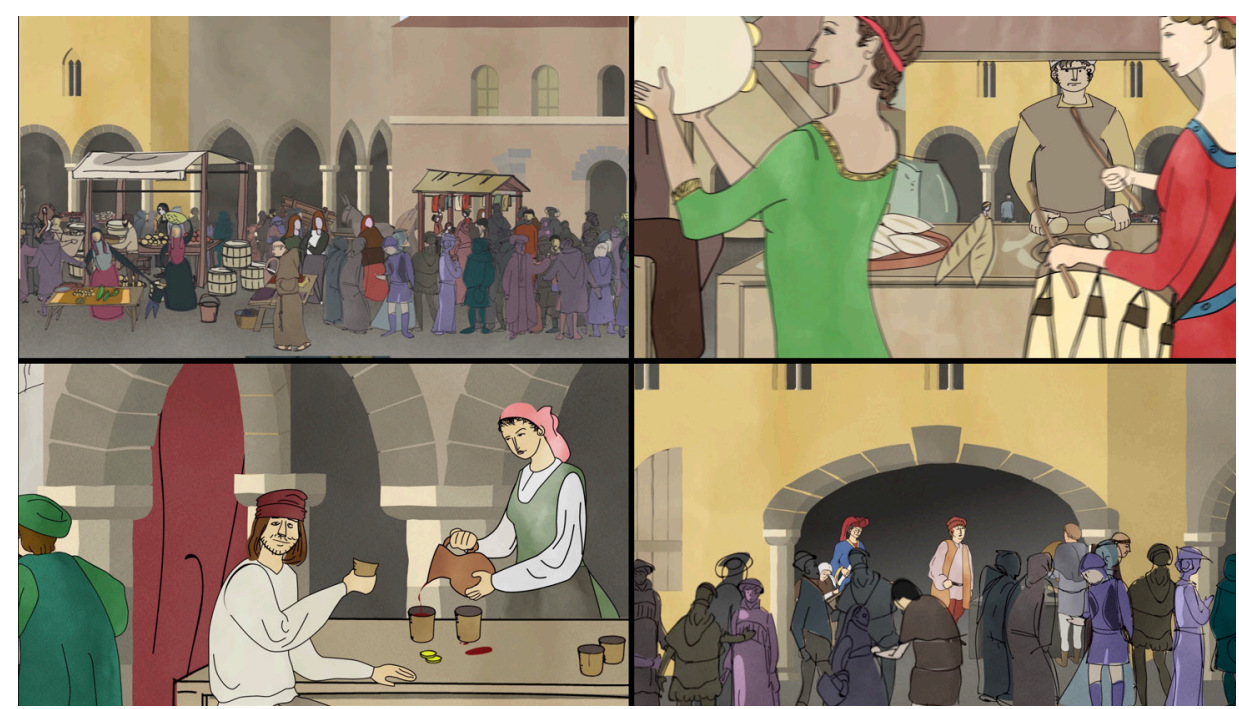

Fig. 12 The $A$ day at the Market film presents an immersive re-construction of a typical day in Medieval Sassari. 
The intentional absence of editing cuts is directed at offering to the contemporary public a spatial model of the Medieval city that can be ideally superimposed on the Sassari of today. Other narrative means - a voiceover narrator directly addressing the characters populating the market's stalls, which in some cases 'respond' by peeking into the camera - even a short 'Disney-like' music intermezzo depicting a group of dancing female musicians - are intended instead to remark the primarily fictional component of this specific artifact, and hence its distance in interpretativenarrative terms, from the previous two.

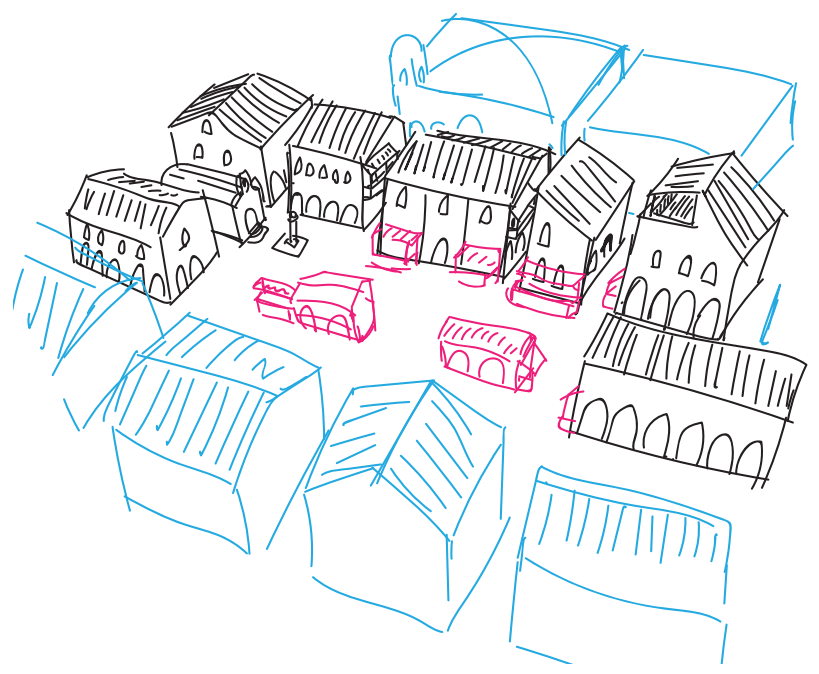

Fig. 13 Pre-production sketch of of Sassari's medieval city center as it was re-enacted in the $A$ day at the Market film. Based on a continuous long shot, the film cross-sections the entire market square incorporating reference to surviving fragments of the medieval structure presenting a mental map of the medieval structure that todays' inhabitants may superimpose over their perception of the actual city.

\section{Conclusions}

An applied research project has allowed us to confront with the dissemination of an exceptional historic document - the Sassari Statutes of 1316 - exploring the complex relationship existing between the two opposite objectives of preserving historical accuracy and favoring accessibility to a very dense piece of information.

One intensive year of work made possible to lay-out the grounds of a prototype informative framework - centered around three short animated films and a small introductory illustrated booklet - in which a series of different artifacts have been exploited to put this relationship to the test. 
At the heart of the experiment is a reference model in which the gradual parting from the nominal source's authenticity (as found in the original document) is complemented by an increase in the - intentional - contextualization and reinterpretation of the available raw information.

Along this line of work, and keeping as our main objective the making of the original source's contents accessible, we have experimented with ways to address this relationship by combining original 'facts' - units of information extracted from the original Statuti text - into narrative patterns that could help a public of non-specialists to relate to an otherwise very distant informative whole.

This approach had invariably affected the design of the prototype artifacts we developed for the project. Despite the very diverse ways - in terms of narrative structure, organizational pattern style and visual/animation language - in which the three films and small illustrative booklet we produced for the project have been developed, they all, we believe, result in a valuable insight on the possible trade-offs between a consistent representation of historical facts and their mise-en-scene aimed at improving their actual accessibility.

\section{References}

Abdullah, R., Hubner, R., Pictograms, Icons \& Signs. Thames and Hudson, London 2006

Frutiger, A., Sign and Symbols. Their Design and Meanings, Van Nostrand, New York 1989

Bolzoni, L., The Web of Images, Routledge, 2018 (Bolzoni, La rete delle immagini, Einaudi, Torino, 2002)

Madau Diaz, G.: Il codice degli statuti del libero Comune di Sassari, Editrice sarda Fossataro, Cagliari 1969

Neurath, O., International Picture Language, Kegan Paul, Trench Trubner \& co., London 1936

Panofsky, E., Perspective as Symbolic Form, Zone Books, New York, 1991

Rosenberg, D., Grafton, A., Cartographies of Time. A History of the Timeline, Princeton Architectural Press, New York, 2010

Smellie, K. B., Our Two Democracies At Work London, Toronto, G. G. Harrap \& company Ltd., 1944

Yates, F., The Art of Memory, Routledge, London, 1966

Zorzetti, N., Dimostrare e convincere: I'exemplum nel ragionamento induttivo e nella comunicazione. In: Mélanges del'Ecole française de Rome. Moyen-Age, Temps modernes, tome 92, n. 1, 1980. pp. 33-65 


\title{
The Role of Movement in Data Visualization: Animation as an Agent of Meaning
}

\author{
Valeria Burgio $^{1}$ and Matteo Moretti ${ }^{1}$ \\ ${ }^{1}$ Free University of Bolzano \\ valeria.burgio@unibz.it; matmoretti@unibz.it
}

\begin{abstract}
If we look at data visualizations as signifying machines, in which every element is meaningful, what is the contribution of animation to the construction of meaning? What does motion or animation add in terms of significance to different kinds of graphics? Does it add something in terms of realism? How can animation be an implementer of meaning, dramatizing the sense of data or expressing doubt about the data itself?
\end{abstract}

\section{Introduction}

Animation in graphics can have different functions:

1. At a pre-perceptive level, it draws attention

2. At a syntactic level, it creates connections

3. At a semantic level:

- it introduces time and change into the visualization

- it literally depicts movement

- it highlights and dramatizes certain data.

We will now quickly see some examples of these functions at work, and then focus on two case studies, to see how in these cases animation has been used not only to attract attention, create connections and enhance meaning, but also to introduce new semantic shades in the reading of the data visualization.

\section{Drawing attention}

At a primitive pre-attentive level, one of the first kinds of visual information we get, together with color and texture, is movement (Healey, 2012). This is due to evolutionary strategies for the survival of a man as an animal: as a prey or as a predator, it was vital for a man to detect movement to run away from something trying to catch him, or to catch something running away from him (see Arnheim, 1954, chapter 8; Cairo, 2012: 102-105). Thus, elements moving in a targeted way in a graphic immediately focus and direct the viewer's gaze (also see Finke and Manger, 2012: 184) 


\section{Creating connections}

Movement creates a conjunction between different actions performed by the same subject. It can connect two charts, with a relation of coordination or subordination. Technically speaking, the graphic configuration in fig.1a is a clustered bubble chart, organized as a pie chart. The fact that the passage between the total (fig. 1a) and the single departments (fig. 1b) is animated creates a correlation between the total (in

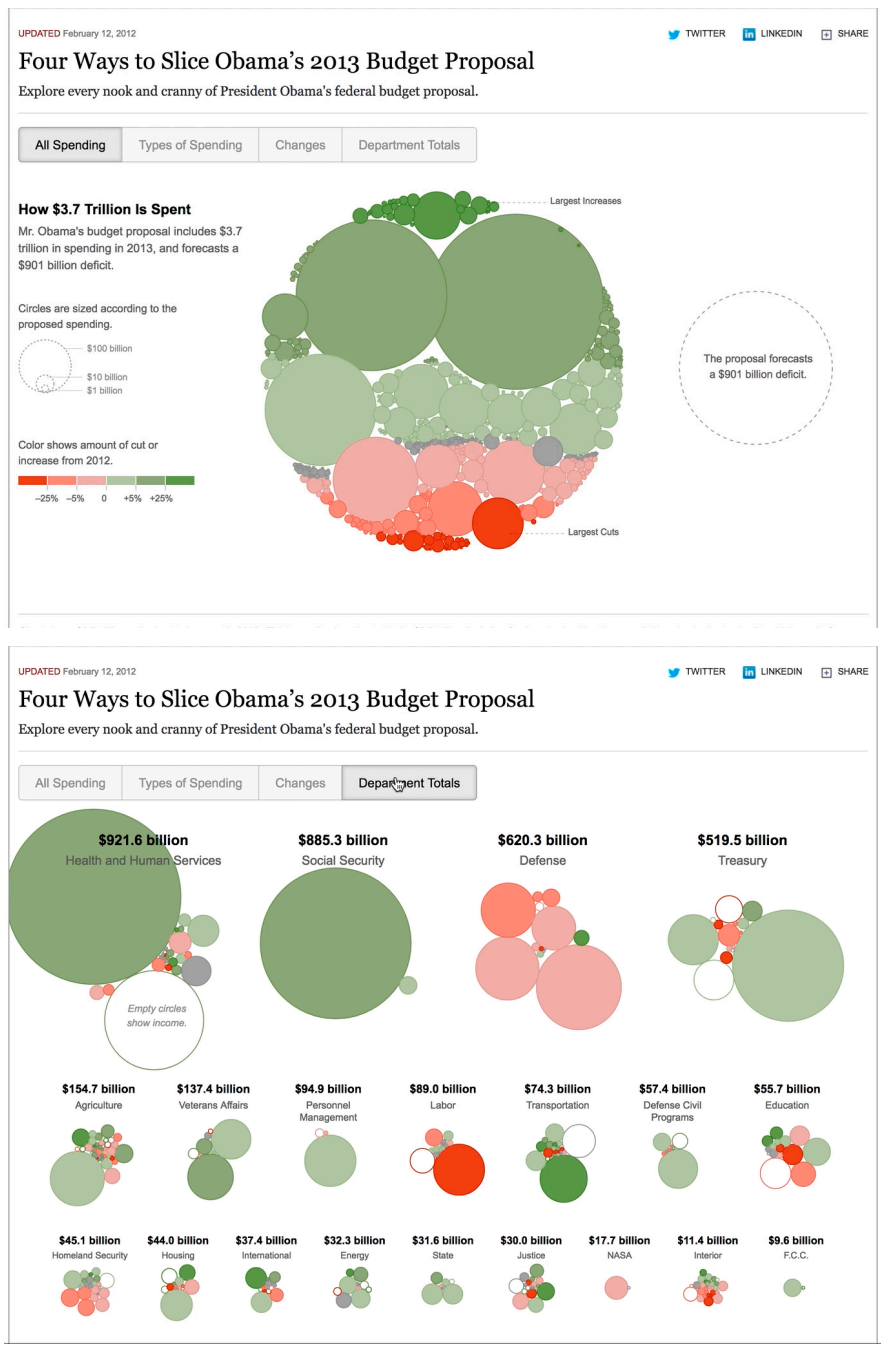

Fig. 1a and 1b. Two frames of the graphic "Four Ways to Slice Obama's 2013 Budget Proposal" published in New York Times, February 12, 2012 (designer: Shan Carter).

https://archive.nytimes.com/www.nytimes.com/interactive/2012/02/13/us/politics/2013budget-proposal-graphic.html 
percentage) and the parts of it, avoiding the accusation to bubble charts to make comparisons and proportions impossible (for a critic of bubble charts, see Tufte, 1983: 71 and Cairo 2012, 39-44). Bubble charts can indeed always be clustered. Here animation allows to focus on one single item without losing connection with the whole subject. It constructs a relation of subordination between the total and the parts, that can be individually analyzed.

\section{Semantic level}

\subsection{Expressing transformation during time}

One of the main functions of motion in graphics is that "temporal sequences of events can be rendered graphically. In addition, time can be slowed or accelerated at will to emphasize or speed up processes" (Finke and Manger, 2012: 24). It is banal to say, but the main contribution of animation in graphics is the introduction of time and progress in the description of a phenomenon, thus also enabling hypotheses for the future. In the famous animated timeline 200 countries, 200 years, 4 minutes directed by Hans Rosling and BBC four (2010), the progressive growth of income and life expectancy in all the world in the last decades let the viewer expect a continuation of the same trend in the future, when everybody is supposed to move towards the top right corner of the screen (fig. 2).

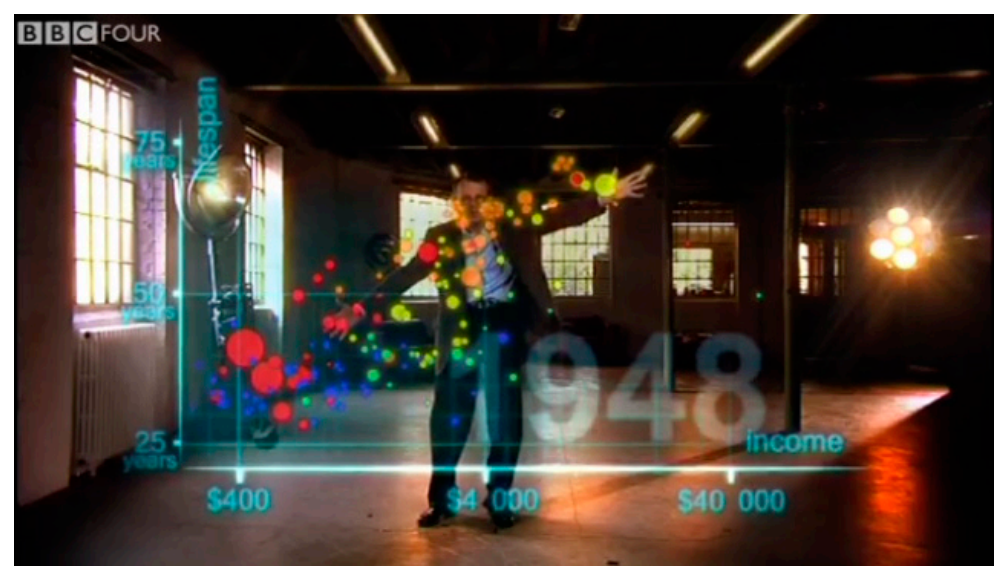

Fig. 2. A frame from the short documentary " 200 countries, 200 years, 4 minutes", Hans Rosling, BBC four, November 30, 2010. http://www.bbc.co.uk/programmes/p00cgkfk

Other animated visualization can on the contrary warn about the possibility of a catastrophic future if trends continue in the same direction they are going now. Diller, Scofidio + Renfro's animated video installation Exit (fig.3), presented at the Fondation Cartier in 2008 and during Copenhagen Summit on climate change in 2009 
let us foresee the increase in mass migration in the 21st century, due to phenomena such as climate change, floods and submersion of coastal land as well as conflicts (Virilio, 2009).

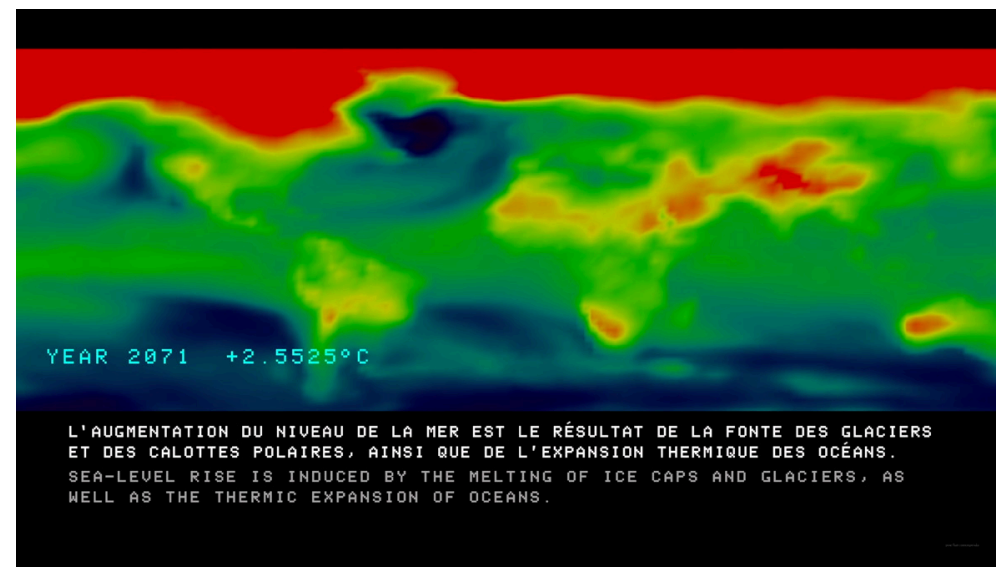

Fig. 3. A frame from the video installation "Exit", 2008-2015. Scenario "Rising Seas, Sinking Cities". Collection Foundation Cartier pour l'Art Contemporain, Paris. CDiller Scofidio + Renfro, Mark Hansen, Laura Kurgan and Ben Rubin.

\subsection{Depicting movement (time + space)}

It is difficult to represent flows in static graphics. Flow is the essence of the moving image. And population flows are the essence of our contemporary times. So, the representation of flows through the traceability of the routes and animated maps go hand in hand (fig. 4 and fig. 5).

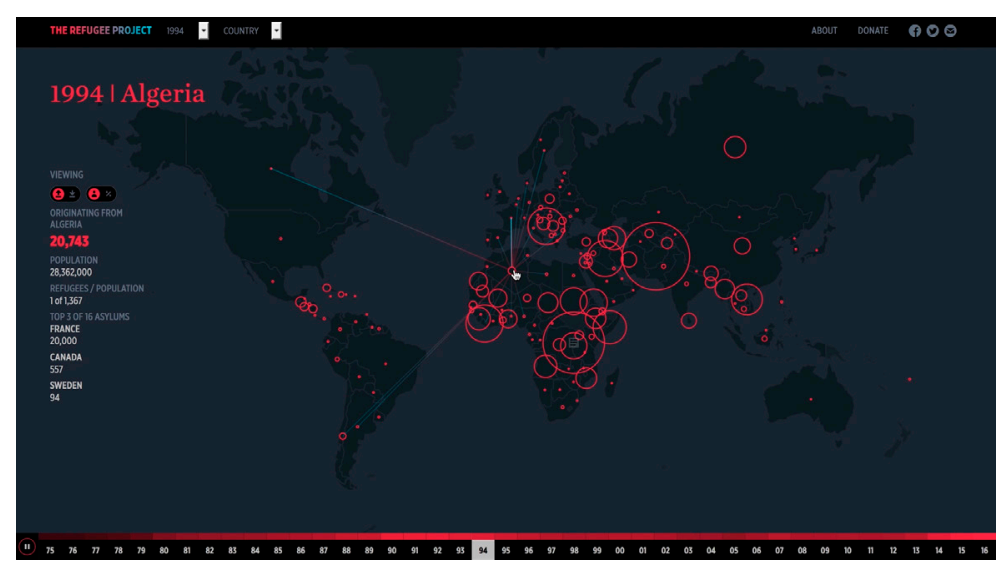

Fig. 4. A frame from The Refugee Project, 2014, by Hyperakt and Ekene Ijeoma. http://www.therefugeeproject.org 


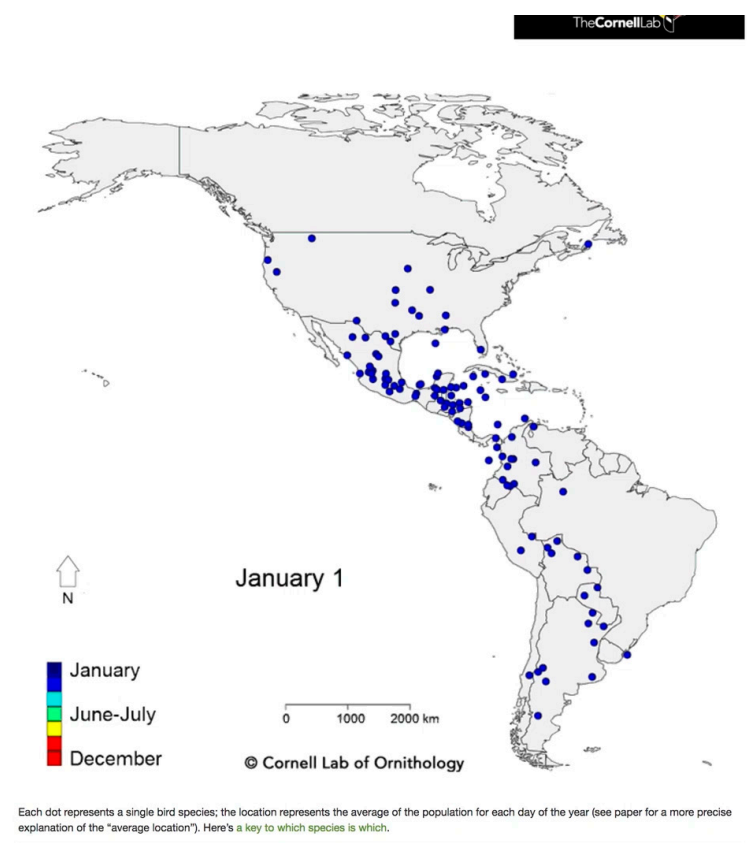

Fig. 5. A frame from an animated bird migration map, (c) Cornell Lab of Ornithology, January 2016. https://www.allaboutbirds.org/mesmerizing-migration-watch-118-bird-speciesmigrate-across-a-map-of-the-western-hemisphere/

\subsection{Highlighting and dramatizing}

The use of animation to make statements more effective and memorable dates back to the invention of animation itself. The pioneer of this use of animation for stressing a particular moment in storytelling was, again, in the entourage of Otto Neurath. It was Paul Rotha, director of one of the first documentary using animated isotype graphics, The World of Plenty (1943). There's a tone of irony and skepticism in Rotha's use of animation, as also stressed by Marie Neurath (1946) and Purdon (2016: 144.150): "First all little figures stand on the same level, which is explained as the average income. Then some lose their level, moving down - these have less than the average. Others go up. There is one figure that does not seem to stop, up and up it goes. There is a laughter of surprise" (M. Neurath, 1946) (fig. 6).

It is the same feeling one has when viewing the famous fragment of Al Gore's documentary "An inconvenient truth" (2006) where the former US vice president follows with his body and even the use of an elevator the increase of temperature due to global warming. In this case, it is not only the voiceover that adds drama to the narrated facts, but also the proxemics of the speaker. Hans Rosling knows this very well: in the already mentioned animated scatterplot, he accompanies with his physicality the moments of rise and fall of human demographics ("What a 
catastrophe!" he exclaims, while following with his body the drop of life-expectancy during the first world war).

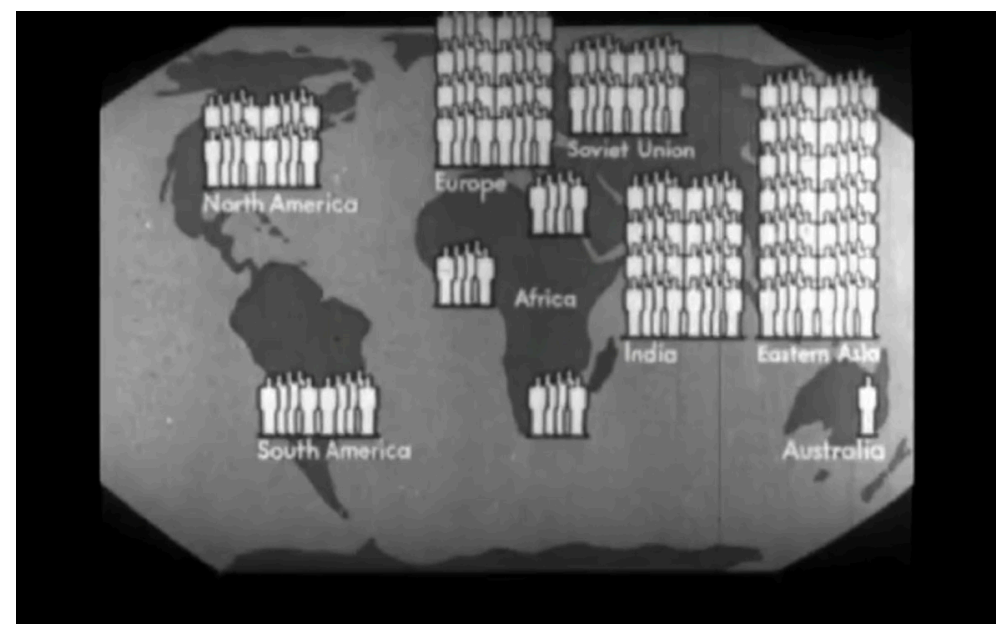

Fig. 6. A frame from The world of plenty, Paula Rotha, 1943.

Speaking about the use of isotype in animation, Marie also highlights Otto Neurath's perplexities about the use of charts in films, as the viewer had a limited amount of time to perceive the content and could not slow it down for their better understanding. Also Tufte's focus on small multiples - illustrations sequenced over time like the frames of a movie showing small sequential changes in data - is a declaration of preference for a time that is displayed in space rather than compressed in an animation (Tufte, 1990: 67-79).

\section{The role of animation in Europa Dreaming}

We will now investigate how animation was used in Europa Dreaming, a project about the return of borders in Europe.

\subsection{Transition: syntactic function}

One of the core visualizations of Europa Dreaming connects two different datasets in order to show the human transits across Europe. The first visualization (fig. 7a) shows the countries of arrival of the migrants, while the second one (fig. 7b) presents the destination countries requested by first-time asylum applications. Hypothetically relying on a more conventional visualization, the data could have been represented by two separate charts. Instead, the datasets about landings and asylum countries are connected in a single visual discourse through the use of an animated transition. 


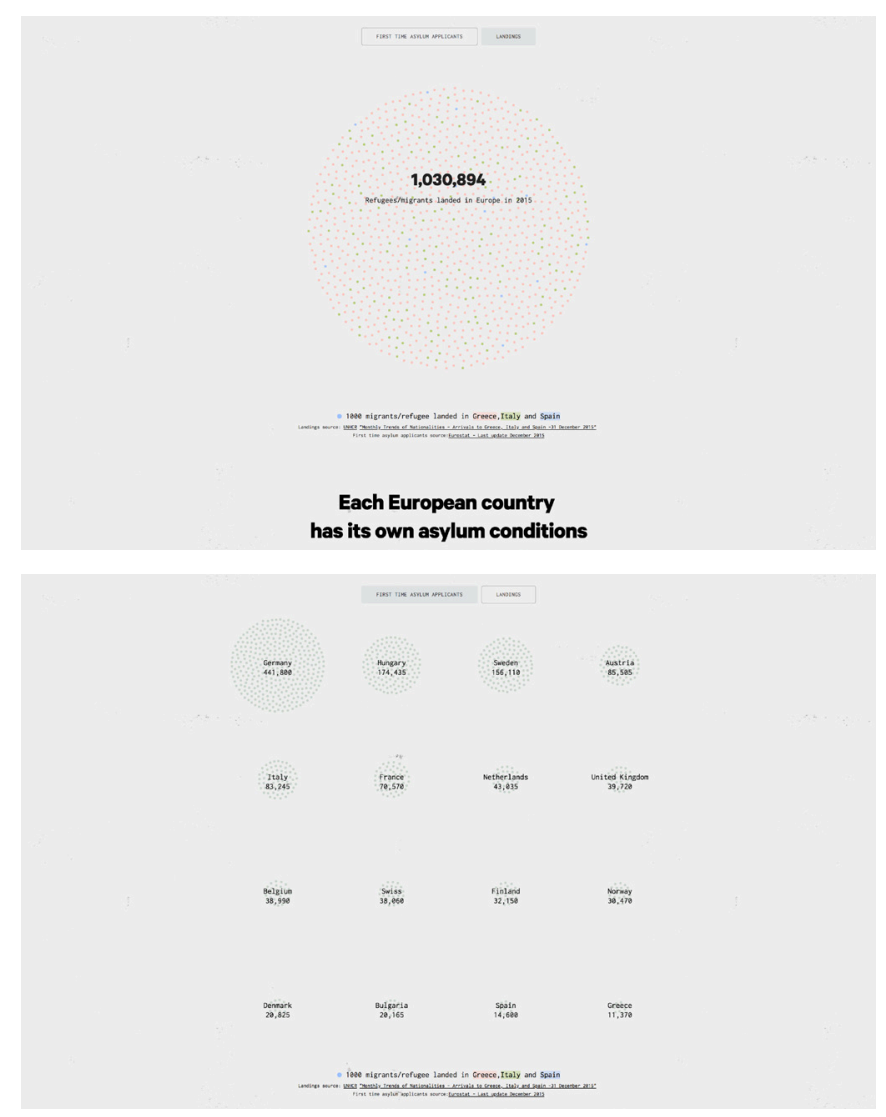

Fig. 7a. The unordered agglomerate randomly visualizing the landing countries of the migrants, Europa Dreaming, 2016. http://www.europadreaming.eu

Fig. 7b. The dots that were forming the million refugees cloud, displace on a grid, forming a series of 16 sub-clouds, Europa Dreaming, 2016.

This means that the 1030 small dots that are clustered together in a cloud depicting the 1,030,894 refugees who landed on the European coasts in 2015, suddenly begin to move randomly and relocate on a grid, forming a series 16 subclouds and generating the visualization of the main asylum application countries. The smaller bubble charts are based on the same principles as the previous one. The transition transforms two different visualizations into a single animated chart that switches between two statuses, depending on the user's choice. In other words, this animated transition connects the first visualization to the second one, creating a continuity between the moment in which migrants disembark and the future they have in mind.

Conceptually speaking, the design process shifted from the visualization of the mere numbers (landings and asylum applications) to the visualization of the people (who landed and applied). The transition from one graphic to the other reinforces the idea that it is the same persons who disembark and ask for asylum. People are represen- 
ted as a human swarm driven by a strong intentionality (the movement with which they pass from the first agglomerate to the desired countries is very direct), which is nevertheless left to roam slowly and randomly about in a limbo that is called "first country of arrival" by the Dublin regulation.

\subsection{Expressive use of animation: the human swarm}

The little dots of the first graphic (the cloud representing the countries of arrival, fig.7a) are slowly animated, evoking a living, organic agglomerate, like a nervous crowd observed from above, moving incessantly within a limited circular area. This design intervention gives rise to a visual metaphor, recalling the migrant movements constrained by the EU borders that they tried to break through in every possible way. This movement, then, does not represent a process, a passing of time, but on the contrary a situation of suspension, of waiting. The use of dots in the graphic, while remaining strictly abstract, manages to stand for people in movement, much more than the bubbles or sectors usually adopted to represent numerical quantities.

\subsection{Expressing uncertainty}

The randomness introduced in this dot-based pie-chart has also the aim of demonstrating the difficulties encountered in managing data about migration: not only is it difficult to evaluate the quantities of migrants who landed in each country (they were sometimes counted twice, or not counted at all), it is also difficult if not impossible to follow their paths across EU borders once they leave or escape from the first reception center they were assigned to.

Another infographic for which it was difficult to gather reliable enough data is the one about the times for processing asylum requests in different countries (Fig. 8).

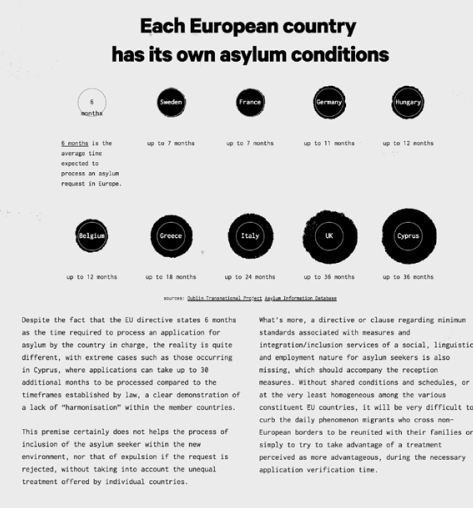

Fig. 8. Time for asylum's processing, Europa Dreaming, 2016. 
Even though the European normative on this matter establishes that the maximum timeframe to process an asylum request has to be no longer than six months, the single countries are far from respecting the law and usually take much longer. The unpredictability of the waiting time, which makes migrants float in a limbo for several months, if not years, is expressed through the movement of dripping and imprecise style of the black circles. The measure of their area should stand for the maximum waiting time for the migrants, but the animated overflowing of their border gives no certainty about it. The figurative reference to ink, bureaucracy and dribbling liquid enriches the image with further meaning which does not settle in the mere communication of numbers.

\section{Conclusions}

In the case study we analyzed above, animation has the three functions mentioned at the beginning of this paper: it draws attention; it creates meaningful transitions and, above all, gives additional connotation to numerical display. If animation is always perceived as the inclusion of a time element in a graphic, in the case analyzed the time that is depicted is a time of waiting and helplessness. The movement of swarming and the absence of clear borders in the visualization also introduces the issue of uncertainty in the data retrieved. 


\section{References}

1. Arnheim, R. (1954). Art and Visual Perception. A psychology of the creative eye. Berkeley, CA, USA: University of California Press ( $2^{\text {nd }}$ ed. 1974).

2. Cairo, A. (2012). The Functional Art: An introduction to information graphics and visualization. Berkeley, CA, USA: New Riders.

3. Healey, C.G. (2012). Attention in Visual Memory in Visualization and Computer Graphic in IEEE Transactions on Visualization and Computer Graphics. Volume: 18, Issue: 7, July 2012.

4. Finke, T., \& Manger, S. eds. (2012). Informotion: animated infographics. Berlin: Gestalten Verlag.

5. Neurath, M. (1946), Isotype in Films. Neurath (Marie), "Isotype in films" in ScannanJournal of the Portlaoghise Film Society 1, 3. Republished in: http://isotyperevisited.org/1946/06/isotype-in-films.html

6. Purdon, J. (2016). Modernist Informatics. Literature, Information and the State. Oxford: Oxford University Press.

7. Tufte, E.R. (1983). The Visual Display of Quantitative Information. Cheshire, CT: Graphics Press.

8. Tufte, E.R. (1990). Envisioning Information. Cheshire, CT: Graphic Press.

9. Virilio, P. (2009). "Stop Eject" in Native Land. Stop Eject. (Virilio P., Depardon R., Diller Scofidio + Renfro, Hansen M., Kurgan L., Rubin B.). Paris: Actes Sud. 


\title{
Is what is visually believable necessarily true? The case of JACHALAY an "informative" film
}

\author{
Eleni Mouri \\ Assistant professor of animation, Graphic design department \\ TEl of Athens, Greece \\ mourye@teiath.gr
}

\begin{abstract}
Who are JACHALAY? Who could refer to and discuss about the Jachalay with certainty? Probably no one. They have been there, just over the centuries. We could only estimate and guess, since there is no communication at all".

"Jachalay" film (2012), is the thesis film of students Manos Gerogiannis and Giannis Zoumakis for the Graphic Design department of TEl of Athens.

The film's main idea is: Can somebody narrate the most blatant lies in a believable way?

Francis Vanoye's believed that in the development of narrative in literature and cinema, the signifier is developed in the form of expressive material and expressive form, while the signified in the conceptual material and conceptual the form.

So the following question appears: Which expressive form will be used in the signifier, to make the signified as much as possible believable?

At the same time the informative animation is the main instrument to visualize complex information, fast and clear, because the dramatic elements used in inform animation, aim to explain and inform. Inform animation uses info graphics in motion that means moving optical information representations of elements and knowledge; aiming at the fast, clear and direct communication. This communication uses visualized symbols and the viewer decodes them automatic.

In this context, we analyze the particular film by using it as a case study of how one could narrate the most absurd lies in the most believable way using infographics and animation language

Mainly, through this case study, we deal with the following questions:

- When we use fake information or plausibility half-truths, it is possible this audiovisual material to contain propaganda?

- How easy is through the artificial image, which is so easily created today, to become the recipients of misinformation?
\end{abstract}

Key Words: animation, info-graphics, informative animation, signifier, signified, propaganda, misinformation, verisimilitude 


\section{Introduction}

Arts evolution is parallel to the involvement of companies in the artistic institutions and their cohabitation with the mass culture. Company sponsorships of great artistic events or organizations cultural production aid this reconciliation. Therefore, the artist has been transformed from an activist who impeaches into a celebrity. The result of that is a general spiritual guidance of political aims: what Gramsci called hegemony.

Antonio Gramsci believes that hegemony as means of spiritual guidance or leadership in the cultural and social aspect of society. He explain that, for a particular group or class, in order to secure hegemony, it would not be necessary for them to take control of the state coercive mechanism. They would have to claim the "cultural domination", meaning the mind of the people. They would have to impose and redefine "common sense" according to their goals. This way, they could found general consent without securing the voluntary consent by supporting the state repressive mechanism. [1]

\section{Animation as a cultural product}

Nowadays, art is embraced by technology, assisting in the mass production of art. The same happened with anti-culture - the art of activists who oppose to the hegemony of the neo-liberal culture - which has been respectively helped by technology. Narrative animation has connected filming with painting and sculpture, and photography with graphic design. I has influenced as well the presence of nonreal narration in cinema. Gradually, this mix is established as a rule, which leads to the creation of a new narrative model.

By the other hand information is more direct when it is expressed through symbols. The result is the rapid visualisation of complex and clear information. The goal is to enrich the viewer's knowledge regarding a particular subject, an opinion and transmitting messages by guiding the audience towards an aim. Narrative information is being used on the signifier, while the signified is known-scientific material.

The structure of inform animation can be developed in three levels, depending on the desired target group; the visual attraction of the viewer, the understanding of the information and the maintenance of the transmitted knowledge through time.

\section{The case study movie}

The central idea of "Jachalay" movie [2] sets the following question: Could a signified become believable, if the signifier is truthful? The signifier is expressed through 
animation and infographics for maximum conveyance of reality. However, the signified is a lie.

The narrative form of the movie, the signifier, follows the linear narration of a documentary, meaning a non-dramatized narration. Documentary is a cinematographic type which describes reality. Therefore this non-dramatized narration distances the viewers who therefore accept that what they see as a description of reality. "Jachalay" contains interview shots [3] - however, everything the interviewees say are lies -, animation and digitally manipulated historical photographs. "Jachalay" uses as well infographics, of fake medical representations, in order to convince the audience of the presence of medical research. So, the signifier (form) becomes beautiful and truthful while the signified (content) are constructed lies. Narrator's language in most shots of the film, is English, which offers an extra layer of validity for Greek audience. Greek subtitles are used when necessary.

\section{Conceptual and cinematic analysis of the film}

The movie begins with eight shots of the first scene. All shots are from medium close until extreme close up. The camera is always eye-levelled for directness.

The focus is on one middle aged "actor", in his office, in front of several bookshelves, who says that he saw certain creatures called "Jachalay" but they did not affect his life. The actor's figure refers to the average literate European, therefore somebody who cannot be easily convinced by the any phenomenon. He speaks in English, placing the narration in northern Europe.

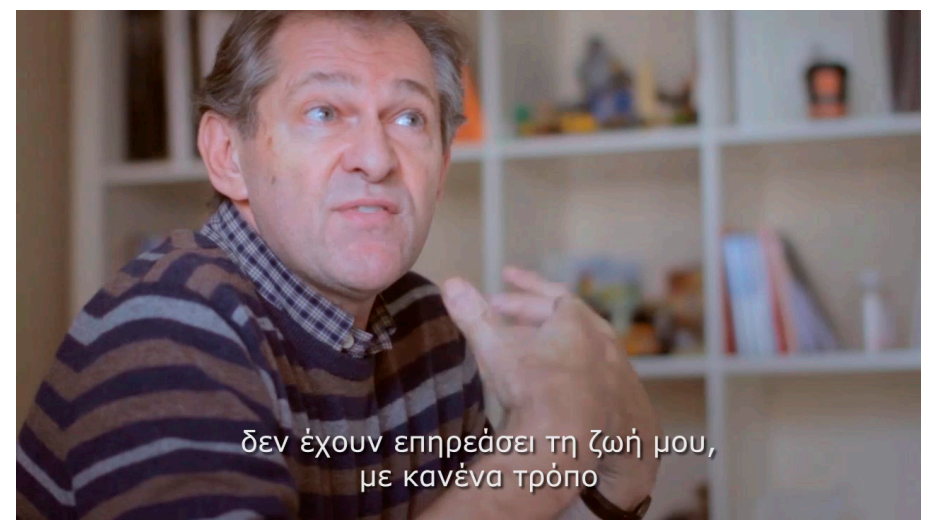

Fig. 1.

The next shot is introduced with dissolve in the titles scene, whilst the narrator is setting the main question; who could explain what are the "Jachalay"? 


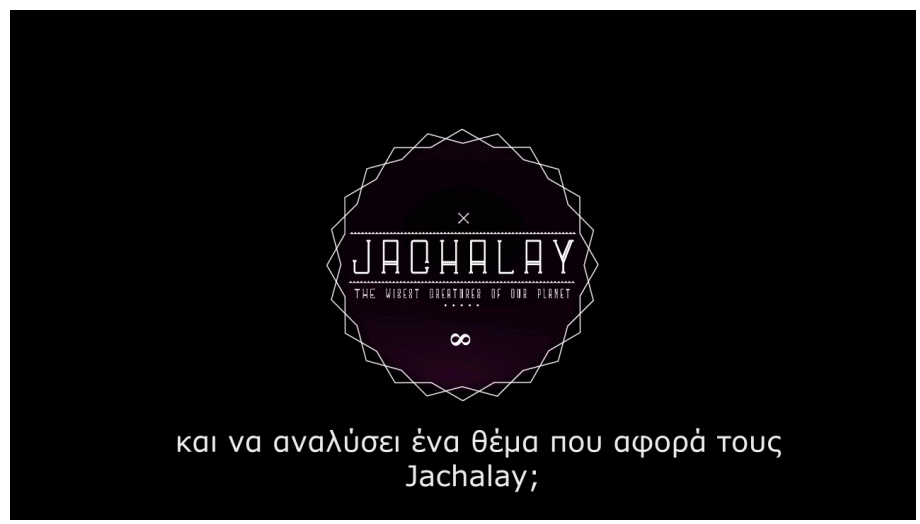

Fig. 2.

Next scene is post produced: three different European landscapes, with water as their common element, contain a "Jachalay" creature. The narrator explains there has never been any communication between humans and "Jachalays". Hence it is evident that they exist everywhere but they remain uninvolved in everything around them.

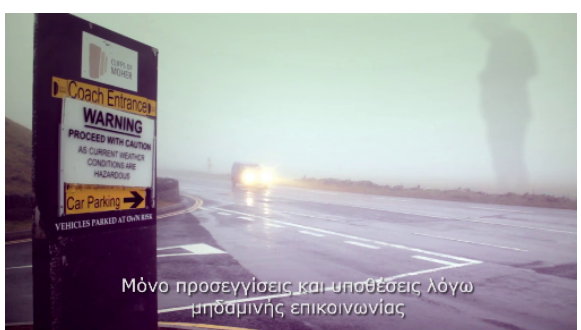

Fig. 3.

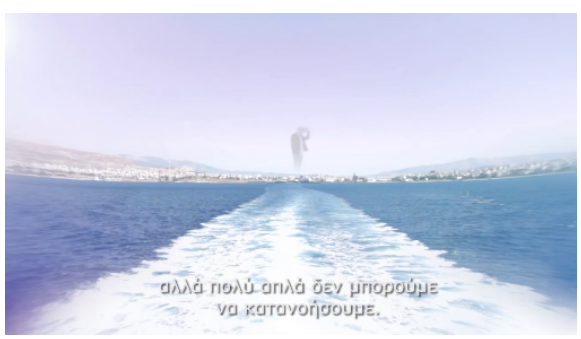

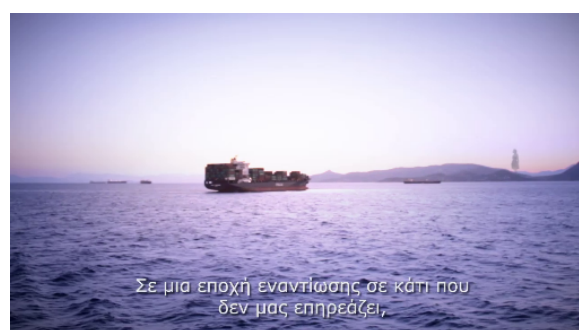

Fig. 4.

Fig. 5.

The fourth scene, an interview, is composed by five shots filmed in the Central Public Park of Athens. The shooting is medium and extreme close up where the camera is aiming a bit higher (little plongee) from the main subject. In that way the actor is transformed to a friendly character to the audience. The interviewed is a young 
Greek speaking man, a chilled out character who is claiming that all beings have a reason to exist.

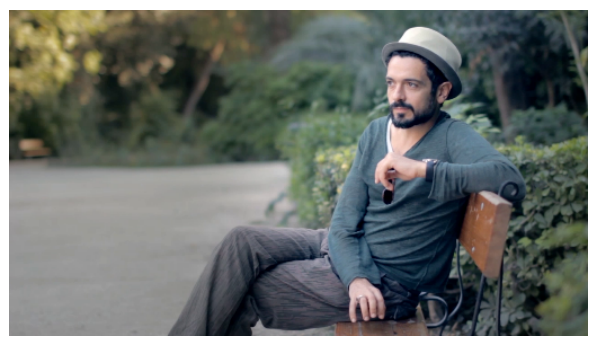

Fig. 6.

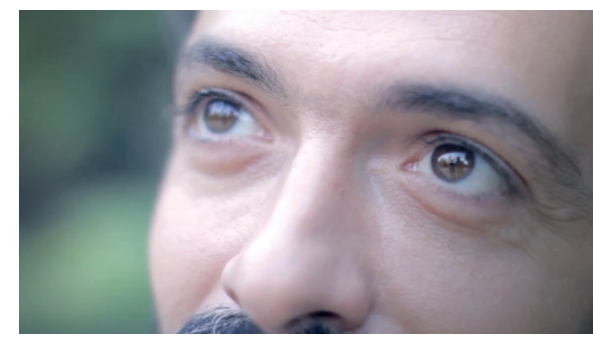

Fig. 7.

The fifth scene is a single shot, situated in North Europe where for the first time a "Jachalay" figure is moving. This suggests, that "Jachalays" are alive.

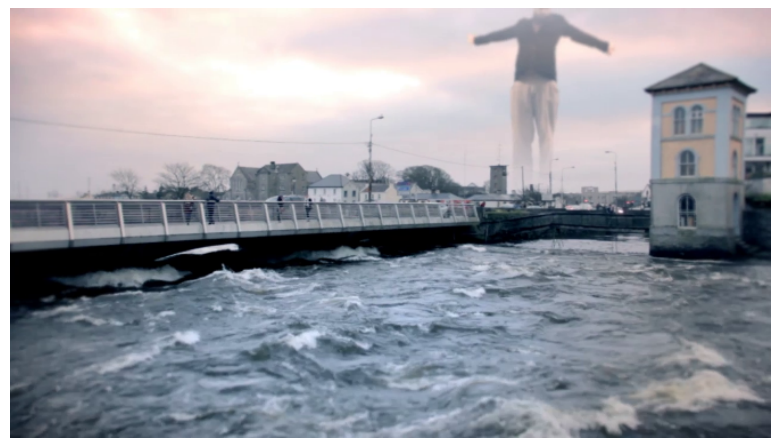

Fig. 8.

Sixth scene, an interview, situated in North Europe as well, begins with a full shot of someone stopping a middle aged lady in the street. The next five shots are close ups in order to emphasise the lady's facial expressions. She's narrating about witnessing "Jachalays" herself.

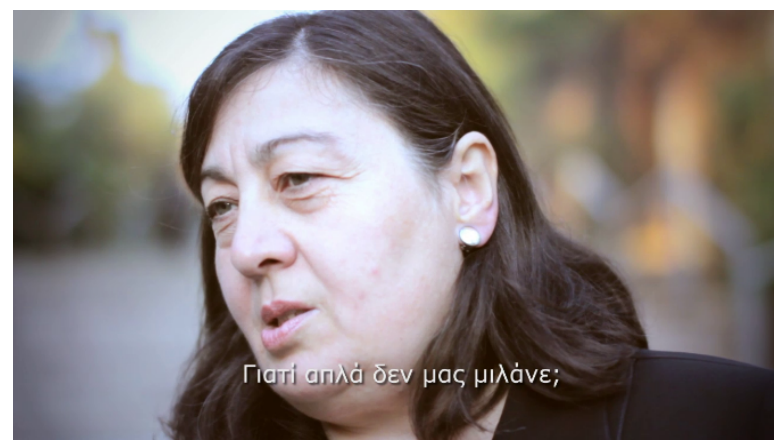

Fig. 9. 
Seventh scene is animated.

Rudolf Arnheim says: "A good image avoids pointless detail and chooses its features accurately by transmitting the important information with clarity." [4]

Following that remark, four shots presenting "medical" material, switch like an old view master in order to give the sensation of archive images. The narrator (voice off) describes that this material has been recently found, implying as well their old nature. This is also supported from the illustration's style which resembles to Leonardo Da Vinci's anatomy drawings.

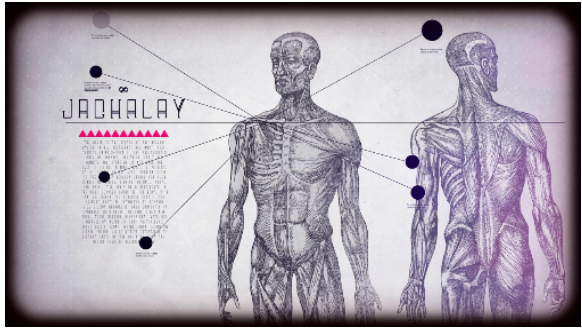

Fig. 10.

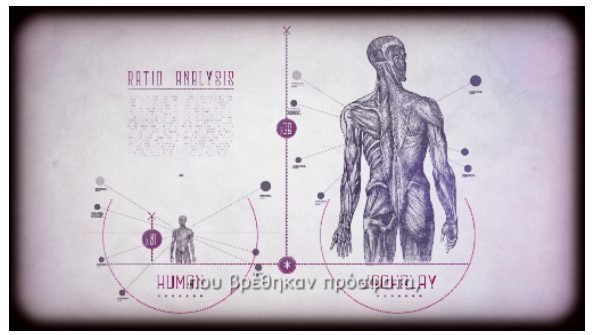

Fig. 11.

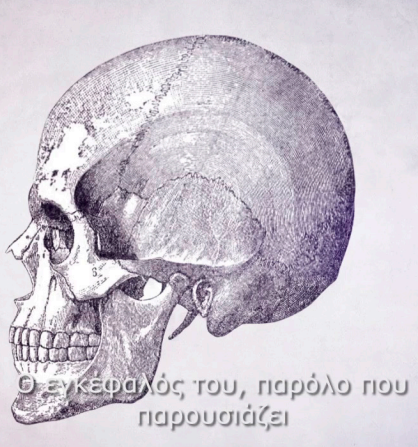

Fig. 12.

The last illustration, is a skull which dissolves and reveals a brain.

The old fashioned illustration becomes "alive" through informative animation and colour, which transfer the audience to the present. The narration reveals that the differences between a human brain and that of a "Jachalay", have been discovered. The informative animation is being enriched with additional elements which explain, the differences, visually with the use of abbreviations and descriptive text... 


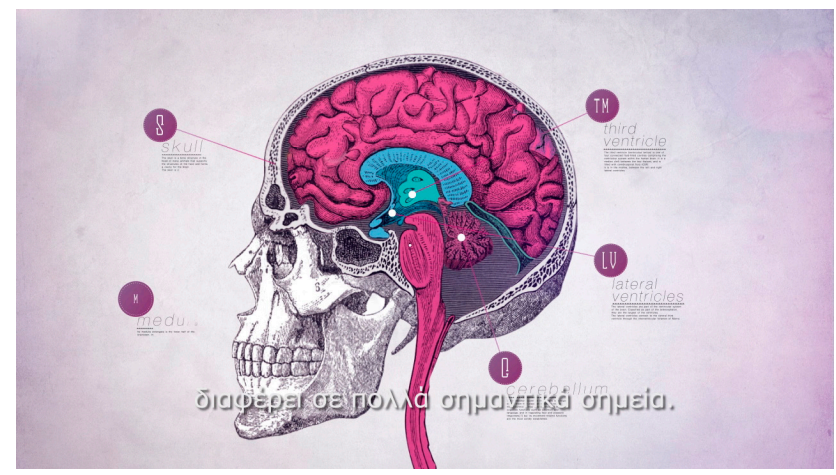

Fig. 13.

...whilst the details on what differentiates the human brain from "Jachalay"s are being fully "mentioned"...

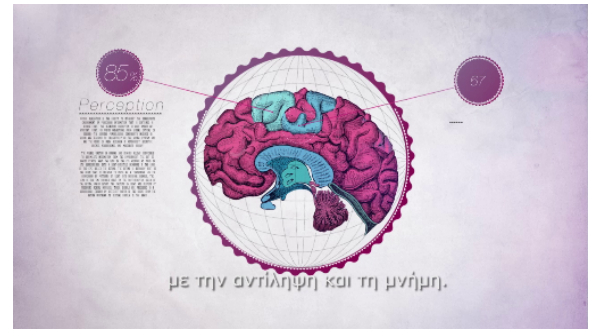

Fig. 14.

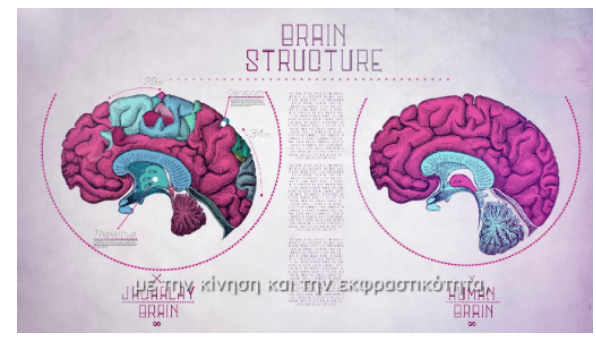

Fig. 15.

... and it gradually concludes to the two brains images so that "we can see" their differences.

The use of informative animation for the signifier, underscores validity, works like "evidence".

It describes "scientifically" the body differences by the use of medical illustrations. The comparative analysis of the two "brains", of this shot functions as a condensed conclusion. So, everything which has been previously narrated looks like scientific facts.

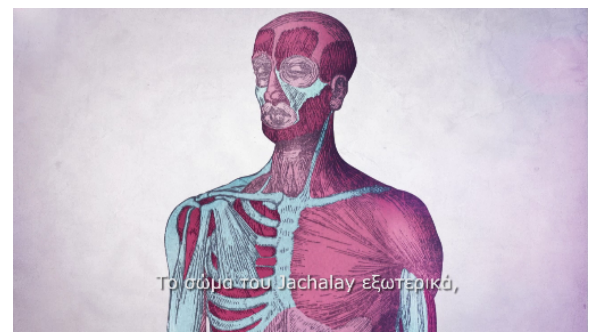

Fig. 16.

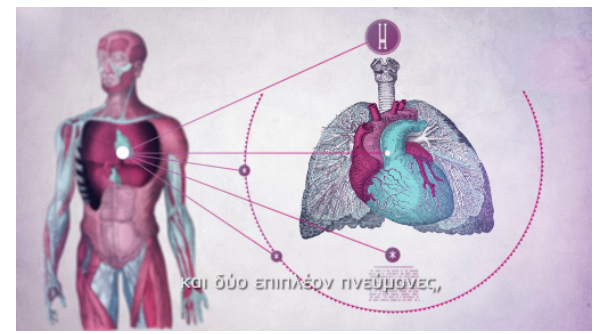

Fig. 17. 


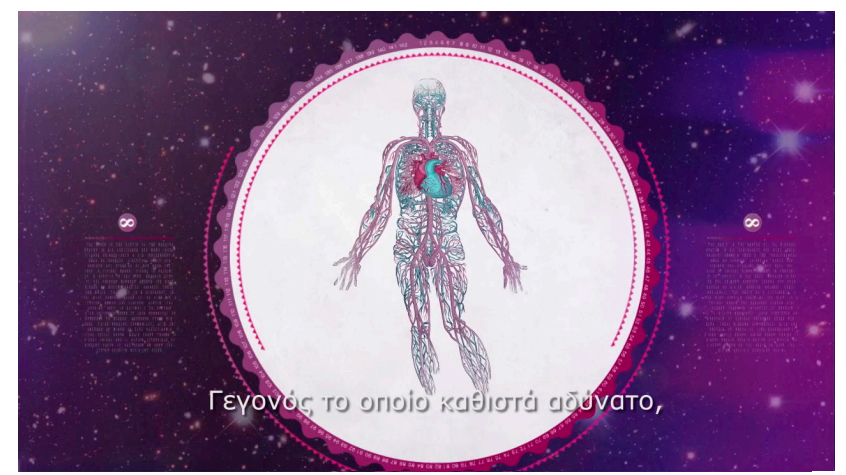

Fig. 18.

Next shot presents an illustration of Atlas. The absurd conclusion that follows this shot is that Atlas, who is lifting the World in his arms, is, perhaps... their originator!

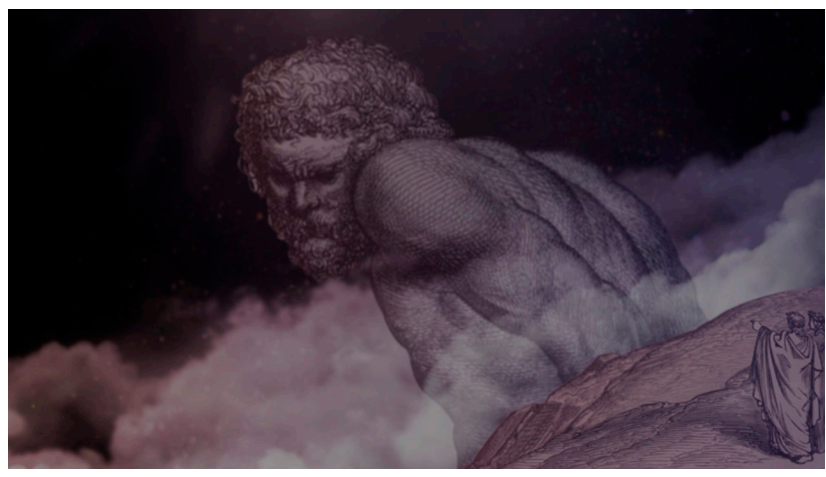

Fig.19.

Eighth scene contains digitally manipulated well known historical photos. "Jachalays" are dressed each time in a specific historical era's clothing. This choice emphasises the validity of facts.

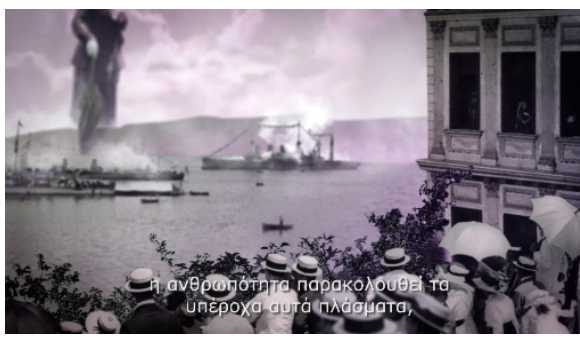

Fig. 20. End of $18^{\text {th }}$ century at the riverboats.

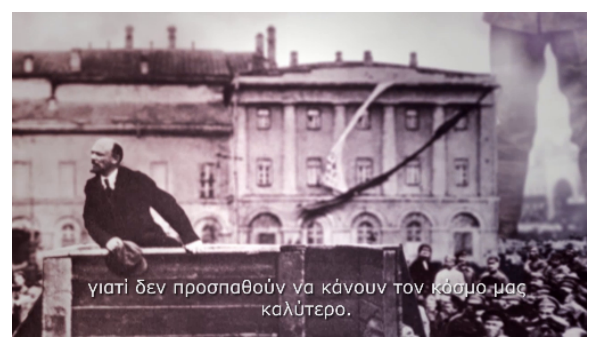

Fig. 21. Beginning of $20^{\text {th }}$ century, Russia, October revolution. 

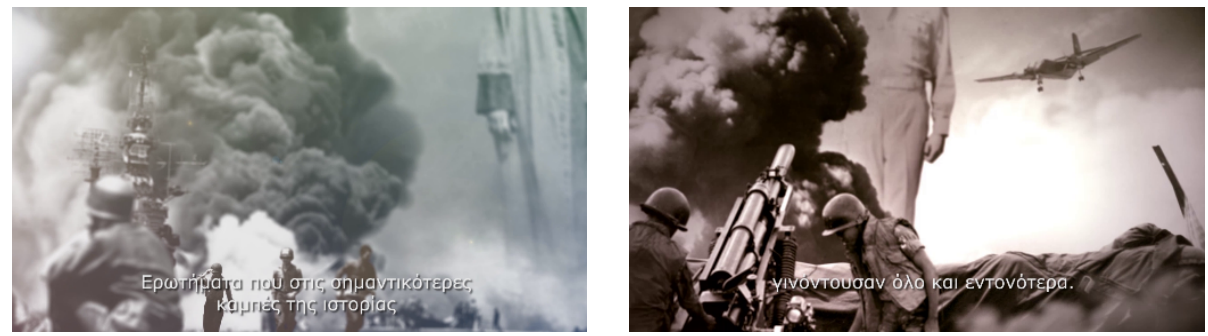

Fig. 22, 23. $2^{\text {nd }}$ World War, mid-20 ${ }^{\text {th }}$ century.

Ninth scene is composed by live shots: an old Greek man who has experienced Second World War, is describing what he "saw". He says that during bombarding in Greece, "Jachalays" were always present.

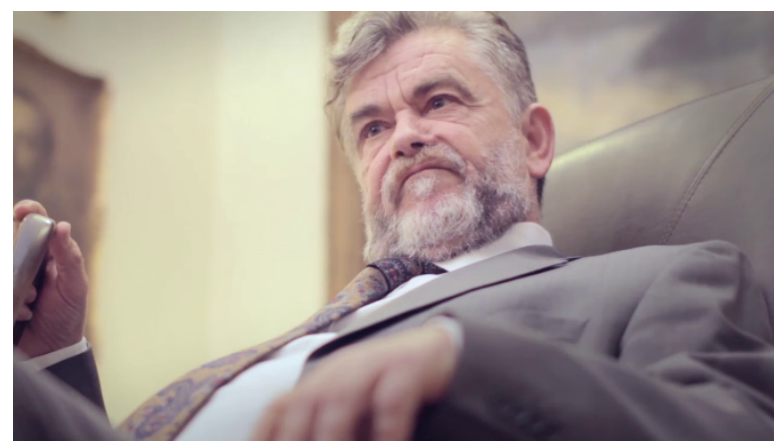

Fig. 24.

The fourth shot, is a complete reconstruction of historical photos, following the previous narrative model.

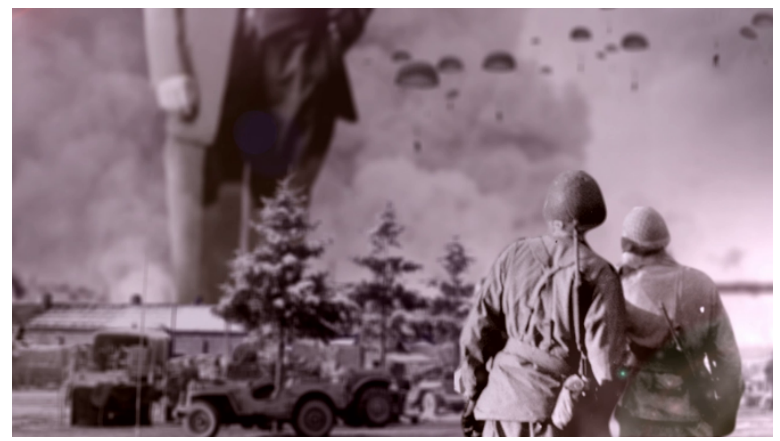

Fig. 25.

The narration continues with four close shots of the seated actor. In the fifth medium shot, he narrates whilst standing up, looking directly at the camera which is placed in a lower level than him. The camera angle implies the tension created by his words... 


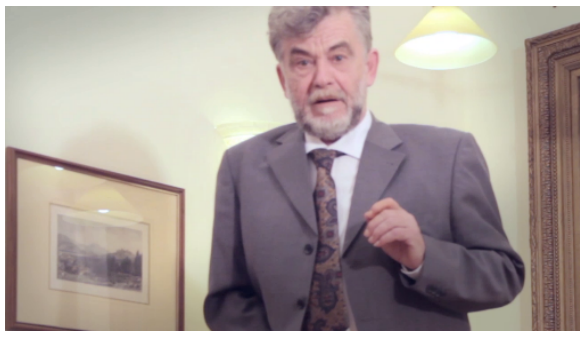

Fig. 26

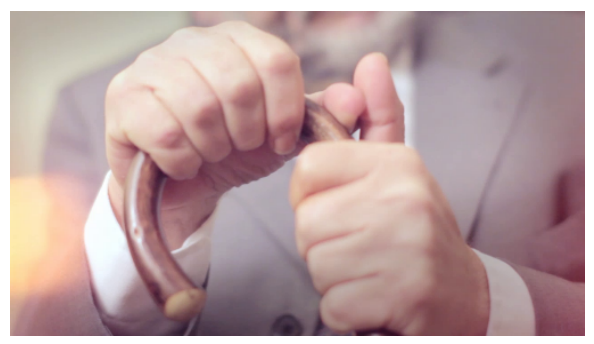

Fig. 27.

In the tenth scene, the shots are external. Through compositing the "Jachalay" figures, are placed in different landscapes.

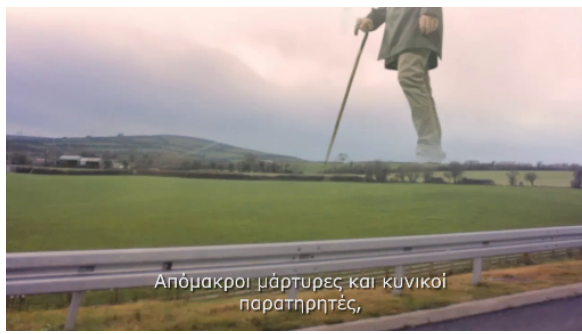

Fig. 28.

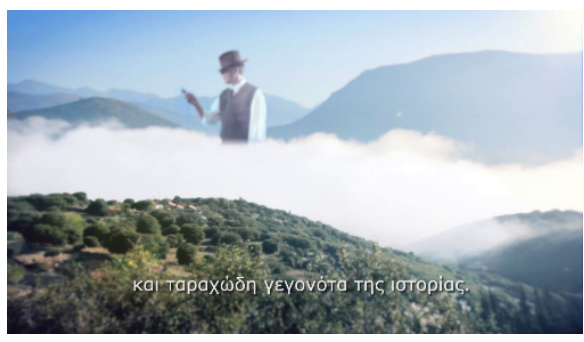

Fig. 30.

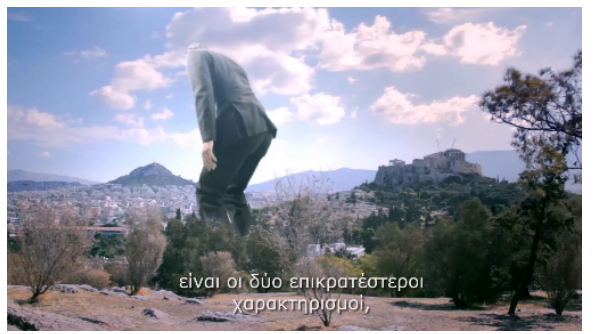

Fig. 29.

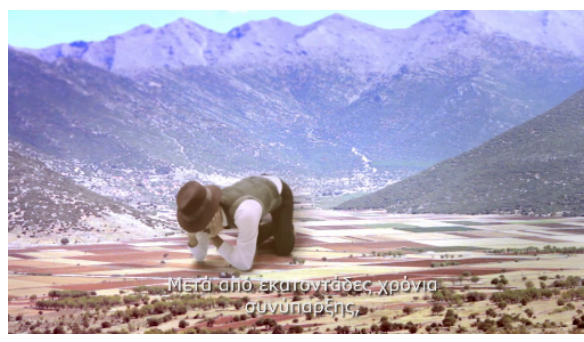

Fig. 31.

In the eleventh scene, through a time jump, the young greek man in the park while being interviewed comes to the conclusion that "Jachalays" never offered anything to the humanity. Next shots conclude all interviews with similar declarations.

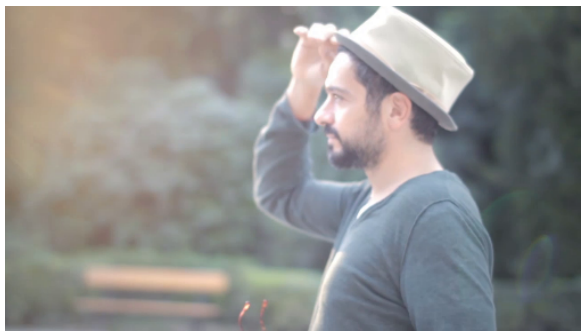

Fig. 32.

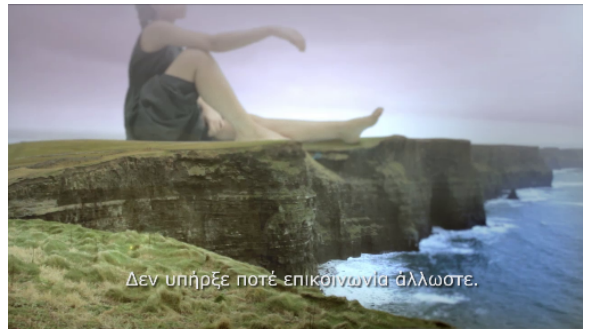

Fig. 33. 


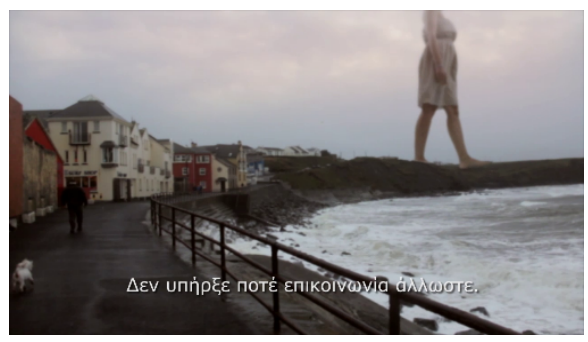

Fig. 34.

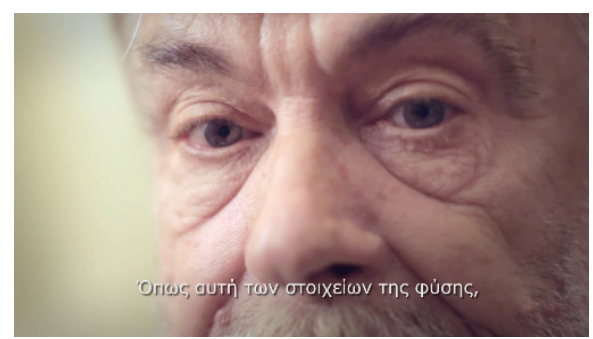

Fig. 36.

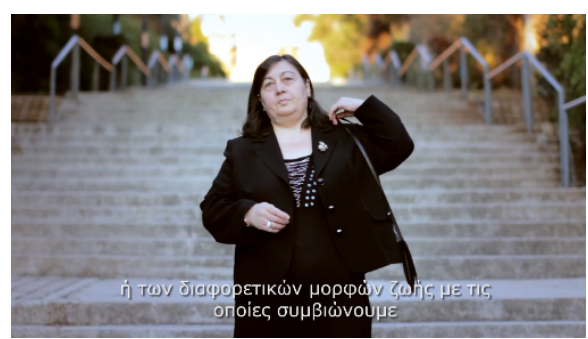

Fig. 38.

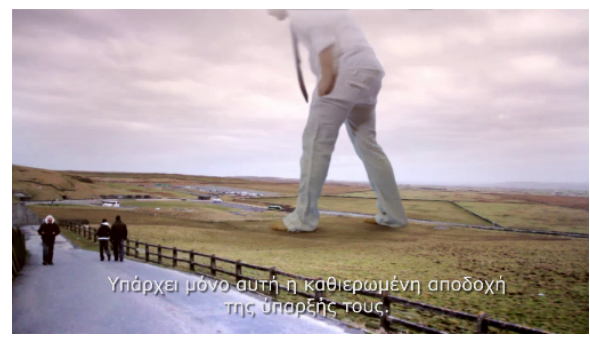

Fig. 35.

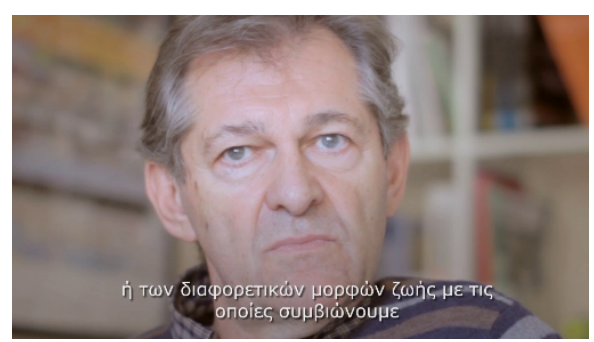

Fig. 37.

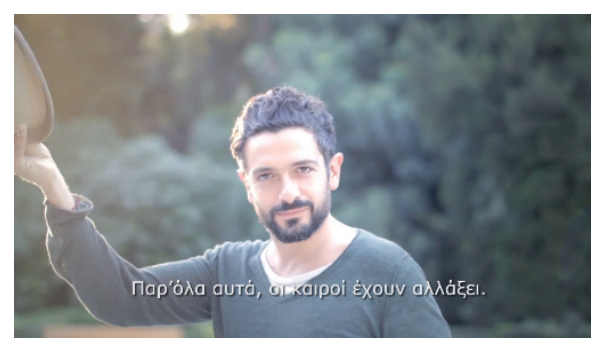

Fig. 39.

The final scene introduces a young girl as the "problem solver".

"Is there really a "why"? "Since I remember myself, they simply existed.", she says, before leaving the frame.

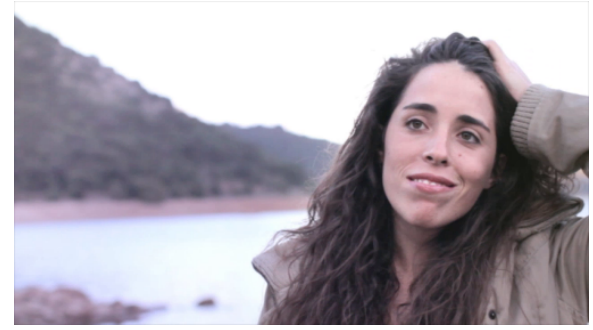

Fig. 40.

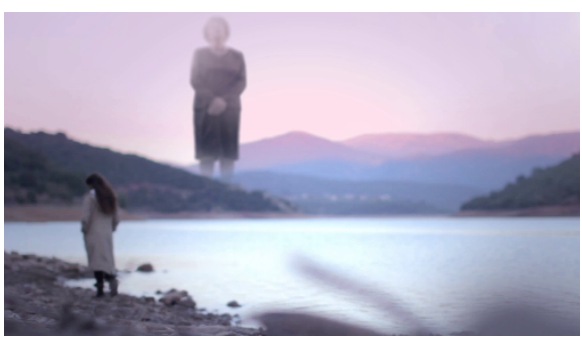

Fig. 41. 


\section{The aim of the case study film}

In "Jachalay" film, the signified is fake. It is a monckumentary movie and this is quite obvious. However several narattive techniques that the above film uses can be generally used in order to misinform.

The suggested issue is the following: When the signifier is constructed in a convincing way, the signified becomes even more convincing. Visual narratives can transmit truths as well as intentional lies in a potent way.

If the transmitted information consists of fake mixed with truth facts, it is easy for the viewer to get trapped and become victim of misinformation.

Rudolf Arnheim explains that: "The appearance of every section depends on small or big scale on the structure of the whole, and the whole, respectively, is influenced by the nature of its' sections." [4]

Therefore, if part of the work includes known elements like historical photos and scientific illustrations, then the whole work looks like real.

Through the above case study, we deal with the phenomenon of propaganda, used for hegemonic purposes. We will examine several other examples that use manipulated images, in order to misinform.

\subsection{Examples}

\section{Donald Trump's campaign}

Donald Trump during his 2016 campaign referrences to the "Intercept website". Shots of refugees in Hungary, have been used during the refugee crisis of 2015, when Syrian refugees had fled from Budapest to Austria, seeking for a passage to Germany. [5]

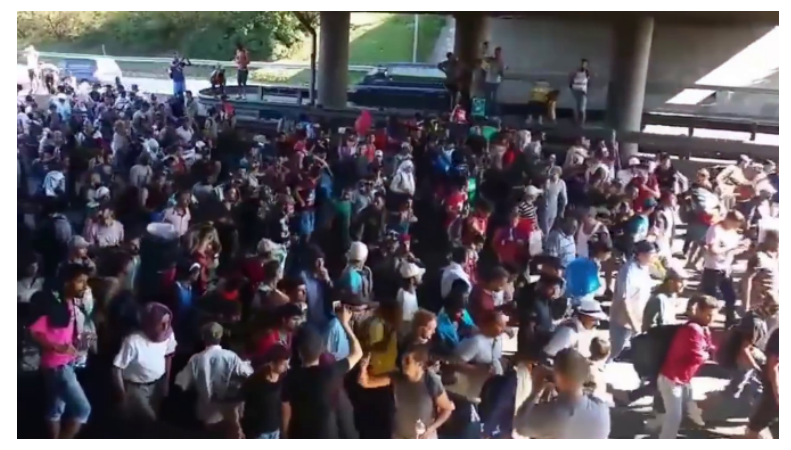

Fig. 42.

These frames were edited with his campaign video, 0.39 , presenting as the refugee hordes were crossing the borders of the USA from Mexico, making them convincing as they relate to real events happening in the USA. 
The video has been shot by a foreign reporter for New York Times. He confirmed at the website Intercept that he did not approve the use of plans in the advertisement. "Being a son of Palestinian refugees who benefited from the generosity of Jordan, a naturalized American who had been accepted to the country even after 9 September, and working as a war correspondent, the last thing I wanted was to use these shots to" dress " the Tramp's xenophobic and abhorrent message, says Nabih Boulo.[6]

\section{SIGGRAPH 2017}

\section{Synthesizing Obama: Learning Lip Sync from Audio}

In the SIGGRAPH 2017 conference, the researchers Supasorn Suwajanakorn, Steven M. Seitz and Ira Kemelmacher-Shlizermanfrom University of Washington, presented Synthesizing Obama: Learning Lip Sync from Audio [7]

Audio and visual material of Barack Obama's speeches was used. The researchers reconstructed the material in a way that an unreal conversation existed in a real time. Although the researchers used legit sound material for their study, they seamlessly reconstructed and detoured Obama's phrasing. The plethora of audio - visual material of Obama led to his selection. It proves that misinformation can happen in Media.

"Given audio of President Barack Obama, we synthesize a high quality video of him speaking with accurate lip sync, composited into a target video clip. Trained on many hours of his weekly address footage, a recurrent neural network learns the mapping from raw audio features to mouth shapes. Given the mouth shape at each time instant, we synthesize high quality mouth texture, and composite it with proper 3D pose matching to change what he appears to be saying in a target video to match the input audio track. Our approach produces photorealistic results". [8].

\section{Social media}

\section{Website Ellinika hoaxes}

The below example involves transmitting racial hate.

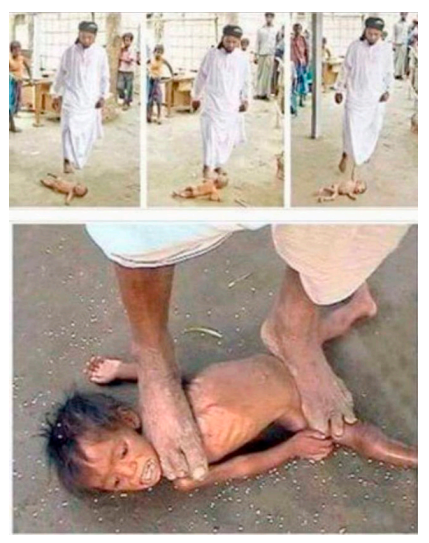

Fig. 43.

Under the title, "He was unlucky to be born by Christians in an Islamic country. They were exemplary murdered!" [9] 
It is a photo collage. The three top photos show Amzad Fakir, Bangladeshi energy therapist, who was arrested beginning of 2010 due to his method of practice.

The other photo shows another energy therapist from Indian, called Jamun Yadav, who claims to be half-god and who transmits energy to toddlers' necks through his feet.

The point is that these rough pictures are followed by a massive headlines which promote hate between two different religions.

\section{The other side of the coin}

Chantal Mouffe, in "Democratic paradox», poses the following question:

"Is it still possible for the artistic practices to play a critical role in the society where the difference between art and advertising becomes, gradually, more vague and where the artists and workers of culture have become one with the capitalistic production?"[10]

The answer is yes. The same narration and means can be used in favour of activism. The overturn of the information and art embracement with the neoliberal political theory, comes through various pathways. These practices can contribute to the questioning of the leading hegemony, by using the same means but with honesty.

\subsection{Examples}

\section{Website Beautiful Trouble}

"The Beautiful Trouble is a book, web toolbox and international network of artistactivist trainers whose mission is to make grassroots movements more creative and more effective". [11]

In the site presented an interactive info graphic all the information about theTactics, Principles, Theories, Case Studies and Practitioners of the most popular movements on the world. [12]

This is an example of world complexity communication on activism.

\section{Artistic practises}

\section{Reclaim the streets}

New artistic activism is trying to question the current consent by various means.

Respectively, the critical art foments the dispute and reveals everything that the leading consent and political correct. The artistic praxis seeks to give a voice to everyone who's being condemned by the remaining hegemony.

The new artistic activism is trying to question the current consent by various means. Civilian movements like "Reclaim the streets" [13] "Our streets are as full of capitalism as of cars and the pollution of capitalism is much more insidious" says RTS at the M41 London on $13^{\text {th }}$ July 1996. 


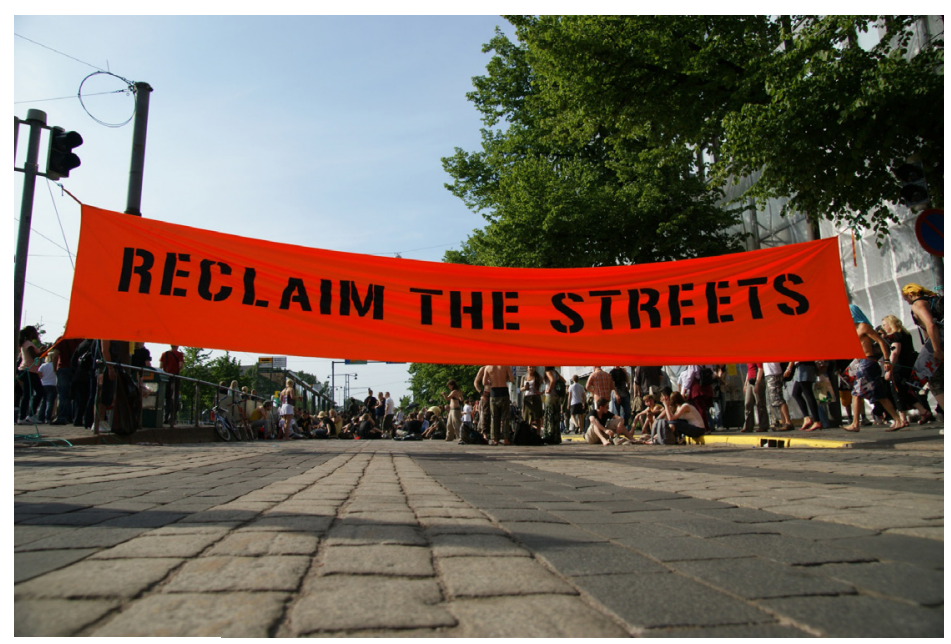

Fig. 44.

\section{Occupy Wall Street}

Another civilian movement, the Occupy Wall Street (OWS) was become as a protest movement on September 17, 2011, in Zuccotti Park, in New York City's Wall Street financial district. The central slogan "We are the 99\%" refers to the global economic inequality. At October 15, 2011 receiving global attention and spawning the movement against economic inequality worldwide as present it the info graphic. [14].

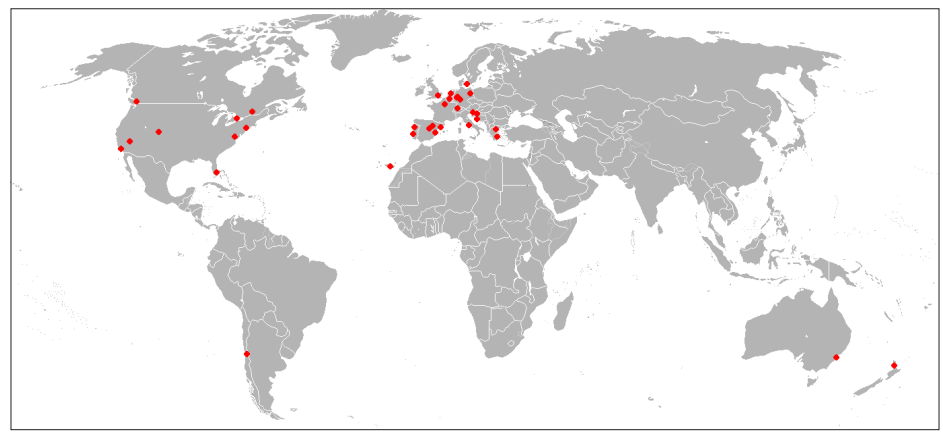

Fig. 45.

As in website [15] write, "Occupy Wall Street is a leaderless resistance movement with people of many colors, genders and political persuasions. The one thing we all have in common is that We Are The 99\% that will no longer tolerate the greed and corruption of the 1\%. We are using the revolutionary Arab Spring tactic to achieve our ends and encourage the use of nonviolence to maximize the safety of all participants". 


\section{The Yes Men}

"The Yes Men" question how to use internet and performance in "the Identity Correction". This is an example of overturning propaganda.

The commencement happened with the change in the boxes of the recorded speech of Barbie and G. I. Joe, where appealing the Media's attention was proved to be easy. This is the weapon of their political sabotage.

"We discovered people and institutions who commit terrible actions against others and we familiarized with their identities, in order to correct them. Correction of identity, instead of identity theft."

The first identity correction took place in 1999 in Bush's election campaign. After claiming the GWBush.com domain, they uploaded the "corrected ID" of the governor. On the official website Georgebush.com, the governor described himself as an ecologist, supporter of education and helper of the weak, whilst on the corrected version one could see all the information about the governor which was hidden from the average American.

Another famous correction identity is this for the website of WTO to GATT [16] (General Agreement on Tariffs and Trade). At Finland 2003, in a conference of textile industry, a "WTO spokesman" presented the future of formal work wear. [17]

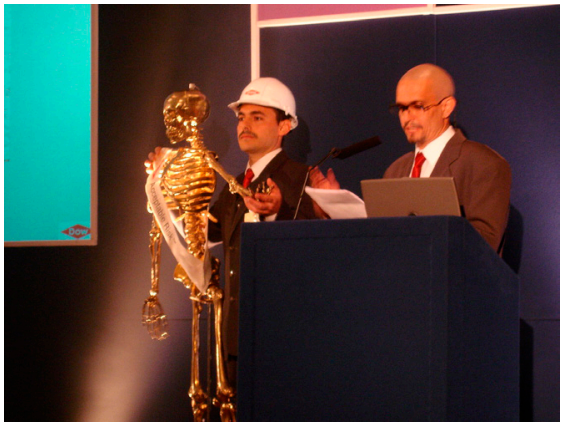

Fig. 46. Gilda, the mascot of Acceptable Risk Calculator, an idea of Dow Chemical's representative, "Erastus Hamm" 28/04/2005

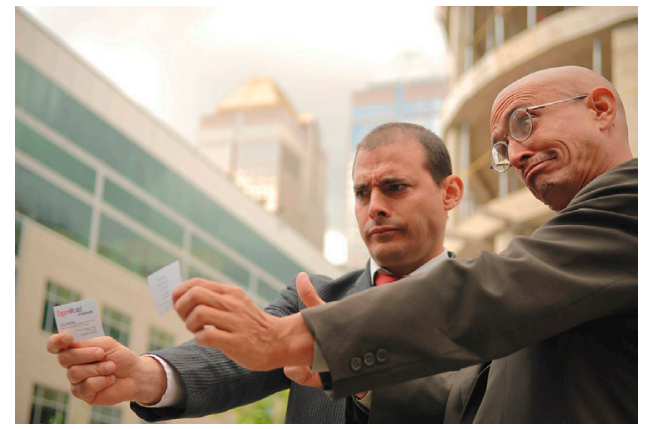

Fig. 47. Andy Bichlbaum and Mike Bonannopose as ExxonMobil executives.

Their actions can be found online on http://theyesmen.org.

The Yes Men, called "the Jonathan Swift of the Jackass Generation" by author Naomi Klein, are best known for infiltrating the world of big business and doing incredibly stupid things to expose the world's biggest corporate criminals. Although fronted by Andy Bichlbaum and Mike Bonanno, their membership includes hundreds or perhaps thousands of secret agents, all of whom were recently acquired in a hostile takeover by the Yes Lab. 
At the moment, the Yes Lab is mainly a series of brainstorms and trainings to help activist groups carry out media-getting creative actions, focused on their own campaign goals. It's a way for social justice organizations to take advantage of all that we Yes Men have learned - not only about our own ways of doing things, but those we've come in contact with over the decade and a half we've been doing this sort of thing. The Yes Lab has offices and work shopping space at NYU's Hemispheric Institute in New York. yeslab.org [18]

\section{Conclusions}

Consequently, Antonio Gramsci's "cultural hegemony" is being achieved with not only the dependence of mass media from economic factors and their involvement with politics, but and with our personal use of mass media and social media. The narcissistic "likes", benefit the pointless over-information, the projection of unimportant and extends misinformation and sciolism. The multi-level evaluation has transformed into accepting or not accepting a fact in a binary system. This results to limitation of critical thought and alienation of people's perception of the world and to the existence of spiritual leadership of the people. Therefore the user should not look for impressive images and easy text of the easily accessible information, which they forget later. The research and evaluation of information from the user themselves is a way of avoiding the phenomenon of misinformation.

Accordingly, the modern educational systems are questionable as their fundamental base of developing the critical thought is needed for a broader approach and limitation of misinformation. 


\section{References}

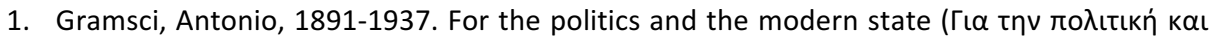
үıа то бúүxроvо кра́тоৎ) Imeresia Athens 2010

2. https://vimeo.com/153368150, https://www.behance.net/gallery/9303965/Jachalay

3. Anna Grimshaw, Amanda Ravetz. Observational Cinema: Anthropology, Film and the Ex-

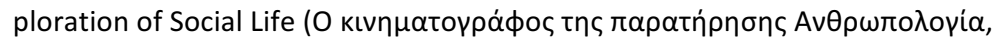

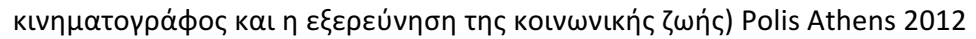

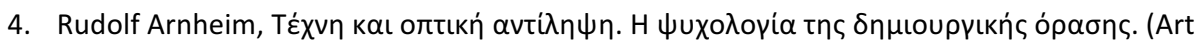
and visual perception, a psychology of creative eye), University of California Press, 1974. Themelio, Athens 2005

5. https://www.youtube.com/watch?time_continue=2\&v=vST61W4bGm8

6. EvageliaBifi article $06 / 11 / 2016$, To Vima (To $\beta$ ń $\mu \alpha$ ) newspaper http://www.tovima.gr/world/article/?aid=842417

7. SIGGRAPH 2017 Full Video: https://www.youtube.com/watch?v=MVBe6_o4cMI

8. https://grail.cs.washington.edu/projects/AudioToObama/siggraph17_obama.pdf

9. http://ellinikahoaxes.gr/2016/03/23/facebook-foto-xristianoi-islam/

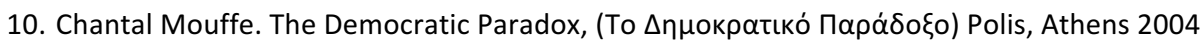

11. http://beautifultrouble.org/

12. http://explore.beautifultrouble.org/\#-1:01110

13. http://rts.gn.apc.org/

14. https://en.wikipedia.org/wiki/15_October_2011_global_protests

15. http://occupywallst.org/

16. https://www.wto.org/ to http://www.gatt.org/

17. $h t t p s: / / w w w . y o u t u b e . c o m / w a t c h ? v=G E u z V M w s K 7 o$

18. http://beautifultrouble.org/practitioner/yes-men/ 


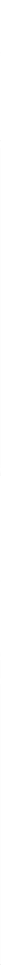




\section{Full papers}

4 : Info-Environments 


\title{
Visual Tools for a Multiple Cross-reading in the Exhibition Context
}

\author{
Alessandra Bosco ${ }^{1}$, Elena La Maida ${ }^{1}$ and Michele Zannoni ${ }^{1}$ \\ 1 Università degli Studi della Repubblica di San Marino, Dipartimento di Economia, \\ Scienze e Diritto, Repubblica di San Marino \\ \{alessandra.bosco, elena.lamaida, michele.zannoni\}@unirsm.sm
}

\begin{abstract}
As researchers who participate in common studies, we need a tool for reading and understanding collected data in its complexity, for analysing and researching the relationship between records at various levels of information within the database, and for getting them networked. This paper presents our project for a visual tool characterized by an interface based on an interactive system for data visualization, which can be configured as required. Graphs and diagrams become part of the process and tools for verifying and enhancing the state of the research.
\end{abstract}

Keywords: visual interactive tool / data visualization / database interface

\section{Text}

In the research program "Enhancement of the cultural heritage in exhibition and museum contexts through the use of new technologies" which began in September 2016 at the University of San Marino, we worked within a contemporary context that is not still completely historicized and not critically addressed. We collected data from traditional sources such as books and articles in scientific journals, but even in exhibition catalogues, designer websites, online blogs and exclusively oral sources such as interviews. After eight months of work on information gathering and data systematisation - with the aim of defining the advancement and the potential of using new digital technologies in the design of exhibition contexts - we experienced how the data could conceal information rather than reveal it.

Today research programs regardless of the disciplinary field of study, often expect that a few people simultaneously pick up information as they interact with wider resource ecosystems, in which contents are increasingly becoming available by free access [1]. So, day after day, sharing, they receive a large mass of data in which they must orient themselves [2].

The variety of the data, systemized and ordered in structured databases, may be queried and filtered. Generally, the different queries lead to identifying an author, a reference, a place, a date, a project or more elements of the same or different 
typologies. The results are often displayed in textual forms that so not provide any hierarchy or links or even associations among data. In this way, researchers don't have an immediate feedback in reading the queries and find it difficult to manage the complexity of the references they have collected.

As researchers who participate in common studies, we need a tool for reading and understanding the data collected in their complexity, for analysing and researching the relationship between records at various levels of information within the database and getting them networked [3]. The aim was to be able to interrogate the data as a whole, systematically ordered, collected and filtered according to parameters and relationships defined in advance, in order to originate dynamic, generative and immediate reading narrations $[4 ; 5]$.

The research led to the development of a project with an interface based on interactive tools for data visualization, that can be configured as required. Graphs and diagrams become a part of the process and tools for verifying and enhancing the state of the research. Scholars can in fact visualize the data to check the accuracy of the stored information, verify any gaps in the collection of data, but also rely on keywords and parameters to understand the connections between records and visualize various narrations.

Following the preliminary process of data collection, representative of the current state of exhibition design, we proceeded to systematize the results choosing parameters to facilitate both cataloguing and searching inside the database.

The project for the visual tool began by observing a series of case studies in data visualization. We focused on how to display people's networks, how use a timeline to display the relationship between catalogued projects and the technology they used and how to display projects identified by keywords.

The first typology of visualization works on networks between people. (Fig.1)

In our project, nodes and relationships between designers are visualized on an interactive map. Data visualization allows us to connect different generations of designers, identifying pioneers, defining membership groups and their followers making it possible to discover the evolution of the project in this area.

We refer to: Santiago Ortiz in Lostalgic [6] (2012) - a complete representation of the scripts of ABC's television series "LOST" - and in the Twitter Company [7] - a visualization showing one week of conversations on Twitter in 2013 - which uses an articulated and dynamic navigation interface [8]. However, our main focus was on The ImpulsBauhaus [9] by Jens Weber and Andreas Wolter (2009) and the Multitouch installation [10] by the Max Planck Institute (2011); projects in which the relationships between people are visualized on interactive maps, the first developed through the use of fiducial markers [11], the second displayed on a multi-touch installation [12]. 


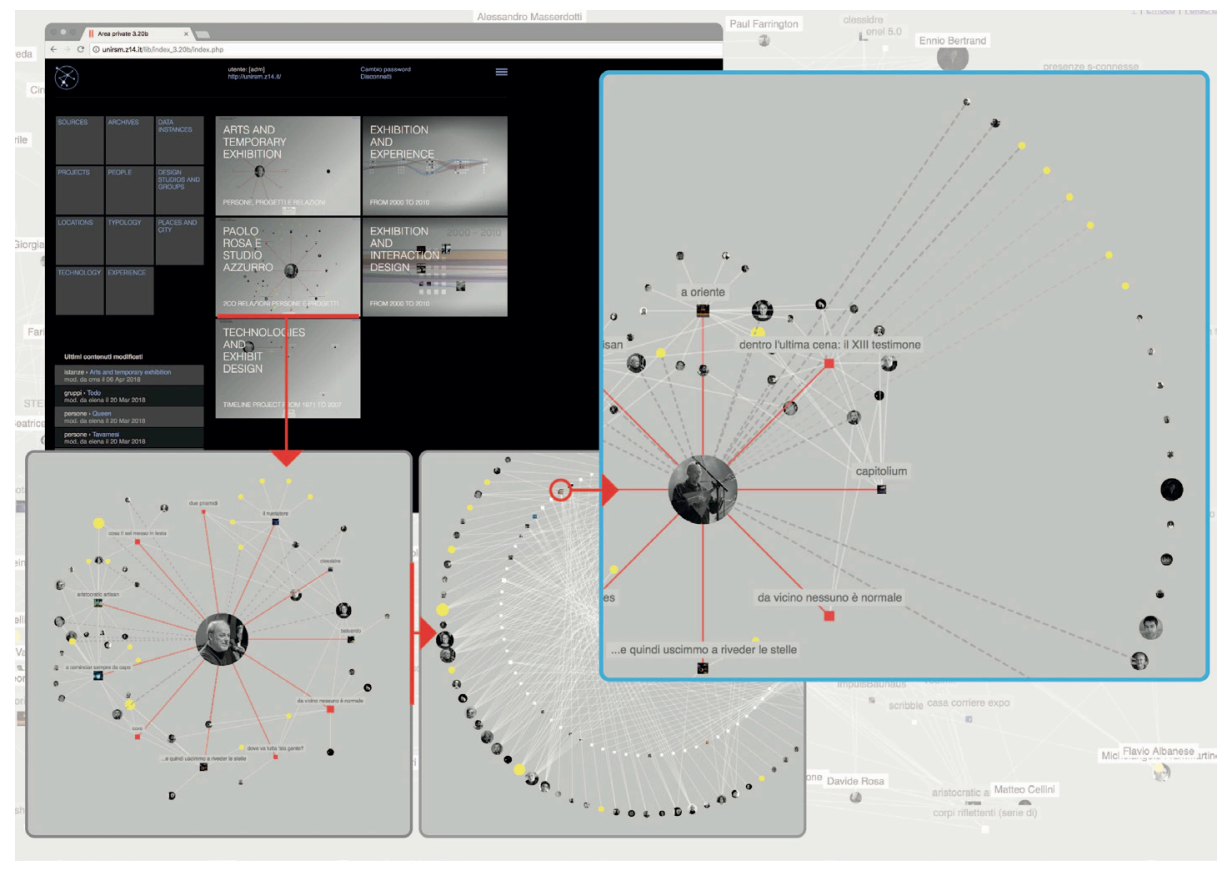

Fig. 1. An example of interactive maps integrated in the designed tool. They visualize nodes and relationships between designers and their common projects.

The second typology analyses data relating to the dimension of time. (Fig.2)

In our project this data visualization displays the relationship between catalogued projects and the technology used to realize them along a timeline. The diagrams with good accessibility and readability show the interactive system that provides the distribution of complex information in a linear development of coloured bands.

We refer to: The MIT Senseable City Lab in Spring spree [13] (2011), which visualizes the financial footprint on a geographic map, underlining consumer behaviour in a defined spatial-temporal range (BBVA bank dataset of transactions) [14]. The Ebb and Flow of Movies: Box Office Receipts 1986 - 2008 [15], by The New York Times group, visualizes Blockbuster's box office revenue and the longevity of bookings from 1986 to 2008 [16; 17]. However, we focused more specifically on The evolution of web [18] designed in 2010-2012 by The Google Research Team, an updated interactive piece based on a static infographic which represented technologies and browsers, illustrating the evolution of the system since the 1990's [19]. And in The Music Timeline [20] by the same group (2014), based on the music library of Google Play Music users, the timeline makes it possible to see how different musical genres grew or shrank in popularity through the years from 1950's to the present [21]. 


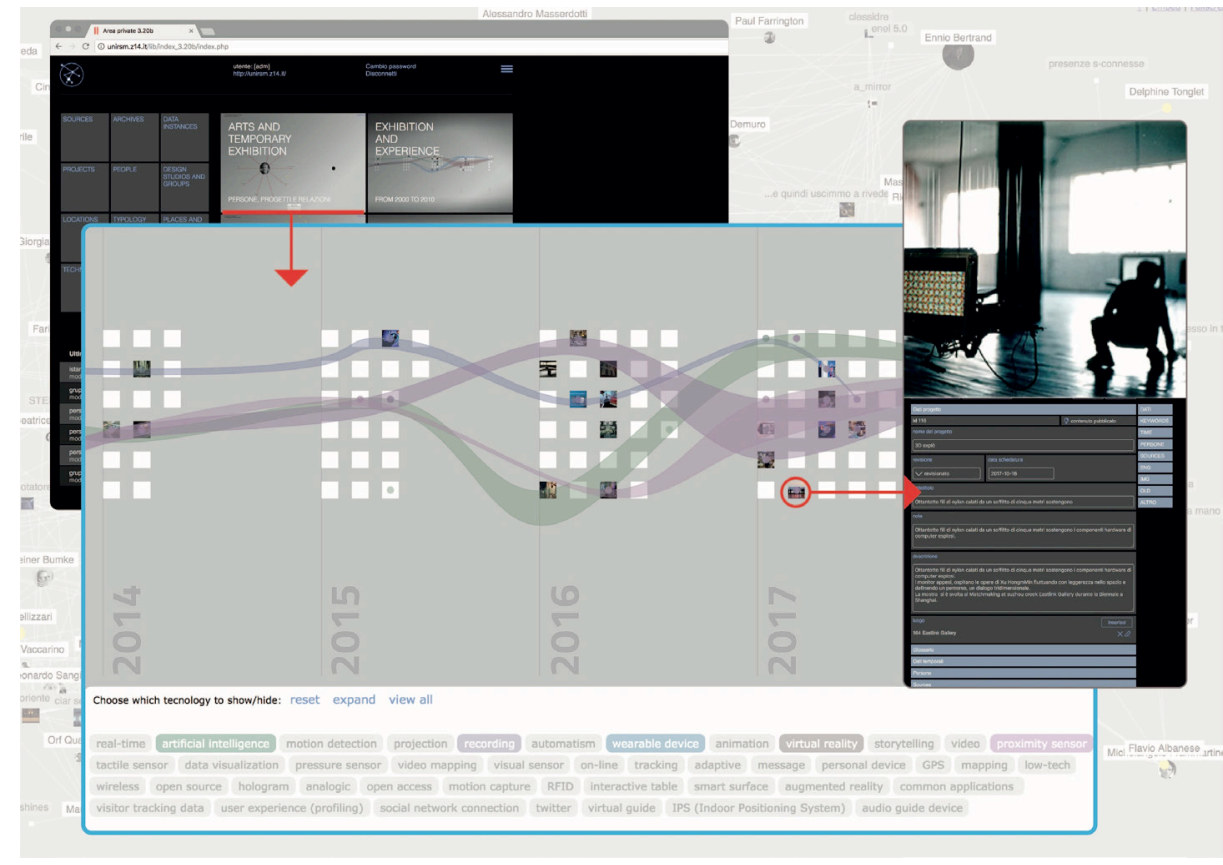

Fig. 2. An example of the visualization which relies on a timeline to display the relationship between catalogued projects and the technology used to realize them.

The third typology investigates relationships between records using keywords, parameters and filters. (Fig.3)

In our project, we explore the reciprocal relationship between the catalogued exhibition projects and the three categories of tags representative of this context: the exhibition typology, the technologies adopted and the variety of the visitor experience. We have provided an interactive network to illustrate the connections between projects through keywords.

We refer to: the website for the exhibition Design and the Elastic Mind [22], by THA Ldt. (2008), which explored the reciprocal relationship between science and design in the contemporary world using new methods of tagging and realizing an efficient contextual browsing of many works [23]. Tags [24], by Google Research Team (2016), that through Machine Learning, using picture recognition, looked at the artworks and generated thousands of tags useful for research [25]. The MIT Senseable City Labs project, Health InfoScape [26] (2011) which analyses data from over 7.2 million anonymized electronic medical records from General Electric's database and creates a disease network to illustrate relationships between different conditions and their effects on health [27]. And How Different Groups Spend Their Day [28], an interactive visualization published in July 2009 by a research group of 
The New York Time journal, which let users explore how different groups in America spend their day $[16 ; 17]$.

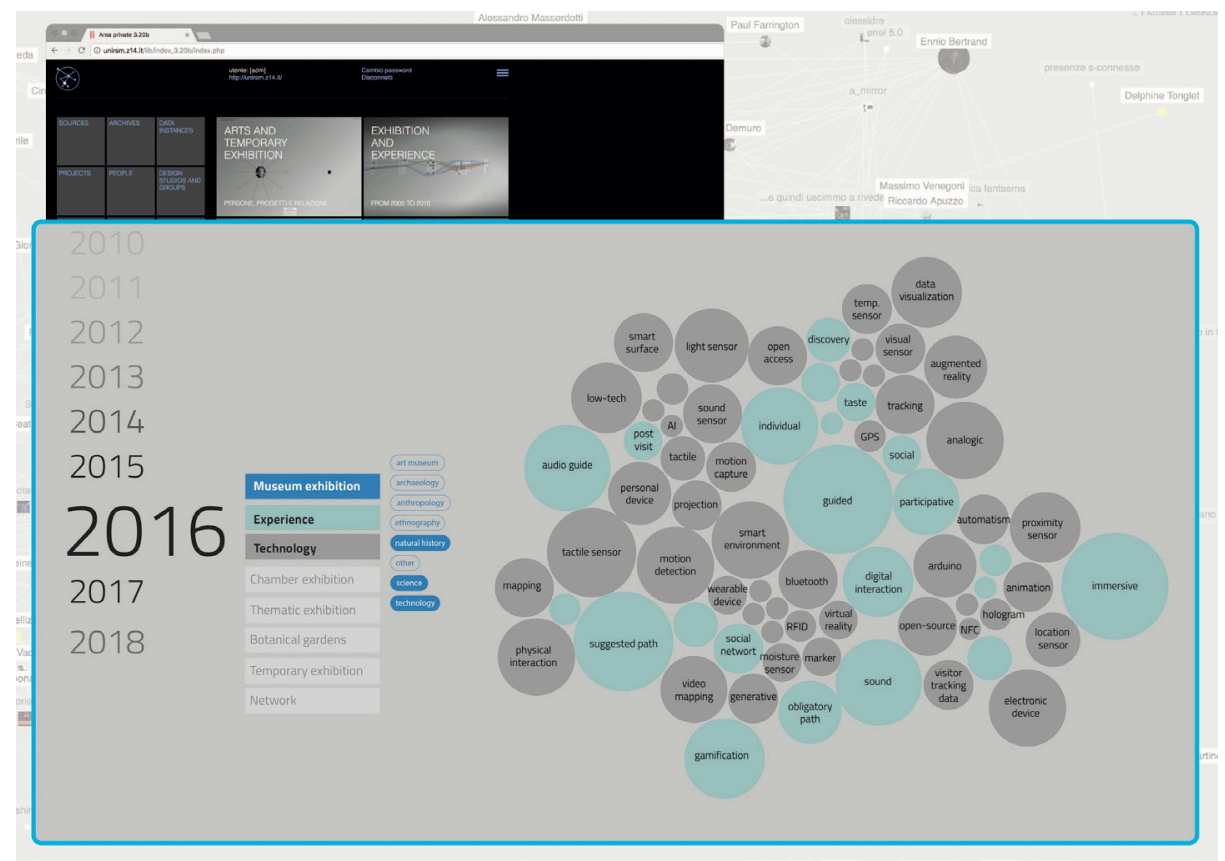

Fig. 3. An interactive visualization example that displays the relationships between the catalogued exhibition projects by tags and keywords.

\section{Conclusion}

The project of the visual interactive tool, currently under development, introduces a free access open system for verifying and enhancing the state of the research. The parameters chosen for cataloguing, which also refer to commonly used language, make the system accessible to a wide range of users.

The integration of data visualization tools into knowledge-building processes is becoming an increasingly relevant project theme, to which designers can give contribute by studying and developing new adaptive interfaces.

The most interesting challenge for the future could be to collaborate with colleagues to implement the system creating new instances and narrations for the contents, even using machine learning to analyse connections and sources. 


\section{References}

1. Dalla Mura, M. (2016, March). Storia digitale e design / 4 - Il digitale come archivio. Retrieved from: http://www.maddamura.eu/blog/language/it/design-e-storia-digitale4-il-digitale-come-archivio/

2. Manovich, L. (2009). Cultural Analytics: Visualising Cultural Patterns in the Era of «More Media». Domus, (Milan), March.

3. Manovich, L. (2012). Media Visualization: Visual Techniques for Exploring Large Media Collections. (K. Gates, A C. Di) (Vol. Media Studies Futures). Malven. MA: Blackwell.

4. Hochman, N., \& Manovich, L. (2013). Zooming into an Instagram City: Reading the local through social media. First Monday, 18(7). https://doi.org/10.5210/fm.v18i7.4711

5. Hochman, N., \& Schwartz, R. (2012). Visualizing Instagram: Tracing cultural visual rhythms (pagg. 6-9). Presented at Proceedings of the Workshop on Social Media Visualization (SocMedVis) in conjunction with the Sixth International AAAI Conference on Weblogs and Social Media (ICWSM-12).

\section{Projects and related references}

6. Santiago Ortiz - http://intuitionanalytics.com/other/lostalgic/

7. Santiago Ortiz - http://moebio.com/newk/twitter/

8. Ortiz, S. (2014, June, 13). Six Months. Eyeo Festival 2014 [Video file]. Retrieved from: https://vimeo.com/113312415

9. Mediarchitecture, - http://mediaarchitecture.de/projekte/impuls_bauhaus-interaktivertisch-interactive-table/

10. Max Planck Institutes - http://max-planck-research-networks.net/

11. Weber, J., Wolter, A., (2015). Interaktive Visualisierungen als Erkenntnismodelle am Beispiel des Projekts «ImpulsBauhaus». Geschichte und Informatik, volume (18/19), 285308. Retrieved from http://blog.ahc-ch.ch/wp-content/uploads/2015/09/12-WeberWolter.pdf

12. Elsevier's Scopus Data Drives Visualization of International Collaborative Research Networks for new Max Planck Science Gallery. (2011, September). Retrieved from: https://www.elsevier.com/about/press-releases/science-and-technology/elseviersscopus-data-drives-visualization-of-international-collaborative-research-networks-fornew-max-planck-science-gallery

13. The MIT Senseable City Lab - http://senseable.mit.edu/bbva/

14. Piovano, L., Andréu, A., Galloso, I., Feijó, C. (2015). A perceptive insight into cities patterns by visualizing urban economies. Presented at Proceedings of the International Conference on Information Visualization Theory and Applications (IVAPP) in 2014.

15. The New York Times http://www.nytimes.com/interactive/2008/02/23/movies/20080223_ REVENUE_GRAPHIC.html

16. Havre, S., Hetzler, B., Nowell, L. (1999). ThemeRiver ${ }^{\text {TM}: ~ I n ~ S e a r c h ~ o f ~ T r e n d s, ~ P a t t e r n s, ~ a n d ~}$ Relationships. In Proceedings of IEEE Symposium on Information Visualization, InfoVis '99, October 25-26, San Francisco CA.

17. Kirk, A. (2010, August). Making sense of streamgraphs. Retrieved from: http://www.visualisingdata.com/2010/08/making-sense-of-streamgraphs/

18. A.A.V.V. - http://www.evolutionoftheweb.com/ 
19. Newman, W.E. (2017). Data Visualization for Design Thinking: Applied Mapping. New York, USA: Routledge Taylor \& Francis

20. Google Research - https://research.google.com/bigpicture/music/

21. Cichowlas, A., Lam, T. (2014, January). Explore the history of Pop -- and Punk, Jazz, and Folk -- with the Music Timeline. Retrieved from: https://research.googleblog.com/2014/01/explore-history-of-pop-and-punk-jazz.html

22. The Museum of Modern Art https://www.moma.org/interactives/exhibitions/2008/elasticmind/

23. Antonelli, P. (2016). Design and the Elastic Mind. New York, USA: The Museum of Modern Art

24. Google Art \& Culture https://artsexperiments.withgoogle.com/tags/detail/\#Figure_drawing

25. Sood, A., Diagne, C. (Eds.). (17 $7^{\text {th }}$ February 2016). Every piece of art you've ever wanted to see - up close and searchable. Vancouver, Canada: TED Conferences, LLC

26. The MIT Senseable City Lab - http://senseable.mit.edu/healthinfoscape/

27. Chen, X. (2011, July). Health InfoScape. Retrieved from: http://xiaojichen.com/2011/health-infoscape/

28. The New York Times http://www.nytimes.com//interactive/2009/07/31/business/20080801-metricsgraphic.html?hp 


\title{
Shaping Complex Identities. Managing Dynamic Brands for Educational Institutions
}

\author{
Veronica Dal Buono \\ University of Ferrara, Department of Architecture, \\ Ferrara, Italy \\ \{veronica.dalbuono\}@unife.it
}

\begin{abstract}
The essay focuses on a set of case studies of educational institutes that recently turned their traditional visual identity into "dynamic". "Dynamic identities" - as defined by literature - can be considered the most innovative outcomes in branding, heavily contaminated by digital tools and strategies, including visual expressions that are variable (differing in space and time), generative (processes connecting to parametric methodologies) and even relational (emphasizing the open and participative approach with users). Design concepts as the one quoted, have reached an application and diffusion phase that warrants recognition of the results in order to transfer the knowledge to the discipline of visual communication so as to be applied in the reality of branding processes for educational institutions.
\end{abstract}

Keywords: dynamic identities / visual identity / institutional communication.

\section{To communicate educational institutions as complex organism}

The realm of cultural and educational institutions, completely incorporated into a globalized society, has clearly assimilated the principles of branding, using communication and visual design tools effectively as the world of corporations has [1].

Moving in a highly competitive environment to achieve results in terms of reputation and number of enrolled students, these organizations implement their differentiation by adopting elements of visual communication in innovative terms.

In this context, visual identity has to answer to multiple levels of purposes: it must reflect the key values which define the group, echo the core mission of the institution (knowledge exchange, talent development, public engagement), represent the complex structure of the organization and, most importantly, its community. 


\section{The shift from static to dynamic identities}

Observing the communication process, while the components of the community, both internal and external, are sending out (visual) messages, official or not official, they generate a collective opinion - an "image" - regarding the institution. This "image" is the core of the corporate identity and needs to be addressed and designed. With the rise of digital and social media, in which sender and recipient use not a one-way media (as the traditional channels) but a relational one (everyone can respond and others can see the response), even the institutional communication has become more complex and demands appropriate tools, involving the visual identity process.

It's possible to say that the level of complexity has exceeded the capability of the traditional identity, based and founded on one single trademark (logo or seal) in which the symbol communicates the same message repeatedly, never changing according to time and context [2].

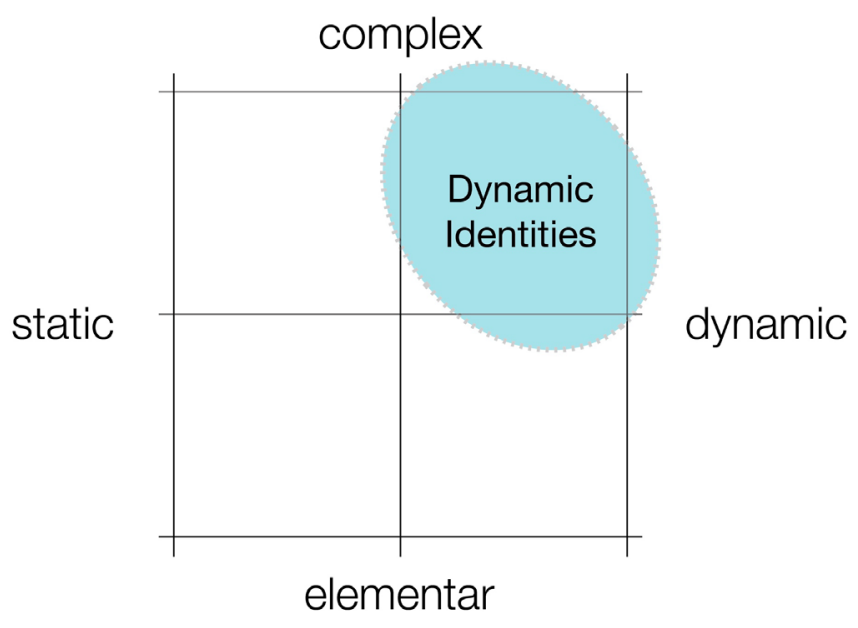

Fig. 1. The position of dynamic identities in the matrix of visual systems.

The aim of this essay is to outline a new approach occurred in shaping institutional identities, observing that in recent years there has been a considerable growing interest in re-branding institutions using dynamic visual identities.

We argue that this evolution is something more than a trend but a relevant shift of method in how educational organizations communicate themselves [3].

Dynamic brands, rather than the ultimate, pre-formulated visual message expressed by a logo, design visual languages. As a matter of fact, while a logo-based identity is the representation of a single idea, a "dynamic identity" (or "flexible" or "post-logo") [4] [5] is a system of elements that can be used by an organization as tools to formulate a multitude of different messages, adapting to varying formats, sizes and contexts. 
This could be considered as the contemporary response to the increased complexity in communication of multiple organizations.

\subsection{Highlighting significant examples}

The following case studies reveal how a systemic approach ensures the recognisability of the institution, through an overall design of multiple and flexible elements.

Let's take the Ringling College as our first example, known to be the first institution to apply an "open" and "co-designed" identity. It transpired in 2008 and has set an example for other designs [6].

The metaphor used is a window that meets a background based on the same proportions (the golden section). The background is a varying patchwork of colours and images. The innovation was that these images could be chosen by an online mechanism, by each member of the college, as a visual voice of the whole community. With this new approach the main logo becomes "relational" and each member of the community is supposed to have his own identity. The variations of contents ensure flexibility while the static frame, as the main element, confirms the recognisability. Through variations the institution can modulate its tone of voice and can shift from a single, monotonous to a multidimensional (Fig. 2).
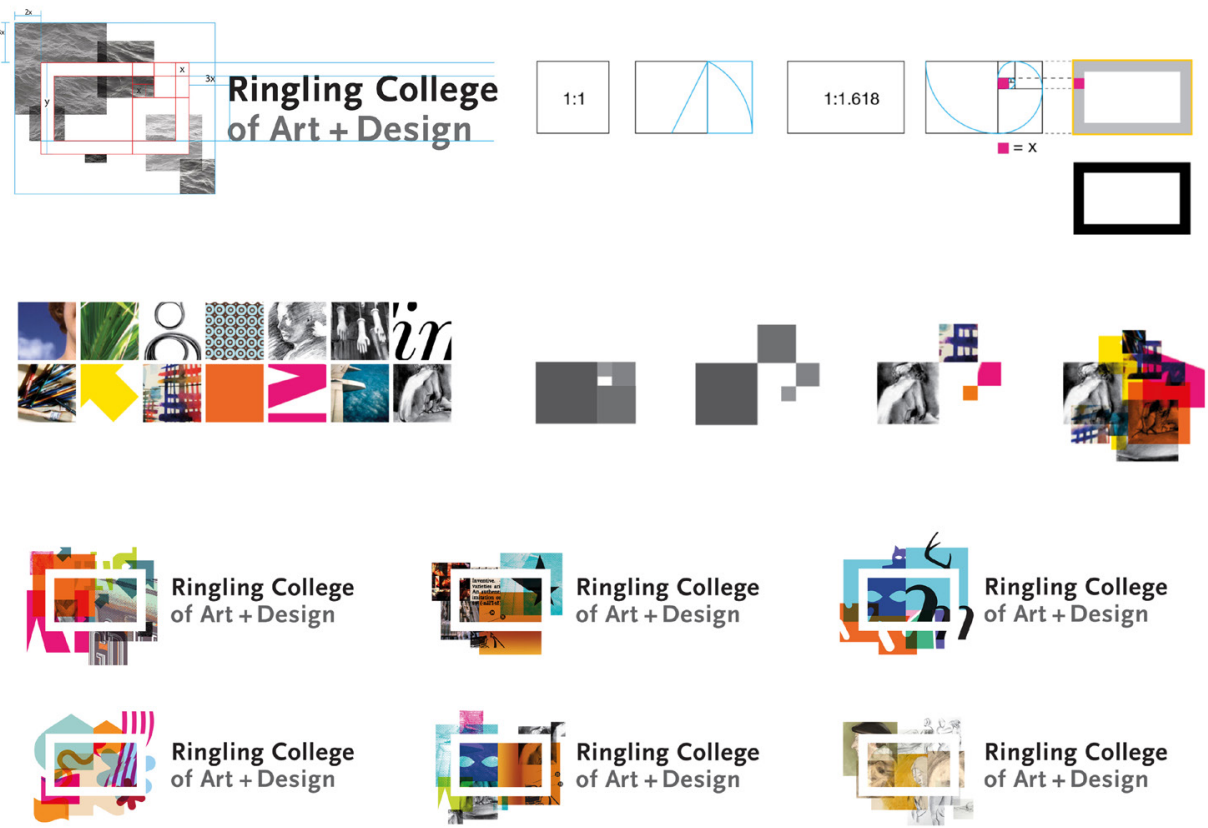

Ringling College of Art + Design

Fig. 2. Ringling College Identity by SamataMason / Collective / Multiple, 2007. 
Next example is the EAD Eindhoven Academy of Design, best known for its engagement with the student body and academic staff. As in the previous example, the metaphor is a frame and the customization is achieved through a written sign inside by each member of the Academy. (Fig. 3)

Thirdly, the OCAD Academy, in Canada, and its results of a workshop experienced by Bruce Mau with the inner students. The idea is more advanced than the previous ones. Customization is attained through drawings realized by highly qualified grad students. The coordinated image is supposed to be managed centrally by the institution (Fig. 4).

Moreover, in that same year, 2011, is the work by The Green Eyl for the Mit Media Lab. This project, so well documented in print and online resources, is no longer applied. It was one of the first projects in which Processing, the generative programme, was used to create 40,000 variations of the logo, one for each member of the Lab (Fig. 5).

Considered as a "celebration logo" of the 25th anniversary of the Lab, five years later Pentagram was asked to design a new permanent visual identity that now is applied. The difference from the previous design consists in the variations of the main logo, limited to the only 25 research centres that form the Lab (Fig. 5).
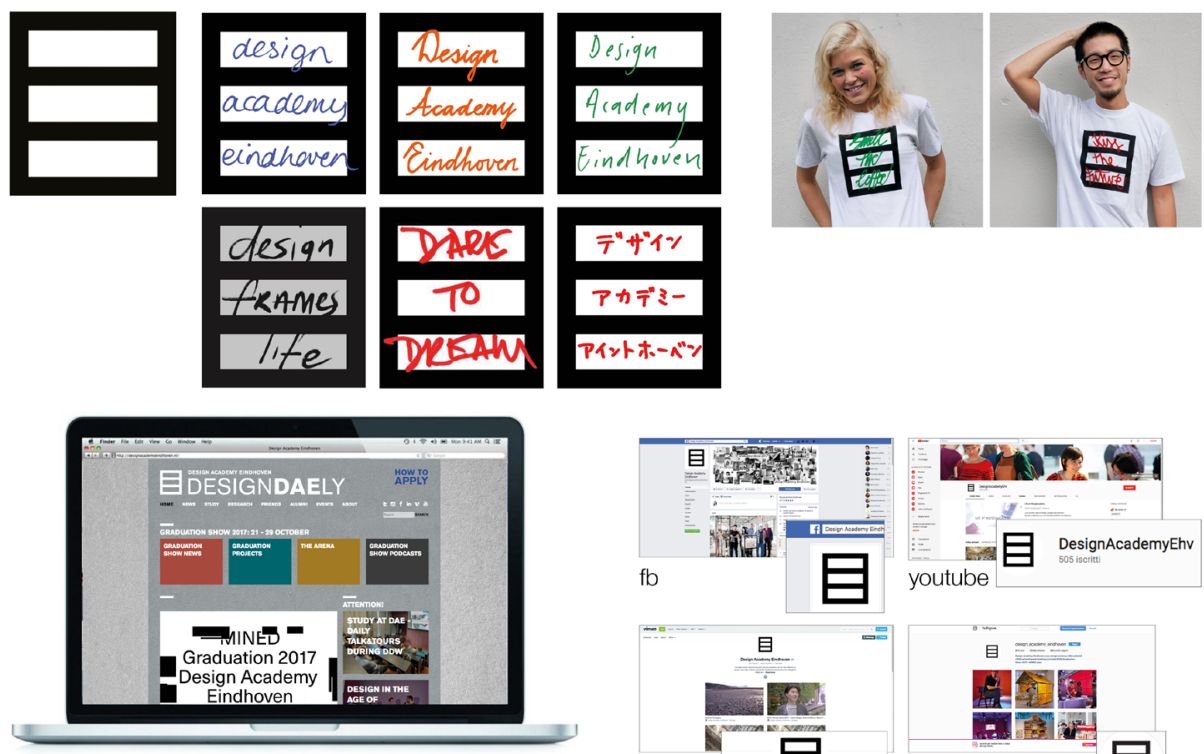

DAE website
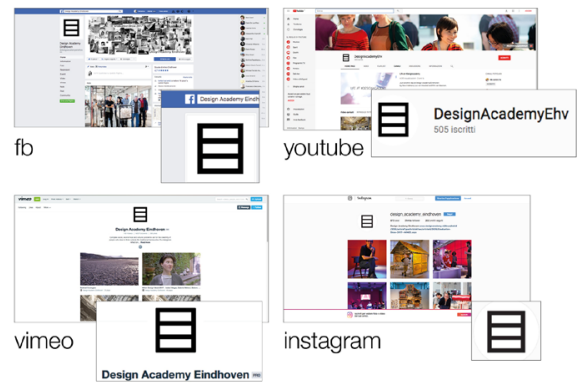

Fig. 3. Design Academy Eindhoven Identity by The Stone Twins, 2009. 

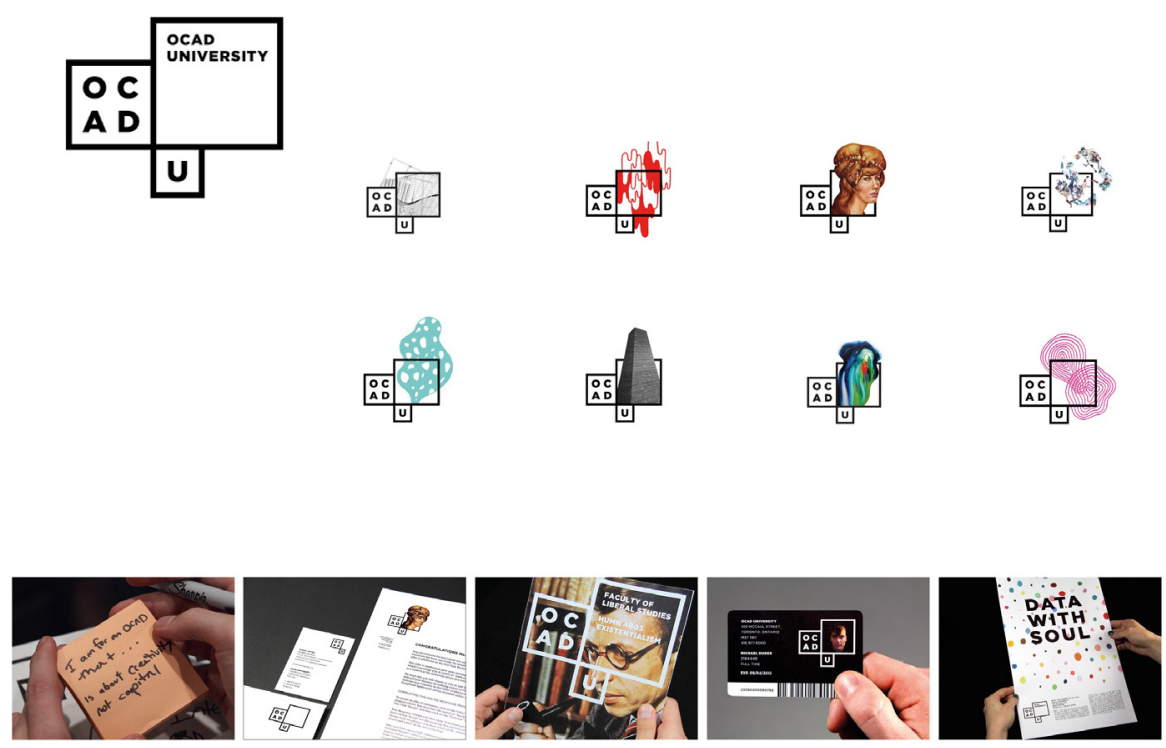

Fig. 4. OCAD University Identity by Bruce Mau with the students, 2011.
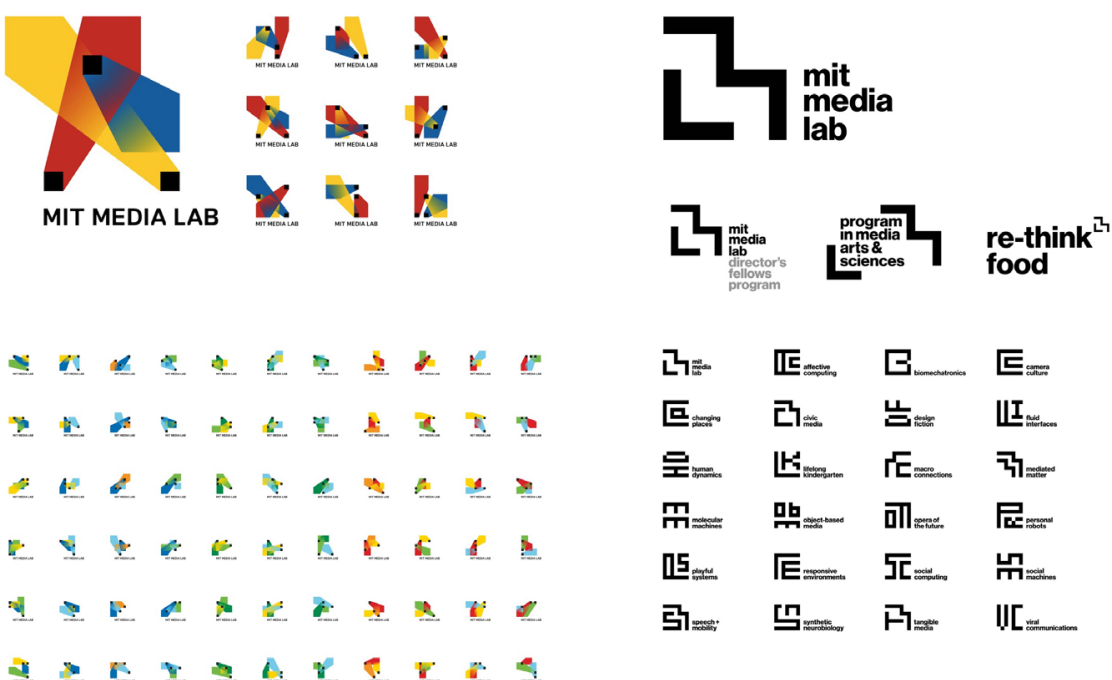

\begin{tabular}{|c|c|c|c|}
\hline 乙䒺 & $\mathbb{\square}$ & 巨。 & 드 \\
\hline 區 & 已凪 & 㟔 & 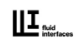 \\
\hline 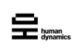 & 는 & 后 & औ= \\
\hline 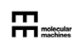 & 맴=ㄴ & 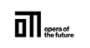 & 屈= \\
\hline ח & 压 & $\bar{J}=$ & 耑= \\
\hline & 乌 & 乃 & $\mathbb{U}[$ \\
\hline
\end{tabular}

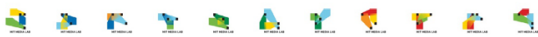

Fig. 5. Left: MIT Media Lab's 25th anniversary, Identity by Richard The, The Green Eyl \& E. Roon Kang, 2011. Right: MIT Media Lab Identity by Pentagram, Michael Bierut, 2014.

Lastly, a case of solid pervasive implementation is THNK, the Amsterdam School of creative leadership, whose identity was created by LAVA, 2012. 
The absence of the "I" in the name is the basis for the logo and for the imagery, used to enrich typography and illustrations. The "I" is used to create a palette of dot symbols used to replace the " $\mathrm{O}$ " in texts or as building blocks for illustrations and infographics (Fig. 6).

It's a clever example of flexibility where the continuous application is guaranteed by the strategic control practised by the organization itself.

These examples reveal that organizations, multi-dimensional in terms of their internal components and audiences, intend to portray and share these contents as value through the perceptual complexity of their visual representation.

Creating a "non-static" visual identity modulates appropriately their tone of voice to different audiences, translating complex information into flexible languages.

Visual systems rather than logo-based identities are, indeed, more oriented to the "process" than to the final result and set rules to be used rather than imposing a solution to be applied. The dynamic design reveals the underlying structures of a complex organization [7].

Compared to the concepts of stability, repeatability and consistency, strictly stated in the corporate identity manual [8], the new approach chooses fluent, expressive languages obtained through the customization of programming by actively involving the user-base of the organization who are transformed into co-authors [9].
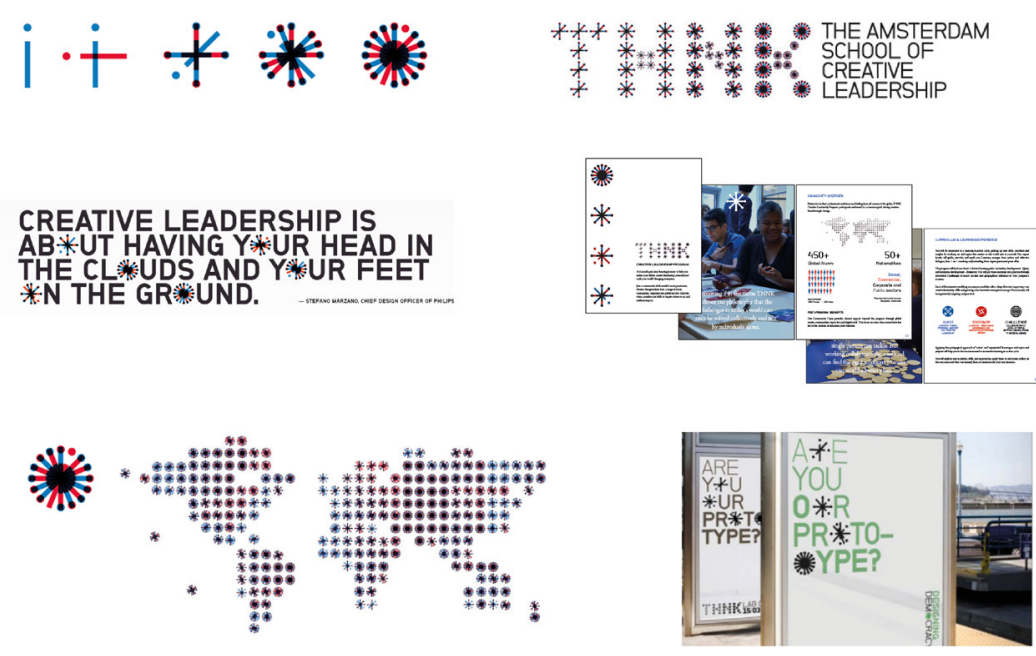

Fig. 6. THNK The Amsterdam School of Creative Leadership Identity by Lava, 2012.

\subsection{Further elements of discussion}

Despite the high level of innovation expressed by dynamic brands, careful attention must be paid when observing the digital environments where these identities are adopted. Although logo-centrism is no longer considered as an imperative, when 
comparing the original visual form of these case studies as stated by the designer, to the implementation disseminated on the Web (such as website as the main imagesharing ecosystem and social media), it's evident that, to be consistent and recognizable, digital environments, in the cases above, stress the main - static - shape of the identity rather than the variations.

\section{To conclude}

The realm of visual identities for educational institutes appears to be a suitable filed of experimentation of dynamic systems. The design of a dynamic systems provides for visual elements, their properties and processes of transformation [10]. It could be said that the realistic implementation of these components depends on the capability, on the talent of the group of communication inside the institution to be influential and able to apply professionally the design strategy.

Nevertheless, the most interesting aspect detectable is that a well-designed and managed dynamic brand doesn't require a unique final result, because it is founded on the principle of creating an open system, that could be selected by external people or influenced by external data. Through balancing constants and variables, according to the principle of searching "unity in variety" [11], implementation could be flexible or static depending on the demand.

\section{References}

1. Blauvelt, A., Lupton, E. (Ed.). (2011). Graphic Design: Now in Production. Minneapolis: Walker Art Center.

2. Anceschi, G., Chiappini, C. (2006). Hard, soft e smart: gli stili registici dell'identity design. Progetto Grafico, 9, pp. 108-111.

3. Lorenz, M. (2017). Des identités visuelle statiques aux identités visuelle flexibles. Graphisme en France 2017. Logos \& identités visuelles, 23, pp. 25-35.

4. Felsing, U. (2010). Dynamic identities in Cultural and Public Contexts. Zurich: Lars Müller Publisher.

5. van Nes, I., Hygues, P. (2013). Dynamic Identities. How to create a living brand. Netherland: Bis Publishers.

6. Torna, C. (2017). Pianta un logo. In Russo, D. (Ed). Identity the colors of project, Proceeding of the International Congress (pp. 90-95). Italia: Palermo University Press.

7. Guida, F.E. (2014). Identità visive generative. Programmare la corporate identity. In $A$ Matter of Design: Making Society trough Science and Technology, (pp. 111-125) Proceedings of the 5th STS Italia Conference. Italia: STS Italia Publishing.

8. Henrion, F.H.K., Parkin A. (1967). Design coordination and corporate image. London, New York: Studio Vista, Reinhold Publ. Corporation.

9. Chiappini, C., Sfligiotti, S. (2010). Open projects. Des identités non standard. Paris: Pyramid.

10. Gerstner, K. (2007) Designing Programmes (3rd ed.). Zurich: Lars Müller Publishers.

11. Maldonado, T. (1991). Disegno industriale: un riesame. Milano: Feltrinelli. 


\title{
User Experience with Mobile Applications for Museums and Exhibition Spaces
}

\author{
Álvaro Sanchis ${ }^{1}$, Nuria Rodríguez ${ }^{2}$, David Heras ${ }^{3}$, Melani Lleonart ${ }^{4}$ \\ 1 \\ Universitat Politècnica de València, Departamento de Pintura \\ \{alsangan@pin.upv.es\} \\ 2 \\ Universitat Politècnica de València, Departamento de Pintura \\ \{nurodca@pin.upv.es\} \\ Universitat Politècnica de València, Departamento de Dibujo \\ \{dherase@dib.upv.es\} \\ ${ }^{4}$ Universitat Politècnica de València, Departamento de Pintura \\ \{mellgar@upv.es\}
}

\begin{abstract}
In this communication, we will analyse the use of resources that are useful in conceptualising museum apps, due to their interesting potential to improve the significance of the visit. Storytelling, gamification, and the inclusion of current technologies such as augmented reality and virtual reality will be determinant for the projection of stimulating, informative spaces. They will contribute to improve the didactic discourse, and the comprehension of complex concepts could be improved. To do so, the combination of the physical layout of the exhibition with overlapping digital layers of information mobile device-based would be essential.

Finally, we will analyse the case of the Ana Juan exhibition, Dibujando al otro lado (Drawing on the Other Side), produced by the Unit Experimental team. This exhibition combines the use of traditional exhibition resources with mobile devices, through a specific app. With it, visitors could experiment an augmented visit, in which different types of digital content were applied. Some of the resources used where game-based, storytelling, augmented reality and virtual reality. The initial design, production and results analysis of this exhibition will be very useful to validate the potential of mobile technology in the creation of significant informative experiences both in museums and other type of settings.
\end{abstract}

Keywords: museography / interactivity / user experience 


\section{Introduction}

The presence of digital technology is one of the characteristic features of today's developed societies. The transformations this technology has made possible over the last decades have modified not only how we communicate, but also how we produce and consume information. Faced with this new paradigm that allows us to share content almost immediately and from anywhere, museums and exhibition centres, anchored to a physical space, are at a distinct disadvantage in spreading the culture and knowledge they contain compared with other hugely popular entertainment media (Rico, 2002, p.43). Given this situation, museums have frequently resorted to technology to improve their offer and win over their target audience, adapting it to the media and languages of modern-day visitors.

One of the main functions of the modern museum is to facilitate the understanding of concepts through the act of exhibition and therefore it frequently uses didactic resources to communicate with its visitors. It is at this point that digital technology plays a prominent role, helping to shape what we know as the 'museography of experience', and enhancing its didactic capacity. These types of resource, used at first in educational museums and later popularized in other areas, became widespread during the last decades of the 20th century, continuously making use of the latest technological innovations. Good examples are the use of typical mass media devices, such as TV or radio (Tallon, 2009). The adaptation of interactivity through the personal computer or the use of the internet to generate new channels of communication were likewise fundamental. (Alcalá, Fernández and Rico, 2009, p. 20)

During these decades, interactive museography took advantage of the characteristics of each medium to reach out to the public, offering novel and attractive experiences with varying degrees of success. The arrival of smart mobile devices, however, is completely revolutionizing the way museums communicate with their visitors, resulting in a definitive rupture with regard to previously used technologies and opening up a new horizon of possibilities yet to be discovered.

\section{Museological interactivity in the era of the smartphone}

The launch of the first smartphone was a wakeup call in the production of digital assets for museums. Several features of these devices were especially relevant and facilitated their mass implementation, most notably their interactive touchscreens, their ability to reproduce multimedia content (audio, video, etc.) and the functionalities of internet connectivity and GPS tracking. For the first time, museums could publish content for consumption on the visitors' own devices, regardless of their location, giving rise to what we know as 'nomadic museography' (Hernández, Martínez and Rojo, 2010, p. 590). 

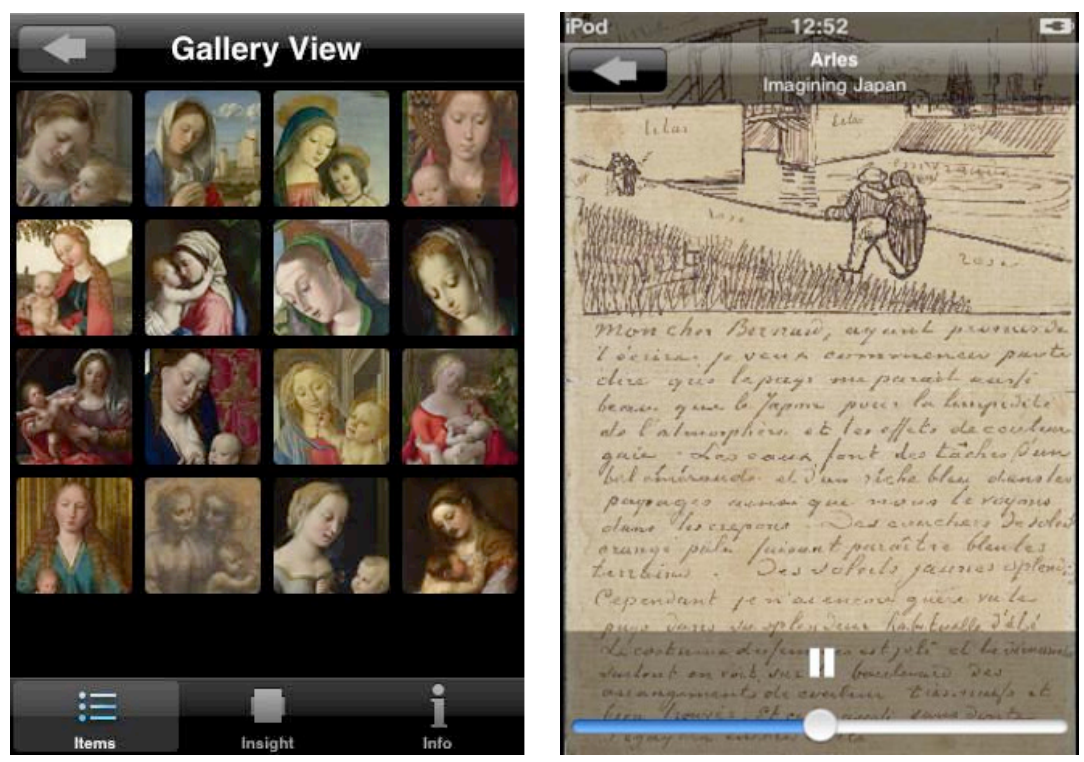

Fig. 1 and 2. Pioneer applications published by museums. From left to right, Love Art (2009) published by the National Gallery in London, and the Yours, Vincent application (2009) produced by the Van Gogh Museum in Amsterdam.

At present, ten years after the launch of the first smartphone, we have a clearly consolidated medium of great interest for museums. According to the survey published by the AXIELL ${ }^{1}$ company, $93 \%$ of the museums surveyed were interested in or already producing some type of interactive digital content in the next year. The experience of our work team confirms that museum institutions show a clear interest in the field of interactivity, but are not familiar with the most appropriate resources and possibilities currently available in order to connect with their different target groups. What resources can museums use to attract visitors? What are the determining factors in making the experience of visiting a museum truly meaningful? As a starting point, we have taken areas of study such as museography and user experience design to detect aspects that are more effective in the creation of meaningful interactive experiences, the fundamental aim of any cultural institution today.

It is essential to understand that the approach, means and strategies used to present an exhibition will result in either a humdrum non-event or a truly meaningful experience for our visitors. Therefore, through the area of user experience design,

\footnotetext{
${ }^{1}$ The study carried out by AXIELL in 2016 surveyed more than 1,000 exhibiting institutions around the world, obtaining information on their use and perception of technology as a museological tool. The study can be found at http://alm.axiell.com/digital-transformationmuseum-industry/ [Consulted 17/10/17]
} 
we can discern some key factors that can guide us on how to detect relevant aspects in the approach to digital museum assets. First, we must understand the dimensions that make for a rewarding experience, which according to Morville (2004) have six distinct characteristics, namely that they are useful, desirable, accessible, credible, locatable and usable. The presence of all of the above will result in a truly rewarding experience.

Taking these dimensions as a starting point, and based on our own experience as consultants and producers of interactive experiences, we have identified three key resources that improve the dimensions proposed by Morville, thus facilitating the creation of positive interactive experiences for museum visitors: first, the use of novel technologies such as augmented/virtual reality, together with key strategies such as storytelling and ludification. We will now break each one of them down in order to analyse their applications in specific projects.

\subsection{Use of new technology: augmented and virtual reality}

Augmented reality and virtual reality are currently two of the most important resources in the interactive audiovisual sector. There are several reasons for this trend. First, as Peter Morville (2004) points out, one of the key aspects in improving a positive user experience is desirability, which is clearly enhanced by users' curiosity and their willingness to try out new products and experiences.

Augmented reality is especially useful as a museological tool because of its ability to amplify the content on display at exhibitions. Thus, the exhibition spaces can be complemented by overlapping information of interest with the traditional exhibition supports in an attractive, playful and effective way. A good example is the interactive sketchbooks developed by the Unit Experimental team in the exhibition Think With Your Hands. Isidro Ferrer \& Pep Carrió sketchbooks (2013), where visitors were allowed to virtually 'browse' the sketchbooks presented in the exhibition inside display cases or printed on panels (fig. 3). It is also possible to use the communicative media of the exhibition (posters, brochures, information sheets) as images that are detectable by the application, thus bringing the user experience outside the halls and allowing a greater dissemination of the digital content that has been developed. 


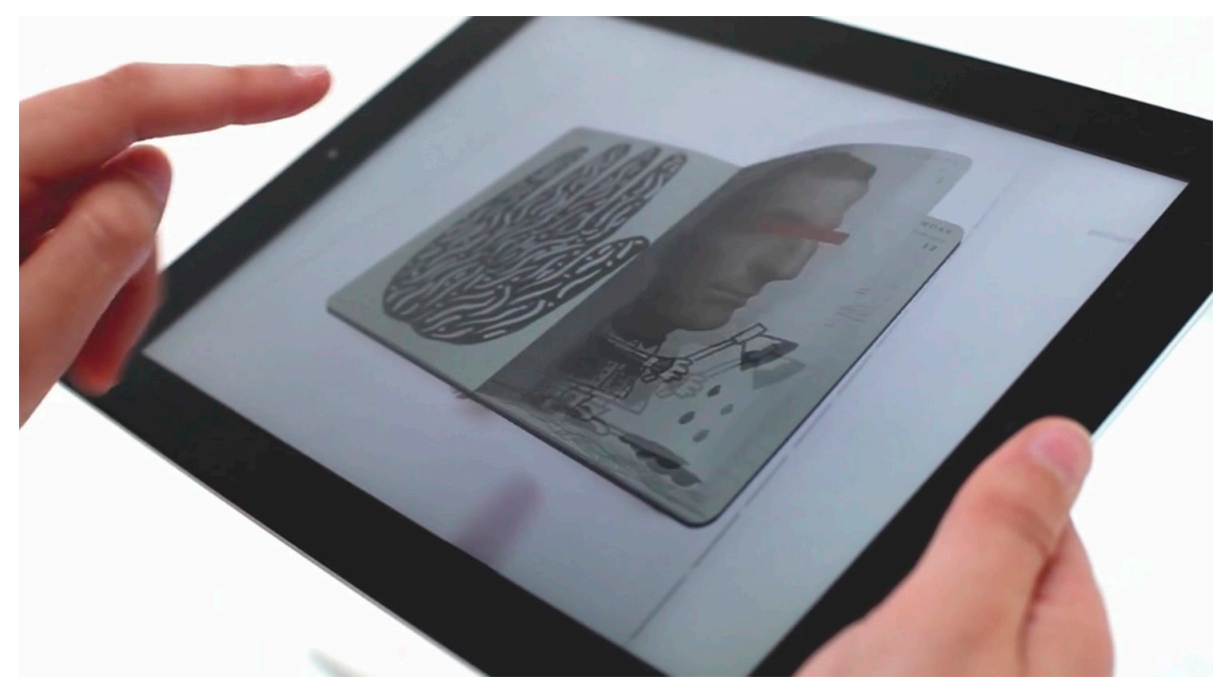

Fig. 3. Interactive sketchbook in the exhibition Think With Your Hands. Isidro Ferrer \& Pep Carrió sketchbooks (2013). Image: Unit Experimental

Similarly, in the EFE'75. History of the First Spanish News Agency (2014), Unit Experimental developed a specific application that used augmented reality to offer additional information about photos, events and key documents, providing audiovisual resources, animations and 3D resources that amplified the visit (fig. 4).

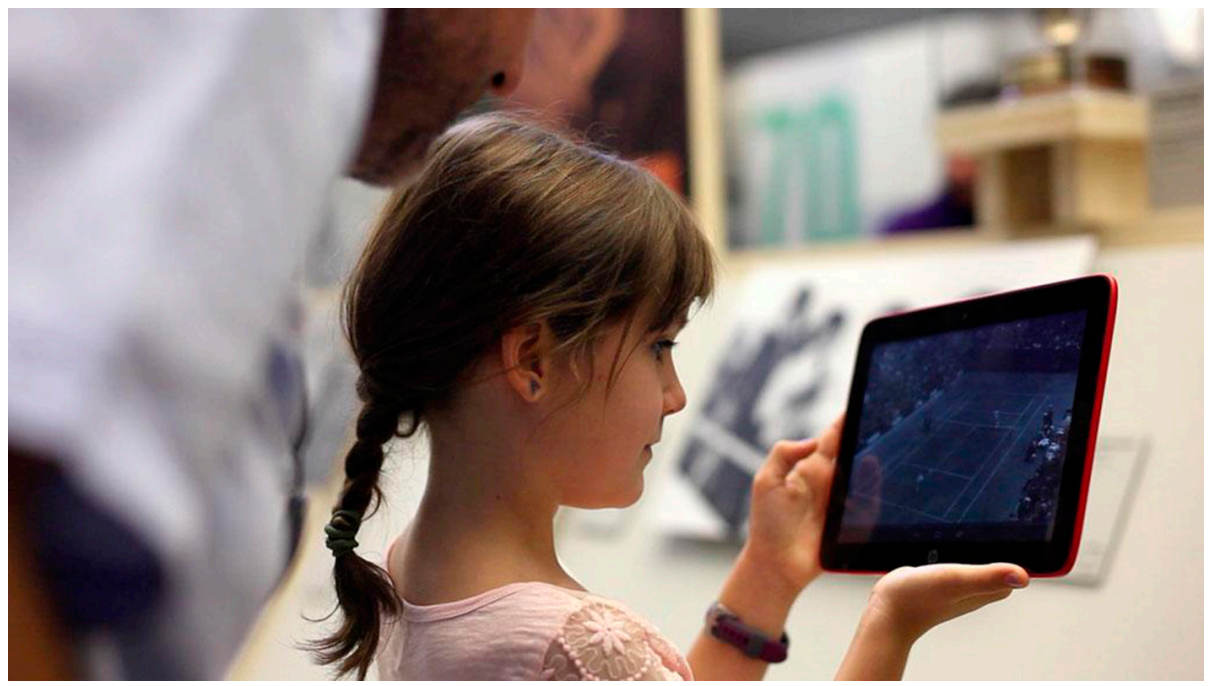

Fig. 4. EFE $75^{\prime}$ application, showing audiovisual content from a news clip. Image: Unit Experimental. 
In parallel, virtual reality is the next step in the simulation of digital experiences, as it offers the total abstraction of reality, immersing the viewer in a completely new environment. It is therefore a high impact resource since it enables the visitor to be transported to ages, situations or realities impossible to experience through other simulation methods. At present, virtual reality arouses special interest within the museological panorama due to the curiosity and intensity that its results provoke in visitors. In this vein, the Dalí Museum in St. Petersburg has presented the Dreams of Dalí VR experience (fig. 5), an interaction based on virtual reality that allows the visitor to enter into a dreamlike universe based on Dalís Archaeological Remini-scence of Millets Angelus (1935), allowing the viewer to discover details about the artist's creative process.

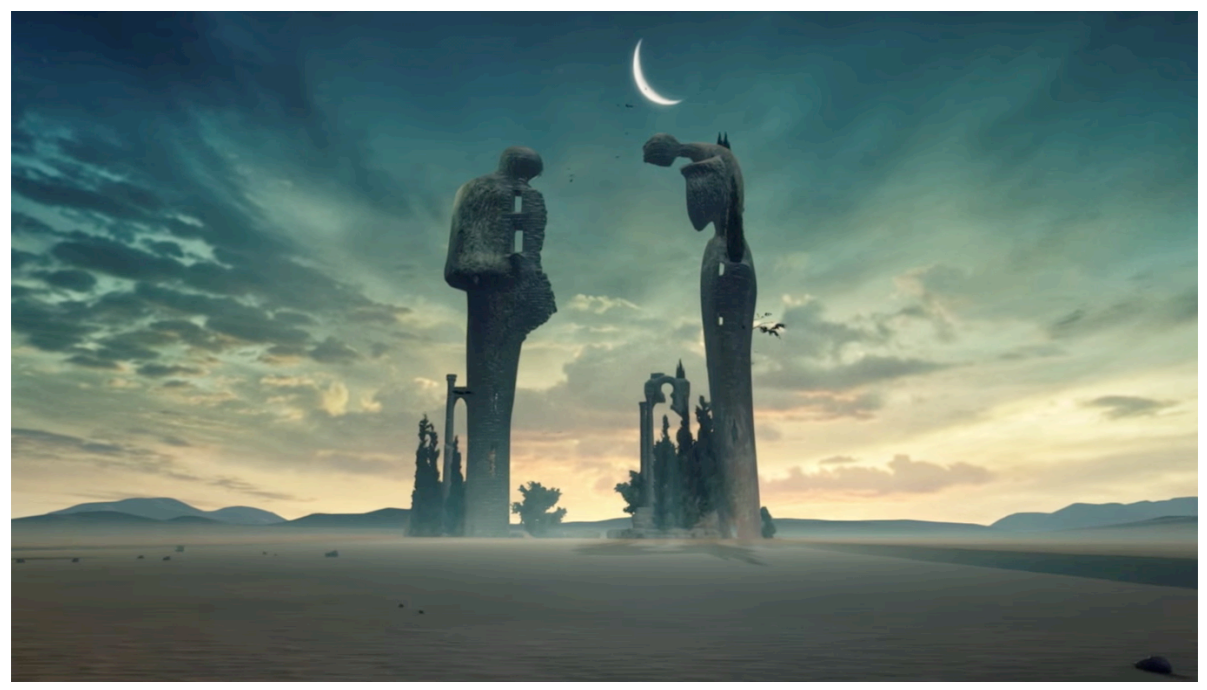

Fig. 5. Dreams of Dalí VR (2017) application. Image: Dali Museum, St. Petersburg

\subsection{Storytelling}

As part of our analysis of the most useful tendencies in the creation of digital museum experiences, it is clear that storytelling is currently one of the most widespread tools, both in the exhibition narrative and the approach to digital experiences. This resource uses the evident capacity and scope of stories as a didactic and communicative tool. Since ancestral times, stories have transcended as a primitive form of communication, given that the use of stories and legends has for centuries been the mode of transmission of culture and traditions (Ruthledge, 2011), with museums later becoming excellent agents for their transmission. The digital field has facilitated the inclusion of these stories in expository approaches, especially mobile devices, due to their multimedia and interactive possibilities. A good example is the Traces Olion application (2017), produced by the Cardiff National Museum, which allows a physical visit to the museum to be combined with a narrative that 
involves the spectator, making them a participant in an adventure where they will learn about the lifestyle of the main inhabitants of the society of this city at the beginning of the century.
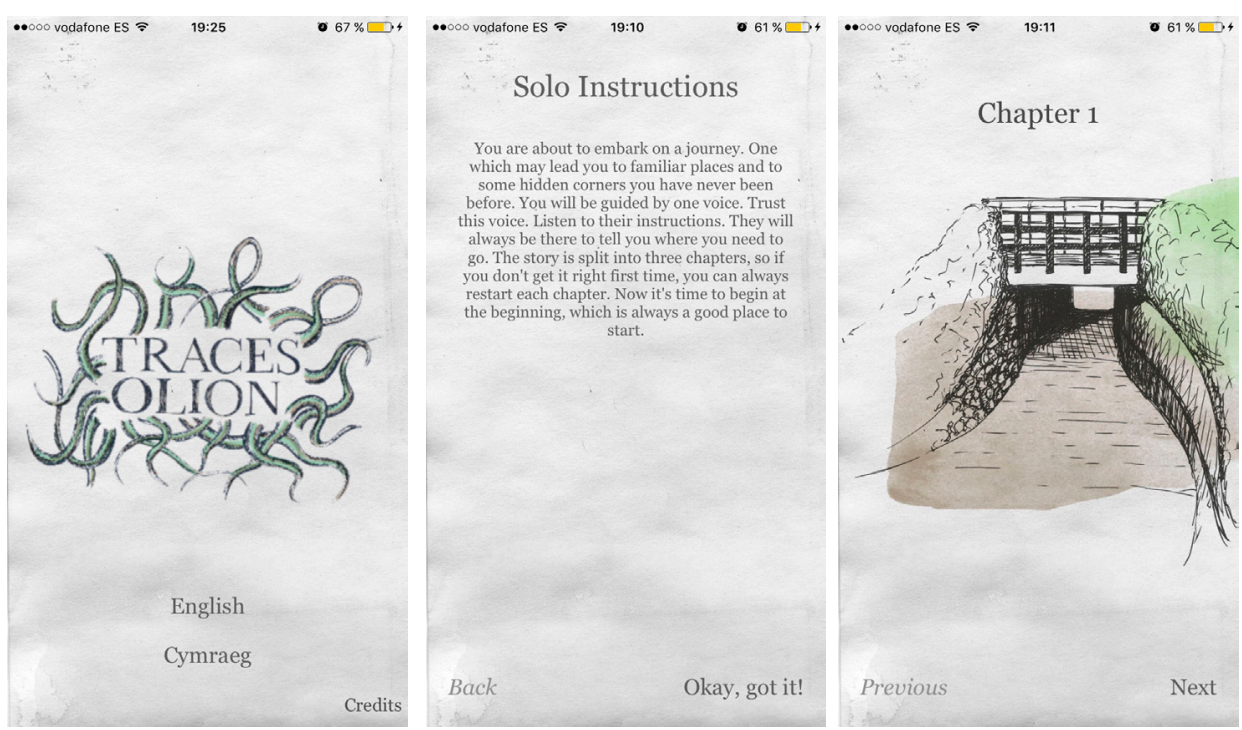

Fig. 6, 7 and 8. Several screenshots from the Traces Olion application (2017). Image: Apple Appstore

\subsection{Gamification}

Gamification has come to the fore in recent years as one of the most interesting resources in interactive museography. This trend stems from the use of resources from the world of gaming applied to environments of all kinds. As Jesse Schell says: "gamification is taking things that are not games and trying to change them so that they are experienced as such."

Firstly, the principles of gamification are consistent with those that form the basis of human learning, which during infancy is grounded fundamentally in play. In adulthood, play is related with fun activities, which are stress-free and entertaining, and therefore the gamification of certain museum-related environments is related to leisure and entertainment as an agent that constructs knowledge (Hernández, Martínez and Rojo, 2010). Secondly, those age groups who were born from the 1980s onwards display an obvious empathy with digital entertainment and video games, as they currently constitute a common medium for their entertainment and culture (Lippenholtz, 2014). For this reason, the use of dynamics close to these spheres will have a positive effect on capturing the attention of museum visitors, generating learning dynamics and an in-depth exploration of complex subjects through action or "doing" (Green and Hannon, 2007). Hence, it is fundamental that the gamified experiences that museums present meet certain criteria, such as: 
- Maintaining a balance between difficulty and user skill;

- $\quad$ Clearly setting out the objectives and tasks to be performed;

- $\quad$ Generating a seamless game experience without obstacles or interferences;

- $\quad$ Combining game content with didactic information in a balanced way;

A good example of how to approach this type of dynamic can be found in the MicroRangers project developed by the American Museum of National History in 2016. In it, visitors are invited to experience an adventure in which, using augmented reality on a card given to each visitor participating in the activity, they take part and help digital characters. The challenges set include ones that involve observing the museum environment to "hunt" for specific specimens and solve puzzles.

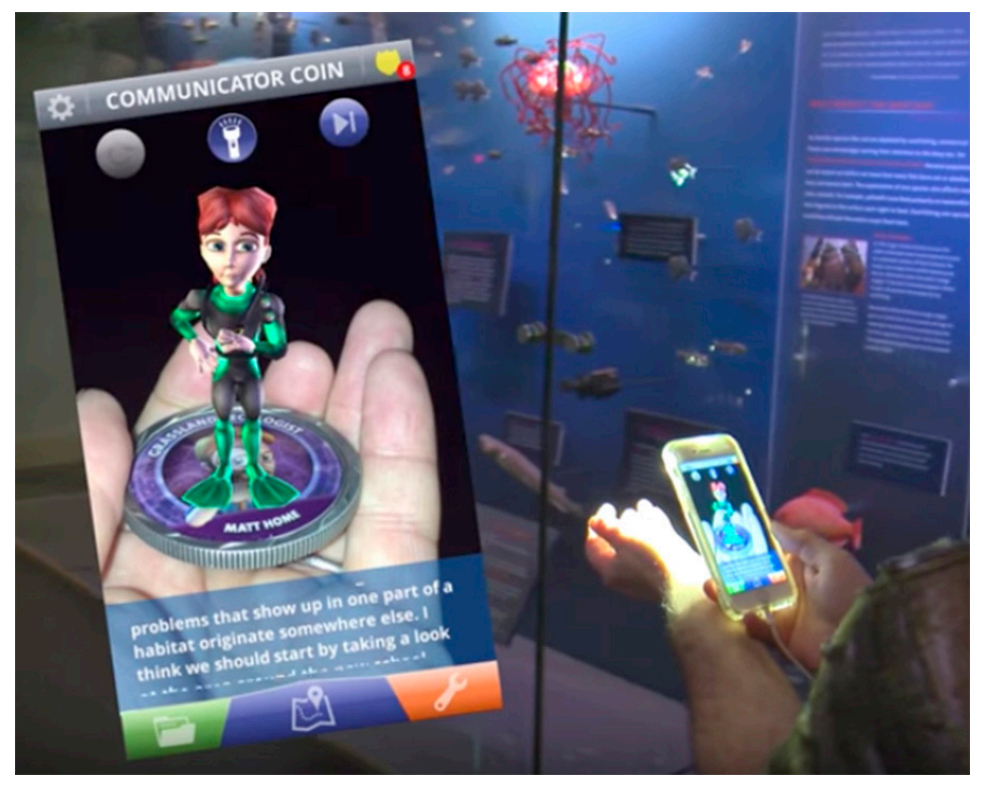

Fig. 9. A virtual character giving instructions in the gamified MicroRangers activity in the American Museum of National History.

At the same time, it is important to stress that due to the different types of visitor a museum may receive, it is crucial to avoid what we call "game-tatorship", that is, to avoid forcing all visitors to participate in the experience, as there may be people who prefer to visit the exhibition without the extra support that an approach of this kind offers. 


\section{Ana Juan, Drawing on the other side: a transmedia exhibition}

The research process related to resources that are useful in the digital interactive activities described in this article are complemented with their practical application in the production of an exhibition. In this project, the Unit Experimental team combine the various different resources analysed with the aim of providing an attractive and meaningful exhibition that allows us to corroborate the intuitions which gave rise to our research. The result was the interactive exhibition Ana Juan, Drawing on the other side, presented for the first time at the Josep Renau Room of the Faculty of Fine Arts (Polytechnic University of Valencia, 2015) and subsequently at the $A B C$ Museum of Drawing and Illustration (Madrid, 2017).

\section{Aims of the exhibition}

The basic approach was aimed at creating an expository montage that would enable the viewer to enjoy two works created by the illustrator Ana Juan: $A$ turn of the screw and Snow White. As well as the physical exposition, we set out to make an application for mobile phones and tablets that shares the same title as the exhibit. In this app, a clear sub-division was created between information integrated in the interface (which organized elements via menus and sub-sections) together with content displayed by means of augmented and virtual reality in the room. The selection of this technology as a tool to organize the navigation also allowed us to integrate the resources we have commented on above, converting the display into a transmedia experience that combined a solid museographic approach with digital support based on story-telling and gamification.

We can summarize as follows the types of interaction that were included and tested in this exhibition:

\begin{tabular}{|l|l|}
\hline Classification by type & $\begin{array}{l}\text { Number } \\
\text { present in } \\
\text { the room }\end{array}$ \\
\hline Interactive large format posters with gamification (challenge to be solved) & 4 \\
\hline Video footage showing Ana Juan's creative process & 17 \\
\hline 3D characters to be viewed in augmented reality & 11 \\
\hline Augmented reality of the Hawthorn mansion & 1 \\
\hline Visit to the Hawthorn mansion in virtual reality & 1 \\
\hline $\begin{array}{l}\text { Virtual interactive theatre, combining a physical scenography with virtual } \\
\text { elements. }\end{array}$ & 1 \\
\hline $\begin{array}{l}\text { Tablets for playing Chapter I of the videogame Erthaland. Snow White's mystery } \\
\text { tale developed by Unit Experimental based on the work of Ana Juan }\end{array}$ & 1 \\
\hline
\end{tabular}




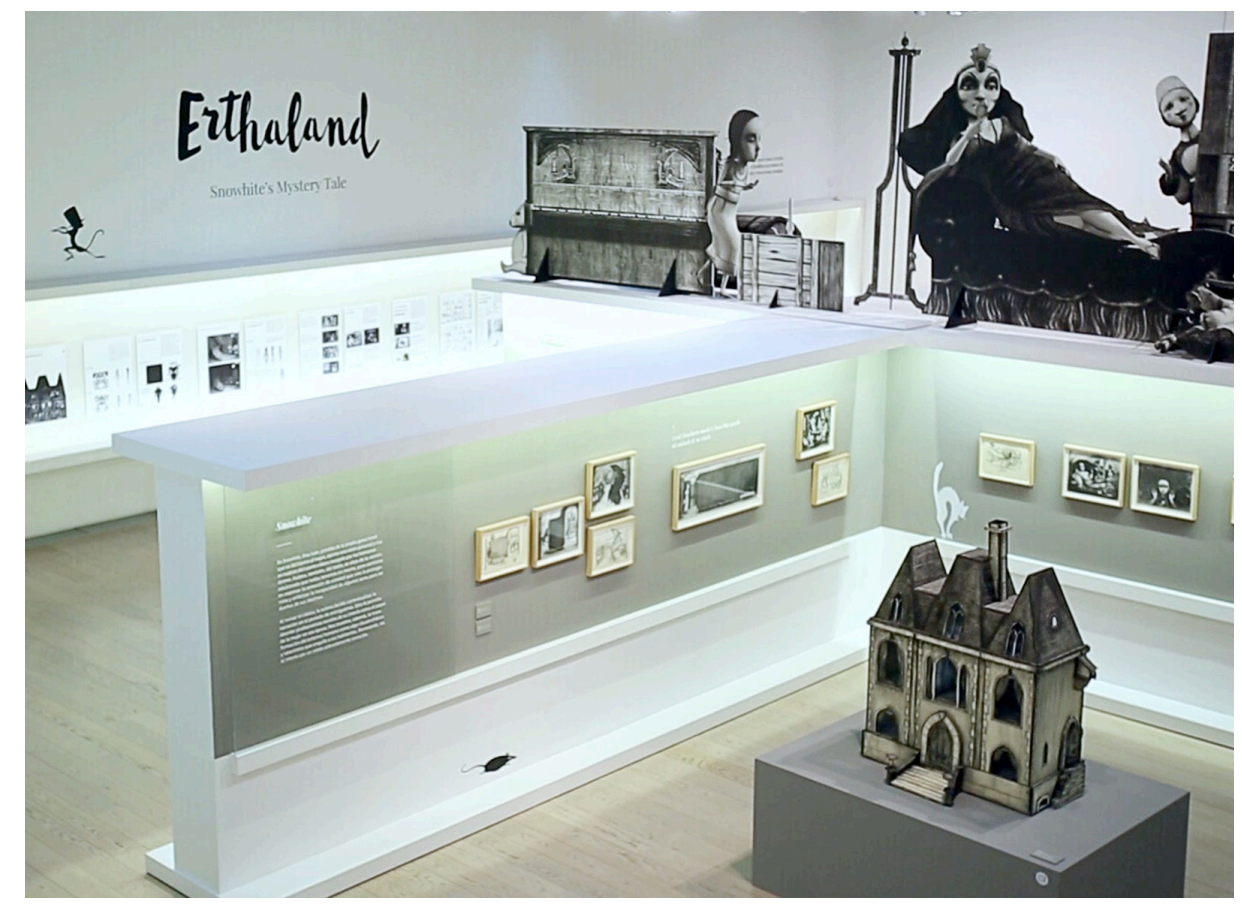

Fig. 10. View of the exhibition Ana Juan, Drawing on the other side (2017) at the ABC Museum of Drawing and Illustration. Image: Unit Experimental.

\section{A gamified narrative experience}

As we have said, the fundamental objective of the approach was to use resources that are typical of story-telling in tandem with gamification to turn the exhibition into a board game where the visitor can overcome the initial challenge and finally win a reward. The visitors who entered the room encountered instructions (signposted on one of the walls using vinyl posters) in which they were encouraged to participate in the activity (fig.11). Thus, in a clear and simple way, the user is invited to play an active role in the narration and be a participant as the heroine flees in this new twist on the classic tale as revised by Ana Juan.

The gameplay dynamic based on augmented reality called for a specific design process to allow for an appropriate and accessible playability. In our case, by focusing with the tablet on any of the four interactive vinyl posters positioned in the room, the visitor was shown an interactive scene that included both the Ana Juan characters and various items of furniture and interactive elements that can be used to solve the puzzle. These mini-challenges called for dynamics combining objects, logic games and memory games. 

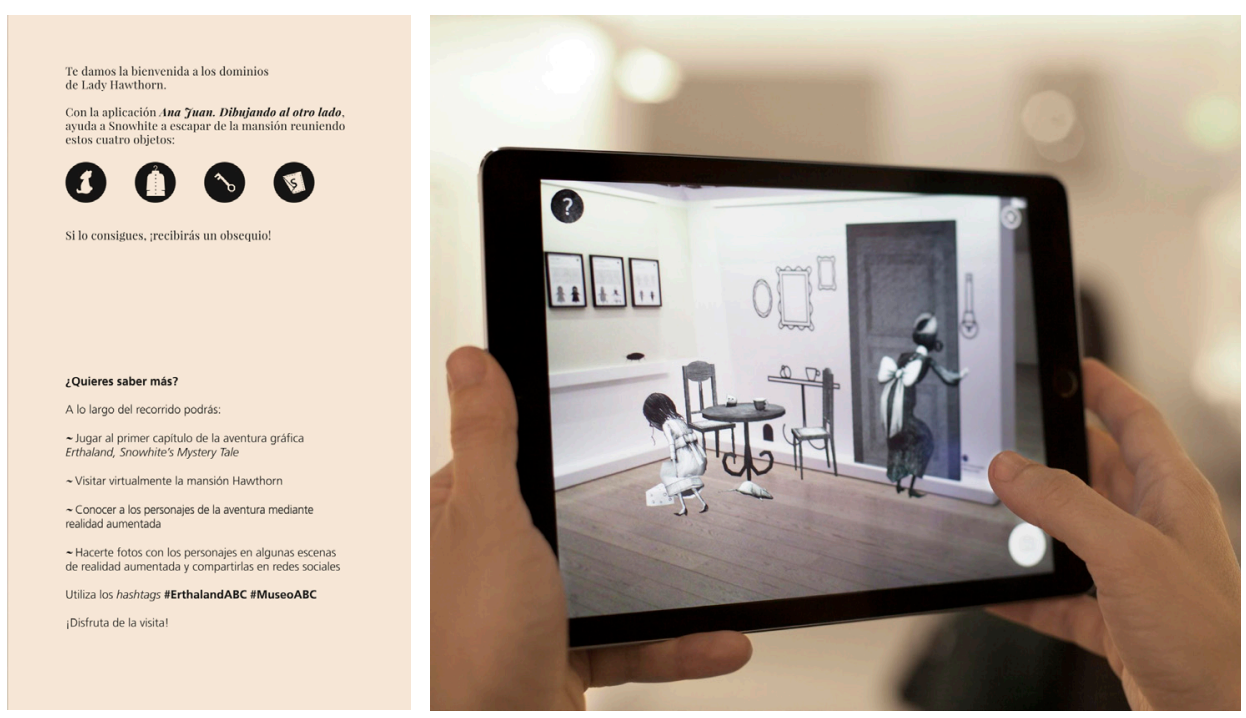

Fig. 11. Poster positioned at the entrance to the exhibition with instructions on the ludic experience. Image: Unit Experimental.

Fig. 12. An interactive vinyl poster that displays a logical challenge by means of augmented reality. Image: Unit Experimental.

To effectively tell the user the objective to be achieved in each interaction, we developed a train of thought for the main character, Snow White, so that through the classic thought bubbles of comics one knows at all times what the character is thinking and, therefore, what objective should be achieved. Visitors could experiment, move and combine the various objects with the characters to solve the four riddles and obtain the objects required to overcome the challenge posed in the room.

Overcoming a challenge is an intrinsic part of the experience of participating in any game. Consequently, we designed a reward that would add value to the experience and fit in with the possibilities and functioning of the museum where the exhibition was staged. Ruling out traditional media such as the room fact sheet or postcards, we designed a new medium in the form of a cut-out, laid out on an A3-size sheet of paper. When cut out and assembled correctly, it made a small-scale replica of the Hawthorn mansion displayed in the exhibition. Furthermore, we were able to add digital interactivity to this cut-out item, enabling the visitors to take home their interactive experience of the room and enjoy the augmented reality experience outside the museum and, what is more, to share it with other potential visitors. 


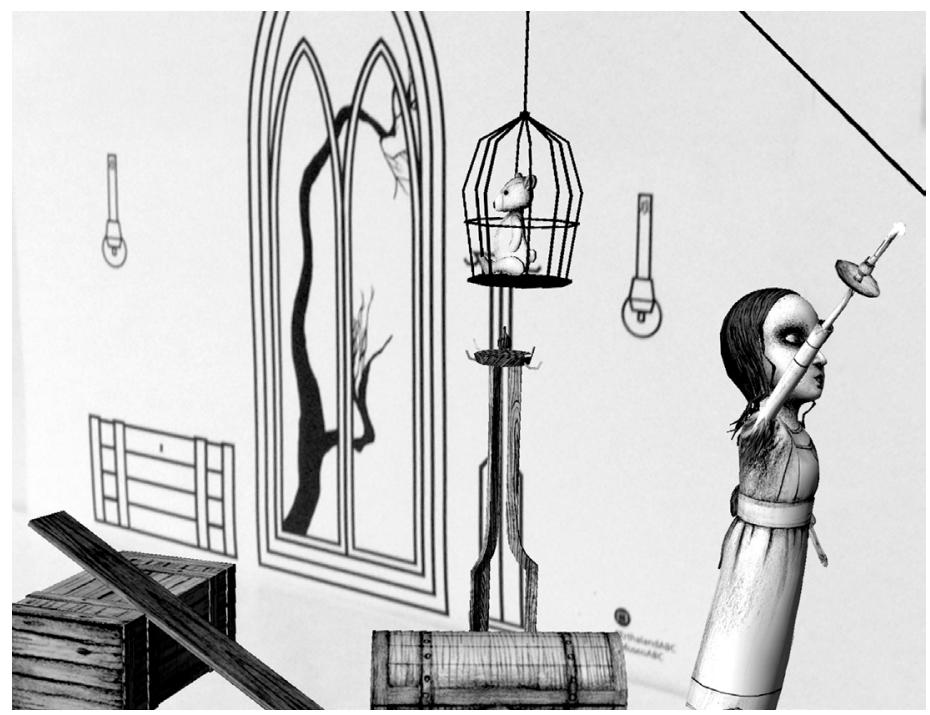

Fig. 13. Snow White solving one of the puzzles in the game experience. Image: Unit Experimental

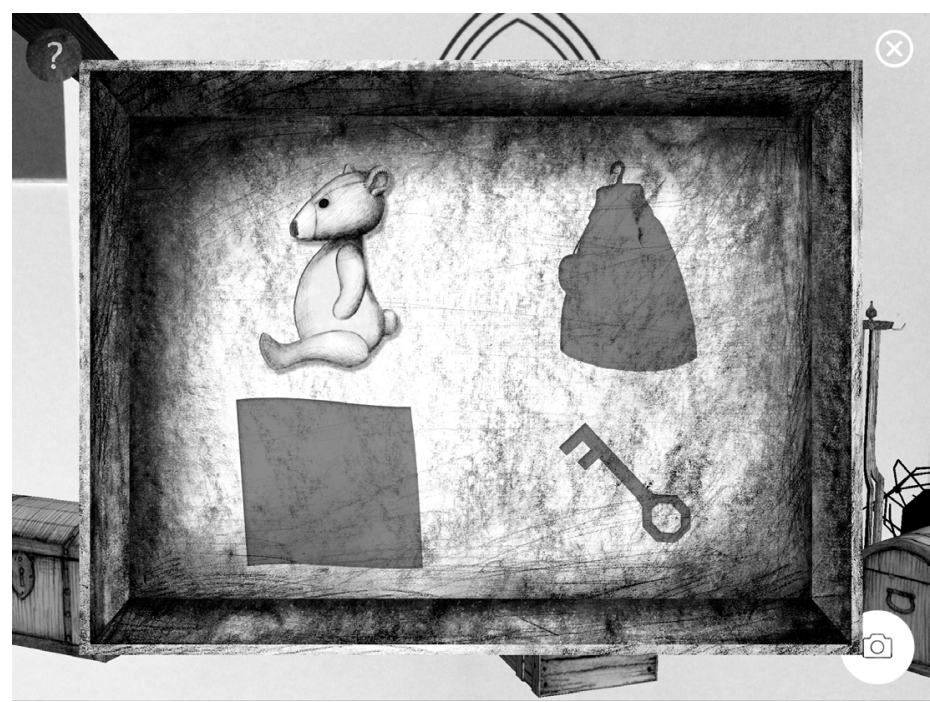

Fig. 14. Shopping list showing the four objects required to overcome the challenge. Image: Unit Experimental 


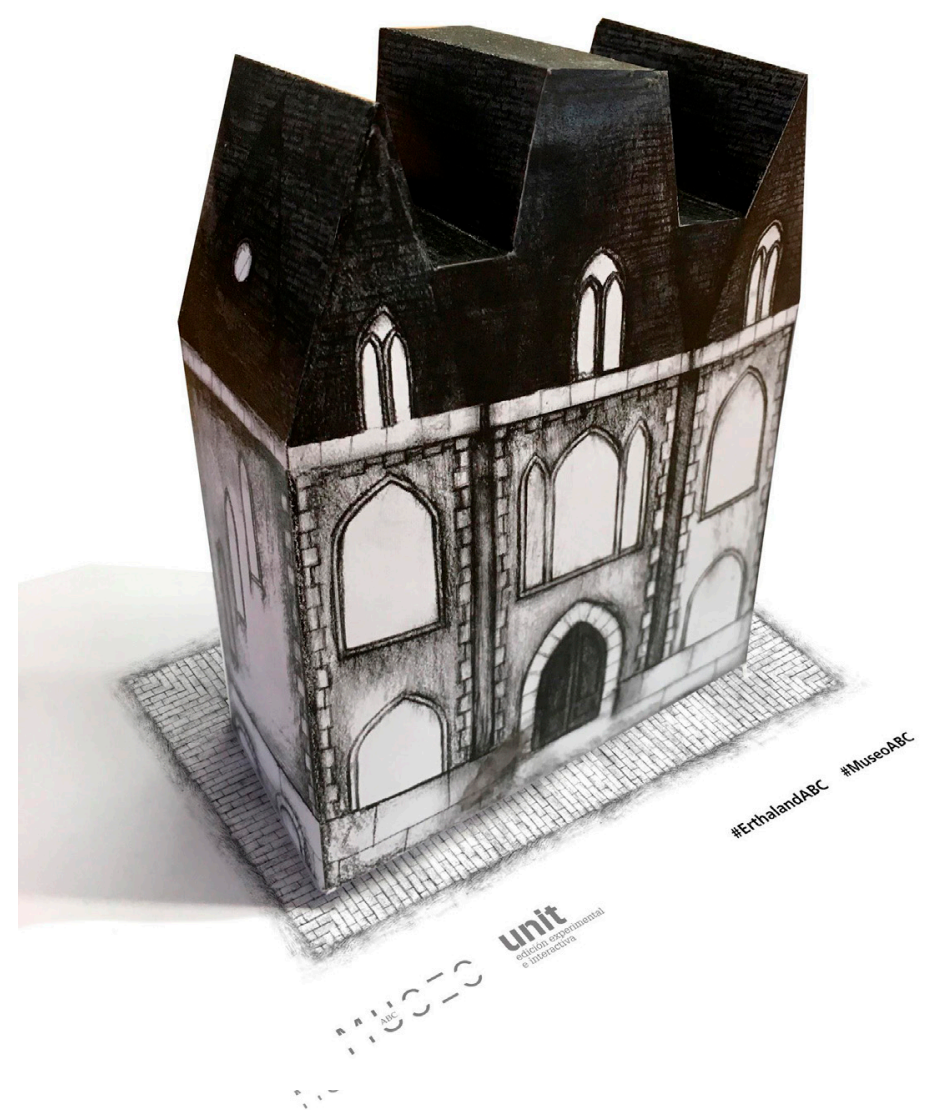

Fig. 15. Photograph showing the cut-out mansion when assembled.

\subsection{Reception and outcome of the exhibition}

Looking at the statistics obtained by the analysis integrated in the application, the interaction types that were most used in the exhibition were:

1. Scenes of the game challenge in augmented reality: $51.2 \%$

2. Augmented reality of the Hawthorn mansion: $13.9 \%$

3. Augmented reality of the cut-out house: $9.5 \%$

4. Interactive virtual theatre: $9.13 \%$

5. Vídeos on the work of Ana Juan: $8.8 \%$

6. 3D characters to be viewed in augmented reality: $5.9 \%$

7. Augmented reality applied to the promotional flyer for the room: $1.7 \%$

In total, 67,231 content activations were recorded (one each time the application detected a target or digital content), the percentages being distributed as follows: 
resenting the total number of people who overcame the interactive challenge in the room. It should be borne in mind that the user could choose to enjoy the full interactivity and participate in the challenge, or enjoy the exhibition and digital content in augmented reality and virtual without the gamified part. Some visitors tour the exhibition by viewing the works and attending to the interactive documentary resources, such as interviews, information about the work process character animations.

The following graphs show the numbers of visitors, which amounted to a daily average of 298 and whose weekly audience did not fall from 1,000 people in any of the three months in which it could be visited, exceeding 1,500 visitors most months. The $A B C$ Museum of Drawing and Illustration has an average of 160 attendees per day, a statistic that underlines the clear success of our interactive feature. Moreover, in surveys and interviews conducted with visitors in the museum itself, we could see that most of them ranked the works of the illustrator Ana Juan above interactivity, thus demonstrating that technology does not exclude the importance of the work itself, but helps to enhance its message and to focus the viewer's attention.

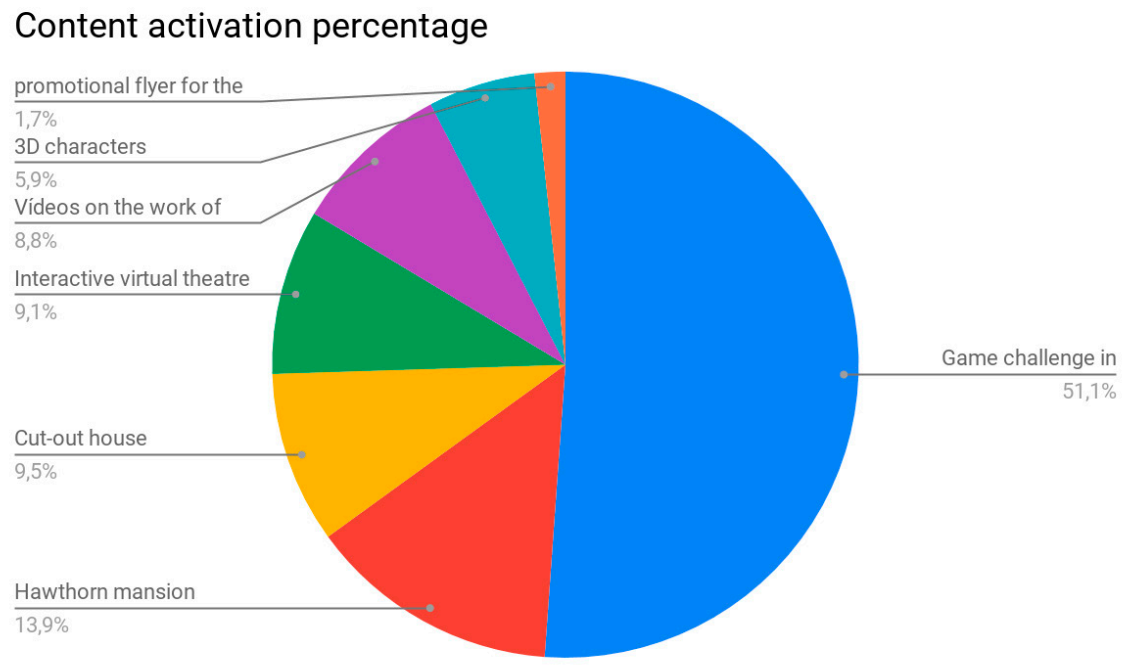

Fig. 16. Graph of activation percentages of augmented reality content 


\section{Asistencia semanal}

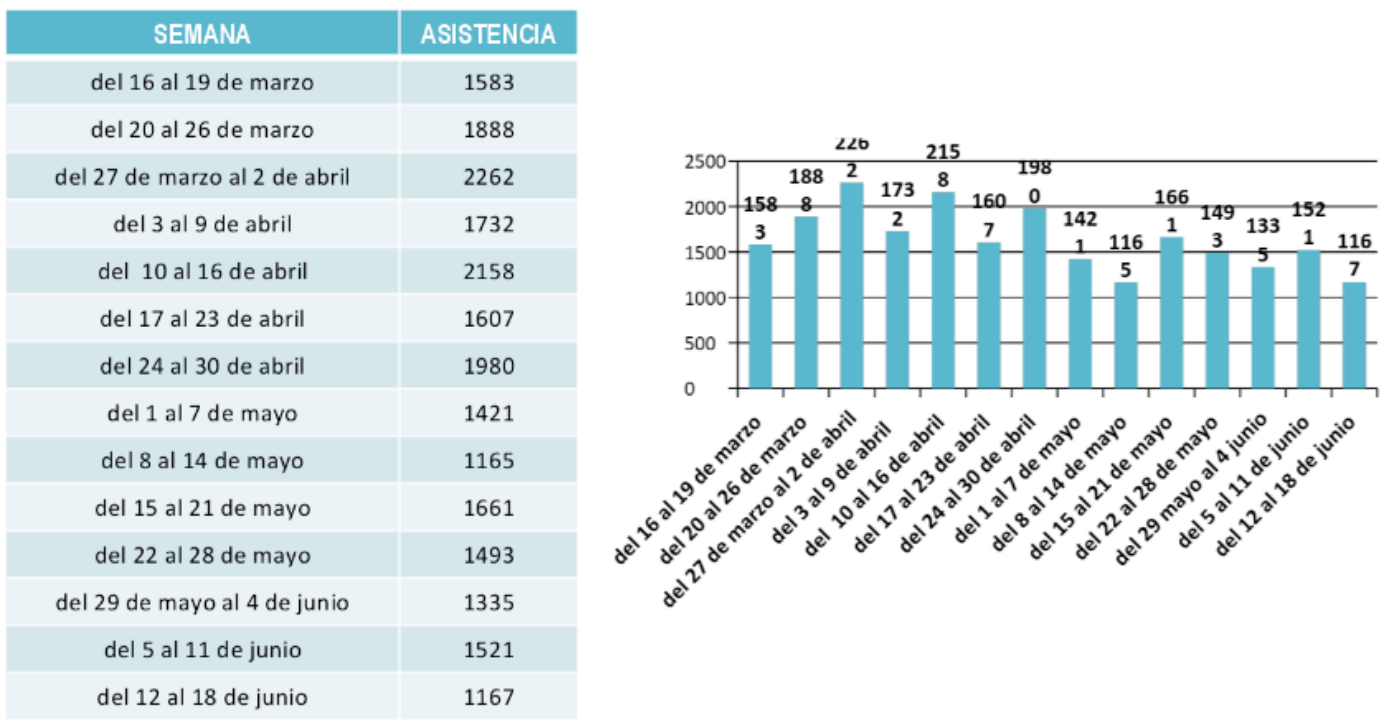

Fig. 17. Graphs showing weekly attendance at the exhibition. Source: ABC Museum

\section{Conclusions}

Having marked out the current strategies of greatest interest in the digital museographic field, and having put them into practice in a specific project such as the interactive exhibition Ana Juan, Drawing on the other side, we can conclude that:

- $\quad$ The relationship between museography and technology is a field of study of great importance due to its usefulness in the transmission of complex content and its presence in visitors' everyday lives.

- The vast number of digital applications produced by museums require specific approaches designed to attract the public using surprising and stimulating interactions.

- $\quad$ Augmented reality and virtual reality are useful tools for adding meaning to the experience of visiting a museum, especially when they are grounded on a teaching and learning narrative.

- $\quad$ Augmented reality is a strategy that offers high accessibility, which allows content to be enjoyed by visitor segments of very diverse ages.

- $\quad$ Storytelling and gamification have been shown to be valuable tools within contemporary museography, proving key to the connection with certain types of audience, and whose potential has not been explored as deeply as it should. 
- Analysing the results obtained from the statistics of the exhibition Ana Juan, Drawing on the other side, we conclude that within the possibilities of augmented reality the success of game experience is clear, thus paving a clear way for exploration of the achievement of meaningful experiences and the transmission of concepts in a playful and educational way.

\section{References}

1. Alcalá, J., Fernández, L., y Rico, J. (2009). ¿Cómo se cuelga un cuadro virtual? Las exposiciones en la era digital. Gijón, Spain: Ediciones Trea.

2. Green, H., and Hannon, C. (2007). Their space. Education for a digital generation. London, UK: Demos.

3. Hernández, F. (2009). Interactividad didáctica y museos. Enseñanza de las ciencias sociales, 8, 91-96.

4. Hernández, F., Martínez, T., y Rojo, M. (2010). Los límites de la interactividad. In Santacana J., and Martín C., Manual de museografía interactiva. Gijón, Spain: Ediciones Trea.

5. Lippenholtz, B. (2014). Gamificación en los museos (I). Documotion.com.ar [online resource] Retrieved from: http://documotion.com.ar/gamificacion-en-los-museos-i/ [Accessed: 15 December, 2015]

6. Morville, P. (2004). User Experience Design. Semanticstudios.com [online resource] Retrieved from: http://www.semanticstudios.com/user_experience_design/ [Accessed: 1 November, 2016]

7. Murphy, C. (2011). Why Games Work and the Science of Learning. Modsim World conference. Virginia Beach: Alion Science and Technology.

8. Rico, J. (2002). ¿'Por qué no vienen a los museos? Historia de un fracaso. Madrid, Spain: Sílex.

9. Schell, J. (2010). When games invade real life. Ted Talks [online resource] Retrieved from: http://www.ted.com/talks/jesse_schell_when_games_invade_real_life [Accessed: 12 December. 2015] 


\title{
Communication strategies for scientific dissemination. The mUNISS Historical Scientific Museum
}

\author{
1 \\ Marco Sironi , Alfredo Calosci and Nicolò Ceccarelli \\ 1 \\ Laboratorio AnimazioneDesign, DADU, Università di Sassari, Italy \\ marcosironi@elitradesign.it, alfredoc@negot.net, nceccare@uniss.it
}

\begin{abstract}
The evolution of multimedia formats and the appearance of an ecosystem of open source solutions for digital communication promotes a process in which the construction of knowledge, once confined to very specific institutions, opens up to the contributions from a variety of new actors. A recent dissemination project for our University's Historical Scientific Museum has allowed us to confront with this emerging scenario.

This paper presents the strategies we adopted for empowering the visitor's experience to a small exhibition space intended as an introductory step to the scientific collections of the University of Sassari. The project may be considered as an attempt to communicate complexity, exploring different ways for disseminating contents, tailoring goals, targeting audiences, to a very specific context and set of resources, in the direction of developing an integrated framework of tangible and digital elements from a locally based cosmopolitan perspective.
\end{abstract}

Keywords: Exhibit Design, Dissemination of Knowledge, Transmediality

\section{A scientific heritage}

In the course of its long history, and especially since the early nineteenth century, the University of Sassari gathered a wealth of objects, instruments, books which although not always and necessarily rare or precious - give shape today to a vast and meaningful collection (Mattone 2010).

Originally intended for educational and research purposes, the Historical Scientific collection of the University encompasses more than 150.000 artifacts of different origin: scientific and laboratory equipment, mineral samples, botanical models, biological, zoological, anatomical samples and so on. Preserved as the legacy of the past, this material is hosted in ten distinct departmental collections - sometimes just by inertia, more often for its historical value. 

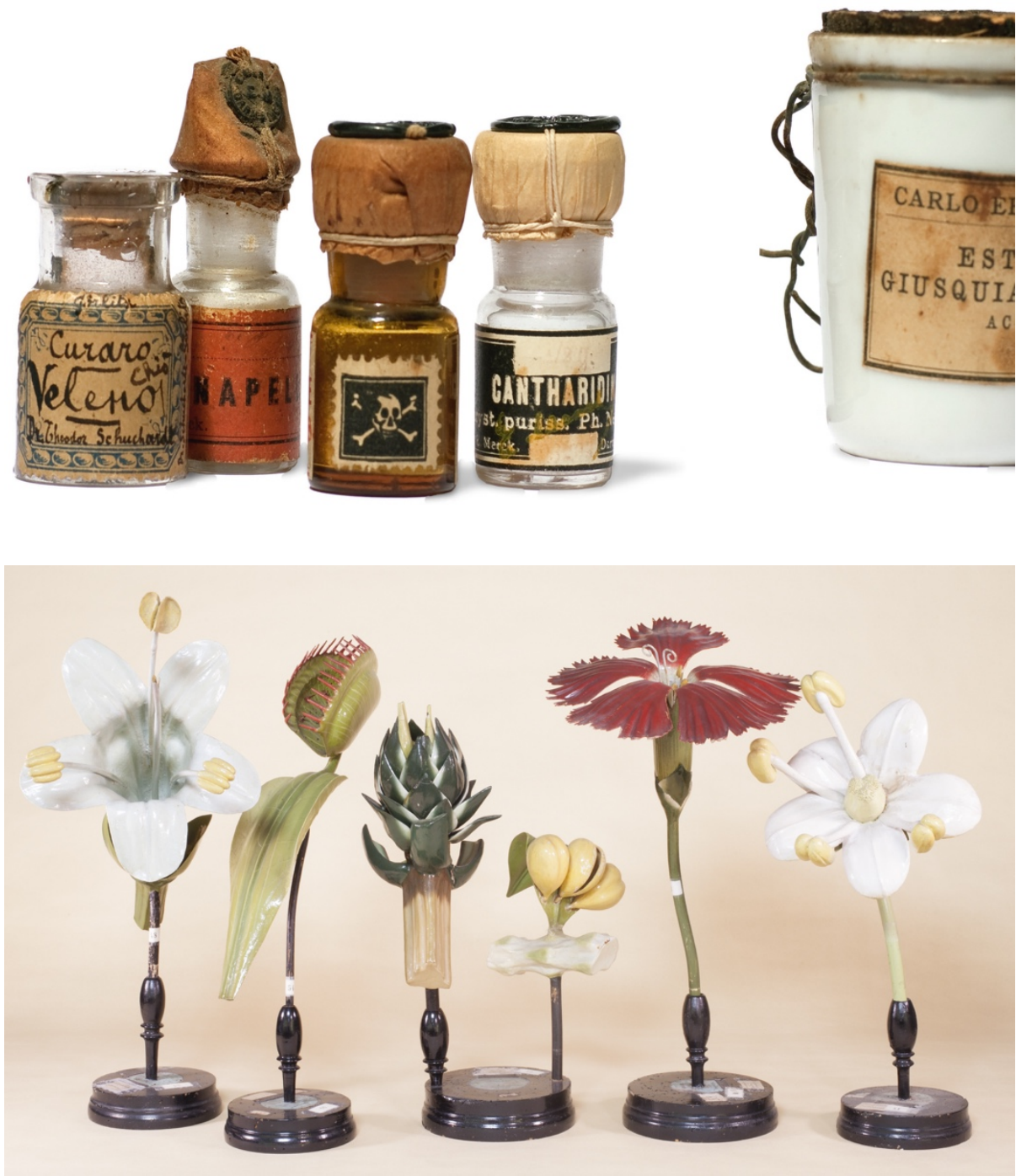

Fig. 1, 2. Selected artifacts from the museum collections: Chemistry, botanical models.

For long, the collections have been scattered in different places, hardly accessible: often unknown even to the University personnel. Under these premises, our project for the mUNISS Museum could not be reduced to a mere question of re-branding or of a signage or communication design, but needed a set of strategic solutions that could play simultaneously at several different levels. As a first step in a general valorization of the Museum collections, and as anticipation of a future re-arrangement of the collections, the University of Sassari planned to set up preliminary exhibition space, almost an introductory hub, and decided to host it in the hall of a new building that was dubbed as 'the snail' for its spiral-shaped plan. 


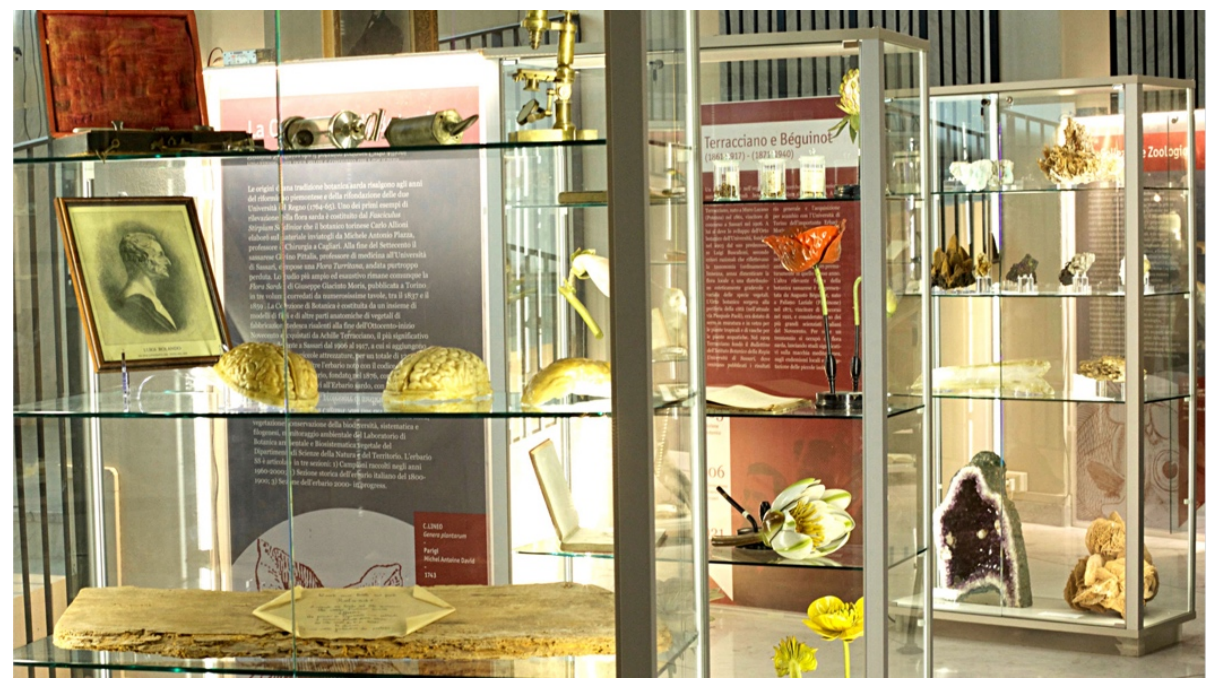

Fig. 3. Views of the exhibition space.

\section{Displaying and connecting a collection}

The very first step was improving the public's accessibility. Despite the limited set of resources - both in terms of available space and budget - we soon realized that arranging the exhibition space with curiosities from the past would not suffice, per se, to bringing the collection back to light.

By definition, a culture - and thereby cultural heritage - cannot exist if it is not shared by a community. Objects on display have very little social value unless they are culturally accessible and if they are not related to a community (Magatti 2009).

The large part of the collections is composed of scientific assets, technical equipment, texts or documents that students, researchers and lecturers would use in their everyday academics activities. The driving idea behind the project became hence reconnecting the collections to a new community of interest, inside and outside the University. In our vision, the most effective way to get in touch with a local audience was by providing a broad frame of reference, a wider perspective that would allow a better understanding of the musealia's cultural value.

A further key element in this strategy was to raise the awareness of the collection's value as a whole, among the UNISS's academic community so to gain its support, even its complicity, for the task ahead. Regardless of its relatively small size, the mUNISS collection can, as an academic museum, be considered part of a global network of scientific heritage. Its existence is testimony, thanks to the University of Sassari, a wide area in the north of Sardinia had long actively belonged to the scientific community since the very beginning.

In this framework, the inner meaning of the dissemination effort connected with the launch of the mUNISS exhibit hub is to connect the "objects on display" with their 
real life context. This may allow the general public to relate with its own conceptual references to this set of artifacts assuming - by doing so - ownership over them as commons goods, part of a cultural heritage. In order to engage this new potential audience, a cultural gap had to be filled, so the approach we decided to take was to exploit the languages and communication means our public is most used to. The project hence moves from the basic selection of meaningful artifacts that are hosted in the exhibition space and plays on the intersection between their physical dimension with the digital one, shaping a hybrid digital library of multimedia artifacts that are part of a wider inter-connected network. A network based on the idea of a variety of contact points capable of engaging a diversified audience. Another key aspect of our project, such a modular approach represents an open and scalable initiative; an agile approach allowing the entire project to grow by small incremental steps.

\section{Exhibition spaces: beyond the "snail"}

The "snail" exhibit space is intended as a first exhibition core, the main hub whose main aim is offering a general introduction to the collections originally hosted in different University departments. The snail becomes hence the place where a

From the collections to the exhibition space... and viceversa.

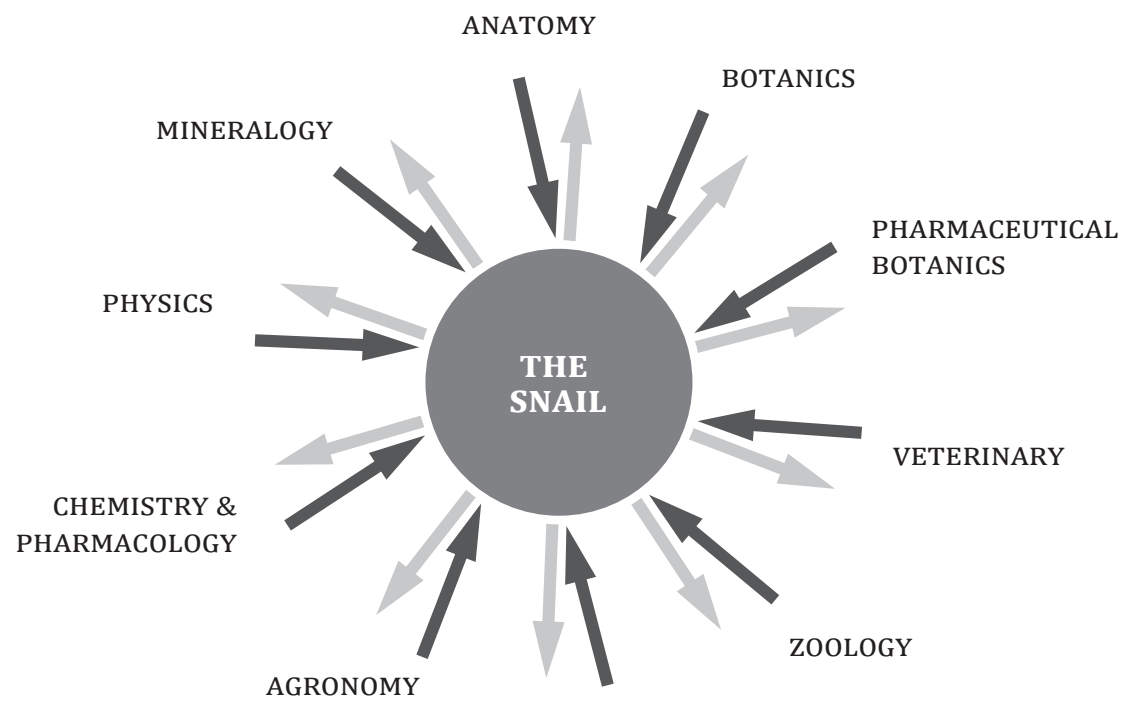

ENTOMOLOGY

Fig. 4. Functional diagrams for the "snail" hub. 
representative sample of University scientific heritage is presented, offering to visitors an anthological vision of the collections: a meaningful "cross-section" of the whole system. The displays have temporary character, and may be periodically re-arranged either for achieving a diversified offer or according to conservation matters.

The main goal of this first exhibit is to stimulate the public's curiosity towards further insights. Metaphorically speaking, we may think of it as a centrifugal gesture - directing the visitor's attention from a core exhibit to the places where the collections are actually hosted - as reaction to an opposite 'convergent' movement that attracts both users and items to the snail exhibition space.

Given its status of tangible core and contact point between the University collections as a whole and the public, the 'snail' exhibition space becomes the focal
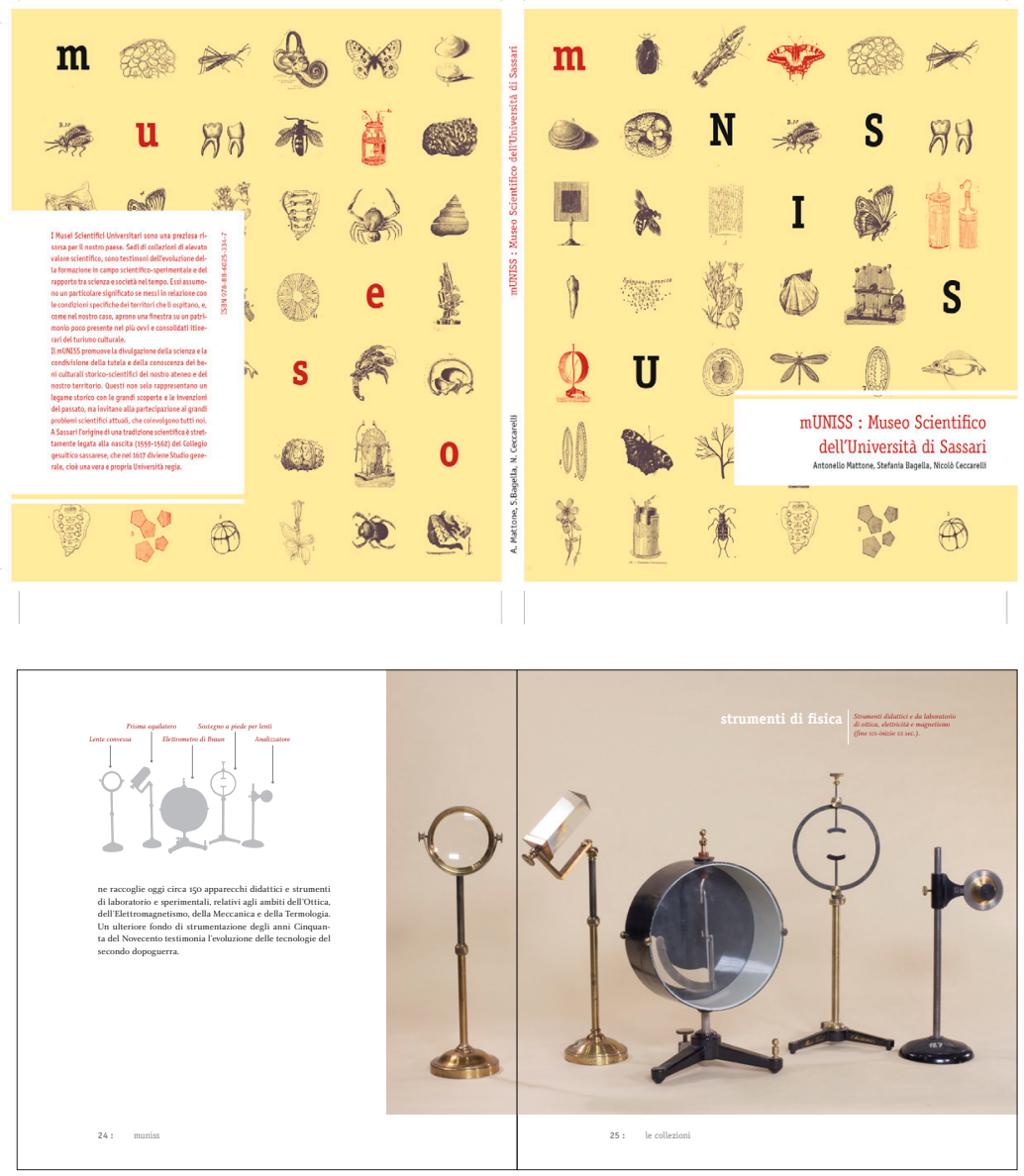

Fig. 5. Examples from the Museum's catalogue: cover and spread page. 
point for a set of communication artifacts we developed during the project: a printed catalogue, a web site and several multimedia artifacts. The development of a strong visual identity and of a system of graphics guidelines played an important role in this perspective, as they provided consistency to every communication element exhibition panels, captions, references - allowing to convey a solid identity for the Museum in every aspect of its contact with its users.

For what concerns the digital component of the project, the website we created to support the Museum's visit is conceived as a symmetrical - delocalized - hub reflecting in many ways the actual installations. Shaped on a simple structure, and divided into clearly navigable sections, the site combines practical information about

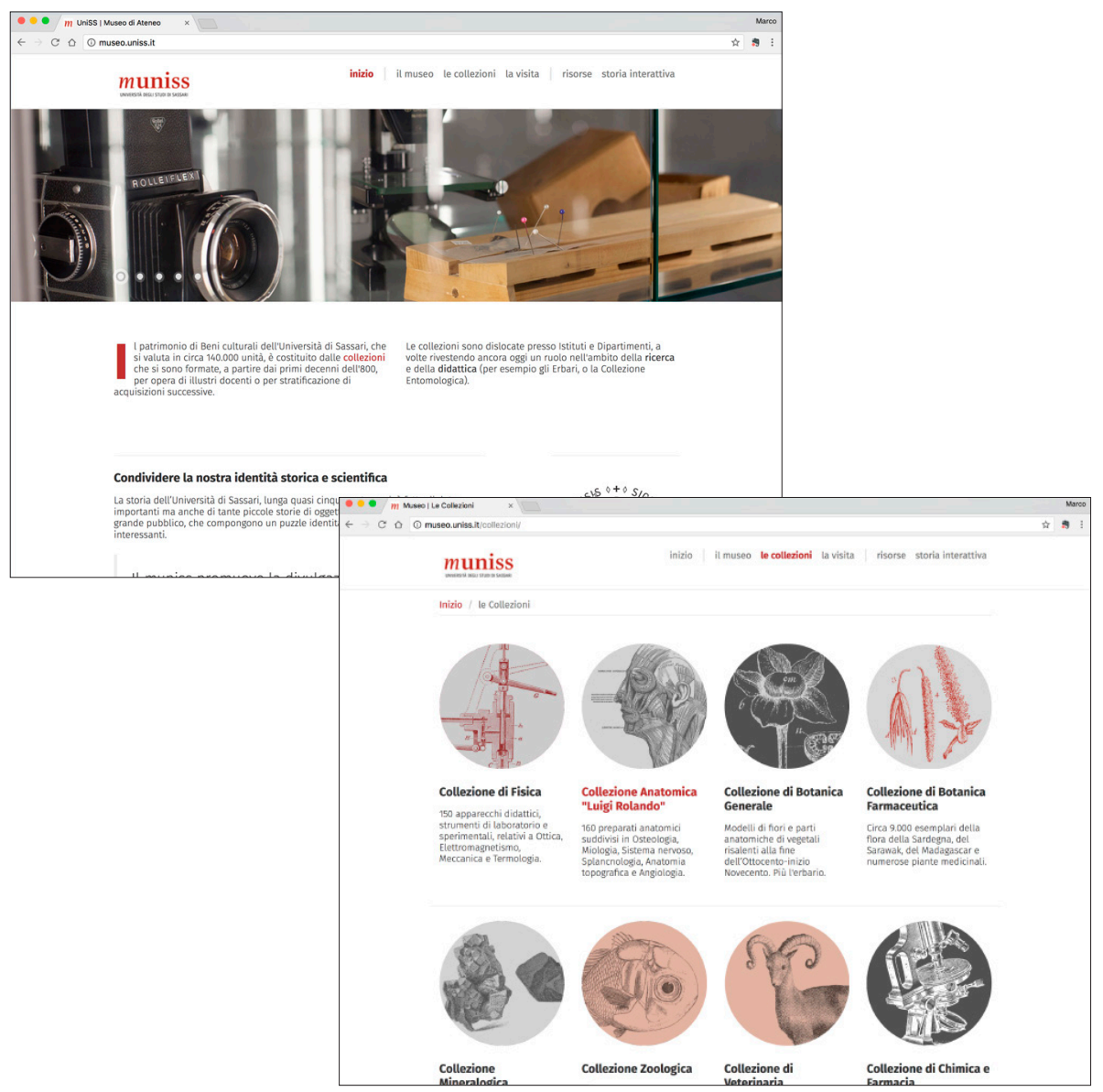

Fig. 6. Home page and Collection index from the website. 
each sub-collection. Its contents aimed at channeling the public's initial fascination risen by the historical artifacts -towards a more comprehensive understanding. This is achieved by relating a meaningful selection of the collection items with science's evolution, history and culture with an appropriate interpretative grid.

A key component of this part of the project is an interactive timeline which is intended either as a tool for on-line visitors and as an aid to run on-site multimedia interactive presentations to the collection. The key objective of this arrangement is to present a conceptual framework representing both the temporal transformations occurred in the relationship between scientific research, culture, politic and everyday life, and how a relatively marginal and peripheral university like Sassari was in fact part of a wider cultural and scientific network.

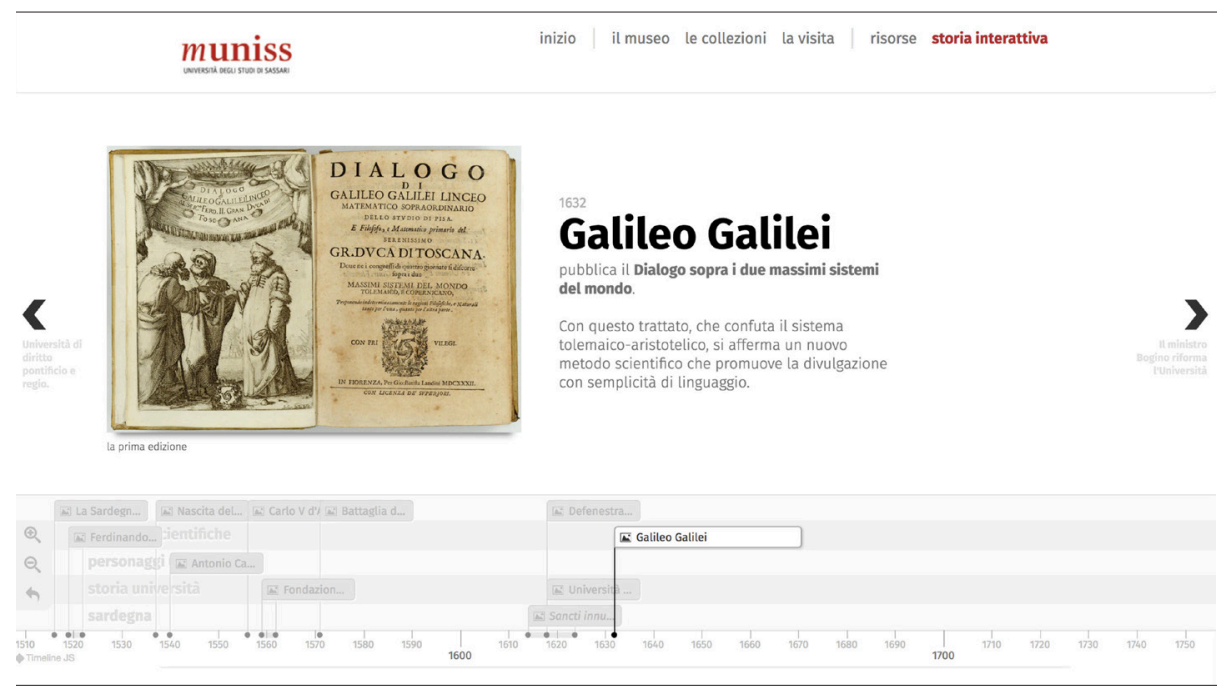

Fig. 7. mUNISS interactive timeline.

This specific objective was sought after by combining the evolution of scientific thought, some historical milestones and a selection of well-known UNISS researchers and of events or taking place in the specific local environment of Sassari and North Sardinia. Based on the open source model developed by North-Western University's Knight Laboratory ${ }^{1}$, the timeline was launched with a basic informative structure, developed under our supervision, and was opened to contributions either by other scholars (either from our university or not) as well as from the general public.

Opening the informative base already available to forms of 'external' contributions, takes a significant role in our digital dissemination strategy. In our vision, every item

1 https://knightlab.northwestern.edu 
belonging to the collections represents an opportunity, a starting point, to investigate further on the scientific topic it was originally designed for. In fact, while scientific instruments are due to become obsolete in time, a large part of the scientific topics maintain their interest and relevance, and evolve with new hypothesis and alternatives explanations.

The website hosts a small library of audiovisual modules that we created thanks for a research grant from the Italian Ministry for University. This first critical mass is intended as a prototype, a starting point to be expanded in the future. The artifacts we created for this section of the website where developed as first elements of three possible series:

1. the "Introduction to the collections" series provides an overview of two (entomology, mineralogy) of the museum main collections. Some of the highlights of each collection showcased and some information about the collection origin and history are also presented.

2. the "Book tales" series is intended as a tribute to the role of printed books in the dissemination of knowledge. The short audiovisual modules we created, present two 19th century volumes (Gray's anatomy, by H. Gray and H. Vandyke Carter, and the Ichonographia by A. Fiori), selected from the University Library's historical collections.

3. The "Experiences" series where developed as multimedia aids to demonstrate the functioning of a selection of the $19^{\text {th }}$ Century historical instruments from the Physics collection. The audiovisuals document the actual experimental conditions, recreated with the assistant of an expert and integrated by 3D and computer visualizations we expressly developed for the project.

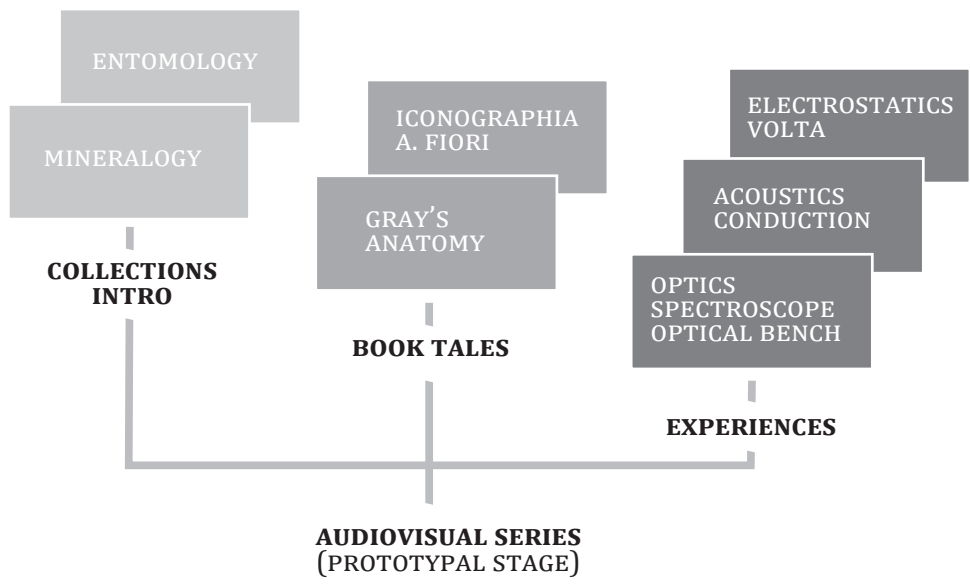

Fig. 8. The audiovisual modules hosted in the digital library. 
The audiovisual modules have been thought as learning tools, to be experienced either independently by individual users or in a guided environment, such as a classroom. The modules were developed and made available hoping they would be shared and distributed through social networks.

The idea behind their creation was in fact that, once on-line, they could become part of a wider network of scientific open-access contents. In this perspective, the informative artifacts we developed for the project represent - following the path of others institutions like the Gabinetto di Fisica of the University of Florence ${ }^{2}$ or the $\mathrm{MIT}^{3}$ - our humble contribution to a new digital scenario in which "Massive Open Online Course" (MOOC) and others less structured contents contribute in reshaping the landscape of formal and informal education.
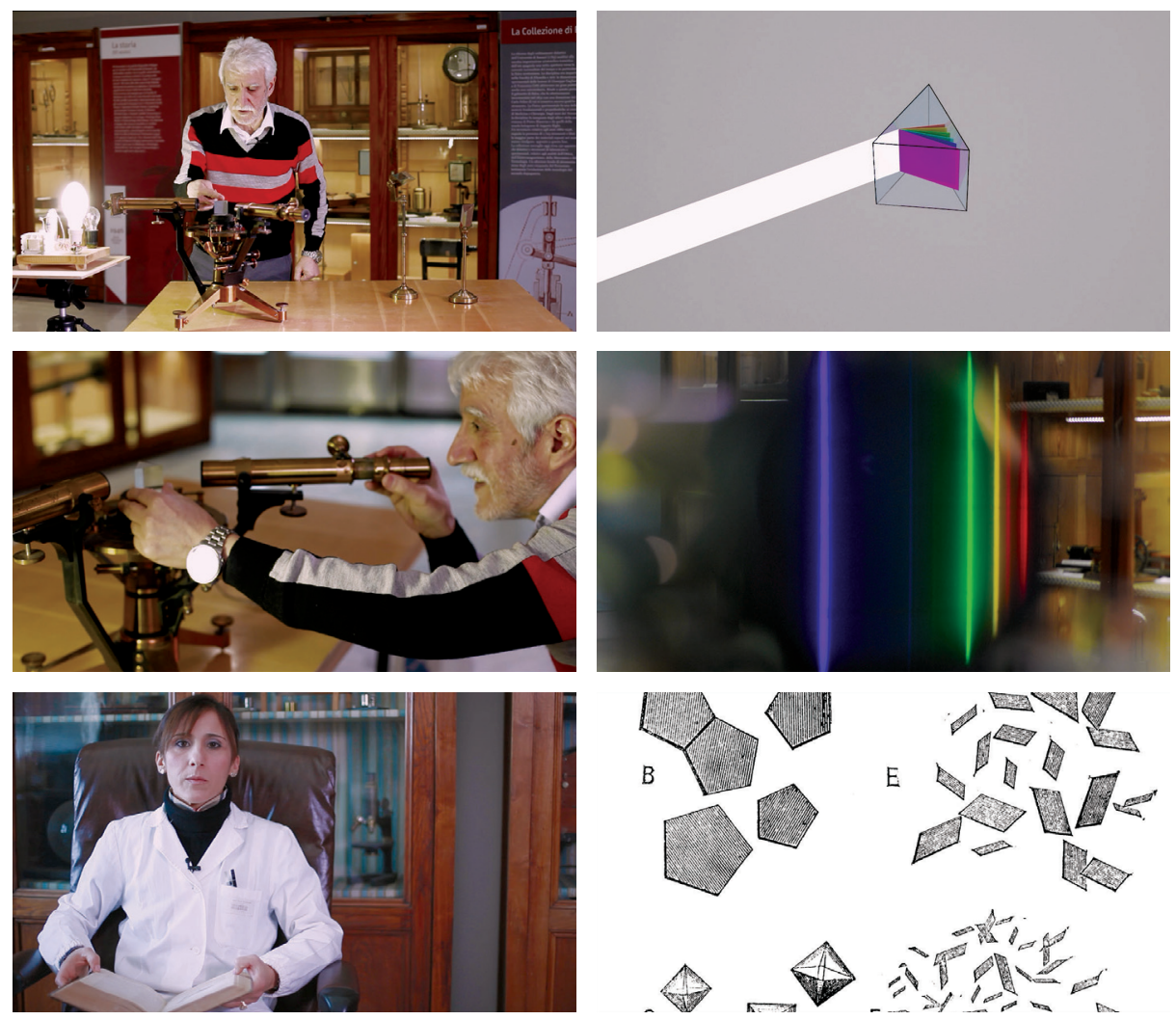

Fig. 9. Frames from the audiovisual artifacts hosted in the digital library.

\footnotetext{
${ }^{2}$ Università di Firenze - Gabinetto di Fisica: http://www.fstfirenze.it/gabinetto-di-fisica/

${ }^{3}$ MIT Open Courseware: https://ocw.mit.edu/
} 
The direct involvement of various members of the academic community as experts, consultant, co-creators and - often - even as presenters in front of the camera, was a great opportunity for consolidating a community of interest around the museum's activities. The idea of involving the university academic body in the development and production of such audiovisual contents was instrumental to stimulating the local community in having a part in the new museum project.

Promoting such an involvement, we believe, ought to be considered a main asset for any kind of cultural enterprise, in terms of developing a fruitful and dialectic interaction with its public. On the other side, speaking in strictly technical terms, although possibly more effective in productive terms, resorting to professional speaker as presenter would have not been as effective as the presence of a member of the actual community.

Digital media represents a great opportunity to enhance the way heritage information can be delivered to a museum's public, at the many different stages of their complex relationship. Online-contents can be used before the visit, during its planning, or after that, as an opportunity for recall to memory or for further inquiry. And of course they can, to some extent, substitute the visit itself. Nevertheless, in our vision for the mUNISS project, the coexistence of both the physical and digital dimensions does provide the opportunity of orchestrating a more comprehensive experience.

\section{PHISICAL SPACE}

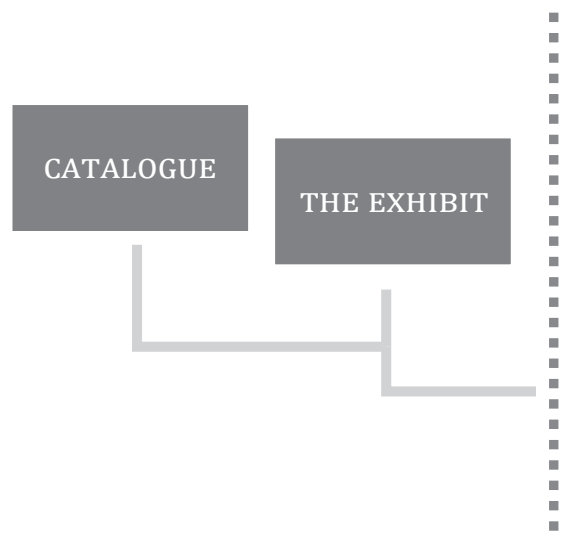

VIRTUAL SPACE

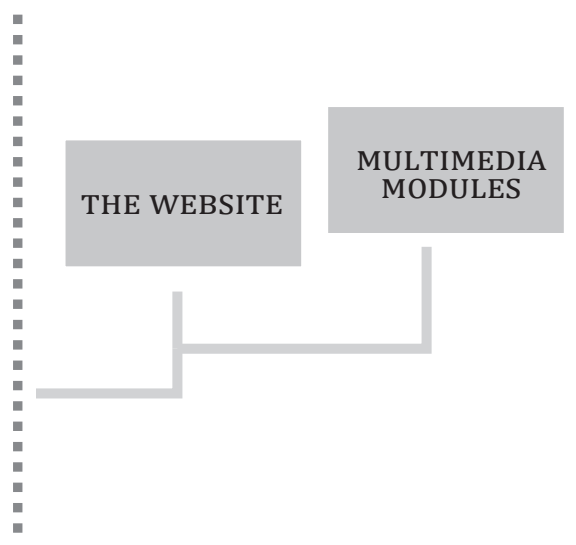

Fig. 10. Having the physical and virtual dimensions interplay. 


\section{A systemic approach}

The reference model for our project is a contemporary and multidisciplinary systemic approach based on a strategy in which a complex "multi layered" system of informative elements gives shape to a peculiar approach to communication. Designers are increasingly (Anceschi 2003) taking the role of "directors" or "coordinators" rather than of "creators". An essential requirement for pursuing this approach is to foster a fluid dialog among the various stakeholders involved in the project. Such a dialogic attitude, today a frequent component of design practices, has strong roots in the tradition of Italian design. This is the case, for instance, of the work carried out in the 50's and 60's by some well-known authors. In Albe Steiner's or Roberto Sambonet's graphic work - that anticipated today's generative approach to logos and monograms, for instance, (Camuffo et al. 2012) or in the exhibit design projects by Castiglioni, Tovaglia and Huber, and noticeably in the "comprehensive" and "integrated" designs by Achille and Pier Giacomo Castiglioni (Migliore et al. 2018).

\section{Conclusions}

The strategic criteria upon which the mUNISS project was developed are inherently systemic, as they take advantage from the active intersections between various design disciplines, underlining their common roots and tracing new areas of application in the domain of communicating complexity.

Our approach starts by giving up any methodological shortcuts or off the shelf solutions. In this approach, basic preliminary research is carried out to generate a "conceptual cartography" and letting, once established the final goal/destination of our design journey, the project 'find its own way to its solution' - approaching the final goal by a progressive fine tuning process. Along this eventful path, different skills and design elements of knowledge need to be orchestrated and combined in order to converge towards to a common integrated design proposal.

By operating strategically, communication design can efficiently contribute to the diffusion of knowledge. It can promote its dissemination by helping - new and old public institutions playing their role in the contemporary scenario of global and digital communication networks.

In mUNISS' project key role is played by the contribution of a wide area of potential users-actors (Manzini 2015), urged to take action, often by sharing their knowledge and their passionate relationship with the collections and with the artifacts on display. In our vision, this is a key step towards sowing the seeds for the birth of a first nucleus of a new community. 


\section{References}

Anceschi, G. (2003, June). Progetto grafico. Progetto Grafico, n. 1, p. 3.

Camuffo, G., Piazza, M., Vinti, C., Annicchiarico S. (Eds). (2012). TDM 5: Grafica italiana. Mantova : Corraini.

Lorenc J. (2007). What is exhibition design? London, Rotovision.

Magatti, M., (2009), Libertà immaginaria. Le illusioni del capitalismo tecno-nichilista, Feltrinelli : Milano.

Manzini, E. (2015). Design when Everybody Designs. An Introduction to Design for Social Innovation. Cambridge, MA : the MIT Press.

Mattone, A. (2010), Storia dell'Università di Sassari, 1, Nuoro : Illisso Edizioni.

Migliore, I., Servetto, M., Lupi, I., Ossanna Cavadini, N. (Eds). (2018). Achille Castiglioni visionary. The installational alphabet of a designer director. Milano : Skira.

Università di Firenze - Gabinetto di Fisica: http://www.fstfirenze.it/gabinetto-di-fisica/ MIT Open Courseware: https://ocw.mit.edu/ 


\title{
Visualising Spatial Complexity of Urban Sites
}

\author{
Alan Mee \\ UCD School of Architecture Planning and Environmental Policy, \\ University College Dublin, \\ Richview School of Architecture, UCD Richview, Dublin 14, Ireland \\ alan@mee.ie
}

\begin{abstract}
Recent research has linked urban design to artistic practice, and it is suggested that urban design could become refocused if conceived of as an integrative art of place. However, the urban design research methods literature is silent on the topic of artistic practice, and therefore the potential for interpretative, abductive knowledge to emerge from creative visualisation in urban design is under-appreciated. More specifically, regarding evaluation for urban design, complexity theories of cities claim that understanding complexity in particular enhances our ability to organise knowledge in relation to cities, and it is further argued that complexity theory responds to a need for a knowledge leap in planning, design and maintenance of cities, to rise to global urban challenges and crises. In this context, visualising spatial complexity of urban sites through artistic practice is useful to urban design. The specifically spatial complexity of urban sites, (as the spatial component of urban complexity), has not previously been explored, evaluated or visualised for urban design. This paper argues that in creatively visualising spatial complexity, multi-scalar, relational and temporal aspects of the urban built environment can be captured, and this visualisation communicates a unique 'signature' of each urban site.
\end{abstract}

Keywords: Spatial complexity / urban design / artistic practice / visualisation.

\section{Introduction}

In this paper, a conceptual framework of visualising spatial complexity of urban sites is developed, to represent a prior evaluation which measures three issues and nine criteria of spatial complexity, in order to reveal and understand the relationships between compositional, configurational and systems aspects of urban sites. In the first section, related concepts of spatial complexity, representation and visualisation theory are briefly defined and discussed. The second section looks at the role of artistic practice in urban design visualisation. The third section sets out the visualisation approach of this study and the data transformation tasks undertaken. 
Then three key tools for visualisation of the evaluation of spatial complexity are proposed: Tables, Plots and Boxes. These devices are employed in order to capture the explored and evaluated conditions in a visually coherent complexity frame. Examples of these are illustrated, and the tools are compared in relation to the data dimensions spectrum of digital visualisation. Four particular benefits to urban design practice of employing appropriate visualisation of spatial complexity are suggested. Firstly, to stimulate urban design process: secondly, to bring visual clarity to quantitative assessment: thirdly, to allow qualitative interpretation by a wide community around evaluation, and lastly, to allow formal measurement and informal interpretation of results Following discussion of the visualisations presented, some conclusions and further recommendations are proposed in relation to visualising spatial complexity of urban sites.

\section{Spatial complexity, representation and visualisation theory}

The urban environment is complex [1], [2] and complexity is associated with data rich environments [3] like cities. In this context, information visualisation is transforming understandings of urban environments. Regarding evaluation for urban design, complexity theories of cities claim that understanding complexity in particular enhances our ability to organise knowledge in relation to cities, and it is further argued that complexity theory responds to a need for a knowledge leap in planning, design and maintenance of cities, to rise to global urban challenges and crises. In the spatial sciences, the concept of spatial complexity (the spatial component of urban complexity) has a large visual dimension, and has been categorised by pattern recognition in pixels of aerial views at large scales [4], classification of spatial complexity of rural landscapes [5] and recognition of fractal or geometrical patterns across population, remote sensed imagery and street network representations [6]. Research has sometimes implied that the visual dimension is the predominant property of spatial complexity [7] and the concept of visual complexity has an extensive supporting literature [8], [9], [10], [11]. While other important research focuses on the theoretical, mathematical, configurational aspects of spatial complexity, this paper focuses on visualisation of spatial complexity. While theoretical concepts of 'visuality' and 'scopic regime', relating to the ways in which both what is seen and how it is seen are socially constructed, it is sometimes suggested that the 'privileging' of the visual empowers the researcher, thus reducing objectivity. It is argued that understandings of visualisation require knowledge about provenance as well as the social work that the image does' [12]. In the field of visual research, a critical visual methodology approach [13] is proposed in the analysis of visual culture, including close attention to the actual visual artifact, thinking about the social conditions and effects of visual objects, and consideration of the researchers approach to viewing images. Visual research methods for design tend to emphasise the visual features of the built environment [14] and include evaluative responses for urban design [15], whereby general principles in aesthetics related to urban environments are sought. 
Stanczak [16] emphasises the need for reflexivity in considering visual research methods ${ }^{1}$, and this paper adopts an abductive reasoning logic approach to visualisation of spatial complexity, making reasonable and logical claims, without being definitive [17].

Data-informed urbanism [3] is seen as a key emergent phenomenon globally, as cities are increasingly the generators of big data. This form of urbanism is being complemented and replaced in some instances by data-driven, networked urbanism as 'cities are becoming ever more instrumented and networked, their systems interlinked and integrated, and vast troves of big urban data are being generated and used to manage and control urban life in real-time' [3]. In this context, developments such as 'city-dashboards' (live feeds of real-time data communicated to citizens) are improving on simply providing raw data by producing visualisations that aid interpretation and analysis, especially for non-expert users, 'allowing citizens to monitor the city for themselves' [17]. Although visualisation is not new ${ }^{2}$, visual representation of data has emerged as a significant factor in communicating complex data sets including evaluation related to urban environments. The intersection of researcher and tactics or tools is subject of debate in artistic research ${ }^{3}$ and in architecture and design [18], where tools are sometimes associated with a 'practice' rather than a 'research' aim. In defining the term 'tools' in relation to urban design evaluation processes, Gil describes the term 'tool' as 'used in a broad sense, encompassing a range of design and decision-support instruments' [19], the meaning adopted in this paper. In the broader research on spatial complexity by the author (of which this paper forms a part) ${ }^{4}$ two distinct types of 'tool' are employed: evaluation tools and visualisation tools. Only the visualisation tools are concentrated on in this paper.

\footnotetext{
${ }^{1}$ Stanczak (2007), in discussing visual research methods for social sciences, describes an epistemology of visual research methods, as follows: 'just as subjectivity and realism interact in the space between the image and the viewer, the same happens between the producer of the image and the subject or content. We may select the time and space that we want to capture, but the mechanical operation of the camera will document all that is before it in that moment. In other words, the camera is susceptible to the selectivity of the operator, but it is not selective once the shutter is opened (Collier \& Collier, 1986)' [16].

${ }^{2} \mathrm{Dr}$ Snow's linking of the spread of cholera to water supply in London in 1854 is an early example of data visualisation [20].

${ }^{3}$ Lesage (2009) describes the concept of artistic research as follows: 'The notion of artistic research implies that artistic practice can be described in a way more or less analogous to scientific research. An artistic project, then, begins with the formulation, in a certain context, of an artistic problem, which necessitates an investigation, both artistic and topical, into a certain problematic, which may or may not lead to an artwork, intervention, performance or statement, with which the artist positions himself/herself with regard to the initial artistic problem and its context' [21]. The distinction of the artistic research approach as defined here from the urban design research approach of this study is discussed in Section 4.5.2.

${ }^{4}$ See (Mee, 2017) PhD titled: 'Exploring, Evaluating and Visualising Spatial Complexity of Urban Sites'. Abstract available at https://arrow.dit.ie/appadoc/79/
} 


\subsection{Artistic practice and urban design visualisation}

This section briefly addresses art practice and urban design visualisation. In relation to evaluation results of urban design analysis, numerous researchers have recently linked urban design and artistic practice [22], [23] with a proposal that urban design could become refocused if conceived of as an integrative art of place [23]. In information design, Tufte sees the world as 'complex, dynamic, multidimensional; the paper is static, flat. How are we to represent the rich visual world of experience and measurement on mere flatland ?' [24]. In his book, 'Beautiful Evidence', Tufte emphasises the importance of including multiple types of evidence in research: 'Evidence that bears on questions of any complexity typically involves multiple forms of discourse. Evidence is evidence, whether words, numbers, images, diagrams, still or moving' [25]. Onwuegbuzie et al's presentation of a broad taxonomy of visual representation of mixed methods research includes connections made to mixed methods research outputs generally, suggesting that graphical methods have particular strengths in this regard [26]. The recent urban design research methods literature is silent on the topic of creative or artistic research methods [27]. As regards the relevance of the art of urban design, (or of 'art' to the practice of urban design) it was demonstrated in the wider study by the author, especially in the exploratory stages, that the interpretative, artistic interpretation of the infographics employed enable 'abductive' knowledge to emerge, and that this knowledge contributes to later, more hard-scientific, evaluation results. Hence, it can be concluded that the interpretative, creative aspects of urban analysis do have a place in urban evaluation and therefore do contribute to urban design practice.

\subsection{Visualisation approach and data transformation tasks}

Having discussed the links between spatial complexity, representation and visualisation theory, and then focused more directly on artistic practice and urban design visualisation, this section moves to describing the visualisation approach of this research and paper and some of the data transformation tasks undertaken. Prior evaluation of three case study urban sites in Dublin, Ireland, was undertaken in the wider study, and the approach to visualisation of results is the focus of this paper. Three sites were evaluated as having distinct and contrasting conditions of evaluated spatial complexity: low (Carmanhall), medium (Ballymun) and high (Liberties). In case study research it is a primary strategy that data sources, data types or researchers are triangulated appropriately, in order that it can be established that phenomena have been explored and viewed from multiple perspectives. Clear and accessible visual representation of this multi-scalar and multi-criteria analysis is important in this regard. Correlation and comparison of case study data enhances overall data quality based on the principles of idea convergence and the confirmation of findings [28]. The data gathered converges to illuminate the cases as well as the conditions studied in a new way. The fact that indices of spatial complexity vary related to time, scale and geography, and that these necessarily vary in each demonstrative case 
study unit, means that linkages between cases and indices become a rich source of descriptive account of phenomena.

In information design, a distinction is made between data visualization and infographics, whereby the former is associated with algorithmic generation and the latter with manually generated images. Data visualization, in categorization terms, is considered to have two types, exploration and explanation (lliinsky et al, 2011:7), and each suggests different approaches and tools. So while exploratory data visualizations are associated with high levels of granularity, where large amounts of data are in play, at the data analysis phase of a project, the narrative emerging from the data is still to be set. Explanatory data visualizations, in contrast, are seen as connected more to facts which are already known to the designer/researcher, and to reporting more concrete results, and as part of the presentation phase of a project.

However, Iliinsky [29] also proposes a third category, which is useful to this study, the hybrid 'exploratory explanation data visualization', seen as 'a curated dataset' [29], which is presented in a way that allows the reader to interact with the dataset in some way. Information, persuasion and visual art are also considered relevant and important in understanding concepts of data visualization [29], and it is in this respect that the connection between data visualizations and urban design as art becomes important to this study. Iliinsky [29] suggests that there are three main categories of explanatory visualizations based on the relationships between the three necessary players: the designer, the reader, and the data, considered as three essential supports to effective explanatory (or hybrid) data visualization. However, the dominant relation between two of these elements will determine the type of data visualization needed. Informative, persuasive and 'visual art' data visualizations are considered the three types to consider in deciding on data visualization type or categorisation. So while informative visualizations distill information into consumable form (eg. for a newspaper), persuasive type visualizations seek to change a readers mind about something, from a specific point of view. The third category, visual art, is considered to serve primarily the relationship between the designer and the data [29]. Visual art is considered to be 'unidirectional' in form, that is, the reader may not be able to decode the visual presentation to understand the underlying information [29]. So while 'both informative and persuasive visualizations are meant to be easily decodable-bidirectional in their encoding-visual art merely translates the data into a visual form' [29]. From the review of the data visualization literature, it is concluded that the majority of the visual representations in this study are in the hybrid 'exploratory explanation data visualization' category. Exploratory infographics are especially employed in the exploratory 'whole-city' explorations of spatial complexity. However, exploratory data visualizations are also derived and employed. These are especially used in visualising the case study evaluations, to further informative and persuasive aims of the overall study. As regards data transformation tasks, three key tools for visualisation of the evaluation of spatial complexity are employed: Tables, Plots and Boxes. Each is employed both in linear, consecutive fashion (Table prepared first, then Plot, etc) but also all three can be used simultaneously and iteratively (for example in urban designing) in a complexity frame. 


\subsection{Evaluation Table}

An Evaluation Table is proposed as the first key tool of visualisation of the evaluation of spatial complexity. This tool has two data dimensions (across top of Table and vertically along one side), is updated manually and results in a shallow, infographic type output. In terms of data transformation [30], quantification of qualitative data is shown in the Spatial Complexity Evaluation Table, where urban morphological complexity analysis, though including 'metrics' also has a more qualitative, text driven aspect, leading to evaluation. In this study, qualification of quantitative data involves interpretation of mathematical measures of spatial complexity (for example 'integration'), broadening descriptions into high, medium or 'low'. In order to visualise that equal weightings applying to these criteria are interrelated, and in order to allow comparisons across cases, colour weightings are applied to the Table. A matrix is recommended in data analysis for comparison of quantitative and qualitative data. In this research, the primary matrix-type evaluation tool takes the form of the Spatial Complexity Evaluation Table, and (at a lower level) a separate matrix of compositional complexity metrics, represented as a Table of Compositional Criteria. The separate matrices allow that data can be compared within, between and across urban sites, but also with other data from previous studies of the constituent criteria of spatial complexity. In this way, individual characteristics of the sites (like for example, evaluated density) can be compared, or the spectrum of densities evaluated across three urban sites in Dublin could be compared directly with international examples, in order that proposed design densities are shown to be appropriate. This is an example of the first of four particular benefits to urban design practice of employing appropriate visualisation of spatial complexity: to stimulate urban design process.

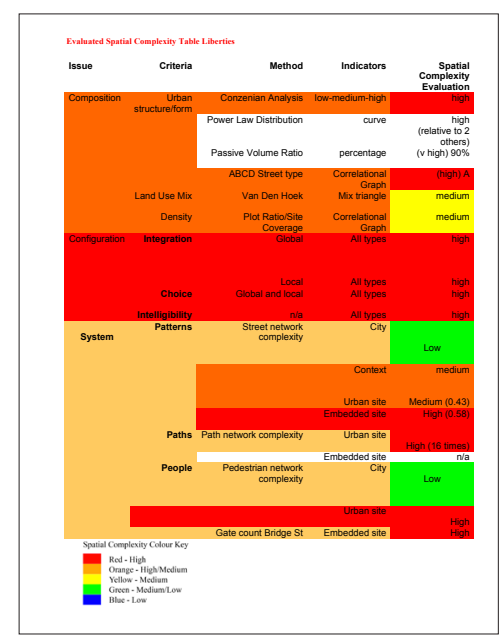

Fig. 1. Coloured Spatial Complexity Evaluation Table 


\subsection{Spider Plot}

Spider plot is proposed as the second key tool of visualisation of the evaluation of spatial complexity. This tool has nine data dimensions (around a centre of the graphical web, nine evaluated criteria of spatial complexity are recorded graphically, from low, at the centre, to high, at the edge). Although this graphic is updated manually it results in a relatively medium rich 'data depth', but still exists as an infographic type output. As regards visualization tools in the decision-making process related to evaluation, in particular for complex issues, so-called 'spider analysis' is recommended for comparative and scenario studies [31]. Defined as 'an analytical tool, which can be used to visualize the relative strengths and weaknesses of the selected case studies or different scenarios for various chosen factors' [32]. It functions, not as a mathematical tool, but as a visual analysis instrument. The 'spider' refers to the appearance of a spider's web, and the scores of each factor are plotted on an axis which has lowest scores at the centre, working outwards towards higher values. The resulting image is called a spider plot. According to Baycan-Levent, the scores may be qualitative (ie. ordinal rankings) or quantitative (eg. standardized on a 10 point scale). In recent urban design evaluation, Serra, Gil, \& Pinho [33] have used this model to illustrate and apply a 'taxonomic nomenclature' evolving street patterns, and Mehta has used this format to visualize indices of evaluation of public space. Mehta argues that the value of the index developed is 'not in absolute values or scores but by the graphic representation of the spaces' [34]. A spider plot format can visually summarise both the quantitative and qualitative aspects of the urban site evaluations, and in simple form can be based on either lines alone, or lines and colour. Quick summary impressions of relative levels of evaluated spatial complexity can be achieved with spider plots, and visual comparisons within, between and across urban sites are improved by spider plot preparation. This is an example of the second of four particular benefits to urban design practice of employing appropriate visualisation of spatial complexity: to bring visual clarity to quantitative assessment.

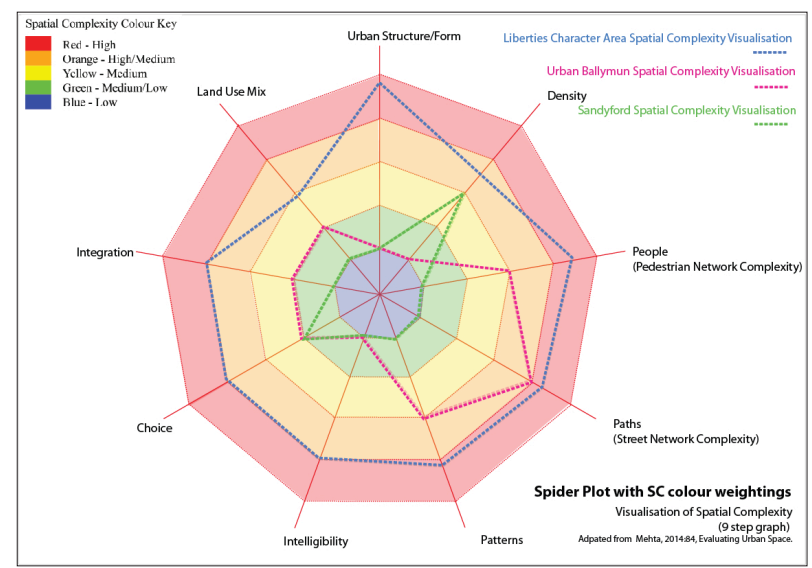

Fig. 2. Coloured Spatial Complexity Evaluation Table 


\subsection{Databox}

A Databox is proposed as the third key tool of visualisation of the evaluation of spatial complexity. This Spatial Complexity Databox tool has thirty-six data dimensions (three spatial dimensions, $X, Y$ and $Z$, as axes of a display cube, time as a fourth 'dimension', and nine evaluated criteria of spatial complexity, recorded graphically in 'heat-map' terms, on volumetric digital models of urban blocks and structures). The incorporation of a temporal dimension adds a dynamic aspect to the tool. This graphic could be updated automatically and algorithmically. It results in a rich 'data depth', and therefore can be categorised as an explanatory data visualisation type output. The concept of a 'spatial data cube' is defined as a unit of organisation of spatial data which facilitates data mining and 'organization of data into multidimensional structures and hierarchies' [35]. Two important components of the Spatial Complexity Databox, the 'voxel' and a 'spatiotemporal database', are now described. Hong's conceptualization of the 'voxel' or 'volumetric pixel' was developed in order to facilitate a theory of 'interdependant urbanism', which involves, in the authors terms, 'simulating interdependent complexity, beyond prescriptive zoning' [36]. Hong suggests that this innovation can improve on land use and development zoning in cities. Hong also argues that computation can play a major role in urban design, 'by leveraging performance based zoning standards instead of prescriptive rules'. His innovation is in representing performance of the urban environment through 'simultaneous evaluation' of variables ('daylighting, building cores, proximity to parks, programming and other factors') in order to give immediate feedback to designers, planners and stakeholders about the existing urban environment as well as potential urban design scenarios. He employs Rhinoceros and its Grasshopper plug-in software in conjunction with the programming language Python. After describing a number of novel tools which pertain to 'the generation of maximum envelopes' of urban form (for example seek optimal design forms related to sunlight and sky exposure) Hong goes on to discuss the idea of the 'voxel' (short for volumetric pixel) as a way to subdivide this overall mass and imbue it with qualitative data in the form of both inputs and outputs ${ }^{5}$. In another innovative approach to visualization of spatial data, Hahn et al define a 'spatiotemporal database' as a 'spatial database that stores spatial objects that change with time' [35]. These trends in urban data visualization are reflected in other enquiries, including investigations from architecture like 'information urbanism', [37] and 'parametric urbanism' [38], and geographical research into 'data-driven, networked urbanism' [15] though the latter is still primarily represented in two dimensional plan. These two concepts, of the 'voxel' and a 'spatio-

\footnotetext{
${ }^{5}$ Hong describes the advantages of the voxel as follows; 'Designers have the freedom to assign any number of parameters to the voxels, limited only by computation power. For our test case we included such factors as minimum daylight factor, views, circulation, and proximity to open space. From these inputs, qualitative outputs, or 'readings', of data are produced. The voxels thereby become an interconnected mesh, as data output from one voxel can be fed into the input of another, allowing interdependencies to ripple through the entire model.' [36].
} 
temporal database' are incorporated within the idea of the Spatial Complexity Databox proposed in this paper. The Databox is in digital form, and can be manipulated by any user of the interface, with no technical or professional training required. This is an example of the third of four particular benefits to urban design practice of employing appropriate visualisation of spatial complexity: to allow qualitative interpretation by a wide community around evaluation.

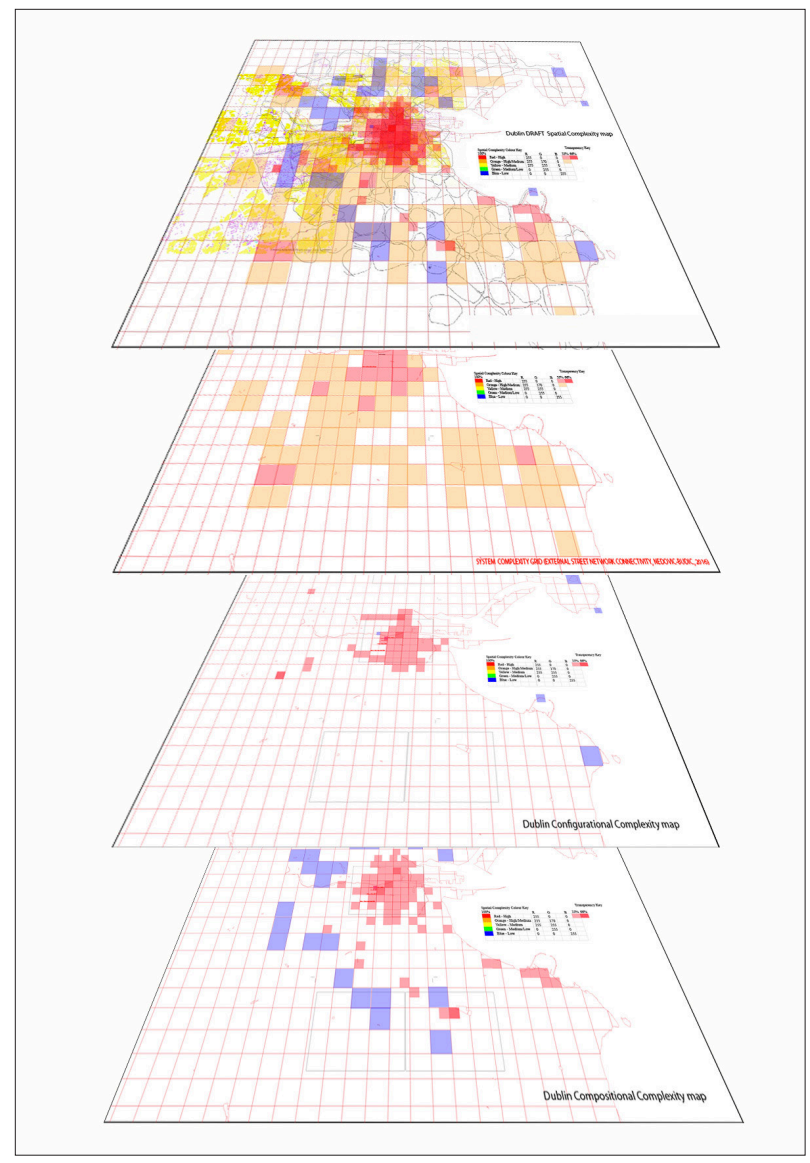

Fig. 3. Spatial Complexity Databox

\section{Discussion}

In summary, three key tools are proposed for visualisation of the evaluation of spatial complexity: Tables, Plots and Boxes. As described, all three can be used simultaneously and iteratively to represent evaluation, but also have other applications (for example in urban designing) within a complexity frame. Seen together, these visualisations graphically establish a unique 'signature of spatial complexity' for each urban 
site. The visualisation involves communicating quantitative analysis and also qualitative data, judgement in graphically representing and joining both, and combining these in a visually clear form. This is an example of the last of four particular benefits to urban design practice of employing appropriate visualisation of spatial complexity: to allow formal measurement and informal interpretation of results to be combined.

\section{Conclusions}

Spatial complexity (the spatial component of urban complexity) has previously been visually represented in hard-scientific domains through pattern recognition in pixels of aerial views at large scales [4] classification of rural landscapes through macro scale mapping [5], and recognition of fractal or geometrical patterns across populations, remote sensed imagery and street network representations [6].However, these approaches tend towards a single scale of analysis, single disciplinary applications, and are fixed or 'static' snapshots of a moment in time. This paper (and the wider study) confirms that dynamic visualisation of spatial complexity incorporating some key tools can improve on more 'hard-scientific' (or 'science of cities') evaluation of urban sites, related to description of evaluation. In creatively ${ }^{6}$ visualising spatial complexity, multi-scalar, relational and temporal aspects of the urban built environment can be captured. It is shown that artistic visualisation of spatial complexity contributes to improved urban design practice and more detailed understanding of existing urban site conditions. Furthermore, it is demonstrated that visualisation of evaluation of urban sites matters to urban design. Four particular benefits to urban design practice of employing appropriate visualisation of spatial complexity are suggested. Firstly, to stimulate urban design process: secondly, to bring visual clarity to quantitative assessment: thirdly, to allow qualitative interpretation by a wide community around evaluation, and lastly, to allow formal measurement and informal interpretation of results to be combined, which in turn involves a wider group of stakeholders around evaluation.

6 In defining what constitutes 'creative' in this context, Caliskan (2012) [39], distinguishes between artistic or creative invention (essentially independant of any functional or pragmatic incentives) and Gero's definition of 'design' ('goal-oriented, constrained decision-making, exploration and learning activity that operates within a context that depends on the designer's perception') (Gero, 1990 ) [40][39]. 


\section{References}

1. Barredo JI, Kasanko M, McCormick N, et al. (2003) Modelling dynamic spatial processes: simulation of urban future scenarios through cellular automata. Landscape and Urban Planning 64: 145-160.

2. Rydin Y, Bleahu A, Davies M, et al. (2012) Shaping cities for health: complexity and the planning of urban environments in the 21st century. Lancet 379: 2079-2108.

3. Kitchin R. (2015) Data-driven, networked urbanism. Data and the City Workshop, Maynooth, Co. Kildare, Ireland.

4. Haghani T. (2010) Fractal Morphology \& Urban Complexity. Phd Thesis, School of Architecture, BIAD, Birmingham City University (BCU), UK.

5. Laterra P, Orúe ME and Booman GC. (2012) Spatial complexity and ecosystem services in rural landscapes. Agriculture, Ecosystems \& Environment 154: 56-67.

6. Batty M. (2011) Building a Science of Cities. Cities: 1-8.

7. Bhat R. (2014) Understanding complexity through pattern languages in biological and man-made architectures. 2014 8: 10.

8. Lynch K. (1984) Reconsidering the image of the city: Springer.

9. Heath T, Smith S and Lim B. (2000) The complexity of tall building façades. Journal of Architectural \& Planning Research 17: 206-220.

10. Tucker C, Ostwald M, Chalup S, et al. (2005) A Method for the Visual Analysis of the Streetscape. University of Newcastle.

11. Ostwald MJ, Vaughan J and Tucker C. (2015) Characteristic visual complexity: Fractal dimensions in the architecture of Frank Lloyd Wright and Le Corbusier. Architecture and Mathematics from Antiquity to the Future. Springer, 339-354.

12. Fyfe $G$ and Law J. (1988) Picturing power: visual depiction and social relations: Routledge.

13. Rose G. (2007) Visual Methodologies An Introduction to the Interpretation of Visual Materials, London: Sage Publications.

14. Sanoff H. (2016) Visual Research Methods in Design (Routledge Revivals): Routledge.

15. Nasar JL. (1994) Urban design aesthetics the evaluative qualities of building exteriors. Environment and Behavior 26: 377-401.

16. Stanczak GC. (2007) Visual Research Methods: Image, Society, and Representation: SAGE Publications.

17. Kitchin R. (2014) Big Data, new epistemologies and paradigm shifts. Big Data \& Society 1.

18. Nilsson F and Dunin-Woyseth H. (2014) Design Education, Practice, and Research: On Building a Field of Inquiry. Studies in Material Thinking 11.

19. Gil J, Duarte, José. (2013) Tools for evaluating the sustainability of urban design: a review. Proceedings of the ICE - Urban Design and Planning 166: 311-325.

20. Minty E, Maccallum P, Fisher J, et al. (1995) Scientific Visualisation: A Practical Introduction.

21. Lesage D. (2009) Who's Afraid of Artistic Research? On measuring artistic research output. A Portrait of the Artist as a Researcher. Antwerp: The Academy and the Bologna Process/MuHKA: 84-93.

22. Boyko CT, Cooper R, Davey CL, et al. (2010) Informing an urban design process by way of a practical example.

23. Marshall S. (2015) Refocusing urban design as an integrative art of place. Proceedings of the Institution of Civil Engineers Urban Design and Planning 168: 8-18.

24. Tufte ER. (1990) Envisioning Information, Cheshire, Connecticut, USA: Graphics Press.

25. Tufte ER. (2006) Beautiful evidence. New York. 
26. Onwuegbuzie AJ and Leech NL. (2007) Validity and qualitative research: An oxymoron? Quality \& Quantity 41: 233-249.

27. Carmona ME. (2014) Explorations in Urban Design An Urban Design Research Primer, United Kingdom: Ashgate Publishing Ltd.

28. Knafl KA and Breitmayer BJ. (1989) Triangulation in qualitative research: Issues of conceptual clarity and purpose. Qualitative nursing research: A contemporary dialogue: 193-203.

29. Iliinsky N and Steele J. (2011) Designing data visualizations: Representing informational Relationships: O'Reilly Media, Inc..

30. Cresswell JW. (2009) Research Design Quantitative, Qualitative, and Mixed Methods Approaches, London: Sage.

31. Baycan-Levent T. (2005) Urban spiders: a comparative framework for evaluation and scenario analysis. Sustainable Urban Development: The environmental assessment methods. 236.

32. Rienstra SA and Nijkamp P. (1998) The role of electric cars in Amsterdam's transport system in the year 2015; a scenario approach. Transportation Research Part D: Transport and Environment 3: 29-40.

33. Serra M, Gil, Jorge, Pinho, Paulo. (2013) Unsupervised classification of evolving metropolitan street patterns. In: Y O Kim HTPaKWS (ed) Ninth International Space Syntax Symposi$u m$. Sejong University, Seoul.

34. Mehta V. (2013) Evaluating Public Space. Journal of Urban Design 19: 53-88.

35. Han J, Kamber M and Pei J. (2011) Data mining: concepts and techniques: Elsevier.

36. Hong J. (2012) Interdependent Urbanism. In: Schröpfer T (ed) Ecological urban architecture: qualitative approaches to sustainability. Walter de Gruyter, $140-150$.

37. Tang $M$ and Anderson J. (2014) Information Urbanism: Parametric urbanism in junction with GIS data processing \& fabrication. ARCC Conference Repository.

38. Schumacher, P., 2009. Parametricism: A new global style for architecture and urban design. Architectural Design, 79(4), pp.14-23.

39. Çaliskan O. (2012) Design thinking in urbanism: Learning from the designers. Urban Design International 17: 272-296.

40. Gero JS. (1990) Design prototypes: a knowledge representation schema for design. Al magazine 11: 26. 

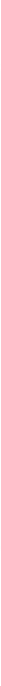
02. Junior track 
Lorella Camellina

IUAV University of Venice,

Santa Croce 191 Tolentini, 30135 Venezia, Italy

lcamellina@iuav.it

\section{Venice Vega Park: history, "more media" and new narrative paradigms}

Established in Porto Marghera in 1992, Vega, the Venice Scientific and Technological Park (STP), aimed to be a research and innovation hub and an instrument for the reclamation and urban regeneration of the city's former industrial district. Vega forms a cluster of approximately 60 companies today but still, it is not viewed as the innovation landmark it was supposed to be, ostensibly because of its past reputation. In 2016 various local stakeholders decided to set up a multidisciplinary research group (IUAV and Ca' Foscari) with the primary purpose of reactivating the Park. The work explores the role that, in this context, Information Design and Data Visualization may serve in conceiving a new narrative paradigm to tell the evolution of the area in the form of an interactive application.The research drew on theoretical references and case studies claiming the disappearance of concepts such as old or new media in favor of the new "more media", and the cancellation of "design neutrality" in favor of visualizations based on specific datasets and representations (Manovich, 2008).

Indeed, the interactive application in question, accessible from a touch foil, allows to navigate three main section (photo database, treemap, data visualization) discovering different materials about Vega and their relationships (Lima, 2011). The choice of these materials resulted from the following steps. A preliminary analysis consisted in mapping historical sources on Porto Marghera. It revealed an abundance of documents that bears witness to the vibrancy of the area in the 


\section{ASSETS}

Interactive data visualization about VEGA's main contemporary assets: digital connectivity and accessibility by public transports.

\section{INFORMATION}

Button to access an overlay of

information about the section.

DATAVIZ ZOOM IN

From a six-hour visualization, to a

two-hour visualization.

\section{RETHORICS}

Treemap based on rethorics related to VEGA.

\section{EVOLUTION}

Database of selected historical

images retrieved from severa

archives.

\section{RESET}

It synchronizes the three sections of

the interface to the starting level.

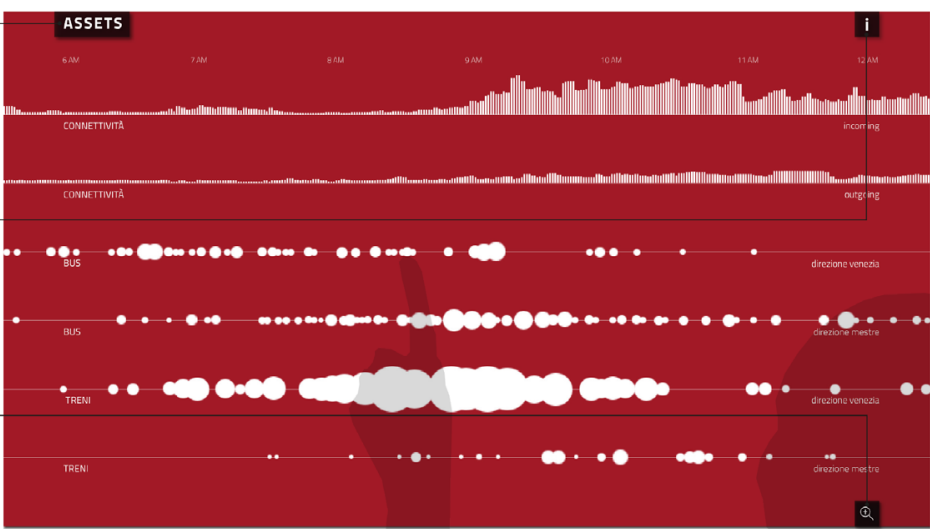

RETHORICS
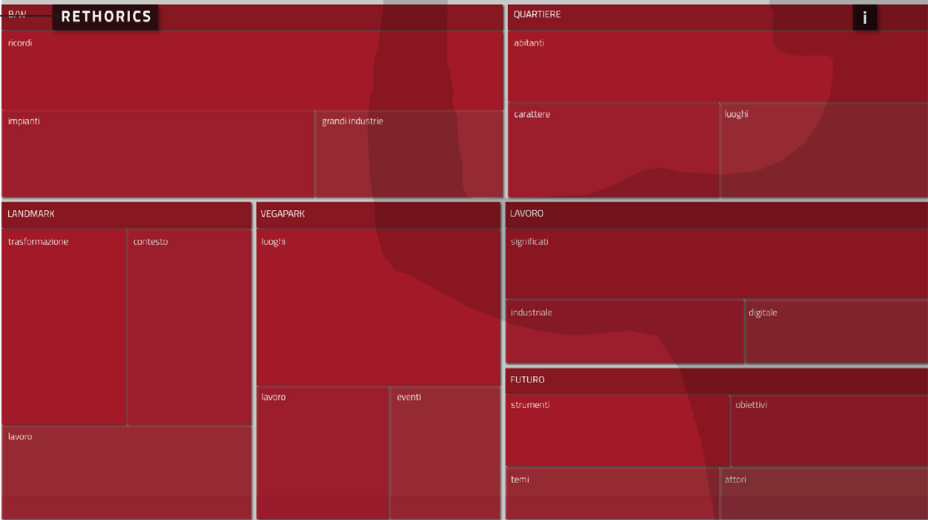

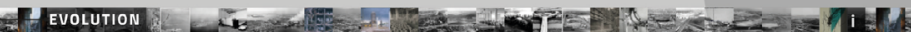

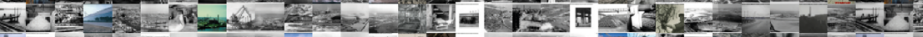

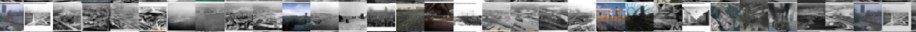

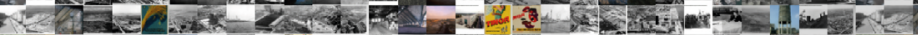

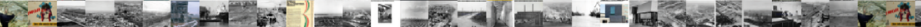
b. Fal

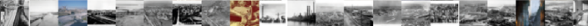

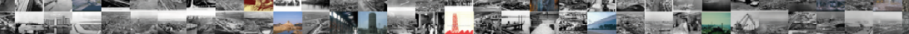
(1)

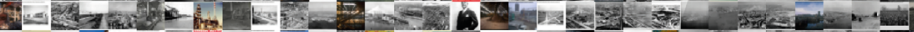

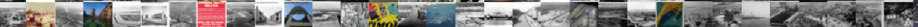

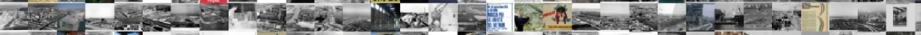

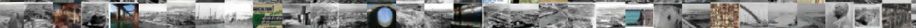

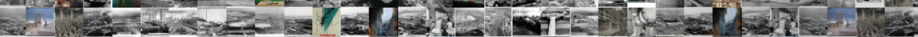

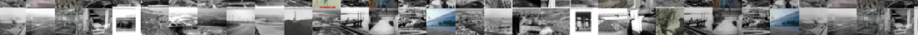

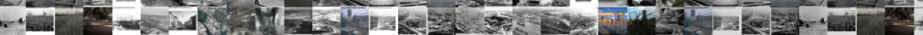

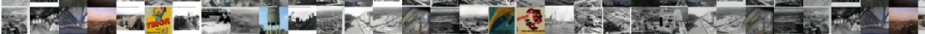

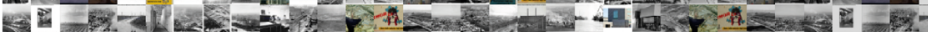
W.

$$
\mathrm{V}=G \mathrm{t}
$$

Fig. 1. The home screen of the interactive application, navigable from touch-foil support. 
twentieth century. What came to light is the absence of a single structure that can illustrate Venice's industrial past. The resources retrieved from the archives were skimmed in order to tell the historical transformations. The criteria applied to better address the overall project were two: the first to collect historical photographs to provide a visual story the local community could quickly empathize with; the second to consider images of industries that predated Vega as it exists today, to better understand the collective imagery that continues to be associated with the Park. Significant metadata (date, description, source and a few tags) were added to each image. It created a database of cultural objects related to the history of Vega: the first contribution to be included in the interface (LUST, McWilliams, Reas, 2010). Secondly, the study of the extensive bibliography about Porto Marghera highlighted many persisting rhetoric. Above all, the negative one stemming from a notorious past of poor working conditions, heavy pollution and workers' riots. The one that saw the separation of the area from its social value during the decommissioning of the industrial pole. The latest one for which the STP was the chance to activate innovative entrepreneurship. The research chose to reformulate a selection of these texts to be translated into visual treemaps through Text Mining. The goal was to display thematic groups of terms to reveal unusual semantic associations, explaining or subverting the existing rhetoric. It was the second form of "datization" used in order to tell the Park (Cukier, Mayer-Schönberger,
2013). Lastly, a detailed investigation of Vega's current situation pointed out the existence of aspects that can enable the development of a contemporary digital working scenario. Indeed, the STP boasts an excellent broadband connection (up to $300 \mathrm{Mbps}$ ) and a strategic geographical location in Italy's northeastern infrastructural network. Vega is easily accessible by public and private transportation, and is appealing to digital companies. Numerical and statistical datasets were retrieved to substantiate and make visible these positive assets (i.e. interactive datasets on digital connectivity, statistics about people traveling to and from Vega by train or bus, parking statistics, etc.). The translation of them into data visualization formed the third section of the application.

Building on these materials, the design intent was to develop a new narrative paradigm of Vega. Translating cultural artifacts into data means activating new ways of understanding reality, hindered so far by the absence of adequate technologies (Manovich, 2008). The interactive application is seen as a modern tool to structure, discover and add value to visual materials concerning Vega, offering an original way of understanding its complexity. In conclusion, in the case of Vega "datization" makes it possible to structure the visual imagery related to the history of the Park, finally making it accessible to a wider audience (Bruno, 2016). This new narrative paradigm seeks to dispel the fear of clinging to the past so that Vega may finally look to the future. 


\section{Book}

Cukier, K., Mayer-Schönberger, V., (2013). Big Data: una rivoluzione che cambierà il nostro modo di vivere e già minaccia la nostra libertà. Milan, Italy: Garzanti Libri.

Hessler, J., (2015). Map. Exploring the world. London, UK: Phaidon.

Lima, M., (2011). Visual complexity. Mapping patterns of information. New York, New York: Princeton Architectural Press.

LUST, McWilliams, C., Reas, C., (2010). Form+Code in Design, Art, and Architecture. New York, New York: Princeton Architectural Press.

Lupi, G., Posavec, S., (2016).

Dear Data. New York, New York:

Princeton Architectural Press.

Volli, U., (1994). II libro della

comunicazione. Milan, Italy: Il Saggiatore. from https://goo.gl/ZzZCVM.

Manovich, L., (2008). Introduction to Info-Aesthetics. Retrieved from https://goo.gl/1Pv4jB.

Manovich, L., (2012). Museum without walls, art history without names: visualization methods for humanities and media studies. Retrieved from https://goo.gl/drUpAi.

Manovich, L., (2015). Exploring urban social media: Selfiecity and On Broadway. Retrieved March 01, 2017 from https://goo.gl/vPfX7A

\section{Journal paper}

Ciracì, F., (2013). Mitologie 2.0: digital platforms and umbrella terms. $\mathrm{H}$-ermes. Journal of Communication (1), 109-126. Retrieved from https://goo.gl/CsFqv7.

Costa, P., (2016). Human-Data Experience Design: progettare con $\mathrm{i}$ personal data. MD Journal (2), 12-23. Retrieved from https://goo.gl/bGNQJM.

\section{Website article}

Avanzi Sostenibilità Per Azioni srl, et al., Community hub. I luoghi puri impazziscono. (2016) Retrieved from https://goo.gl/5TbQ2e.

Bruno, N., (2016). Interactive News Stories, what's next? Retrieved 
Lorella Camellina

IUAV University of Venice,

Santa Croce 191 Tolentini, 30135 Venezia, Italy

lcamellina@iuav.it

Gian Andrea Giacobone

University of Ferrara, Dept of Architecture,

Via Quartieri 8, 44121 Ferrara, Italy

gcbgnd@unife.it

\section{Exploring humanity combining Data Visualization with Digital Art}

Abstract. The paper presents two interactive installations that make use of datasets about the University of the Republic of San Marino to increase its visibility through Digital Art and meaning. Vibrancy translates sound in a continuously updated materic flow. Its goal is to show the vivacity of the University, quite isolated and located in an ancient monastery in the inner city of San Marino. This, to tell the restless movement that characterizes the School. Vibrancy's software detects, processes and translates noises into movement. Metadata Juice explores human relationships mediated by the Internet, representing invisible data and digital relations generated in the virtual web space. The stream of information comes from the University firewall and its representation is associated with the binary code syntax. Data are translated into a hydraulic circuit, creating simultaneously a connection between analogue and digital realities.

Keywords: Dataset / Digital Art / Dataviz

\section{Introduction}

University is an anthropologic place, made by people who daily participate to the construction of its identity through culture and knowledge in form of invisible raw data. The paper presents two installations - developed in the Interaction Design Lab 2, taught by Daniele Tabellini, at the University of the Republic of San Marino - that try to explore the character of that site, depicting and processing information from several hidden datasets based on human behaviours. The educational path was articulated through close readings of the projects, practices of Information \& Data Visualization and Digital Art.

\section{Methodology}

The design process has been developed through three phases, turning collected data into physical experiences: Dataset, Dataviz, Dataphys.

The starting question was which type of data to collect as project material. Dataset consisted in a preliminary analysis about the spatial and conceptual context. It was useful to define significant datasets of Unirsm, reading its daily life and discovering its criticalities and strengths. The choices were dictated both by the narrative potential of data and how highlighted their contents aspects (Cairo, 2013). Dataviz allowed finding appropriate expressive forms by associating different datasets, understanding their sources, the elements they are composed of, and their dimensional appearance in relation to their temporal variability (Tufte, 1983). In fact, particular attention was paid to the fourth dimension, time, founding 
asset of any dynamic interaction as real-time mapping (Simanowski, 2011). Various graphical interpretations were experimented to identify the most efficient method to communicate datasets.

Lastly, Dataphys transposed abstract into physical data. Open source tools such as Processing+ and Arduino were used for software and hardware implementation and the phase was related to the development of physical prototypes. Previous Dataviz depictions were an important preparatory step in assigning a tangible form to shapeless information.

\section{Results}

The work led to hybrid metamedium artefacts that made legible invisible data (Manovich, 2010). The projects exposed on this paper are Metadata Juice and Vibrancy. Focusing on the behaviours of people who live Unirsm, they study two different dimensions: virtual and physical space.

Metadata Juice explores social relationships between people mediated by internet. The purpose is to represent the humanity of invisible data and digital relations generated in the web space. The stream of information analysed comes from Unirsm firewall. The representation is associated to the binary code syntax, where 0 and 1 mean if people are logged or not in a specific social platform, during the real-time. The installation translates data into a hydraulic circuit, connecting analogue and digital realities. It proposes different levels of reading, from the analytical representation data to the creation of an audio-visual experience.

Vibrancy is an interactive installation which translates sounds in a continuously updated physical flow. The aim is to show the vivacity of Unirsm, quite isolated and located in an ancient monastery in San Marino Città. This to tell the restless movement that characterizes Unirsm. Vibrancy's software detects, processes and translates noises into movement, with the purpose of emphasizing the visibility of the School.

The spatial contextualization of each installation extended data expressivity to a multisensory level, creating different interpretations, ranging from qualitative analysis of information to the creation of an engaging user experience (LUST et al., 2010). The design process showed that the transition from numerical information to sensorial user experience takes place making visible hidden relationship of data with space and people. The installation becomes a collective artefact and the user, from simple observer, now sees its role in the creation of data (Simanowski, 2011).

\section{Conclusion}

The experiment merged apparently separated domains such as Information \& Data Visualization and Digital Art. It highlighted that they share the same design material (datasets) and how processing tools of the first field are nowadays executive medium in visual art (LUST et al., 2010).

In conclusion, the Lab had a double value for Unirsm. It was precious to better understand the inner human nature of the School through invisible data. On the other hand, it found out new ways to tell the external world the identity of San Marino. 


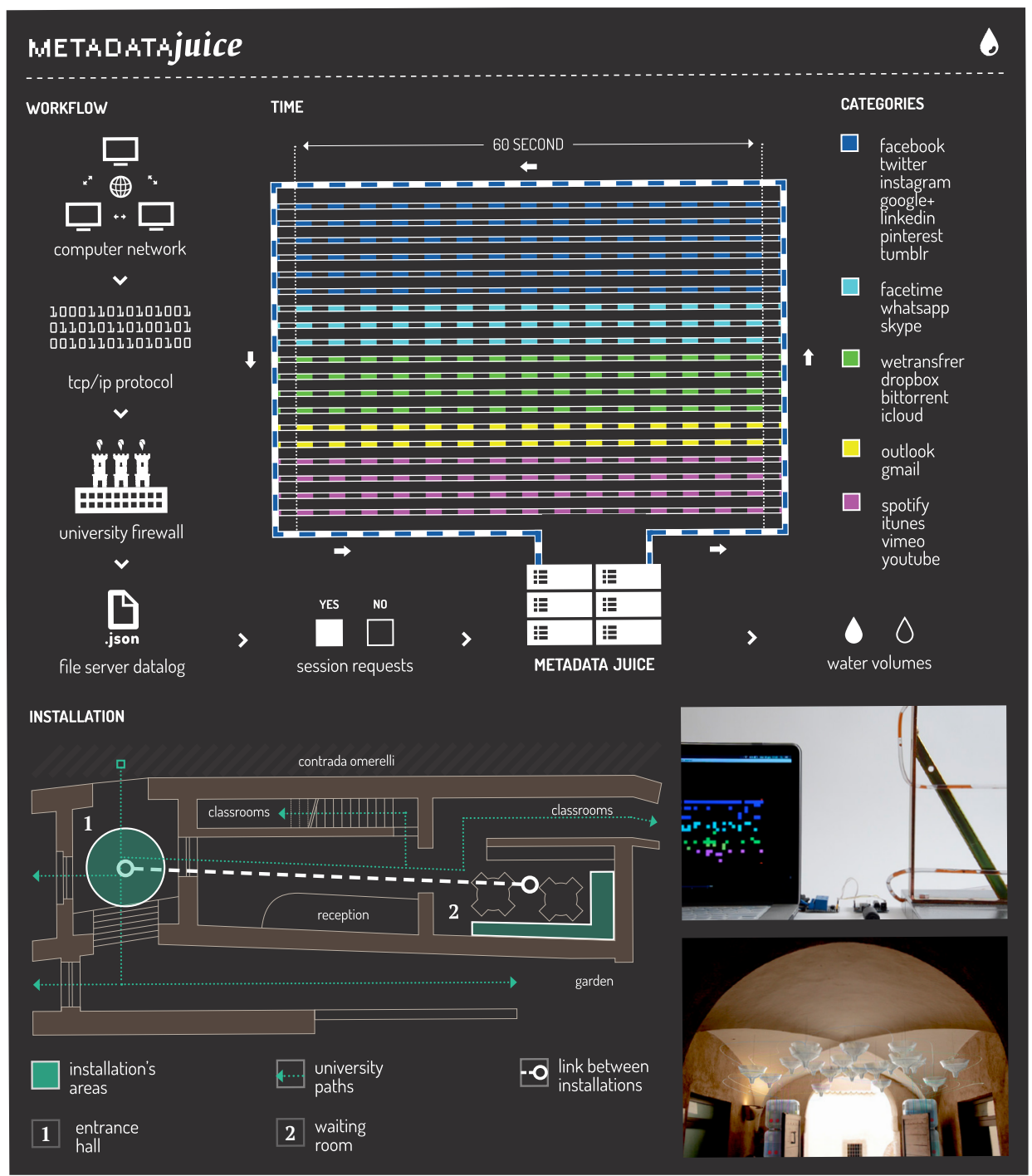

Fig. 1. Metadata Juice's working system, placed in the Unirsm's entrance hall. Republic of San Marino.

Fig. 2. Vibrancy's working system, data processing and visualization and working prototype. Republic of San Marino.

\section{References}

Arnall, T., (2013). Making Visible: Mediating the material of emerging technology. Oslo, Norway: Oslo School of Architecture \& Design.

Cairo, A. (2013). L'arte funzionale. Informatica e visualizzazione delle informazioni. Torino, Italy: Pearson Italia. 


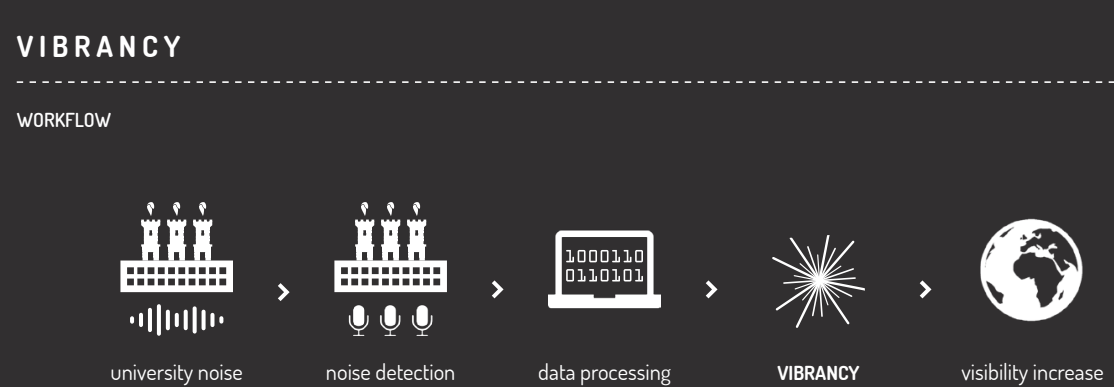

INTERACTIVE DATAVIZ

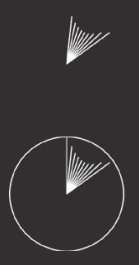

9"/60"
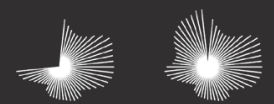

I"x
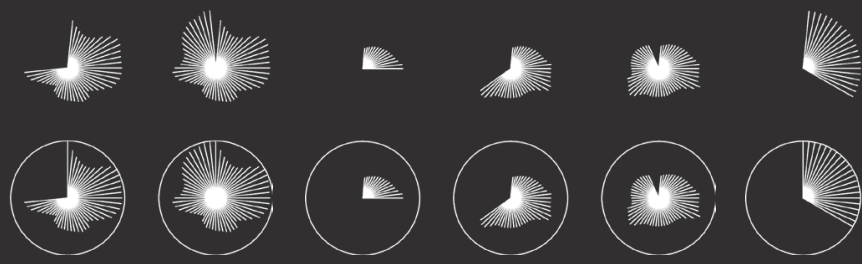

$44 / 60$

$60 " / 60^{\circ}$

$15 \% / 60^{*}$

$39 " / 60$

$56 / 60$

$20^{\prime \prime} / 60^{-}$

WORKING PROTOTYPE
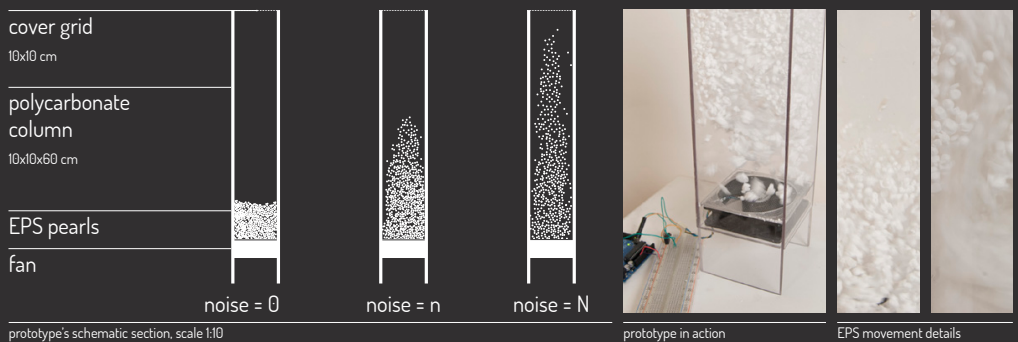

LUST, McWilliams, C., Reas, C., (2010). Form+Code in Design, Art, and Architecture. New York, New York: Princeton Architectural Press.

Manovich, L. (2010). Software Culture. Milano, Italy: Edizioni Olivares.

Simanowski, R., (2011). Digital art and meaning. Reading kinetic poetry, text machines, mapping art and interactive

installation. Minneapolis, Minnesota: University of Minnesota Press.

Tufte, R.E., (1983). The Visual Display of Quantitative Information. Chershire, Connecticut: Graphic Press. 


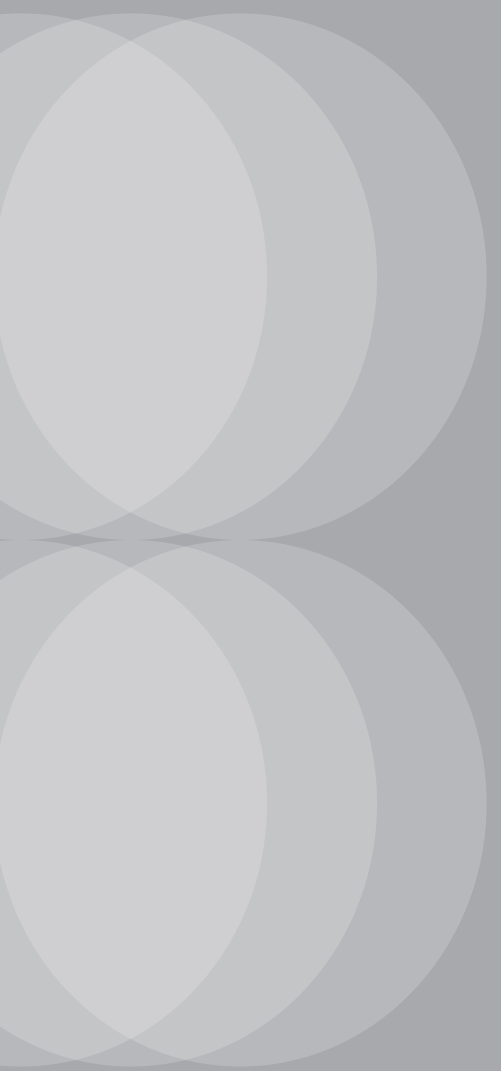


03. Posters 
Teresa Arozena Bonnet

Department of Fine Arts

Universidad de La Laguna

\section{Time Maps. Photography as the Display of Duration}

I recently realized that, as an artist, in deep, what I was always trying to do was to find how to solve a "communication conflict" or, to put it in other way, how to communicate complexity. That's really nothing new. The history of representation is the history of images created by man to understand and transmit life, the complex experience of the world. Artistic practices are always a tool of knowledge that deals with the Real, nothing less. Or, in other words, they are that procedure which frames the Real - understood as the unrepresentable, or as "what can not be said".

To find concepts, affects, values, to discover underlying structures in life, and communicate them. To represent reality, to build it over and over again. To propose it. This is the great play of forms, the waves of the cultural construct, that beat the beaches of the Real, the arena of complexity. There is no way to focus on art and not being in that arena.

In photography, in particular, complexity is often presented through the specific relationship that this medium professes with time. I am interested in an approach to time understood as one of the forms that takes Attention of and Relation.

Many authors who have dealt with specific forms of time in their photographic productions have developed their graphic research through the elements of grid, seriality and sequentiality (difference and repetition, or, "neither identical, nor different") as ways of expressing complexity.

Chrono-photography is an obvious example of this fact (here we have Marey, Muybridge, or Edgerton), but also narrative seriality in photography, or the so-called "cinematographic disassembly" of reality (i.e Allan Sekula), deals with these approximations to complexity through the Relation. Spatial installations in art, or what might be called "informational environments", often play a determining role in developing a network of semiotic links.

In my work I have often worried about how working these ideas. The early series of "El intruso" (2006) already contained the germen of a temporary and sequential search through the photographic support. The works that I present in this poster are two photographic installations developed in 2017, and exhibited at La Regenta Art Center, in Las Palmas de Gran Canaria, within the framework of an individual exhibition in June 2017. In both of them I use a method that I call stacking.

In this photographic installation I try to approach to a "phantom antrophology" (Bataille), which, starting from the real event, or, indeed, from the cultural event, expands towards the sphere of myth.

The method of stacking images, in this work follows the pattern of a Russian Doll (one image inside the other, successively) allows me to propose an approximation to the complexity of the temporal experience by recording and synthesizing different durations in the same static grid. I work without hierarchies, I mean I use both images made by myself along with found footage images taken of Canary history, with the aim of tracking a kind of DNA, trace or inheritance. The conception of seriality and repetition lie in the procedure but also in my subjects (crowd, social rite, entertainment, compulsion, devotion, tourism, merchandise). In this way I try to develop a kind of kaleidoscopic and mythological image-synthesis of my island.

This mythical dimension of the Real is revealed through the traces, the repetitive prints on the skin of photographic support. Are these traces that are automatically staked, almost as scars on the skin of the photographic support, which are revealing themselves the phantom behind things. 

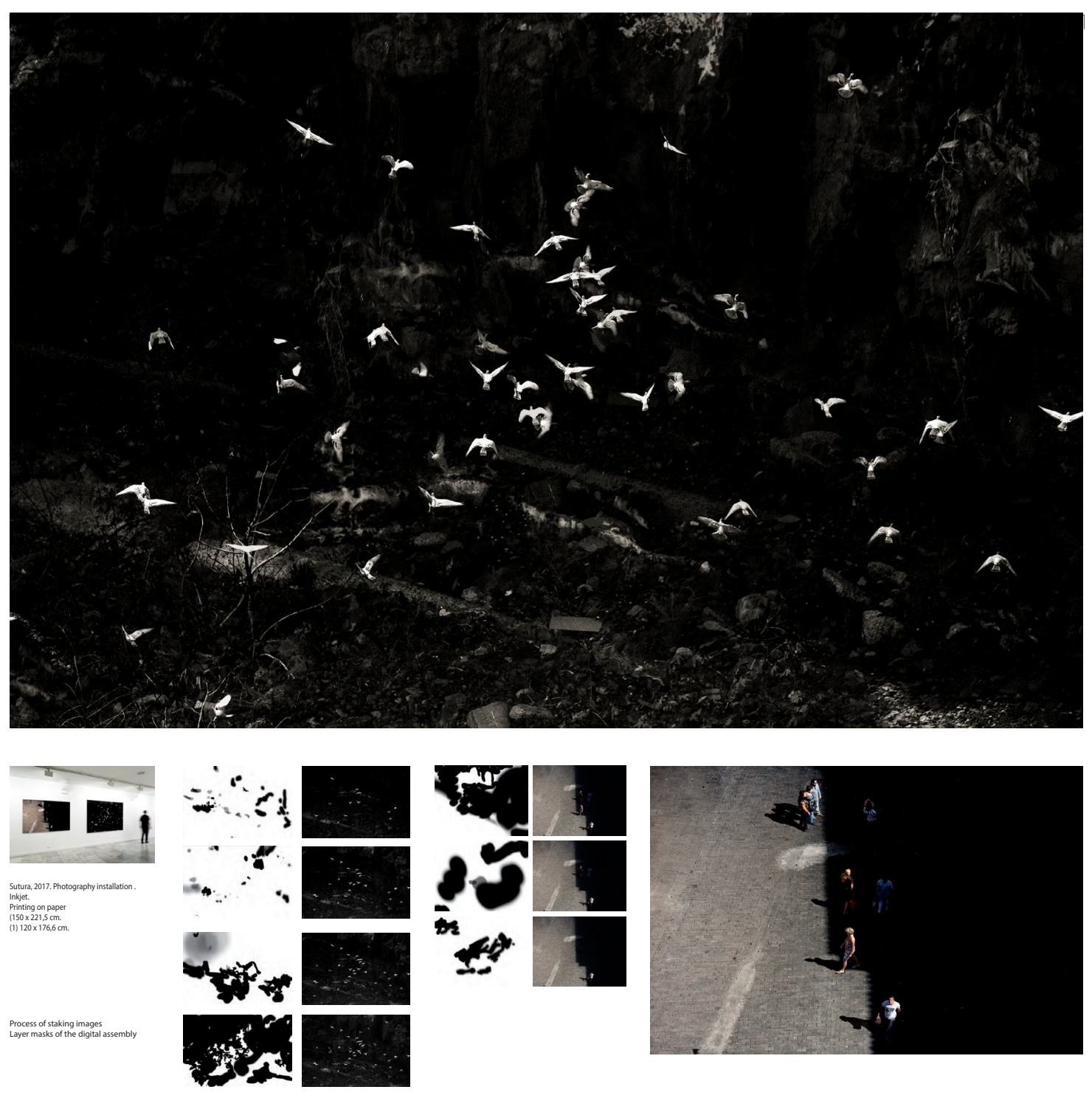
Bernardo Candela

Department of Fine Arts,

Universidad de La Laguna

Canary lslands Design System:

a visual representation of

a theoretical, instrumental and operational model

The concept of Design System can be considered a model that gathers in a single map the dimensions, actors and interrelations a round the Design sector that take place in a delimited territory. Visual interpretations help to graphically represent complex concepts, such as the Design System. Many authors make use of visual interpretations to explain and disseminate their proposals of Design System models.

This poster presents Canary lslands Design System graphic model as a result of capturing the dimensions, actors and interrelations considered part of the system in the Archipelago and it compares various proposals far visual interpretations of the System Design according to its morphology, objective and visualization strategy.
A review of the literature on the theoretical design system models and the documentary study of cases of other territorial realities has been carried out. The initial proposal has been tested through a workshop with stakeholders. Canary lsland Design System allows us to know the state of the art of design as an academic discipline, a professional activity and a creative industry, together with its potential to promote cultural, social and economic development in the Canary lslands.

These have been the preliminary results from the $\mathrm{PhD}$ research. It is still a work in progress. Next steps research will be focus on the visual model refinement, together with its operability. lt is necessary to find representation systems that help visualize the relationships between the actors of the Canary lslands Design System. 
Design System complex networks.

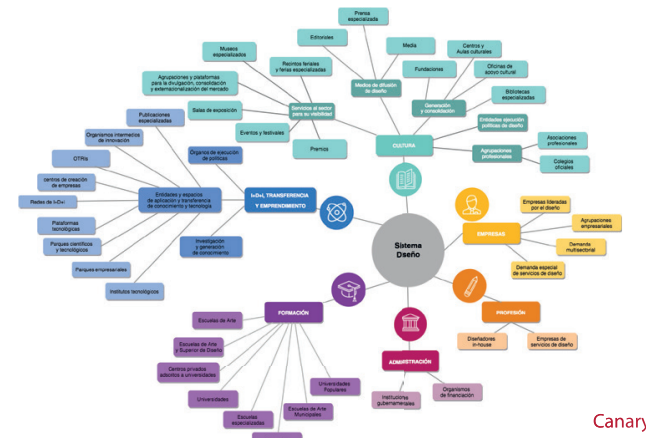

Conclusions

These have been the preliminary results from the $\mathrm{PhD}$ research. It is still a work in progress. Next steps research will be focus on the visual model refinement, together with its operability. It is necessary to find representation systems that help visualize the relationships between the actors of the Canary Islands Design System.

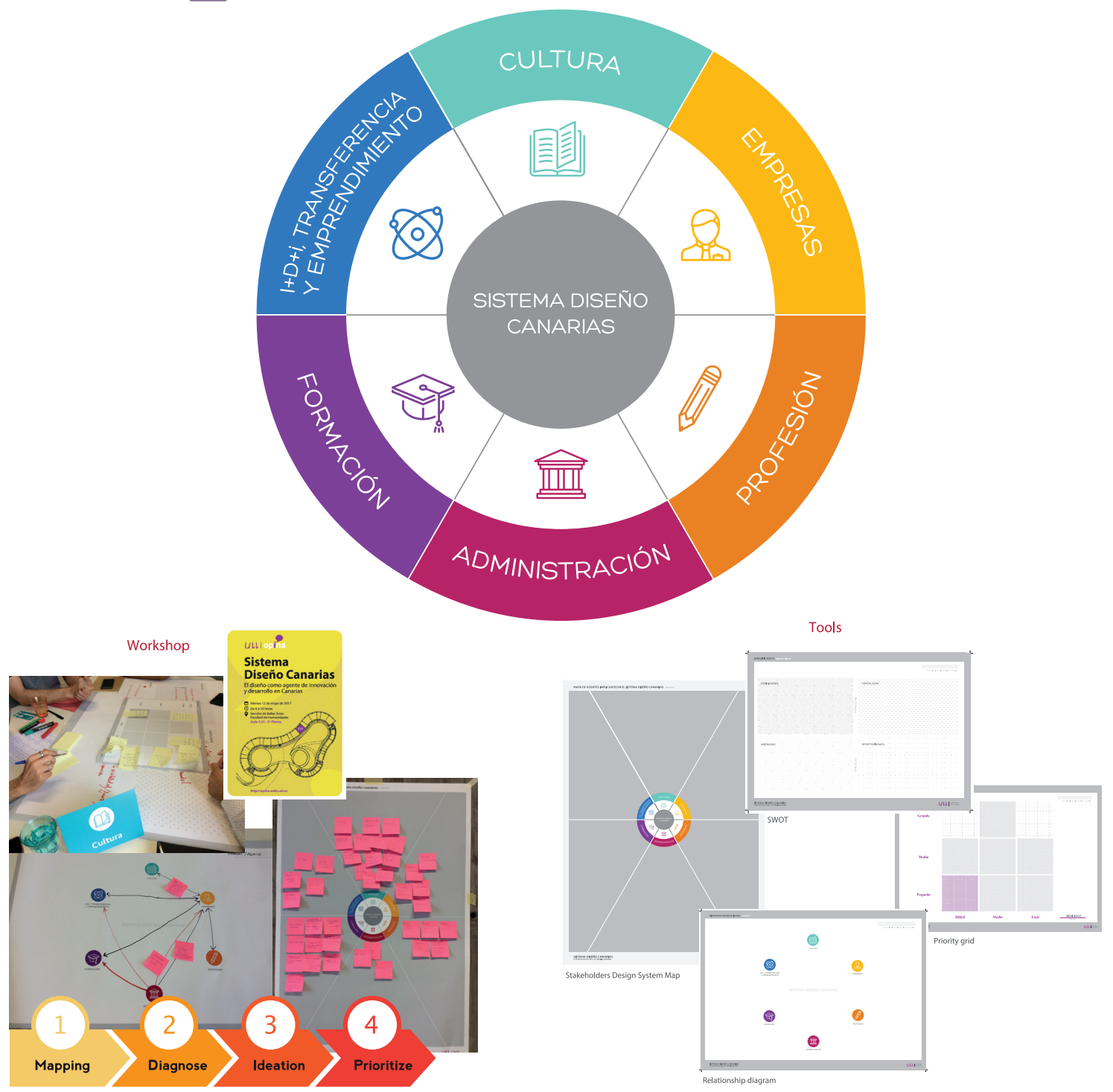


Tania Quindós, Elena González-Miranda

Universidad del País Vasco/

Euskal Herriko Unibertsitatea (UPV/EHU)

\section{Typography and Geometry in an information graphic}

Graphic designers need to structure and build with proportions the linguistic and iconographic signs of the visual systems we carry out. We also need to systematize, organize in a hierarchy, position and measure our designs, in areas such as visual identity, editorial design, or new informative formats to make easier the understanding of complex contents.

To achieve this, we apply concepts that derive from a field of knowledge with origin in Geometry. The history of Graphic Design is responsible for referencing very significant models or processes. We can mention milestones such as Harry Beck's conceptual innovation in 1933 by using a single 45 degree angle on the London underground map (Rendgen 2012); or Rosarivo's method for achieving the divine typographic proportion on the page (Catopodis 2014). We can also highlight the technical innovation for the generation of the curves and paths developed by Pierre Bézier, incorporated in the programs with vector tools and that every graphic designer or type designer currently dominates (Bringhurst 2014).

This contribution shows the preliminary results of a study that examines and revitalizes the links between these two disciplines. Through the bibliographical study of several authors, with this project we wish to identify, classify and propose certain mathematical-geometric procedures and knowledge related to the construction of our visual culture. We will start from the proportions of the page and later we will focus on small details of the letters, essential signs in our daily communication. We will carry out an inventory with concepts such as the golden section, the spreading of the module in the grid, the proportions of the alphabet, units of measurement, sequences, construction patterns as well as other systems of interchangeable parts (Bringhurst 2014, Cheng 2006, Elam 2014). This knowledge applied with good criteria makes the relationship between the components harmonious and consistent.

As a practical goal or a "graphic conclusion", we want to dump this information into an infographics where this content inventory is visualized based on three interconnected areas: page, calligraphy and type design. This diagram will be illustrated with examples of our teaching and professional experience and can be used as educational material and inspiration for the community of students and professionals in graphic design, type design and information design in general. 


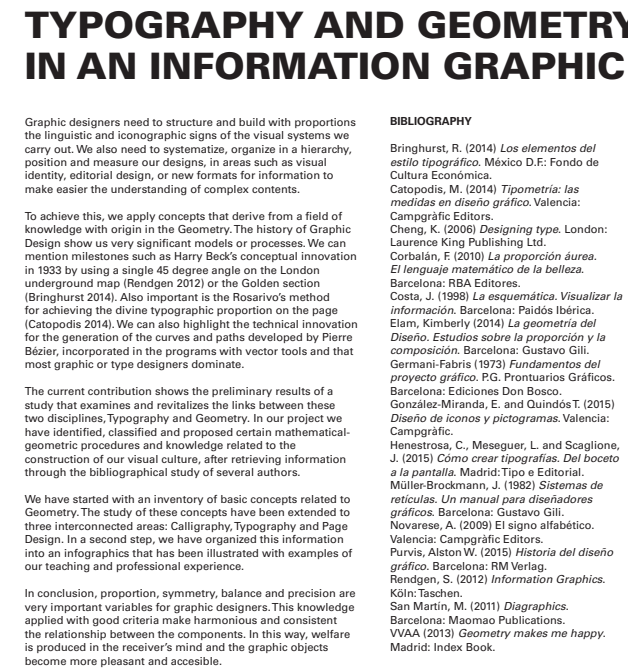

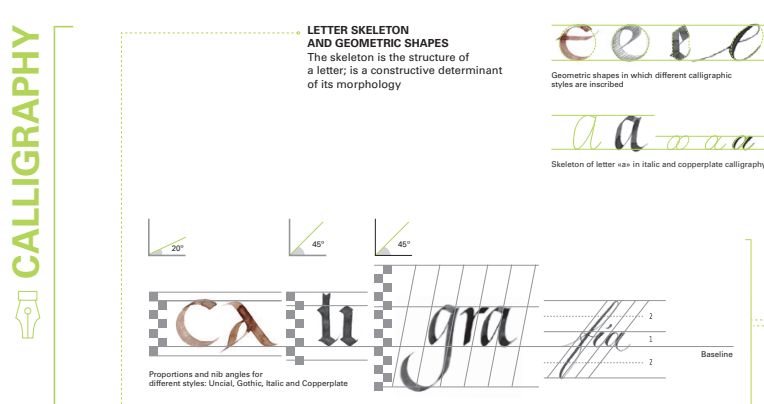

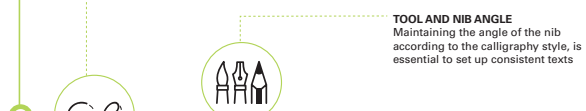

s.

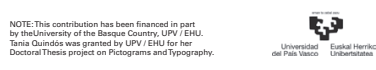

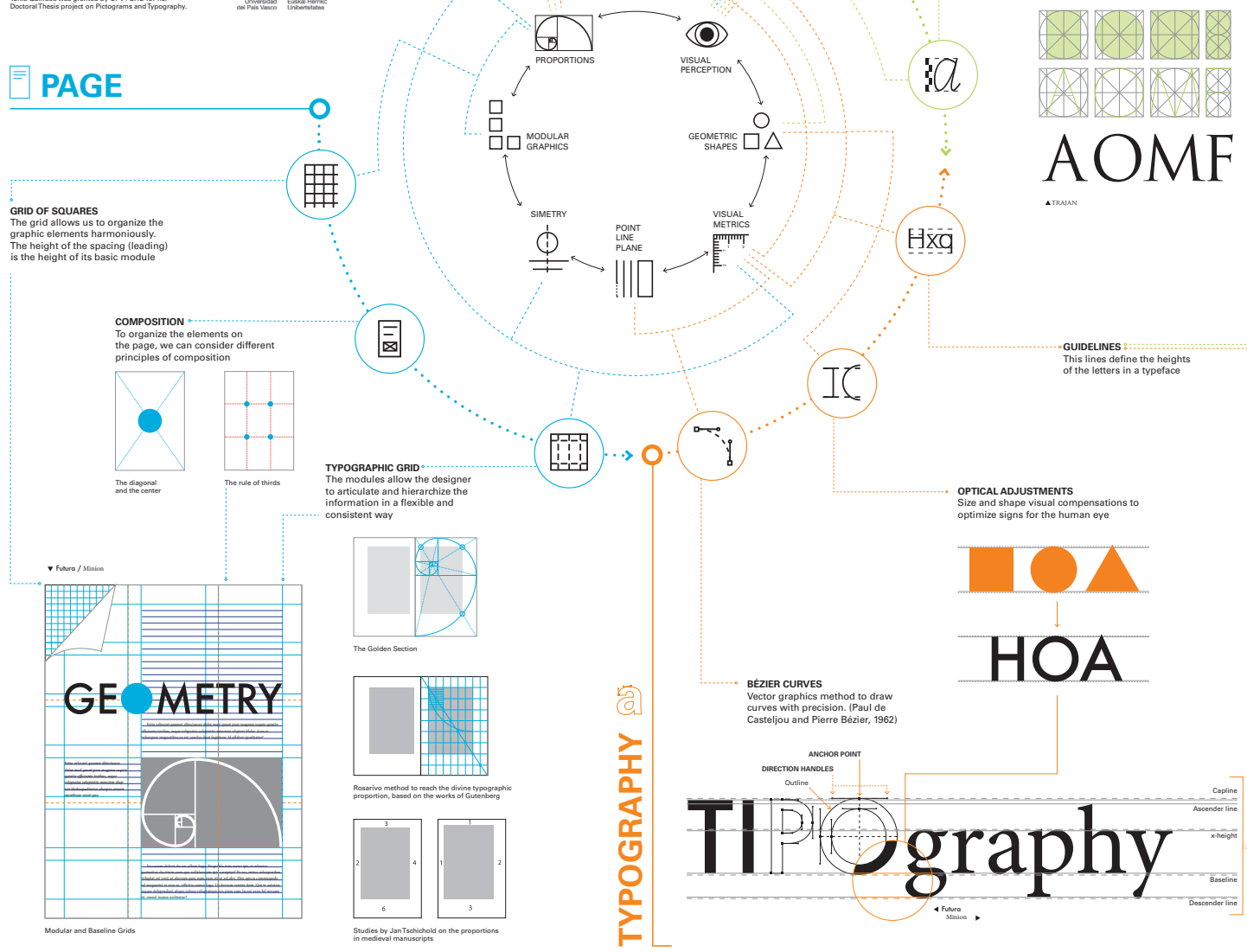

(6) 0 व propoortons

\begin{tabular}{|c|c|c|c|c|c|}
\hline $\begin{array}{l}\text { Author(s) } \\
\text { Tania Quindós } \\
\text { tania.quindos@ehueus } \\
\text { Elena González-Miranda } \\
\text { elena.gonzalezmiranda@ehu.eus }\end{array}$ & $\begin{array}{l}\text { Affiliatiotion } \\
\text { Universidad del País Vasco/ } \\
\text { Euskal Herriko Unibersitatea } \\
\text { (UPV/EHU) }\end{array}$ & $\begin{array}{l}\text { Title } \\
\text { Typography and Geometry in } \\
\text { an information graphic }\end{array}$ & $\begin{array}{l}\text { K-words } \\
\text { Geometry } \\
\text { Typography } \\
\text { Info-graphics } \\
\text { Visual Design Teaching }\end{array}$ & $\begin{array}{l}\text { communicating } \\
\text { complexity } 2017 \\
\text { INTERNATIONAL DESTG CONFEREMCE }\end{array}$ & $\frac{(1 L L}{\begin{array}{c}\text { Universidad } \\
\text { de La Laguna }\end{array}}$ \\
\hline
\end{tabular}


C. Pérez-González, M. Colebrook,

J.L. Roda-García, P. González Yanes,

T. González Dos Santos, V. Plaza Martín

TARO-ULL Research Group,

Universidad de La Laguna

C. Rosa Remedios

Centro Coordinador de Emergencias

y Seguridad 1-1-2 (CECOES)

\section{Analysis of incidents registered by the 1-1-2 Canarias emergency services by using data science techniques with the $R$ software}

The study of alerts received in the emergency services is a very important issue in order to know different aspects of the time and spatial distribution of alerts in a given region. In particular, the Emergency and Security Coordinating Center (CECOES) 1-1-2 of the Government of the Canary Islands records detailed information about the incidents that are reported by the citizens through phone calls. Due to the high volume of information generated over the time in this process, it is needed to apply big data techniques to obtain statistical measures and results of interest. We have used the statistical software R and different libraries (Shiny, Highcharts, Highmaps) to present the data information in different interactive dashboards (time series charts to analyze the time evolution, geospatial representations of incidents density distribution, etc.). In this work we illustrate some of these charts that help the public authorities to study the incidents in the region during the last years. 


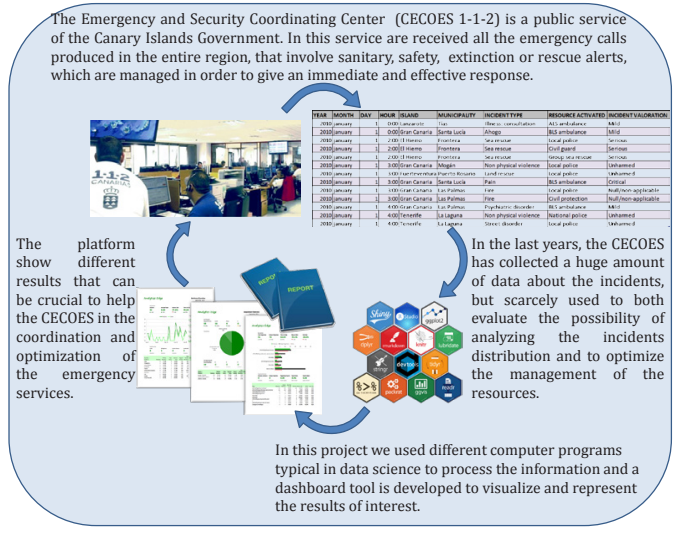

This dashboard shows again multiple options to compare, in this case, the average number
of incidents between different years, months or, even, the time in the day.

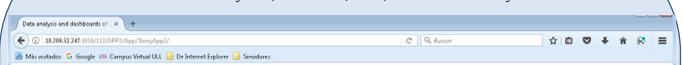
Data analysis and dashboards of 1-1-2 Canarias

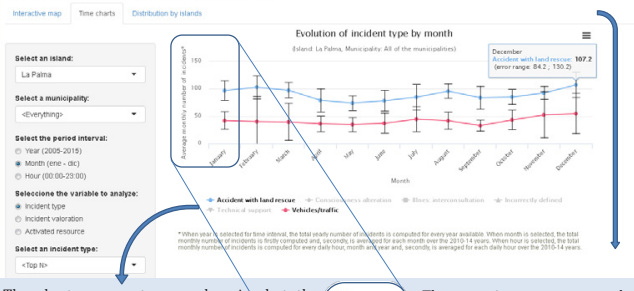

The chart represents several series but the The margin errors around the user can select (over the chart legend) only _- mean (represented as intervals) those to be shown. The time series charts allow us to detect - about the accuracy in computing changes or identify patterns, that is very to the averages.

important in predicting potential future - If the values are over dispersed, the demands of the resources or, even, changes in $(2$, mater average is imprecise.

municipalities.

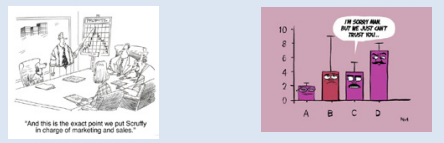

Let's suppose that we are interested to compare the monthly average number of incidents that were associated to critical or exitus assesment in Arrecife (Lanzarote)

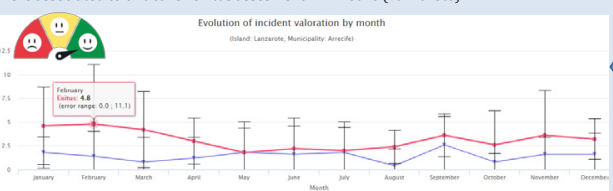

In this case, the example shows the average number of incidents along the day where the activated resources were ALS ambulances (advanced life support) and the local police in Las Palmas (Gran Canaria)
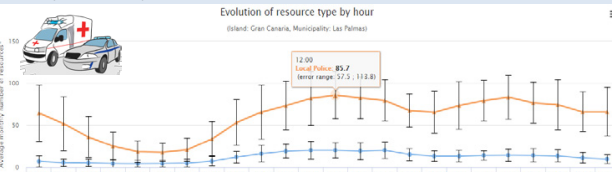

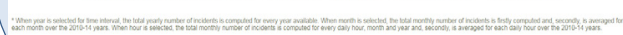

Title:

Analysis of incidents registered by the 1-1-2 Canarias emergency services Authors:

Colebrook Santamaría, M. ${ }^{1}$; González Dos Santos, T. ${ }^{1}$; González Yanes, P. ${ }^{1}$, Pérez-González, C. J. ${ }^{1}$; Plaza Martín, V. ${ }^{1}$;Roda García, J. L. ${ }^{1}$; Rosa Remedios, C. ${ }^{2}$; Affiliation:

(1) Grupo de investigación TARO-ULL (Universidad de La Laguna) (email: cpgonzal@ull.es) ,

(2) Centro Coordinador de Emergencias y Seguridad 1-1-2 (CECOES).

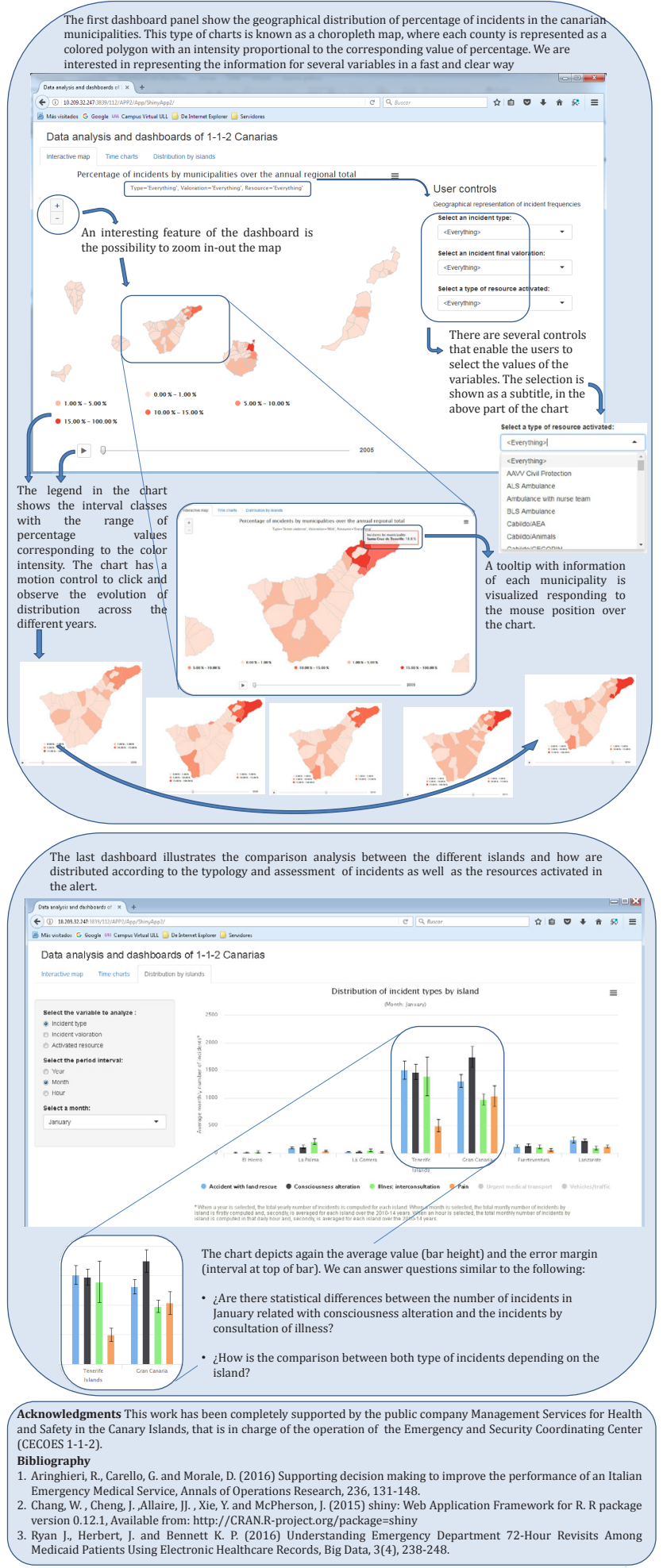

Medicaid Patients Using Electronic Healthcare Records, Big Data, 3(4), 238-248. 
I. Sánchez-Berriel, L.M. Moreno de Antonio

Department of Computer Science and

Systems (Universidad de La Laguna)

E. García Martín, A. Hernández Hernández, B. González González,

A. Cabrera Díaz, J. Alberto

School of Engineering and Technology (ULL)

G. Yanes, R. Betancor-Villalba,

J.J. Hernández

Instituto Canario de Estadística.

\section{Experiences in data visualization of public statistics from the Canary Islands on mobile device}

This poster outlines the experiences in the development of interactive tools for the visualization of public statistics open data. The developed prototypes have been made for web and mobile devices and they allow displaying statistical data collection by the Canary Islands Statistics Institute (ISTAC), both: numerically and graphically. These applications facilitate the analysis of economic, social and environmental variables of the Autonomous Community of the Canary Islands. For this has been used ISTAC BASE, the main system for the storage and spreading of statistics of the Autonomous Community of the Canary Islands. Usually, the statistical analysis is used as a resource for the decision making related to the scope from which the data come from. The purpose of the visualization is to represent them graphically in a clear and precise way, to help in their interpretation, even for an inexperienced public. In all examples, users can select temporal and geographical factors to define their queries. It is important to emphasize that in some cases, aditional sets of indicators have been defined, expanding those from ISTAC, providing users with more information about the reality of society.
All the tools have been designed thinking about its use for the quick and effective consultation of economic, social and environmental data in any location that has internet connection. This characteristic forces us to pay special attention to the usability of the obtained product, so user's tests have been included.

The interest in this subject is due to the limitations imposed by the fact of the reduced dimensions of the screens of the mobile devices. They have allowed design recommendations such as data breakdown, selection of axes, presentation of units, numeric format $o$ and some improvements to facilitate interaction.

Another aspect considered in the design has been the portability to different platforms, reason why all the developments have been realized following strictly the standards of the web. The portability and adaptability of the graphics is therefore a crucial aspect that has been guaranteed with the use of the JavaScript library: D3, based also on HTML, CSS and SVG.

Each of the applications focuses on the following indicators: economic situation, socio-economic indicators at the council level, environmental indicators at the regional level and a personal calculator of the CPI. In the latter case, an API has been developed that allows data to be exposed through a web service for reusing of data by any developer. 


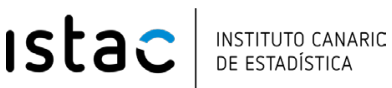

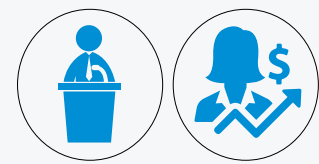

Government and companies

Information is essential in decision making and to measure the efficiency of the taken policies.

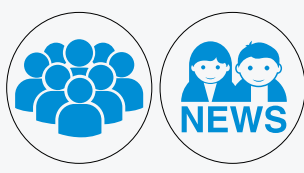

Citizens and media

Each time they demand more data regarding the issues that concern them: economy, environment, population, education, health, etc.

\section{European Statistics Code of Practice}

Principle number 15 refers to the presentation of statistics in a clear and understandable way
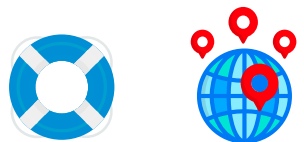

\section{Objectives}

(1) Development of mobile applications to do more easy queries about specific topics

(2) Perform usability tests with users to detect design errors

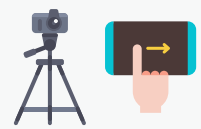

\section{User Experience}

Usability test with users for each application.

Each application up to 7 tasks with 5 users

Operating Systems: Firefox OS, Android User profiles: Statistical experts, computer experts, medium level computer user, low level computer user

\section{Recommendations}

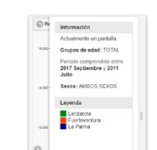

Non-intrusive legends
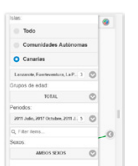

Hierarchical filters

\section{Experiences in data visualization \\ of public statistics from the Canary Islands on mobile device}

\レい $\begin{aligned} & \text { Universidad } \\ & \text { de La Laguna }\end{aligned}$

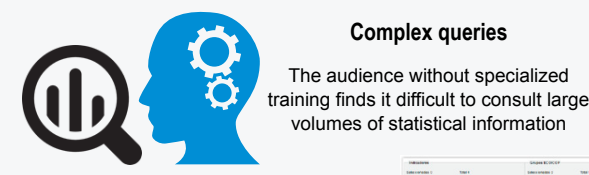

Truthful

Guarantee of data availability

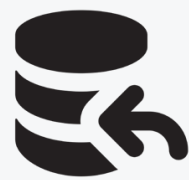

The official statistical agencies are providers of quality socioeconomic data, which offer total reliability

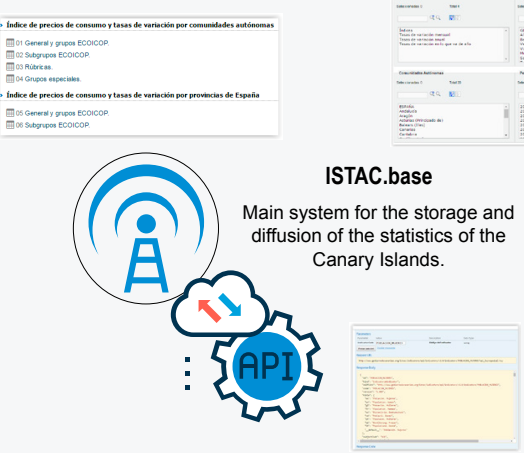

Pulsec app

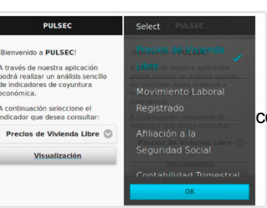

Responsive: Graphics generated using web standards.

Interactive queries: selection lists configured according to the indicato variables

Updated data

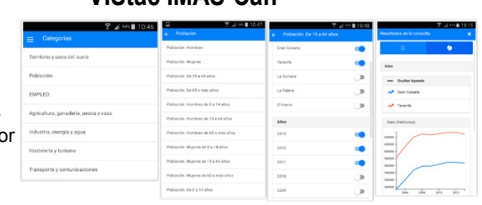

Vistac Situation
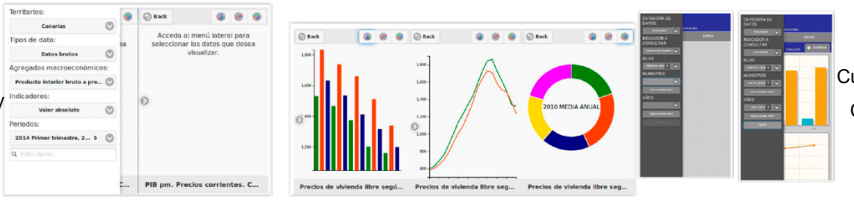

Indicator AP Custom indicators Cross-platform development

\section{Design problems}

The main problems are due to the reduced dimensions of the screen

Tendency to use the mobile in horizontal position

Scarce information in the drawing area

Units are sometimes confusing.

In large series, overflowing of bar plots occurs on the mobile screen.

The user expects information to be placed on the points on the graph

The initial filters generate confusion because a large number of options to be selected

In the screens used for the filters it is expected to find a way to jump to the top of the list
HTML
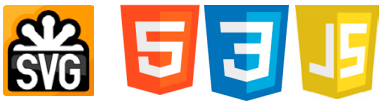

Web standards

\section{Bibliografía}

Castillo, P. N. (2014). Mastering D3. js. Packt Publishing Ltd. Orrù, C., Cuccu, R., Rivolta, G., Sacramento, P., \& Balhar, J. (2017, June).

Multi temporal data visualization in EO mobile apps. In Analysis International Workshop on the (pp. 1-4). IEEE.

UN. Economic Commission for Europe (2009). Cómo hacer (1) MDM__art__Spanish.pd MDM Part2 Spanish pd of Multitemporal Remote Sensing Images (MultiTemp), 2017 9t comprensibles los datos. Parte 1 y Parte 2. Recuperado de: 


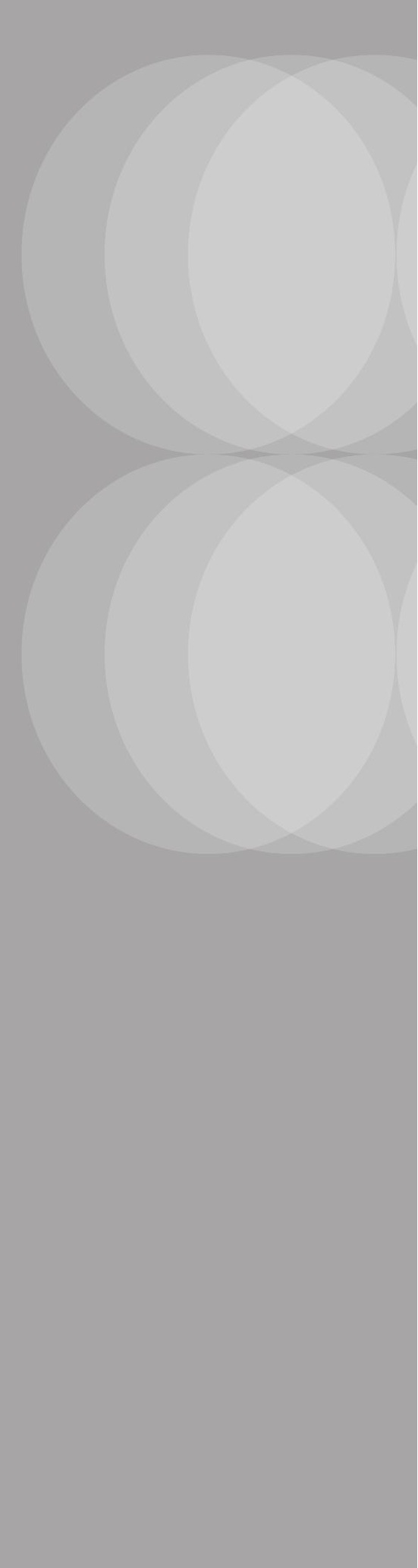


Arozena Bonnet, Teresa (poster) Humanities Fine Arts Department, University of La Laguna, Tenerife, Spain

Betancor-Villalba, Rafael (poster) Instituto Canario de Estadística, Spain

Bollini, Letizia (papers)

University of Milano-Bicocca, Department of Psychology, Milano, Italy

Bonora, Giulia (papers)

Alpaca Società Cooperativa, Ferrara, Italy

Borgenheimer, Lisa (papers)

Free University of Bolzano, Faculty of Art and Design, Bolzano, Italy

Bosco, Alessandra (papers) Università di San Marino, Dipartimento di Economia Scienze e Diritto, San Marino

Brockhaus, Friederike (papers) Chemnitz University of Technology, Institut of Psychology, Chemnitz, Germany

Burgio, Valeria (papers)

Free University of Bolzano, Faculty of Art and Design, Bolzano, Italy

Cabrera Díaz, Alejandro (poster) School of Engineering and Technology, University of La Laguna, Tenerife, Spain

Calosci, Alfredo (papers)

$27,134,212$ University of Sassari, Department of Architecture Design and Planning,

Alghero, Italy

Camellina, Lorella (junior)

IUAV University of Venice, Venezia, Italy

Candela Sanjuan, Bernardo A. (poster) 250

Department of Fine Arts, University of La

Laguna, Tenerife, Spain

Cangiano, Serena (papers)

SUPSI, Canobbio, Switzerland

Ceccarelli, Nicolò (papers)

University of Sassari, Department of

Architecture Design and Planning,

Alghero, Italy

Ciuccarelli, Paolo (papers)

Politecnico di Milano, Department of Design,

Milano, Italy
248 Colebrook Santamaría, Marcos (poster) 254 Grupo de investigación TARO-ULL, Universidad de La Laguna, Tenerife, Spain

256 Dal Buono, Veronica (papers) 189 University of Ferrara, Department of Architecture, Ferrara, Italy

Dalai, Giampiero (papers) Alpaca Società Cooperativa, Ferrara, Italy

De Rosa, Daniele (papers)

Alpaca Società Cooperativa, Ferrara, Italy

De Montfort University, Leicester Media

School, Faculty of Technology, UK

Ferrari, Marco (papers)

ISIA Urbino, Urbino, Italy

García Martín, Eliasib (poster)

School of Engineering and Technology,

University of La Laguna, Tenerife, Spain

Giacobone, Gian Andrea (junior) University of Ferrara, Department of Architecture, Ferrara, Italy

González Dos Santos, Teno (poster)

Grupo de investigación TARO-ULL,

Universidad de La Laguna, Tenerife, Spain

González González, Beneharo (poster)

School of Engineering and Technology, University of La Laguna, Tenerife, Spain

González Yanes, Jesús Alberto (poster) 256 Instituto Canario de Estadística, Spain

González Yanes, Pedro (poster)

Grupo de investigación TARO-ULL, Universidad de La Laguna, Tenerife, Spain

González-Miranda, Elena (pap., post.) 41, 252 Universidad del País Vasco / Euskal Herriko Unibertsitatea (UPV/EHU), Departamento de Dibujo (Diseño), Facultad de Bellas Artes, Bilbao (Bizkaia), Spain

Heras Evangelio, David (papers) 196 Universitat Politècnica de València, Departamento de Dibujo, València, Spain

115 Hernández Hernández, Alejandro (poster) 256 School of Engineering and Technology, University of La Laguna, Tenerife, Spain 
Hernández, Jorge Javier (poster) Instituto Canario de Estadistica, Spain

Imperato, Adelaide (papers)

Alpaca Società Cooperativa, Ferrara, Italy

Invernizzi, Michele (papers)

Politecnico di Milano, Department of Design, Milano, Italy

Jackson, Chris (papers)

Liverpool John Moores University,

Liverpool, UK

La Maida, Elena (papers)

Università di San Marino, Dipartimento di

Economia Scienze e Diritto, San Marino

Lleonart Garcia, Melani (papers)

Universitat Politècnica de València,

Departamento de Pintura, València, Spain

Martini, Berta (papers)

Università degli Studi di Urbino, Dipartimento di Studi Umanistici, Urbino, Italy

Mauri, Michele (papers)

Politecnico di Milano, Department of Design,

Milano, Italy

Mee, Alan (papers)

UCD School of Architecture Planning and Environmental Policy, University College

Dublin, Ireland

Menichinelli, Massimo (papers)

IAAC, Fab City Research Lab, Barcelona, Spain

Mitchell, Ian (papers)

Liverpool John Moores University,

Liverpool, UK

Moore, Anne-Marie (papers)

Liverpool John Moores University,

Liverpool, UK

Moreno de Antonio, Luz Marina (poster)

Department of Computer Science and

Systems, ULL, Tenerife, Spain

Moretti, Matteo (papers)

Free University of Bolzano, Faculty of Art and

Design, Bolzano, Italy

Mouri, Eleni (papers)

Graphic Design Department, TEI of Athens,

Greece
256 Pérez-González, Carlos (poster)

Grupo de investigación TARO-ULL,

Universidad de La Laguna, Tenerife, Spain

Perondi, Luciano (papers)

86,94

ISIA Urbino, Urbino, Italy

Plaza Martín, V. (poster)

Grupo de investigación TARO-ULL,

Universidad de La Laguna, Tenerife, Spain

Profeta, Giovanni (papers)

SUPSI, Canobbio, Switzerland

182 Quindós, Tania (papers, poster)

Universidad del País Vasco / Euskal Herriko Unibertsitatea (UPV/EHU), Departamento de

196 Dibujo (Diseño), Facultad de Bellas Artes, Bilbao (Bizkaia), Spain

Ricci, Donato (papers)

SciencesPo|médialab, Paris, France

Roda-García, José Luis (poster)

Grupo de investigación TARO-ULL,

Universidad de La Laguna, Tenerife, Spain

Rodríguez Calatayud, Nuria (papers)

Universitat Politècnica de València,

Departamento de Pintura, València, Spain

Rosa Remedios, Carlos (poster) Centro Coordinador de Emergencias y Seguridad 1-1-2 (CECOES), Spain

121 Sánchez-Berriel, Isabel (poster) Department of Computer Science and Systems, ULL, Tenerife, Spain

Sanchis Gandia, Álvaro (papers) Universitat Politècnica de València, Departamento de Pintura, València, Spain

Sedlmeier, Peter (papers)

Chemnitz University of Technology, Institut of Psychology, Chemnitz, Germany

Sironi, Marco (papers) University of Sassari, Department of Architecture Design and Planning, Alghero, Italy

Spencer, Jonathan (papers) Liverpool John Moores University, Liverpool, UK

162 Zannoni, Michele (papers)

Università di San Marino, Dipartimento di

Economia Scienze e Diritto, San Marino 


This publication contains the developments of large parts of the communications presented during the 2 nd edition of the International Design Conference 2CO COmmunicating COmplexity, which took place from 23 to 25

November 2017 at the University of La Laguna, in Tenerife, the Canary Islands, Spain.

The conference was jointly organized by the Department of Architecture, Design and Planning of the University of Sassari

(Alghero), Italy, and the Department of Fine Arts of the University of La Laguna, Tenerife, Spain.
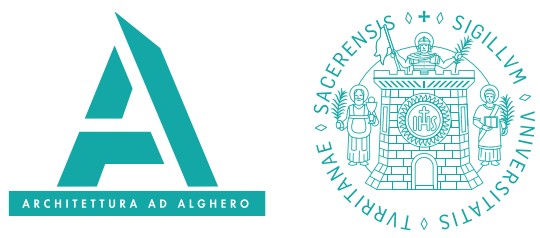

\section{Universidad de La Laguna}

